\title{
BLACKNESS THEORY \\ AND COEFFICIENTS \\ FOR SLAB GEOMETRY
}

May 1959

CONTRACT AT-11-1-GEN-14

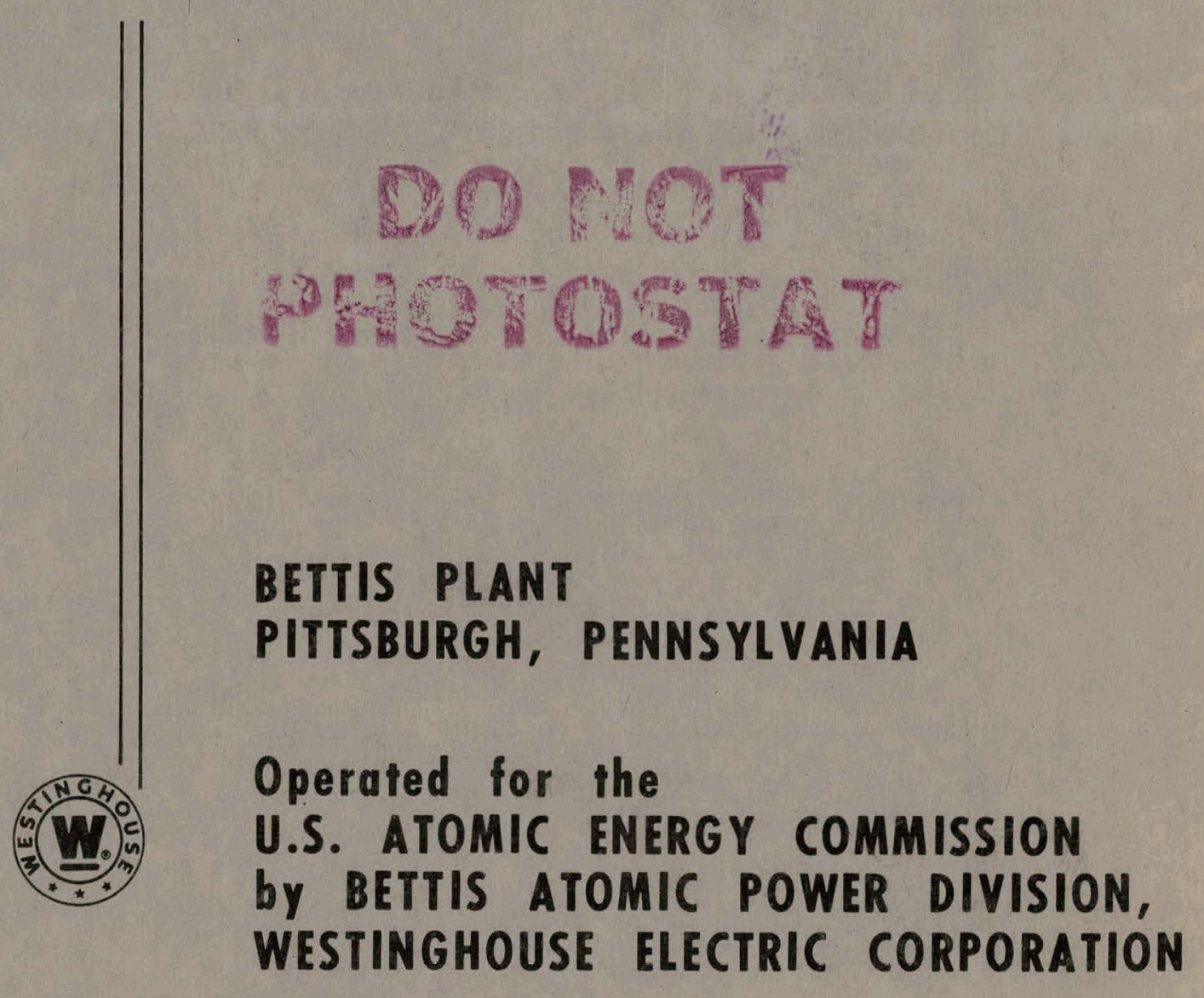




\section{DISCLAIMER}

This report was prepared as an account of work sponsored by an agency of the United States Government. Neither the United States Government nor any agency Thereof, nor any of their employees, makes any warranty, express or implied, or assumes any legal liability or responsibility for the accuracy, completeness, or usefulness of any information, apparatus, product, or process disclosed, or represents that its use would not infringe privately owned rights. Reference herein to any specific commercial product, process, or service by trade name, trademark, manufacturer, or otherwise does not necessarily constitute or imply its endorsement, recommendation, or favoring by the United States Government or any agency thereof. The views and opinions of authors expressed herein do not necessarily state or reflect those of the United States Government or any agency thereof. 


\section{DISCLAIMER}

Portions of this document may be illegible in electronic image products. Images are produced from the best available original document. 


\section{LEGAL NOTICE}

This report was prepared as an account of Government sponsored work. Neither the United States Navy, nor the Commission, nor any person acting on behalf of these agencies:

A. Makes any warranty or representation, express or implied, with respect to the accuracy, completeness, or usefulness of the information contained in this report, or that the use of any information, apparatus, method, or process disclosed in this report may not infringe privately owned rights; or

B. Assumes any liabilities with respect to the use of, or for damages resulting from the use of any information, apparatus, method, or process disclosed in this report.

As used in the above, "person acting on behalf of the Commission or the U. S. Navy" includes any employee or contractor of these agencies to the extent that such employee or contractor prepares, handles or distributes, or provides access to, any information pursuant to his employment or contract with the Commission or the U, S. Navy.

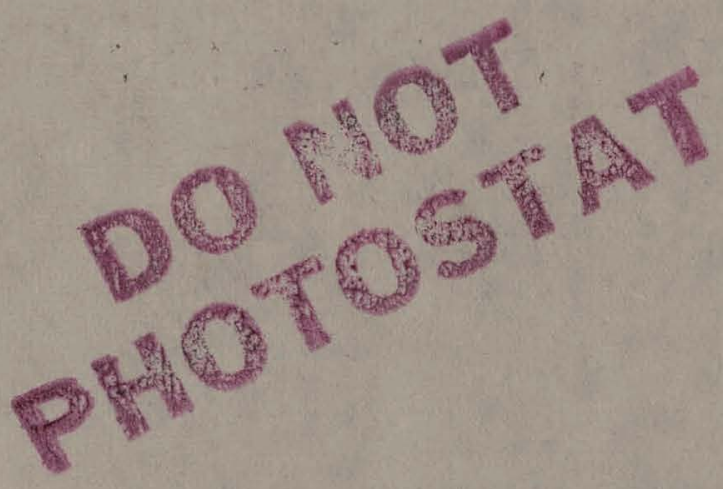


C. W. Maynard

May 1959

Contract AT-11-1-GEN-14

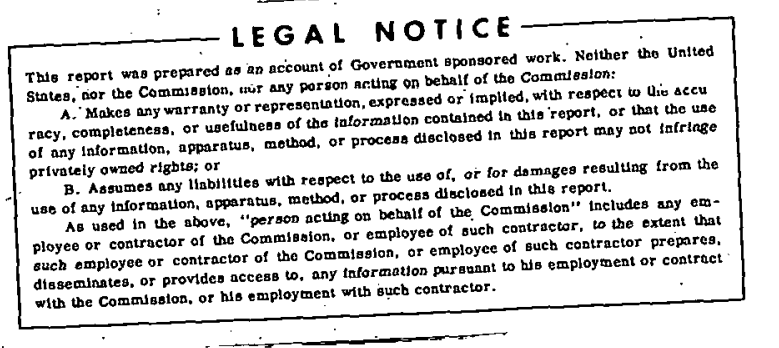

NOTE

This document is an interim memorandum prepared primarily for internal reference and does not represent a final expression of the opinion of Westinghouse. When this memorandum is distributed externally, it is with the express understanding that Westinghouse makes no representation as to completeness, accuracy, or usability of information contained therein.

Operated for the U. S. Atomic Energy Commission by

PITTSBURGH, PA。

Bettis Atomic Power Division

Westinghouse Electric Corporation 
Manager; Pittstargh Naval Reactors Operations Office,

U. S. A tomic Energy Commission

Argonne National Laboratory, W. F。 Miller

Brookhaven National Laboratory, J. Cherniak

Brookhaven National Laboratory, M. Rose

Davi d Taylor Model Basin, H. Polachek

Knolls Atomic Power Laboratory, R。 Ehrlich

Los Alamos Scientific Laboratory; B. Carlson

New York University; R。 Richtmyer

Oak Ridge National Laboratory, A. Householder

University of California Radiation Laboratory, Livermore, S. Fernbach

H. J. Amster

N. Baron .

$R_{0}$ To Bayard

R. J。-Breen

J。 R。 Brown

J. Do Butler

R. Cantwell

$D_{0} R_{0}$ Childs

W. R. Clancey

W. Wo Clendenin

D. Ro Connors

R. C. Cunningham

Jo A. DeJuren

$J$. Ro Feldmeier

M. Jo Galper

R。 Gast

E. $M_{0} \cdot$ Gelbard

M. Goldsmith

J. No" Grace

J. Harlovich

W. H. Hartley

A. F. Henry

S. 0.- Johnson

L. L. Jones

R. To Jones

S. Kaplan

H. Jo Kirk

INTERNAL DISTRIBUTION

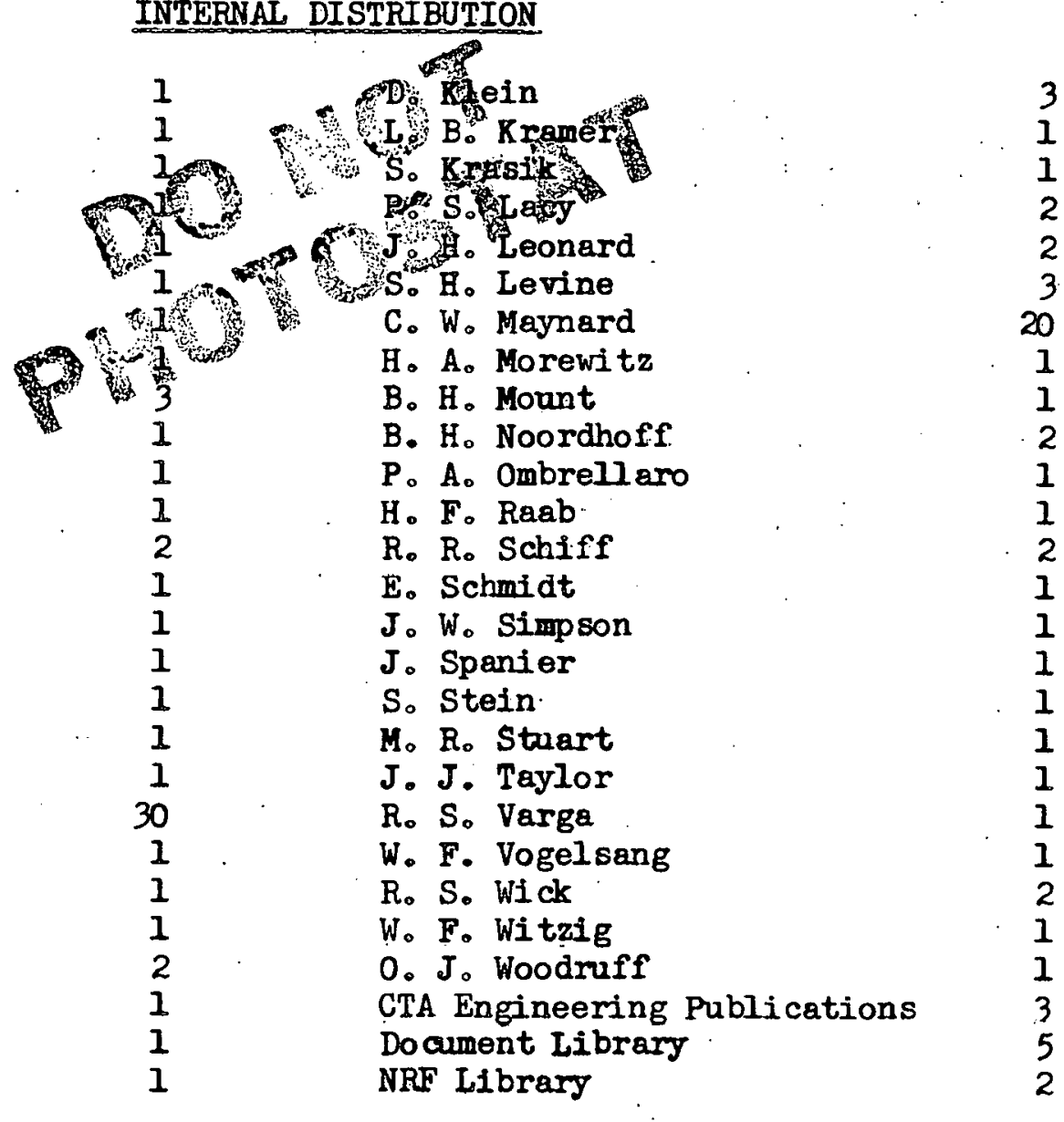

TOTAL 


\section{ABSTRACT}

"Blackness theory" is described as a class of procedures for matching a high order transport approximation in one region to a low order approximation in a second region. The matching conditions are presented as a generalization of the Marshak boundary conditions. The blackness coefficients necessary in setting up the conditions are defined and tables are given for slab geometry.

A method which allows all regions to be treated by means of the blackness coefficients is developed and applied to two region cells. Numerical results are compared with other approximations in situations typical of those encountered in resonance capture and thermal utilization calculations. 


\section{INTRODUCTION}

The term "blackness theory" has come to refer to a class of procedures for matching an approximate solution of the one energy transport equation in one region to a rigorous or very accurate solution in a second region. Such procedures were apparently first used by Placzek to treat purely absorbing media. The matching or boundary conditions; âs formulated here, constitute a generalization of the Marshak boundary conditions. The definitions of the blackness coefficients used in the matching conditions are given first and are related to the capture fractions given by Schiff and Ștein. (1) Next, the conditions are developed for a general three region problem and specialized to cases of particular interest.

A method of treating both regions of a two region cell by means of the blackness coefficients is presented. This "dauble blackness" approximation is then compared to other approximation schemes and a qualitative discussion of the sources of error follows.

\section{BLACKNESS COEFFICIENTS}

The coefficients needed in the matching conditions to be described are obtained by considaring a alab of thickness $T$ isolated in a vacuum as shown in Fig. 1 .

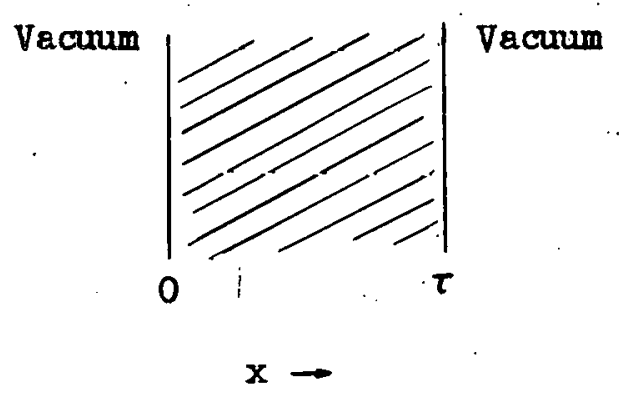

Fig. 1

The alab is assumed to scatter isotropically and has scattering cross section $\Sigma_{s}$ and total cross section $\Sigma$. The angular flux incident on the left boundary is of 
the form $\mu^{n}$ (where $\mu$ is the cosine of the angle between the flux direction and the slab normal) and no neutrons enter the slab from the right. The solution to this problem ast satisfy for $0 \leq x \leq \tau$ :

$$
\mu \frac{\partial \psi_{n}(x, \mu)}{\partial x}+\Sigma \psi_{n}(x, \mu)=\frac{\Sigma}{2} \int_{-1}^{1} d \mu^{\theta} \psi_{n}\left(x, \mu^{\beta}\right)
$$

sabject to

$$
\psi_{n}(0, \mu)=\mu^{n}, \mu>0
$$

and

$$
\psi_{n}(\tau, \mu)=0, \mu<0
$$

The coeffictents of interest are

$$
\mathrm{T}_{\operatorname{mn}}\left(\Sigma \tau, \frac{\Sigma_{s}}{\Sigma}\right)=\int_{0}^{1} d \mu \mu^{m} \psi_{n}(\tau, \mu)
$$

and

$$
R_{m n}\left(\Sigma \tau, \frac{\Sigma_{s}}{\Sigma}\right)=(-1)^{m} \int_{-1}^{0} d \mu \mu^{m} \psi_{n}(0, \mu)
$$

The $T_{m n}$ and $R_{m m}$ are respectively the transmitted and reflected contributions to the outgoing $\mathrm{m}^{\text {th }}$ moments due to a $\mu^{\mathrm{n}}$ incoming flux. They are defined to always be positive numbers and are functions of the optical thickness $\Sigma \tau$ and the scattering to total cross section ratio $\Sigma_{\delta} / \Sigma$.

In addition to the $T_{m n}$ and $R_{m n}$; it is desirable to introduce the escape moments $U_{m}$ detined by

$$
U_{m}\left(\Sigma \tau, \frac{\Sigma}{\Sigma}\right)=\int_{0}^{1} d \mu \mu^{m} \psi_{e}(\tau, \mu)
$$

for the arrangement of Fig. 1. $\psi_{e}(\tau, \mu)$ is the angular flux at the right hand boundary for the problen where no neutrons enter the slab through the boundaries 
but a flat isotropic source of unit density exists in the slab, thus for $0 \leq x \leq T:$

$$
\mu \frac{\partial \psi_{e}(x, \mu)}{\partial x}+\Sigma \psi_{e}(\dot{x}, \mu)=\frac{\Sigma}{2} \int_{-1}^{1} d \mu^{\beta} \psi\left(x, \mu^{\beta}\right)+\frac{1}{2}
$$

with

$$
\psi_{\mathrm{e}}(0, \mu)=0, \mu>0
$$

and

$$
\psi_{e}(\tau, \mu)=0, \mu<0 \text {. }
$$

All escape imoments $\delta_{m}$ except $\delta_{0}$ are related to the $R_{1 n}$ and $T_{1 n}$ by the reciprocity theorem。

Considering a slab with entering angular $f$ ux $|\mu|^{\mathbf{n}}$ at each boundary, the number of neutrons esceping the slab at each boundary is $\mathrm{R}_{\mathrm{In}}+\mathrm{T}_{\mathrm{In}}$. The number of neutrons entering at each boundary is $1 /(n+2)$, thus the escape fraction Is $(n+2)\left(R_{1 n}+T_{I n}\right)$ and the capture fraction becomes:

$$
F_{n}=1-(n+2)\left(R_{1 n}+T_{1 n}\right)
$$

The $F_{n}$ are the quantities tabulated by schiff and Stein, (1) who also relate the escape fractions for an entering $\mu^{n}$ flux to the escape moments for an intemal isotropic flat source. Tho relation obtained io

$$
U_{m}=\frac{F_{m-1}}{2 \Sigma_{a}(m+1)}
$$

or

where

$$
U_{m}=\frac{1-(m+1) s_{1} m-1}{2 \Sigma_{a}(m+1)}
$$

$$
S_{m n}=R_{m n}+T_{m n}
$$

Although the quantities $S_{\operatorname{mn}}$ are not independent of the $R_{m n}$ and $T_{m n}$, they are of See Eq. (7) of Ref。i. 
special importance and are therefore given their own symbol. $S_{m n}$ represents the $m^{\text {th }}$ outgoing half range moment for the entering angular flux $\mu^{n}$ in the case of a cell of half thickness $t=\tau / 2$. $U_{1}$ represents the number of neutrons escaping from each boundary of the slab. Since a source of unit density is present, there are $2 t$ neutrons produced in the slab. Thus $U_{1}$ is related to the escape probability $P_{0}$ through

$$
P_{0}=\sigma_{1} / t
$$

The coefficients presented here are also similar to those presented by other authors. In particalar, our $R_{10}, T_{10}$ and $U_{1}$ are identical to the $R, T$, and $E / 2$ of Wachspress。(2)

In general, the blackness coefficients must be computed numerically: however, in the case of a pure absorber they may be expressed analytically. In this case, there is no reflection and $\mathrm{R}_{\mathrm{mn}}$ is zero. The angular flux is just

$$
\begin{aligned}
\psi_{n}(x, \mu) & =\mu^{n} e^{-\frac{\Sigma x}{\mu}} & & , \mu>0 \\
& =0 & & , \mu<0
\end{aligned}
$$

Therefure

or

$$
T_{m n}(\Sigma T)=S_{m n}(\Sigma \tau)=\int_{0}^{T} d \mu \mu^{m+n_{0}-\frac{\Sigma \tau}{\mu}},
$$

$$
=E_{m+n+2}(\Sigma \tau)
$$

where the $E_{k}(x)$ are the generalized exponential integral functions of order $k$. The values of the $R_{m n}$ and $T_{m n}$ have been calculated for a wide range of $\Sigma T$ and $\Sigma_{g} / \Sigma_{0} \quad$ A discrete ordinates code (3) using the double-Gauss quadrature formula was employed. Twelve, ten, and eight angles were used for optical thicknesses between 0.25 and $1.0,1.25$ and 2.0 , and 2.5 and 20.0 respectively for all except the pure scattering cases. The results have been checked for pure absorbers and for all 4 837006 
scattering ratios where the optical thickness is 20.0. The latter cases are essentially infinite in thickness and in this case the ratio of scalar flux to incident flux can be obtained analytically. Comparison of the thick region results with the analytic results shows an error of less than $0.01 \%$ in all cases. The pure absorber cases were compared with tables of the $\mathrm{E}_{\mathrm{k}}$ functions. For the smallest thickness $(\Sigma \tau=0.25)$ the error was $0.14 \%$, while for all other thicknesses the errors were less than $0.05 \%$. The pure scattering cases were obtained with eight angles and fewer points and are probably only accurate to the order of $1 \%$. The results are tabulated for $m$ and $n$ equal zero and one in Table II. $J_{0}$ which cannot be obtained from the $\mathrm{R}_{\mathrm{mn}}$ and $\mathrm{T}_{\mathrm{mn}}$ is given in Table III and was obtained from calculations with the same code as used for the $R$ and $T$ matrices.

\section{MATCHING CONDITIONS}

The three region case, in which the central region is to be treated only with coefficients which establish conditions on the solutions in the outer regions, is the most general type of problem to be treated. The configuration is shown in Fig. 2 below.

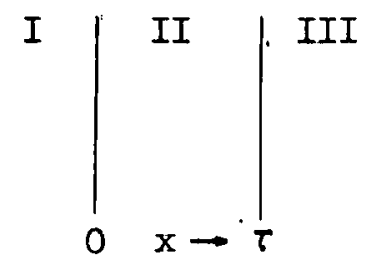

Fig. 2

Region II is restricted to isotropically scattering media and to a flat isotropic source of density $S^{I I}$. The angular fluxes at the two interfaces and in the three regions are designated by:

$$
\psi_{I}(0, \mu), \psi_{I I}(0, \mu), \psi_{I I}(\tau, \mu) \text {, and } \psi_{I I I}(\tau, \mu) \text {. }
$$

An abbreviated version of this table has been published in Ref. 40 
The angular flux at the interface in region $I$ is assumed to be of the form

$$
\begin{aligned}
& \psi_{I}(0, \mu)=\sum_{n=0}^{N} A_{n} \mu^{n}, \mu>0, \\
& \psi_{I}(0, \mu)=\sum_{n=0}^{N} c_{n} \mu^{n}, \mu<0 .
\end{aligned}
$$

In region III at $x=\tau$ the angular flux is assumed given by:

$$
\psi_{I I I}(\tau, \dot{\mu})=\sum_{n=0}^{N} B_{n} \mu^{n}, \mu<0 ;
$$

and

$$
\psi_{\text {III }}(\tau, \mu)=\sum_{n=0}^{N} D_{n} \mu^{n}, \mu>0 。
$$

Entering region II, the flux is considered to be continuous across the boundaries as in transport theory, thus:

$$
\psi_{I I}(0, \mu)=\psi_{I}(0, \mu) \quad, \mu>0 ;
$$

and

$$
\psi_{I I}(\tau, \mu)=\psi_{I I I}(\tau, \mu), \quad \mu<0
$$

Leaving region II, the half range moments of the flux are assumed continuous across the interfaces (since the entering fluxes are al ready continuous, this is equivalent to making the full range moments continuous). Denote the $m^{\text {th }}$ half range moment of the fIux leaving region II at the $x=0$ interface ( $i_{0} e_{0}$ to the left) by $L_{\text {II }}^{m}(0)$, and the left half range moment at the interface in region $I$ by $L_{I}^{m}(0)_{0}$. Similarly, at the interface of regions II and III the right hand moments are denoted by $R_{I I}^{m}(\tau)$ and $R_{I I I}^{m}(\tau)$ respectively。 The boundary conditions on the flux leaving region II can now be stated as:

$$
\mathrm{I}_{I}^{\mathrm{m}}(0)=\mathrm{L}_{I I}^{\mathbf{m}}(0)
$$

and

$$
\mathrm{R}_{I I}^{\mathrm{m}}(\tau)=\mathrm{R}_{\mathrm{III}}^{\mathrm{m}}(\tau)
$$


$L_{I}^{m}(0)$ is given by

$$
I_{I}^{m}(0)=\int_{-1}^{0} d \mu \mu^{m} \sum_{n=0}^{N} c_{n} \mu^{n}=\sum_{n=0}^{N} \frac{(-1)^{m+n_{C}} C_{n}}{m+n+1}
$$

while $I_{I I}^{m}(0)$ is

$$
I_{I I}^{m}(0)=\sum_{n=0}^{N}\left[(-1)^{m} m_{m n}^{m_{n}}+(-1)^{m+n_{T}}{ }_{m n} B_{n}\right]+(-1)^{m}{ }^{m} I_{U_{m}}
$$

Equating these yields:

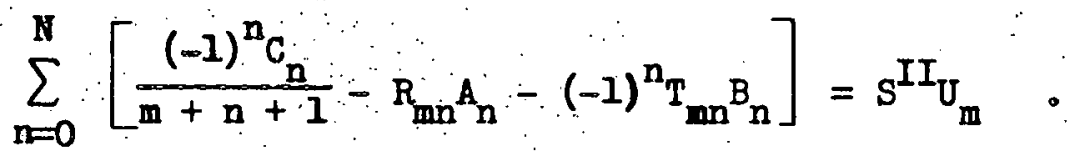

Letting $m$ range from 0 to $N$ gives $N+I$ conditions on the $3 N+3$ variables $A_{n}$, $B_{n}$, and $C_{n}$. At the other interface $R_{I I I}^{m}(\tau)$ is found to be

$$
\mathrm{R}_{I I I}^{m}(\tau)=\int_{0}^{l} d \mu \mu^{m} \sum_{n=0}^{N} D_{n} \mu^{n}=\sum_{n=0}^{N} \frac{D_{n}}{m+n+1}
$$

while $R_{I I}^{m}(\tau)$ is

$$
R_{I I}^{m}(\tau)=\sum_{n=0}^{N}\left[(-1) R_{m n} B_{n}+T_{m n} A_{n}\right]+S^{I I_{U}}
$$

Equating these expressions ylelds

$$
\sum_{n=0}^{N}\left[\frac{D_{n}}{m+n+1}-(-1)^{n_{n}} h_{m n}-T_{m n} A_{n}\right]=s^{I I_{j}},
$$

a set of $N+1$ conditions for $m=0$ to $N$ on the coefficients $A_{n}, B_{n}$, and $D_{n}$. Taken with the previous $N+1$ conditions there are in all $2 N+2$ conditions on the $4 N+4$ coefficients $A_{n}, B_{n}, C_{n}$, and $D_{n}$. This is the correct number of conditions since the conditions are complete at the two boundaries treated and an equal number of conditions can be fixed at the other two boundaries of regions I and III.

Variuus special cases can now be discussed. If for examplc, the boundary vector fluxes in regions I and III are actually expanded in a power series in $\mu$ $t 0$ 
WAPD-TM-168

for the full range of $\mu\left(1, e_{0}-1\right.$ to 1$)$, this requires

$$
A_{n}=C_{n}
$$

and

$$
B_{n}=\ddot{D}_{n}
$$

In this case the matching conditions become

and

$$
\sum_{m=0}^{N}\left[\left(\frac{(-1)^{n}}{m+n+1}-R_{m n}\right) A_{n}-(-1)^{n_{T}} B_{n}\right]=S^{I I_{U_{m}}},
$$

$$
\sum_{n=0}^{N}\left[\left(\frac{1}{m+n+1}-(-1) \cdot R_{m}^{n_{m}}\right) B_{n}-T_{m n} A_{n}\right]=S^{I I_{U_{m}}}
$$

However only $\mathrm{N}+1$ of the $2 \mathrm{~N}+2$ relations can be used in this case. There are correspondingly only $2 \mathrm{~N}+2$ coefficients involved. It turns out that one can match the even or the odd moments and obtain the transport boundary conditions In the limit where $N$ tends to infinity. The odd moments are usually chosen in order to include the first moment which brings about neutron conservation. The reasoning involved in deciding that only even or odd moments can be matched is the same as that given by Stein in WAPL-139. (5) It is only necessary to point out that in matching the vector flux to the right (or left) and the half range moments to the left (or right), one is of necessity matching $\psi$ for $\mu>0$ (or $\mu<0)$ and the full range moments, thus his arguments may be taken over directly. Another special case of considerable interest is that of a slab cell. This case is obtained by taking the center line of region II as an axis of symetry and requiring in the present notation:

$$
B_{n}=(-1)^{n_{A}},
$$

and

$$
D_{n}=(-1)^{n_{n}} C_{n}
$$


Substitation in the matching conditions yields

$$
\sum_{n=0}^{N}\left[\frac{(-1)^{n} C_{n}}{n+n+1}-s_{m n} A_{n}^{n}\right]=s^{I I_{J_{m}}}
$$

at either boundary. This is a set of $N+1$ conditions on the $2 N+2$ coefficients $A_{n}$ and $C_{n}$. In the speciel case of $N=0$, the first moment is usually matched even though it goes. Wth a power of $\mu$ not included in the angular flux. However it is needed for neutron conservation. If full range expansions are used the $C_{n}$ are again equal to the $A_{n}$ and the conditions become:

$$
\sum_{n=0}^{N}\left[\frac{(-1)^{n}}{m+n+1}-s_{m n}\right] A_{n}=s^{I I_{U_{m}}},
$$

where only the $(N+1) / 2$ odd or even $m^{8} s$ may be used.

The matching conditions reduce in spectal cases to a mumber of well known boundary conditions. For example the blackness boundary conditions for the $P_{1}$ approximation in a cell are the same as those given by stein $(5)$ and in the noncellular case are the same as those of coldsmith. (6) If $D-P_{N}$ equations of the same order as the matching conditions were used to calculate the blackness coefficients, the conditions would be identical with those introduced by Bengston for Yvon's method. (7) The boundary conditions presented here may be used in the Bettis FLIP 2 code. (8) The relation between the blackness coefficients and the input parameters of the code is given in Appendix A.

\section{DOUBLE BLACKNESS}

In the previous section, no mention was made of the approximation of the transport equation to be used in the outer regions. It was only necessary to require a full or half range expansion of the solution at the boundary. This 
makes the conditions fit in rather naturally with the $P_{n}$ and $D-P_{n}$ approximations. However, a different approximation can be obtained by use of the transport equation itself in the outer regions provided only isotropic flat sources occur there. The restriction to flat isotropic sources is not necessary in principle, but the escape moments for sources of other shapes would lead to an inordinate amount of tabulation and is thus impractical. Such an approach requires solutions of the transport equation which reduce to powers of $\mu$ at the interface, but these are just the solutions obtained in calcalating the blackness coefficients. Thus if the main interest is in properties of solutions at interfaces, the blackness coefficients can be applied to all regions of a problem. This method will be celled the double blackness (D-BI) approximation. The method is applied here to a two region cell as shown in Fig. 3.

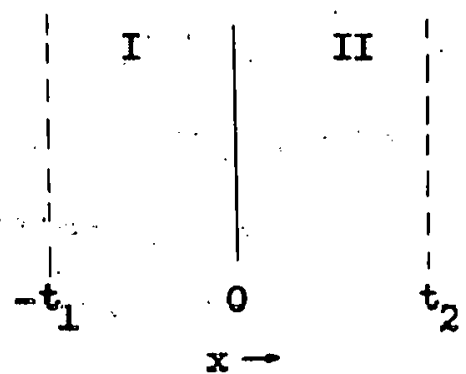

FIg. 3

As blackness coefficients for both regions are to be used, the region referred to Is indicated by a superscript I or II. Flat isotropic sources of density $S^{I}$ and $S^{I I}$ are assumed present in reglons I and II respectively. The angular flux at the interface as in the previous treatment of a cell is assumed to have the form:

$$
\begin{aligned}
\psi(0 ; \mu) & =\sum_{n=0}^{N} A_{n} \mu^{n}, \mu>0 \\
\therefore \therefore: & =\sum_{n=0}^{N} c_{n} \mu^{n}, \mu<0
\end{aligned}
$$


The right going half range mowents in I and II are

$$
R_{I}^{m}=\sum_{n=0}^{k}(-I)^{n} s_{m n}^{I} c_{n}+s^{I} v_{m}^{I}
$$

and

$$
\mathrm{R}_{I I}^{\mathrm{m}}=\sum_{n=0}^{N} \frac{A_{n}}{\mathrm{n}+\mathrm{n}+I}
$$

The left going half range moments are

$$
I_{I}^{m}=\sum_{n=0}^{N} \frac{(-1)^{m+n_{C}}}{m+n+1}
$$

and

$$
\mathrm{L}_{I I}^{\mathrm{m}}=\sum_{\mathrm{m}=0}^{N}(-1)^{m_{S}}{ }_{m m^{I I}} A_{n}+(-I)^{m_{S} I I_{U_{m}}^{I I}}
$$

Equating the two left and right going moments gives:

$$
\sum_{n=0}^{N}\left[\frac{A_{n}}{m+n+I}-(-1)^{n} S_{m n}^{I} c_{n}\right]=s^{I} U_{m}^{I},
$$

and

$$
\sum_{n=0}^{N}\left[\frac{(-1)^{n C_{n}}}{m+n+1}-s_{m n}^{I I} I_{n}\right]=s^{I I_{U_{m}} I I} \text {. }
$$

This is a set of $2 N+2$ equations in the $2 N+2$ unknowns $A_{n}$ and $C$. They can be solved and $\psi(o, \mu)$ constructed. Then $j$ for example is given by

$$
\mathbf{j}=\sum_{n=0}^{N} \frac{A_{n}-(-1)^{n} C_{n}}{n+2}
$$

while $\varphi$ becomes

$$
\varphi=\sum_{n=0}^{N} \frac{A_{n}+(-1)^{n} C_{n}}{n+1}
$$


As an example, the lowest order expansion would be to assume the flux isotropic in both directions, $i_{0} e_{0} \cdot N=0$. The equations for matching the first moments $(m=1)$ are then:

$$
\begin{aligned}
& \frac{1}{2} c_{0}-s_{10}^{I I} A_{0}=S^{I I_{U_{1}}^{I I}}, \\
& \frac{1}{2} A_{0}-s_{10}^{I} C_{0}=S^{I_{U_{1}}^{I}},
\end{aligned}
$$

Here

$$
j=\frac{1}{2}\left(A_{0}-C_{0}\right) \text { and } \varphi=A_{0}+C_{0}
$$

which on solving the equations leads to

$$
j=\frac{s^{I_{U}^{I}}\left(1-2 s_{10}^{I I}\right)-s^{I I_{U} I I}\left(1-2 s_{10}^{I}\right)}{1-4 s_{10}^{I} s_{10}^{I I}}
$$

and

$$
\varphi=\frac{2 S^{I} I\left(1+2 S_{I 0}^{I I}\right)+2 S^{I I} U_{I}^{I I}\left(1+2 S_{10}^{I I}\right)}{1-4 S_{10}^{I} S_{10}^{I I}}
$$

This is called the $\mathrm{D}-\mathrm{B} 1_{0}$ approximation, and it reduces to the ordinary $\mathrm{D}_{\mathrm{P}} \mathrm{P}_{0}$ result for the two region problem if the $S_{m n}$ and $U_{m}$ are calcalated in the $D-P_{0}$ approximation for each region. The next order approximation where $N=1$ (the $\mathrm{D}-\mathrm{BI}$ ) approximation) can be worked out similarly.

\section{APPLICATIONS AND RESULTS}

There are three main types of problems for which the D-BI approximations have been considered. These are the problems of resonance capture in a slab cell, absorption in control rods, and thermal utilization in a cell. Sample calculations have been carried out for the first and third of these problems. In the 
resonance captare problem, the moderator 18 assumed to rewio the neutrons from the narrow group containing the resonance. This results in the moderator beling treated formally as a pure apsorber. The fuel scattering may remove neutrions fros the group or scatter them isotropically depending on whether the resonance 1s assumed thin or thick for fuel moderation. Flat isotropic sources due to slowing In from above the resonance can be introduced in both regions, or in the moderator alone. In either case, knowledge of the current enables a calculation of the resonance absorption. Several series of problems of this type have been solved for the current. In the case of two pure absorbers with a source in the moderating regian, a transport solution in integral form was evaluated numerically. The results are used for comparison and are shown in Fig. 4. The $D-B I_{0}$ and $D-B I_{1}$ approximations ( $f_{0} e_{0}$ using the lowest two orders of expansion); and the $P_{1}$ ?. $D-P_{0}$, and D-P approximations in region II with a blackness treatment of region $I$ have been used to solve the same series of problems. The approximate currents are divided by the corresponding transport solutions and plotted against the optical half thickness of region II holding region I constant. The results are shown in Figs. 5, 6, and 7 for $\Sigma_{1} t_{1}$ equal $0.5,1.0$, and 10 , deviation from one representing the fractional error in the approximation. The D-BI results are not shown on Fig. 7 since they are exact in that case. Figure 5 shows the poorest $D_{-} B 1_{0}$ and $\mathrm{D}-\mathrm{Bl}_{1}$ results for this type problem. These curves show a maximum error of only $0.5 \%$ for $\mathrm{D}-\mathrm{BI} \mathrm{I}_{1}$ and $3 \%$ for $\mathrm{D}-\mathrm{Bl} \mathrm{O}_{0}$, which represents a considerable improvement over the other comparable approximations. The situation encountered in calcalating thermal utilization in a two region slab cell is that of a strong absorber with scattering next to a weakly absorbing but strongly scattering moderator containing a flat isotropic source. The quantity needed to obtain the thermal utilization constant is the ratio of the average flux in the fuel to the average flux in the moderator. This ratio oan be obtained from a knowledge of the source atrength 
in the moderator, the interface current, and the physical parameters of the cell. With a source in the moderator only, the average flux in the fuel is just

$$
\bar{\varphi}_{f}=\frac{j}{\Sigma_{a f} \bar{t}_{f}}
$$

while neutron balance in the moderator gives

$$
\bar{\varphi}_{m}=\frac{s_{m} t_{m}-j}{\Sigma_{a m} t_{m}} 。
$$

The flux ratio is then

$$
\frac{\bar{\varphi}_{f}}{\bar{\varphi}_{m}}=\frac{\Sigma_{a m} t_{m}}{\Sigma_{a f} t_{f}} \frac{1}{s_{m} t_{m}-j} .
$$

This ratio has been calculated using the $D-B I_{0}$ and $D-B l_{1}$ approximations of the current, for a group of problems covering a variety of cells for which the results are avallable from a number of other approximations. (9) A discrete ordinates solution of the problems is also available and has been used for comparison. All results are tabulated in $\mathrm{Table} \mathrm{I}_{0}$. The $\mathrm{D}-\mathrm{BI}_{0}$ results are seen to be comparable in most cases to the $\mathrm{D}^{-\mathrm{P}_{1}}$ approximation while the $\mathrm{D}-\mathrm{Bl} \mathrm{l}_{1}$ results are usually a significant improvement over other epproximations. However, it should be noted again that the problems are for moderators having isotroplc scattering and a flat source. This limits the ability to approximate the thermal utilization where anisotropic scattering and spatially varying sources are important.

A stady of Figs, 5, 6, and 7 shows that all of the approximations have their maximum errors for a cell half thickness in the neighborhood of a quarter. to a half of a mean free path. This is also in agreement with the results in Table I. It appears that for a flat source in a region of this optical thickness, the interface flux varies in a very complicated manner as a function of angle which cannot adequately be represented by a low order polynomial in $\mu_{0}$. Away from 14 $837 \cdot 16$ 
the interface this is still true for these problems but since the blackness coefficients are calculated in a high order approximation, the double blackness approach picks up a considerable part of the error caused by the imposed boundary conditions.

\section{SUMMARY AND CONCLUSIONS}

Blackness coefficients have been defined and tables for low order approximations in isotropicaliy scattering slabs presented. The use of these coefficients has been developed as a system of boundary conditions at an interface. A method of "double blackness" has been described in which all regions are treated by means of the blackness coefficients. This method has been applied to a two region cell and numerical results compared with other approximations. The method is found to give better accuracy than other low order approximations while requiring only the use of the takles and hand calculation. 
INTERFACE CURRENT. IN PURELY ABSORBING: SLAB: CELL WITH FLAT SOURCE IN ONE REGION

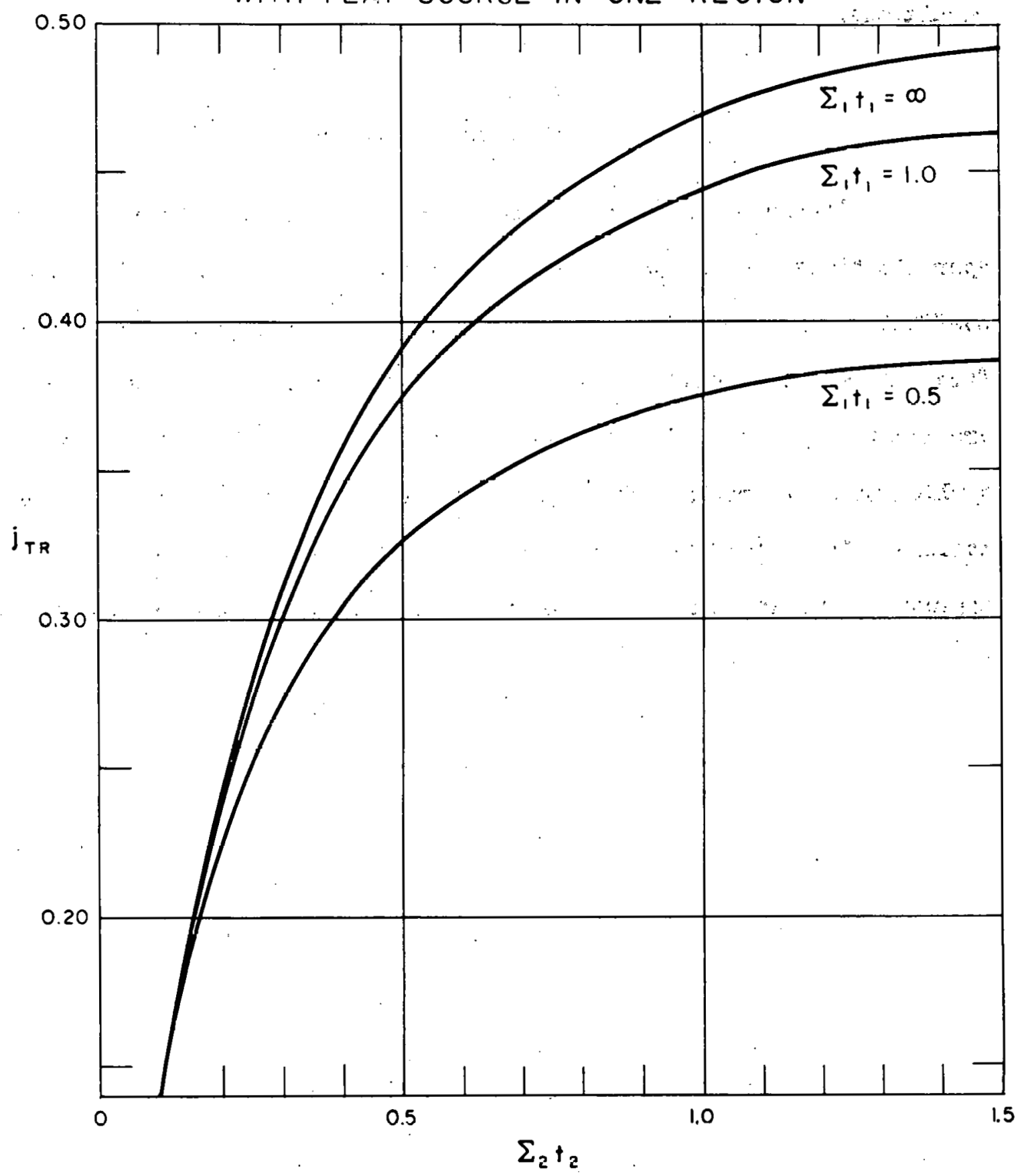


WAPD-TM-168

RATIO OF. CURRENT PREDICTED BY VARIOUS BLACKNESS APPROXIMATIONS TO TRANSPORT THEORY RESULT .

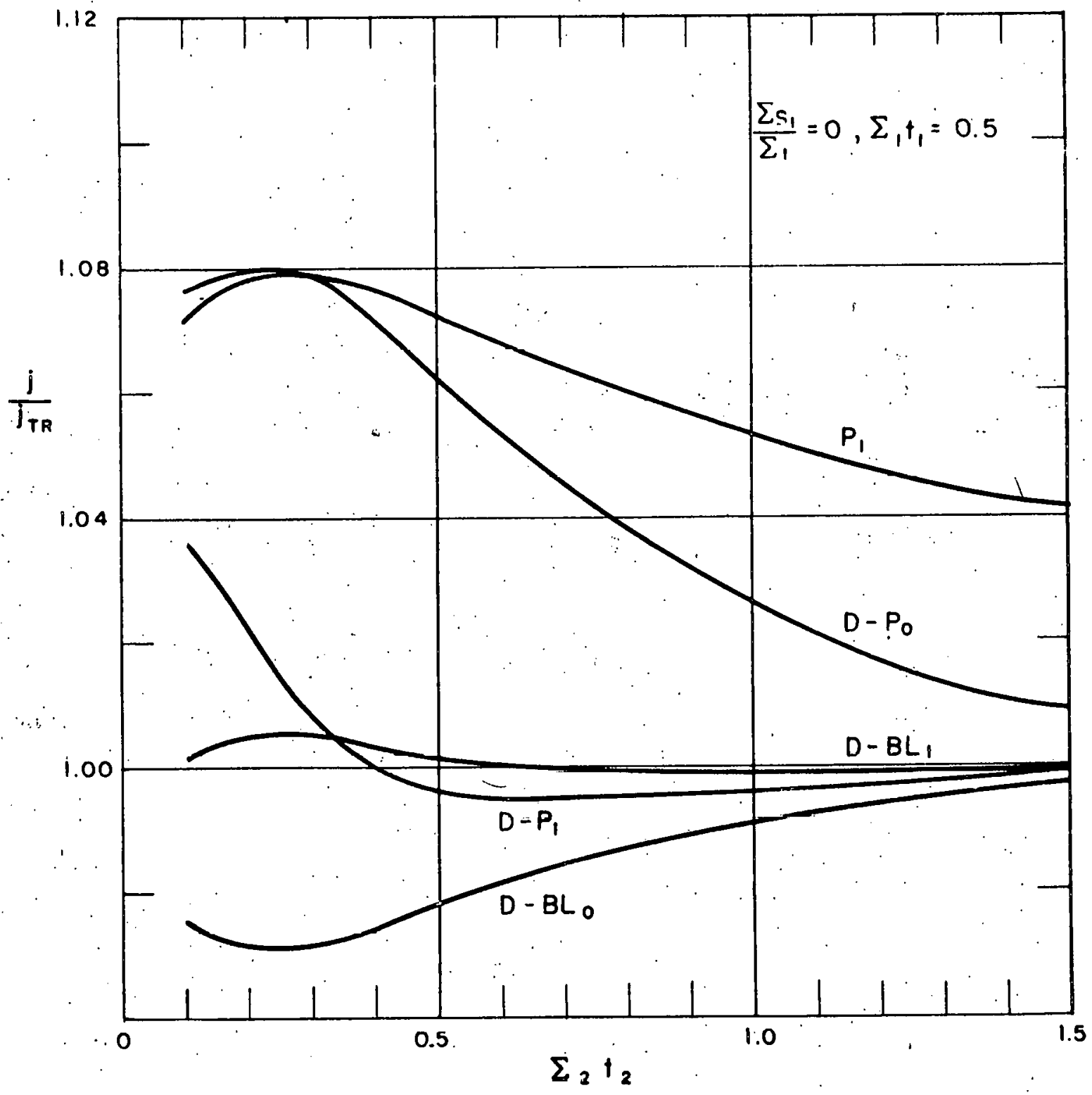

Fig. 5 
WAPD-TM-168

RATIO OF CURRENT PREDICTED BY VARIOUS BLACKNESS

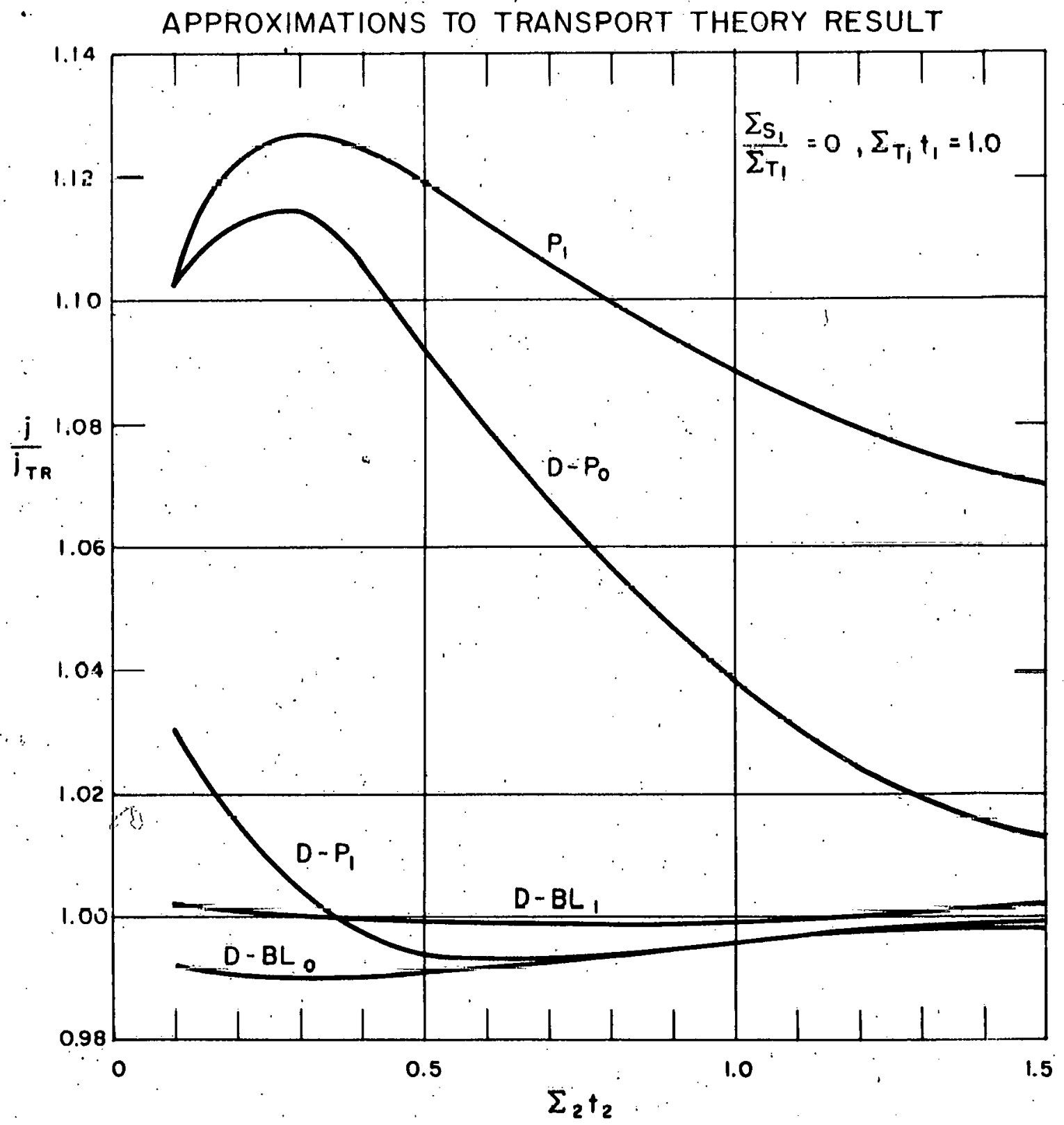




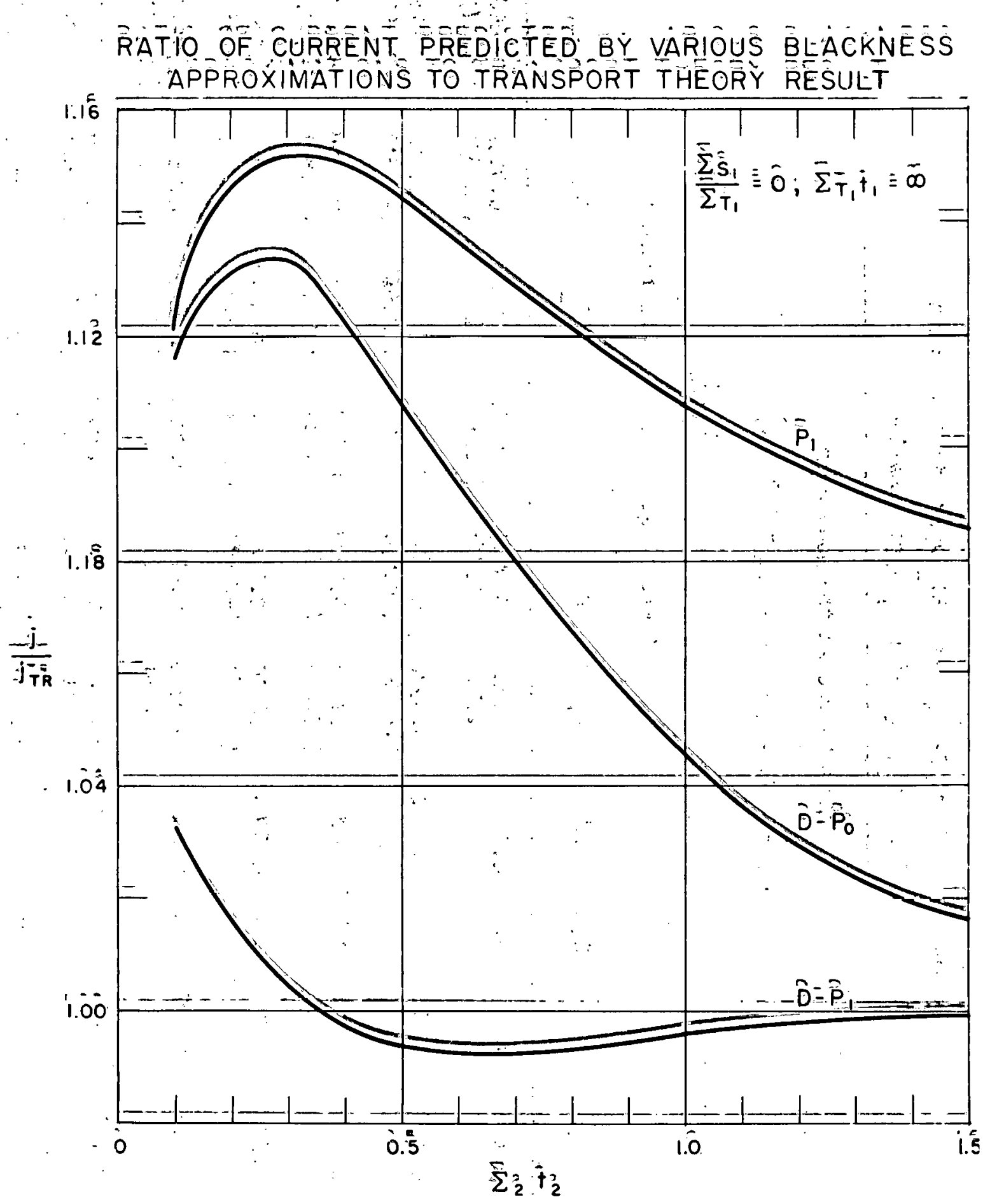


Table I

Comparison of the $\cdot \mathrm{D}-\mathrm{Bl} \mathrm{O}_{0}$ and $\left.\mathrm{D}-\mathrm{Bl}\right]_{1}$ Approximations with the

$P_{1}, D-P_{0}, P_{3}$ and $D-P_{1}$ Approximations

$\stackrel{\infty}{\omega}$

Orit Source in the Moderator

$$
\Sigma_{\text {sf }}=0.3, \Sigma_{\text {am }}=0.02, \Sigma_{\text {sm }}=3.12, \bar{\mu}_{\mathbf{m}}=0
$$

Problem Parameters

$$
\overline{\varphi_{\mathrm{f}}} / \overline{\varphi_{\mathrm{m}}}
$$

\begin{tabular}{|c|c|c|c|c|c|c|c|c|c|c|}
\hline $\begin{array}{l}\text { Problem } \\
\text { Number }\end{array}$ & $t_{m}$ & $t_{\boldsymbol{f}}$ & $\Sigma_{\text {af }}$ & RDR 4 & $\mathbf{P}_{1}$ & $\mathrm{DP}_{\mathrm{a}}$ & $P_{3}$ & $\mathrm{DP}_{1}$ & $D-B 1_{0}$ & $\mathrm{D}-\mathrm{Bl}_{1}$ \\
\hline 1 & 0.127 & 0.127 & 0.1 & 0.9685 & $\begin{array}{c}0.9943 \\
(2.7 \%)\end{array}$ & $\begin{array}{l}0.9925 \\
(.2 .58)\end{array}$ & $\left(\begin{array}{l}0.9888 \\
(2.1 \%)\end{array}\right.$ & $\begin{array}{r}0.9803 \\
(1.28)\end{array}$ & $\begin{array}{c}0.9652 \\
(-0.36)\end{array}$ & $\begin{array}{c}0.9698 \\
(0.1 \%)\end{array}$ \\
\hline 2 & 0.127. & 1.27 . & 0.1 & 0.7824 & $\begin{array}{r}0.8974 \\
(14.7 \%)\end{array}$ & $\begin{array}{l}0.8680 \\
(10.9 \%)\end{array}$ & $\begin{array}{l}0.8310 \\
(6.2 \%)\end{array}$ & $\begin{array}{l}0.7775 \\
(-0.6 \%)\end{array}$ & $\begin{array}{l}0.7721 \\
(-1.3 \%)\end{array}$ & $\begin{array}{r}0.7816 \\
(-0.09 \%\end{array}$ \\
\hline 3 & 1.27. & 0.127 & 0.1 & 0.9209 & $\begin{array}{l}0.9523 \\
(3.486) .\end{array}$ & $\begin{array}{l}0.9377 \\
(1.8 \%)\end{array}$ & $\begin{array}{c}0.9377 \\
(1.8 \%)\end{array}$ & $\left(\begin{array}{c}0.0282 \\
0.3 \%)\end{array}\right.$ & $\begin{array}{c}0.9288 \\
(0.98)\end{array}$ & $\begin{array}{c}0.9177 \\
(-0.38)\end{array}$ \\
\hline 4 & 1.27 & 1.27 & 0.1 & 0.5904 & $\begin{array}{r}0.6410 \\
(8.6 \%)\end{array}$ & $\begin{array}{l}0.5740 \\
(-2.8 \%)\end{array}$ & $\begin{array}{l}0.5977 \\
(1.2 \%)\end{array}$ & $\begin{array}{l}0.5573 \\
(-0.5 \%)\end{array}$ & $\begin{array}{c}0.5966 \\
(1.18)\end{array}$ & $\begin{array}{l}0.5903 \\
(-0.2 \%)\end{array}$ \\
\hline 5 & 0.127 & 0.127 & 1.0 & 0.7881 & $\begin{array}{r}0.9333 \\
(18.4 \%)\end{array}$ & $\begin{array}{l}0.9130 \\
(15.8 \%)\end{array}$ & $\begin{array}{r}0.8789 \\
(11.5 \%)\end{array}$ & $\begin{array}{r}0.8135 \\
(3.2 \%)\end{array}$ & $\begin{array}{l}0.7620 \\
(-3.3 \%)\end{array}$ & $\begin{array}{l}0.7914 \\
(+0.4 \%)\end{array}$ \\
\hline 6 & 0.127 & 1.27 & 1.0 & 0.2300 & $\begin{array}{c}0.328= \\
(42.78) ;\end{array}$ & $\begin{array}{c}0.2786 \\
(21.1 \%)\end{array}$ & $\begin{array}{l}0.2549 \\
(10.8 \%)\end{array}$ & $\begin{array}{l}0.2233 \\
(-2.98)\end{array}$ & $\begin{array}{c}0.2279 \\
(-0.9 \%)\end{array}$ & $\begin{array}{l}0.2272 \\
(-1.28)\end{array}$ \\
\hline 7 & 1.27 & 0.127 & 1.0 & 0.5720 & $\begin{array}{c}0.6591^{\circ} \\
(15.28)\end{array}$ & $\begin{array}{r}0.5933 \\
(3.78)\end{array}$ & $\begin{array}{r}0.6009 \\
(.5 .1 \%)\end{array}$ & $\begin{array}{c}0.5745 \\
(0.48)\end{array}$ & $\begin{array}{r}0.5905 \\
(3.28)\end{array}$ & $\begin{array}{r}0.5692 \\
(-0.58)\end{array}$ \\
\hline 8 & 1.27 & 1.27 & 1.0 & 0.1219 & $\begin{array}{c}0.1333 \\
(9.486)\end{array}$ & $\begin{array}{c}0.1054 \\
(-13.5 \%)\end{array}$ & $\begin{array}{c}0.1230 \\
(0.9 \%)\end{array}$ & $\begin{array}{c}0.1278 \\
(-0.1 \%)\end{array}$ & $\left(\begin{array}{r}0.1219 \\
0 \%\end{array}\right)$ & $\begin{array}{r}0.1219 \\
0 \%\end{array}$ \\
\hline
\end{tabular}

(Percentage errors in parentheses) 


\section{APPENDIX A}

FLIP 2, an IBM 704 code which solves the $P_{n}$ and $D-P_{n}$ equations in alab geometry, can use boundary conditions of the form

$$
\begin{aligned}
& \psi_{0}=a_{1} x_{0}+b_{1} x_{1} \\
& \psi_{1}=a_{2} x_{0}+b_{2} x_{1}
\end{aligned}
$$

to eliminate a symetrically located region in the D-P approximation. $a_{1}, b_{1}$, $a_{2}$, and $b_{2}$ are input parameters. In this case the angular flux is assumed to have the form

$$
\begin{aligned}
\psi(\mu) & =\psi_{0}+3 \psi_{1}(2 \mu-1), \quad \mu>0 \\
& =x_{0}+3 x_{1}(2 \mu+1), \mu<0
\end{aligned}
$$

or more conveniently:

$$
\begin{aligned}
\psi(\mu) & =\left(\psi_{0}-3 \psi_{1}\right)+6 \psi_{1} \mu, \mu>0 \\
& =\left(x_{0}+3 x_{1}\right)+6 x_{1} \mu, \mu<0
\end{aligned}
$$

The blackness matching conditions now give at a left hand boundary

$$
\begin{aligned}
& s_{00}\left(x_{0}+3 x_{1}\right)-6 s_{01} x_{1}=\psi_{0} \\
& s_{10}\left(x_{0}+3 x_{1}\right)-6 s_{11} x_{1}=\frac{1}{2} \psi_{0}+\frac{1}{2} \psi_{1}
\end{aligned}
$$

or

$$
\begin{aligned}
& \psi_{0}=s_{00} x_{0}+3 \cdot\left(s_{00}-2 s_{01}\right) x_{1} \\
& \psi_{1}=\left(2 s_{10}-s_{00}\right) x_{0}+3\left(2 s_{10}-s_{00}+2 s_{01}-4 s_{11}\right) x_{1}
\end{aligned}
$$


WAPD-TM-168

The code input parameters are thus ven in tierms of the blackness coefficients as

$$
\begin{aligned}
& a_{1}=s_{00} \\
& b_{1}=3\left(8_{00}-2 s_{01}\right) \\
& a_{2}=\left(2 s_{10}-s_{00}\right) \\
& b_{2}=3\left(2 s_{10}-s_{00}+2 s_{01}-4 s_{11}\right) .
\end{aligned}
$$

These expressions are also true at a right hand boundary in FLIP 2. 


\section{ACKNOWLEDGMENTS}

The author wishes to thank Dr. S. Stein and Dr. E. Gelbard for many helpful discussions of several aspects of this work and Mr. L. Hagenan whose discrete ordinates codes were employed in obtaining the tables. 
WAPD-TM-168

Table II

Blackness Coefficients for Slabs

$\Sigma \tau$ from 0.25 to 20.0

$\frac{\Sigma}{\Sigma}$ from 0 to 1.0 in increments of 0.1 


$$
W A P D-T M-168
$$

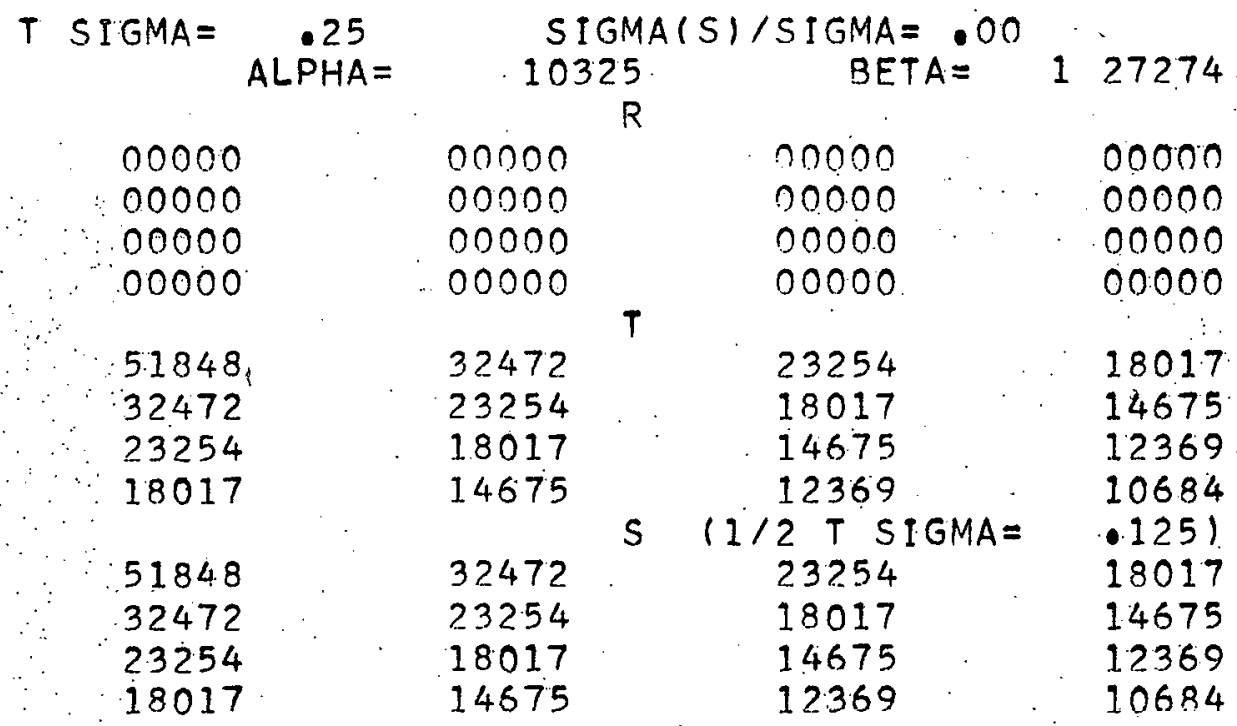

\section{T. $S I G M A=$

$A L \stackrel{50}{\text { PHA }}=$

00000

.00000

00000

00000

32652

22156

16524

13098

32652

22156

16524

13098

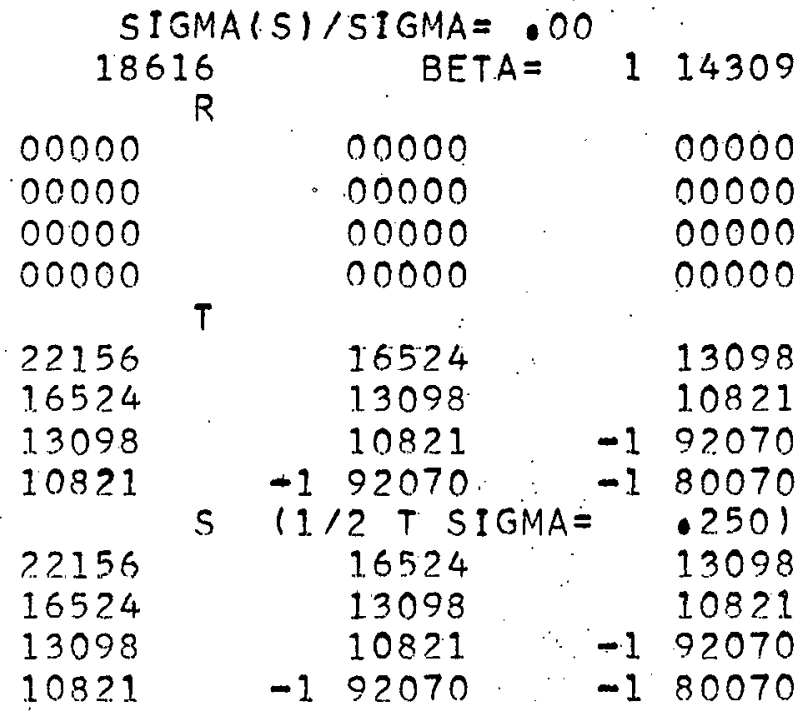

T SIGMA = .

7.5
$A L P H A=$

\section{SIGMA} 25455

00000

00000

00000

00000

15476

11876

$-195822$

$-180098$

$-195822$

21700

15476

11876

$-195822$
.15476

11876

$-19582 ?$

$-180098$

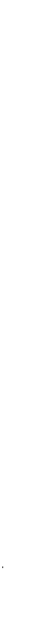

$B E T A=110172$

ก0000

00000

00000

00000

$00000 \quad 00000$

กอחกn

กnกก?

$\begin{array}{llll} & 11876 & -1 & 95822 \\ -1 & 95822 & -1 & 80098 \\ -1 & 80098 & -1 . & 68714 \\ -1 & 68714 & -1 & 60118 \\ (1 / 2 \text { T SIGMA } & = & .375) \\ & 11876 & -1 & 95827 \\ -1 & 95822 & -1 & 80098 \\ -1 & 80098 & -1 & 68714 \\ -1 & 68714 & -1.60118\end{array}$




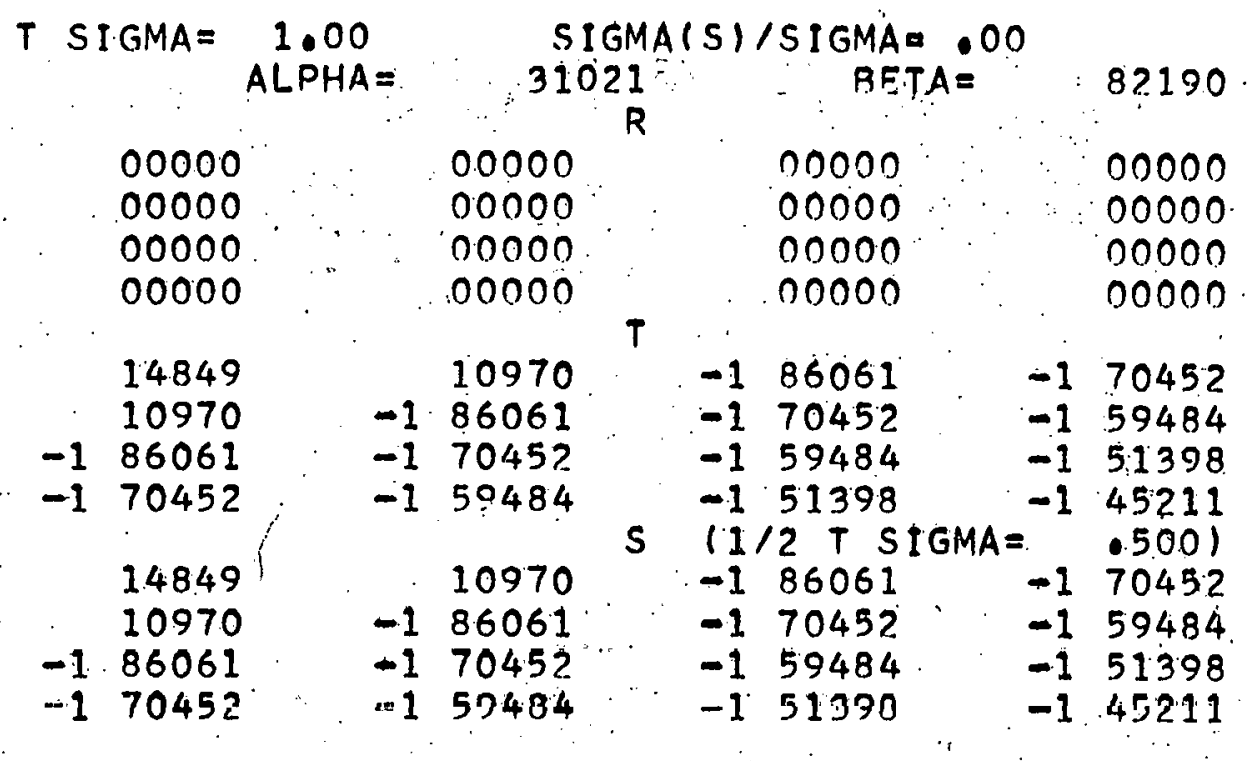

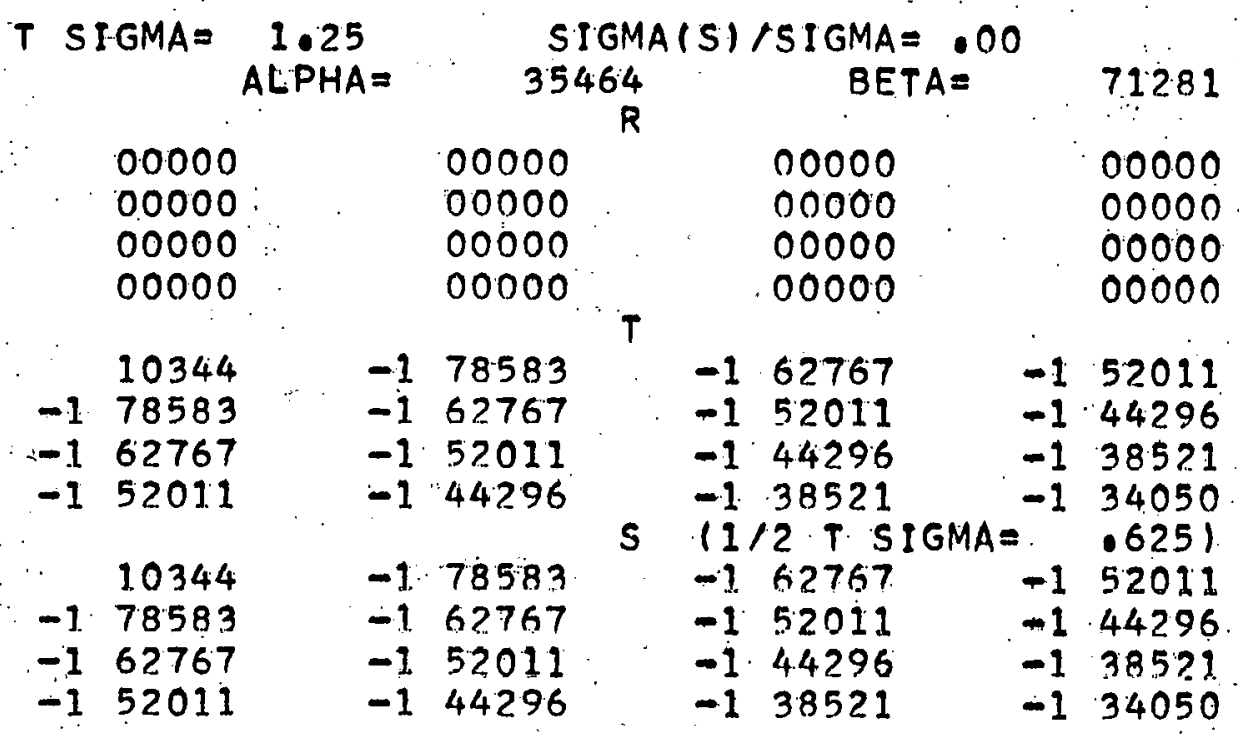

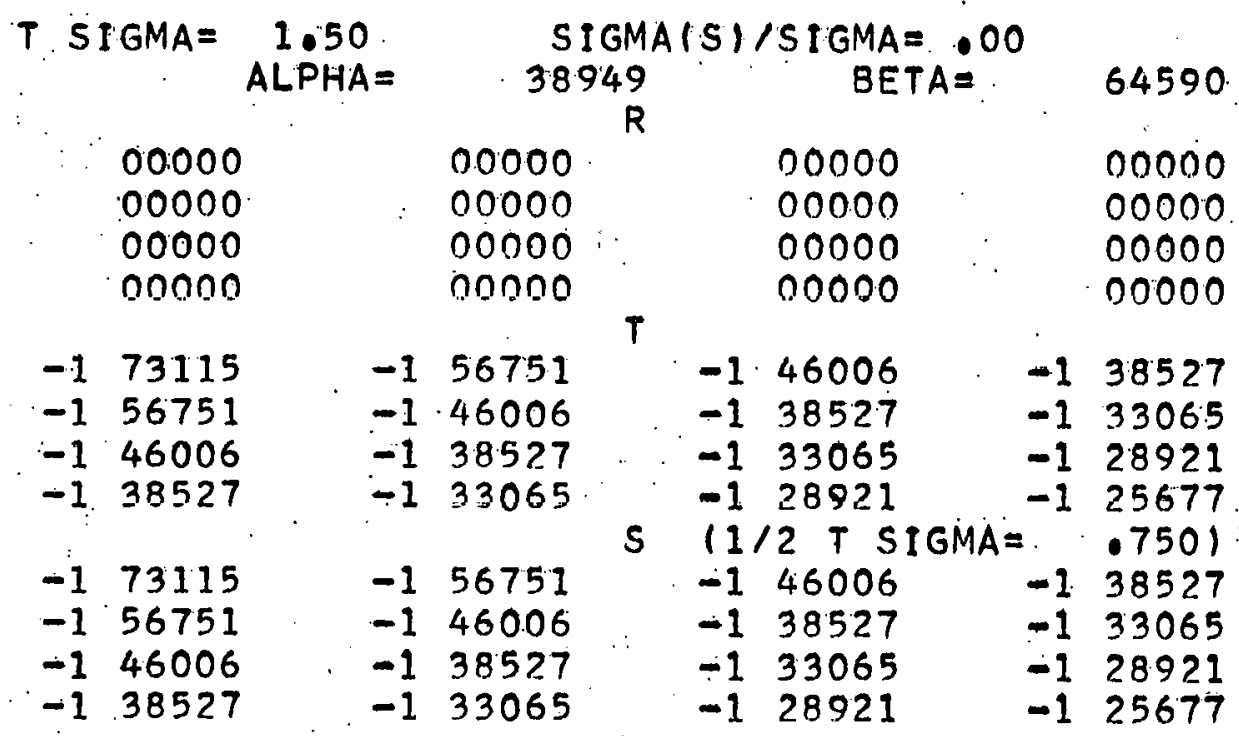


WAPD-TM- 168

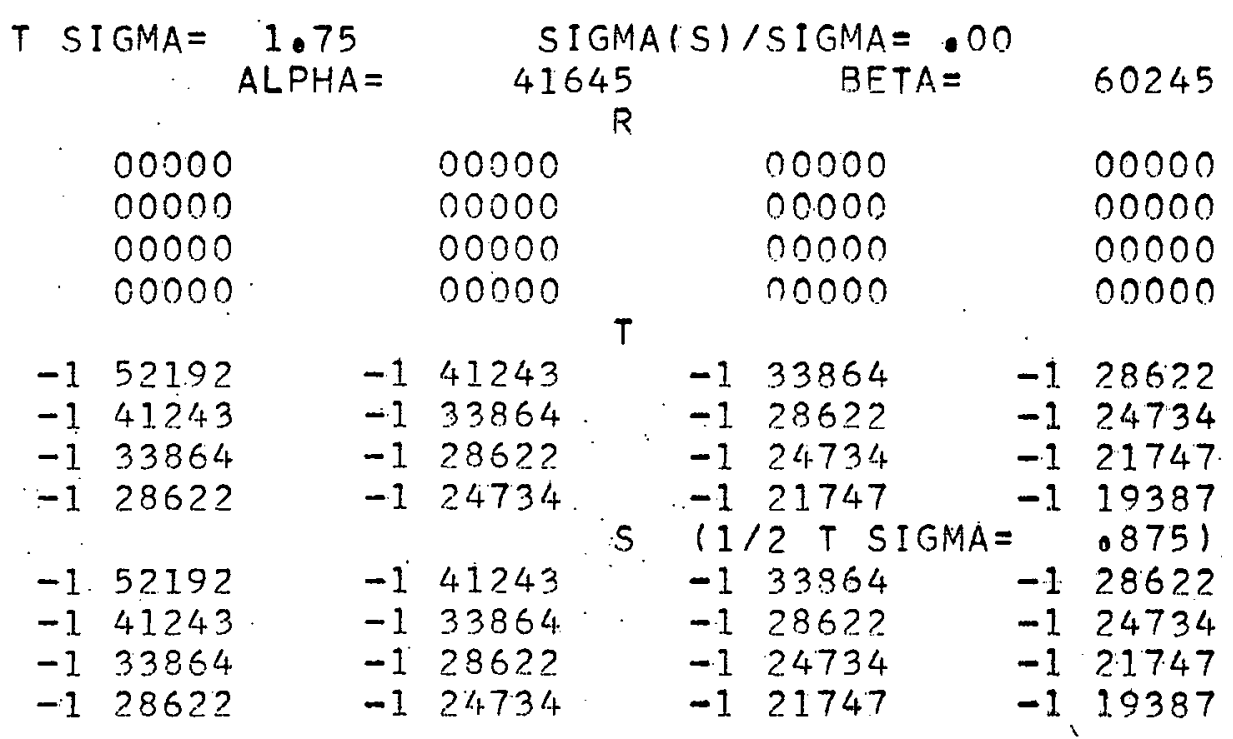

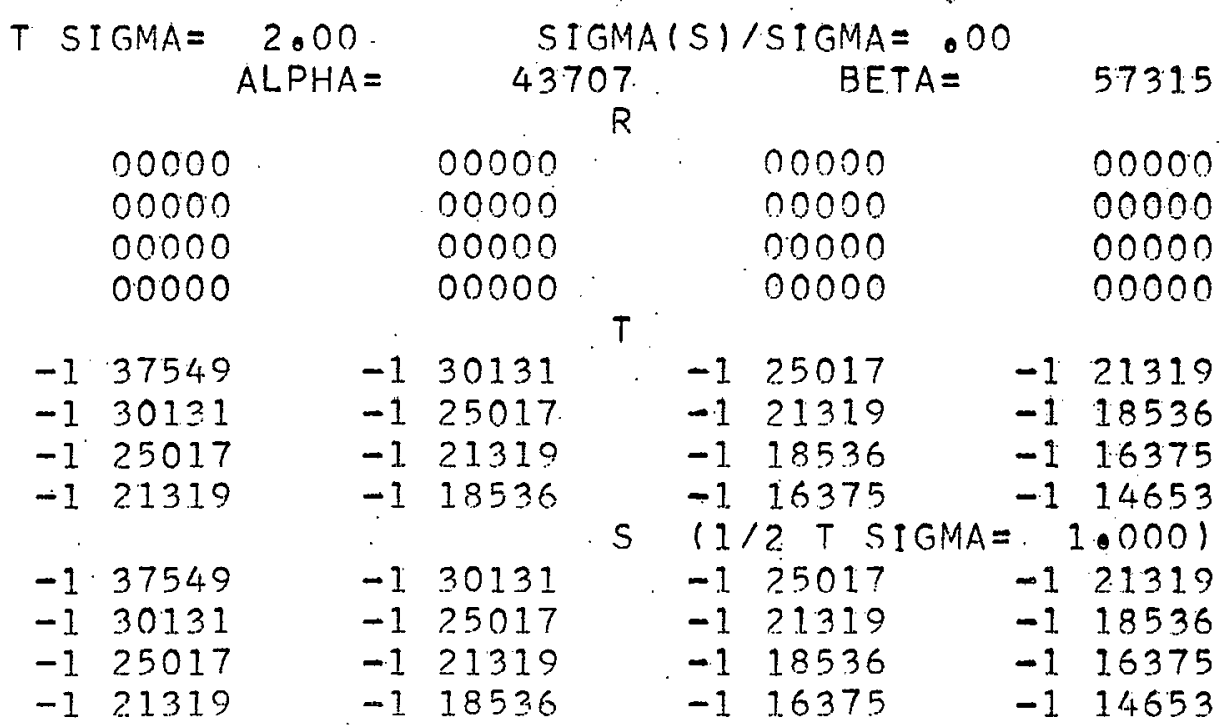

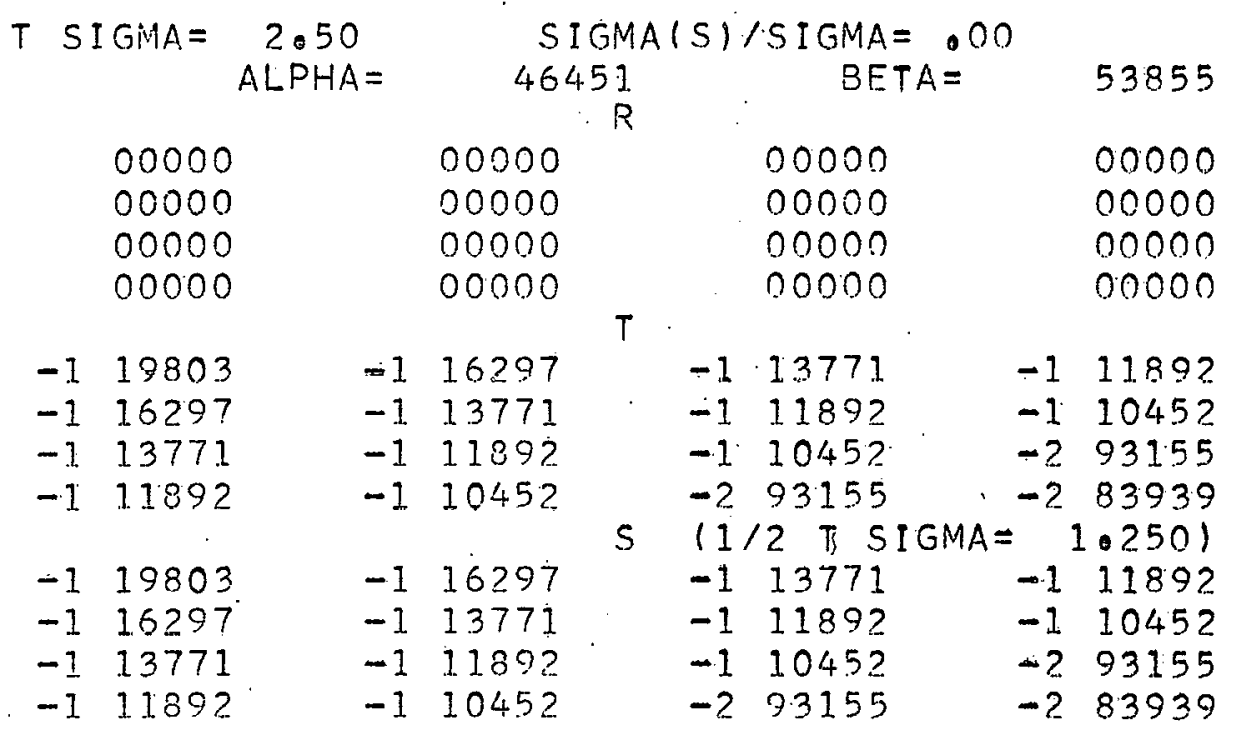




\begin{tabular}{|c|c|c|c|c|c|c|c|c|}
\hline \multicolumn{2}{|c|}{ TSIGMA $=$} & \multirow{2}{*}{$\begin{array}{c}3.00 \\
A L: P H A=\end{array}$} & \multicolumn{5}{|c|}{ SIGMA $S$ SISIGMA $=.00$} & \multirow[b]{2}{*}{$: 52088$} \\
\hline & & & 480 & $\begin{array}{r}05 \\
R\end{array}$ & & $B E T A=$ & & \\
\hline & 00000 & & 00000 & & & 00000 & . & 00000 \\
\hline & 00000 & & 00000 & & & 00000 & & 00000 \\
\hline & 00000 & & 00000 & & . & 00000 & . & 00000 \\
\hline & 00000 & & 00000 & & & 00000 & & 00000 \\
\hline & & & & $T$ & & & & \\
\hline-1 & 10650 & -2 & 89255 & & -2 & 76533 & -2 & 66872 \\
\hline-2 & 89255 & -2 & 76533 & & -2 & 66872 & -2 & 59324 \\
\hline-2 & 76533 & -2 & 66872 & & -2 & 59324 & -2 & 53262 \\
\hline-2 & 66872 & -2 & 59324 & & -2 & 53262 & -2 & 48262 \\
\hline & & & & $s$ & 11 & $2 T$ SIGMA & & 1.5001 \\
\hline-1 & 10650 & -2 & 89255 & & -2 & 76533 & -2 & 66872 \\
\hline-2 & 89255 & -2 & 76533 & & -2 & 66872 & -2 & 59324 \\
\hline-2 & 76533 & $-?$ & $6687 ?$ & & -2 & 59324 & $=2$ & 53262 \\
\hline-2 & 66872 & -2 & 59324 & & -2 & 53262 & -2 & 48262 \\
\hline
\end{tabular}

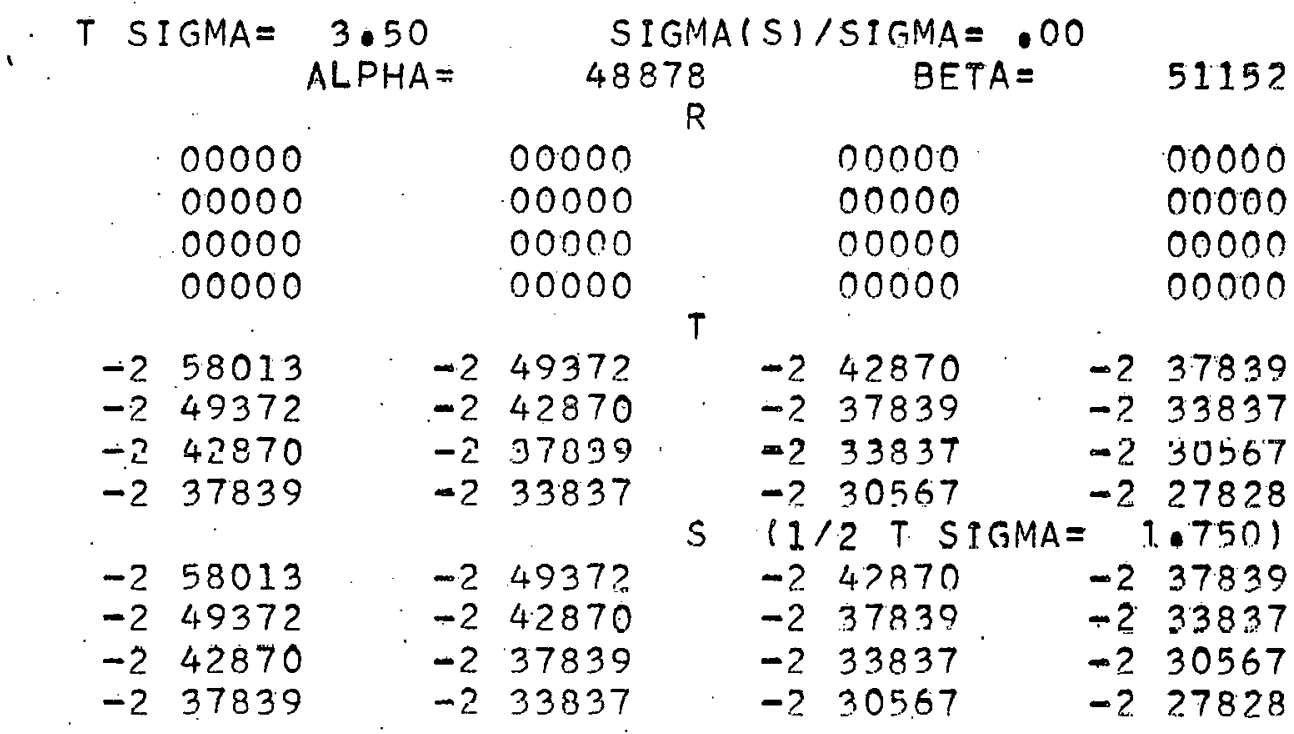

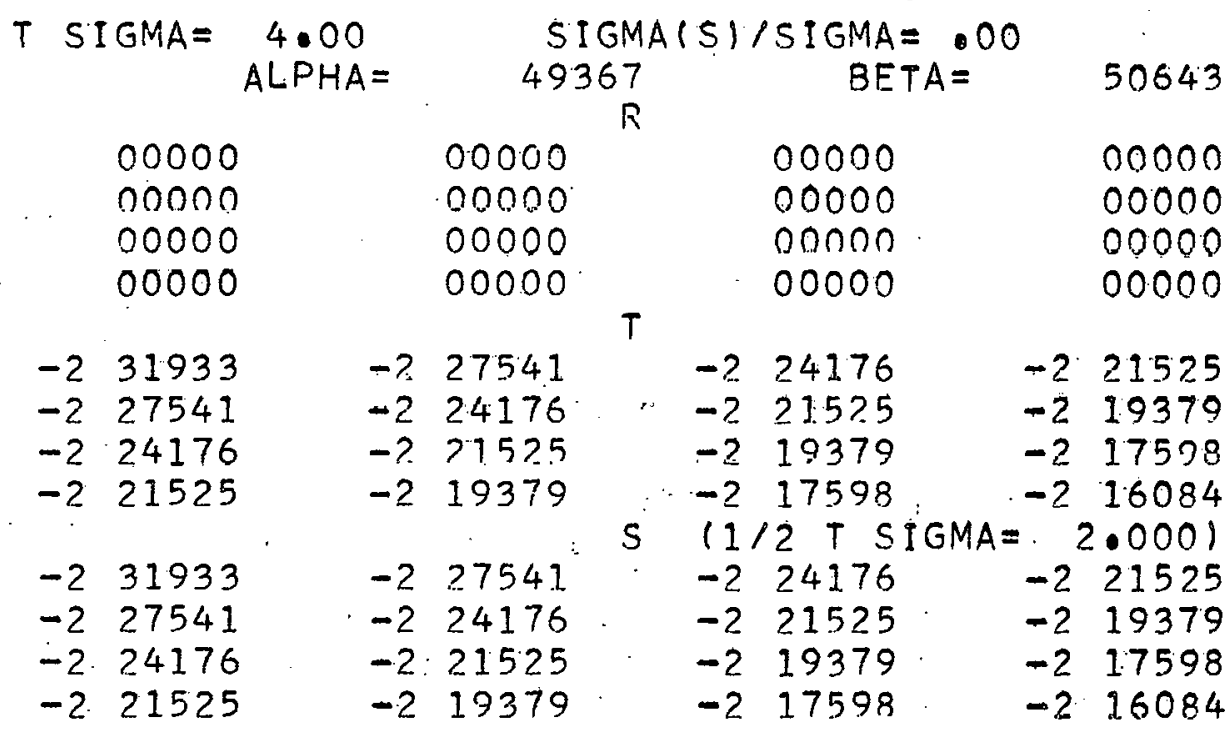


WAPD-TM-168

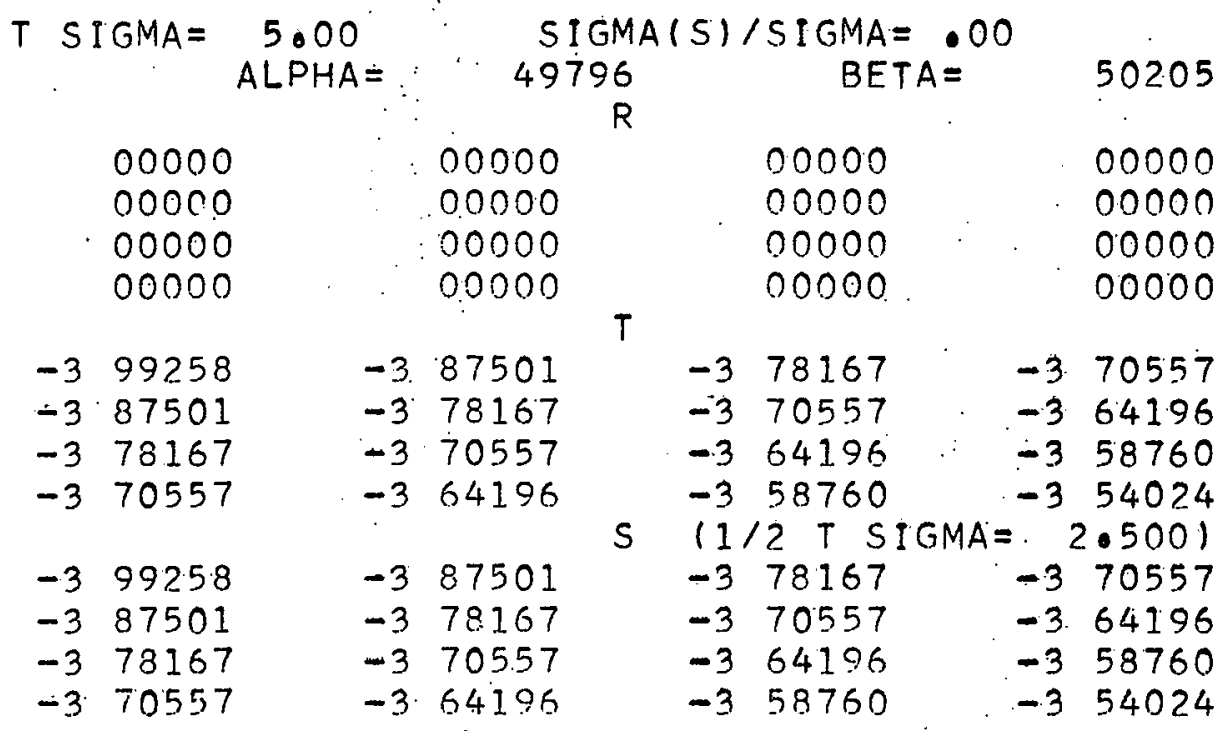

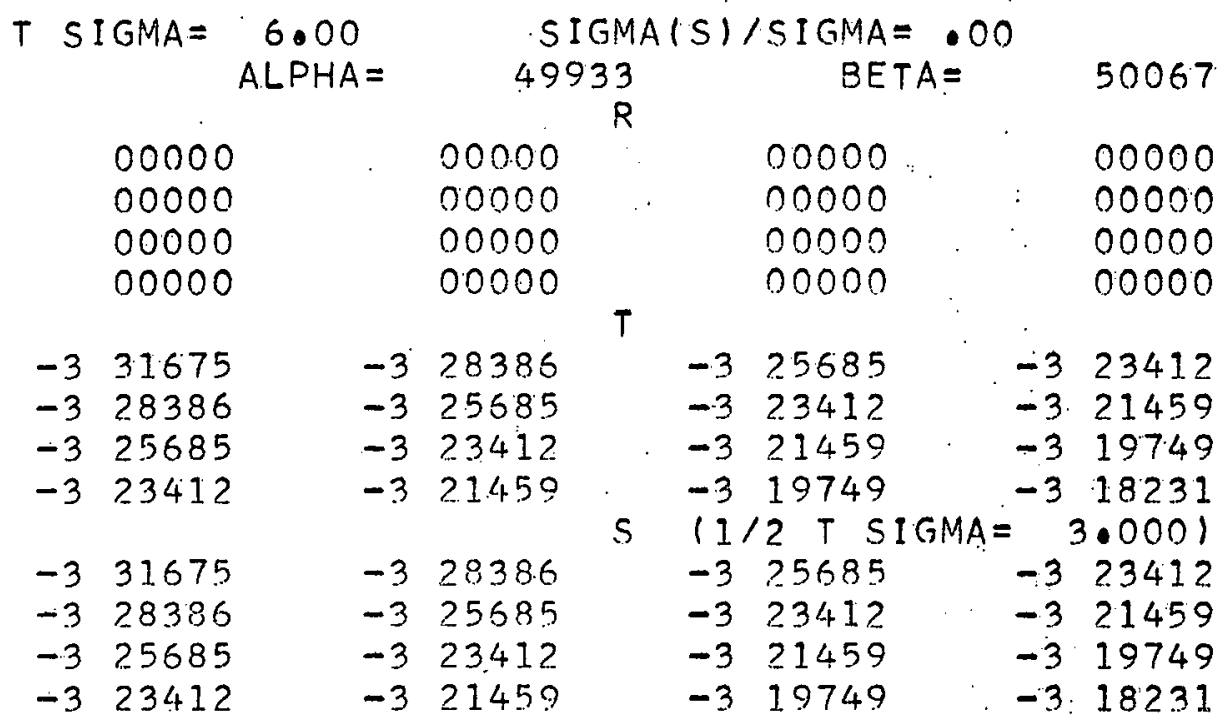

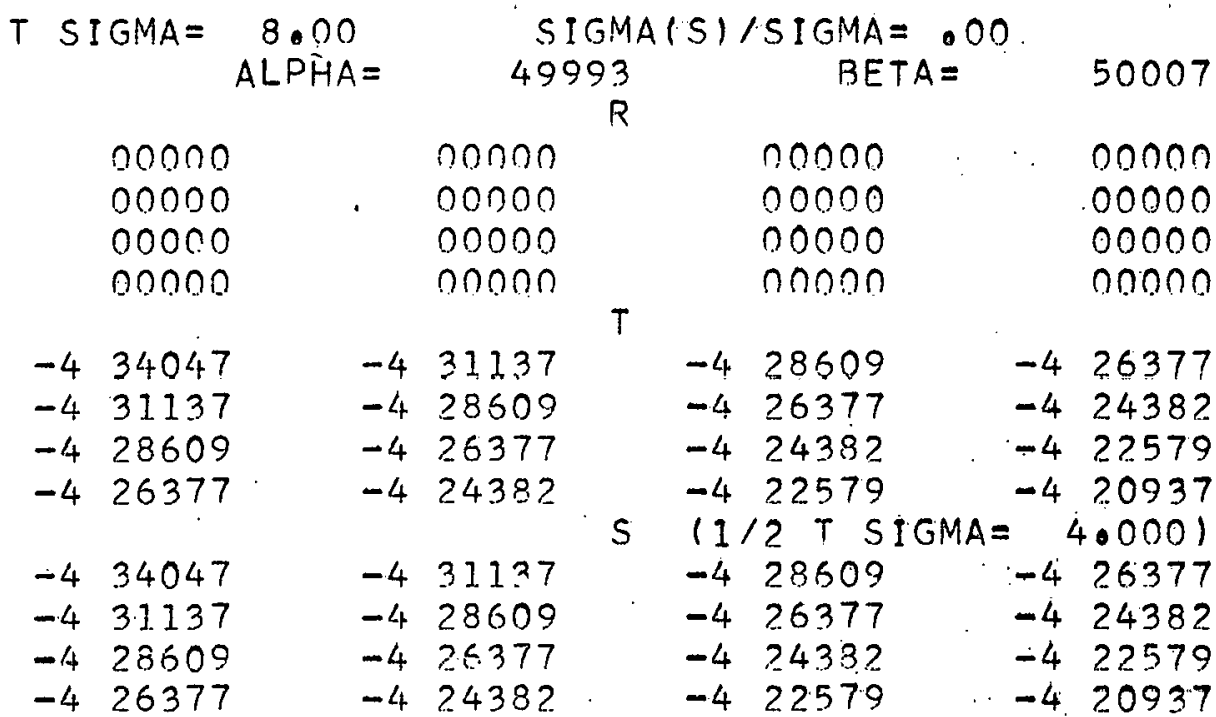


WAPD-TM-168

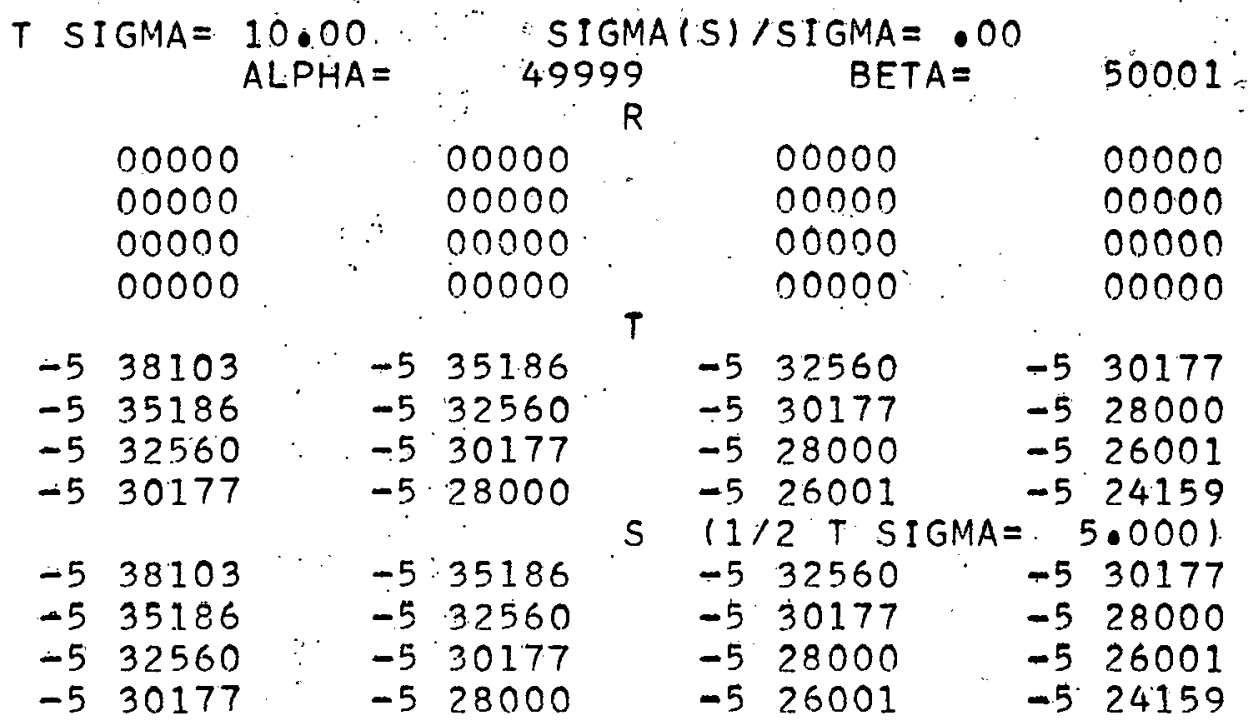

\begin{tabular}{|c|c|c|c|c|c|c|c|}
\hline $\mathrm{S}$ & GMA = & 14000 & SIGM & (S) & $S\lfloor G M A=$. & & \\
\hline 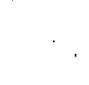 & & $A L P H A=$ & $\begin{array}{r}50000 \\
R\end{array}$ & & BETA $=$ & & 50000 \\
\hline & 00000 & & 00000 & & 00000 & & 00000 \\
\hline & 00000 & & 00000 & & 00000 & & 00000 \\
\hline & 00000 & & 00000 & & 00000 & & 00000 \\
\hline & 00000 & & 00000 & & 00000 & & 00000 \\
\hline-7 & 50417 & -7 & 46847 & -7 & 43549. & -7 & 40494 \\
\hline-7 & 46847 & -7 & 43549 & -7 & 40494 & -7 & 37662 \\
\hline-7 & 43549 & -7 & 40494 & -7 & 37662 & -7 & 35033 \\
\hline-7 & 40494 & -7 & 37562 & $\begin{array}{l}-7 \\
11\end{array}$ & $\begin{array}{l}35033 \\
2 T S I G M\end{array}$ & -7 & $\begin{array}{l}32591 \\
.0001\end{array}$ \\
\hline-7 & 5041.7 & -7 & 46847 & -7 & 43549 & -7 & 40494 \\
\hline-7 & 46847 & -7 & 43549 & -7 & 40494 & -7 & $3766 ?$ \\
\hline-7 & 43549 & -7 & 40494 & -7 & 37662 & -7 & 35033 \\
\hline & 40494 & -7 & 37662 & -7 & 35033 & -7 & 3250 \\
\hline
\end{tabular}

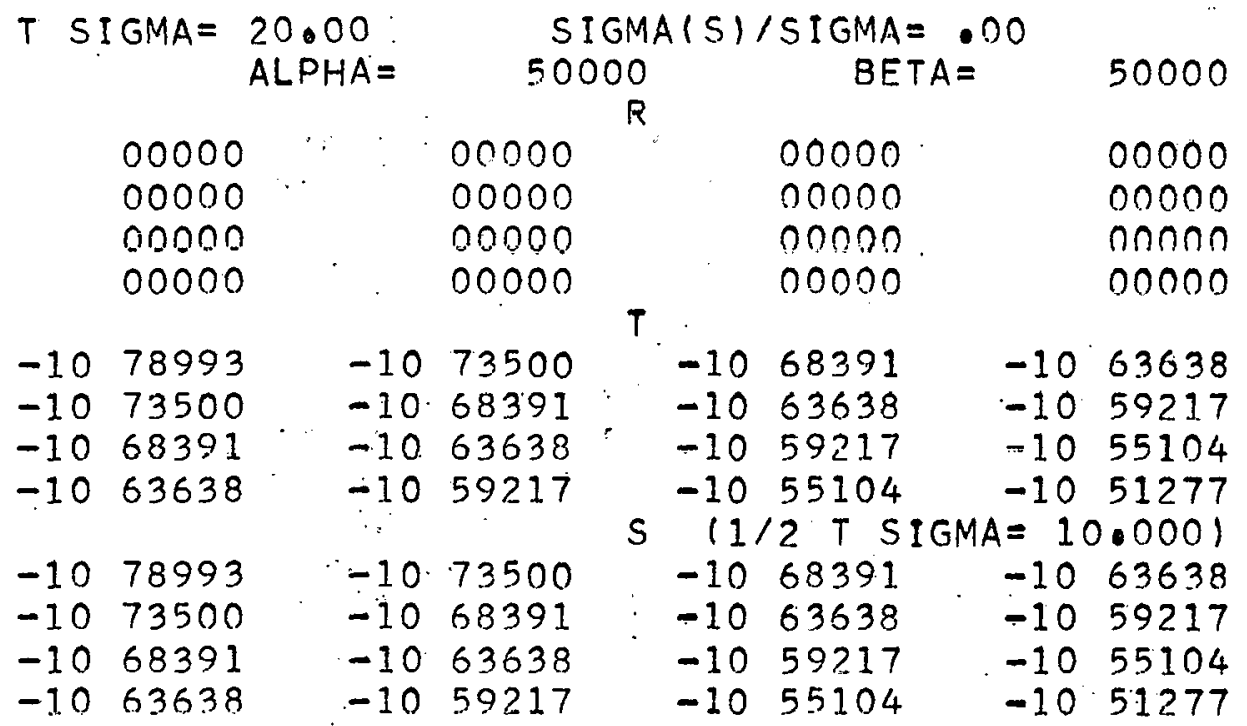




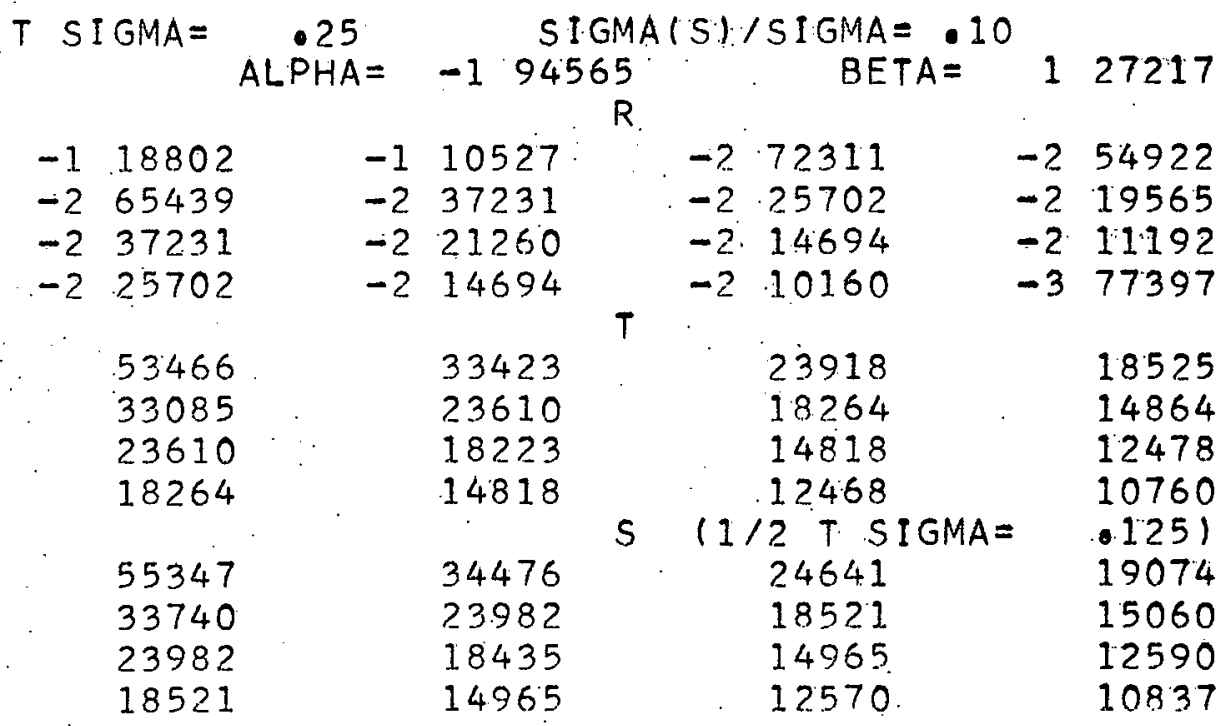

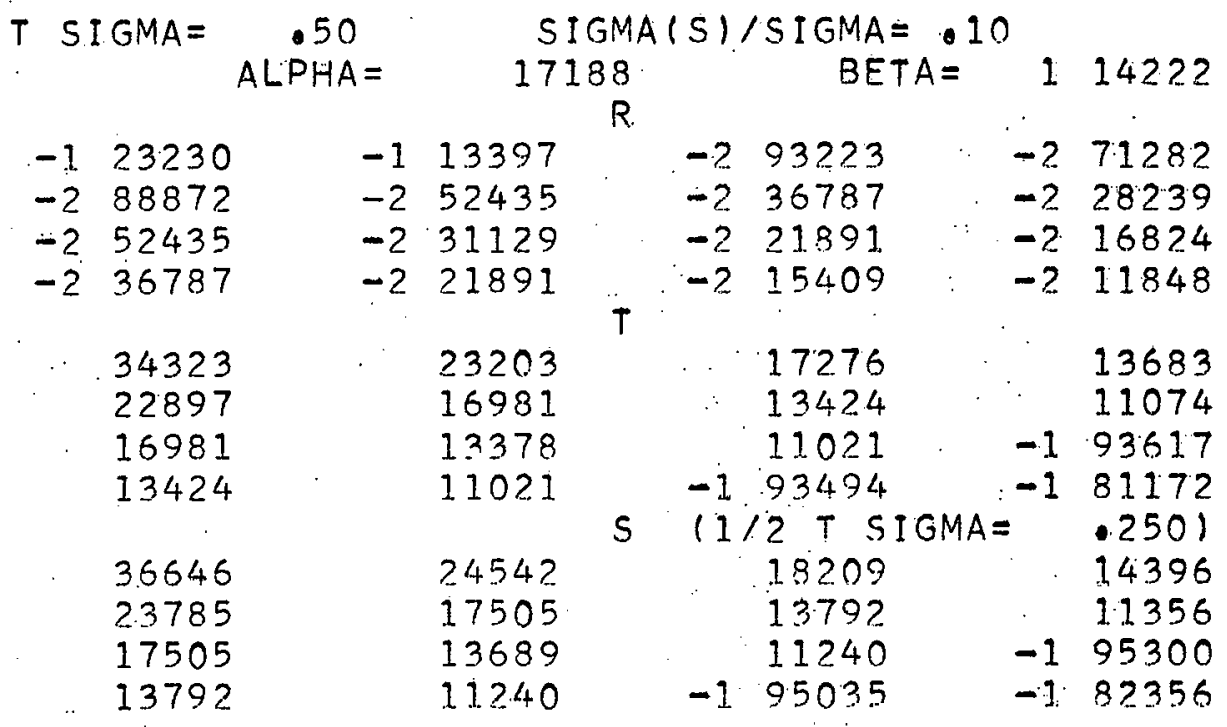

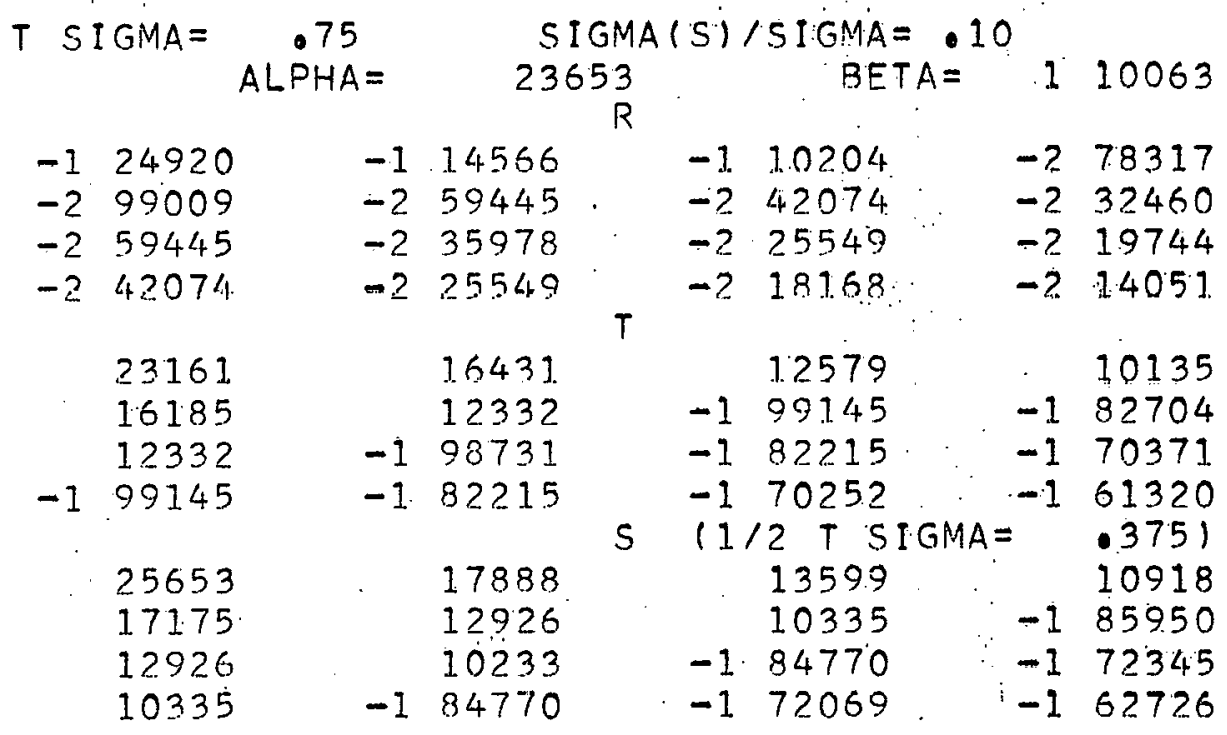




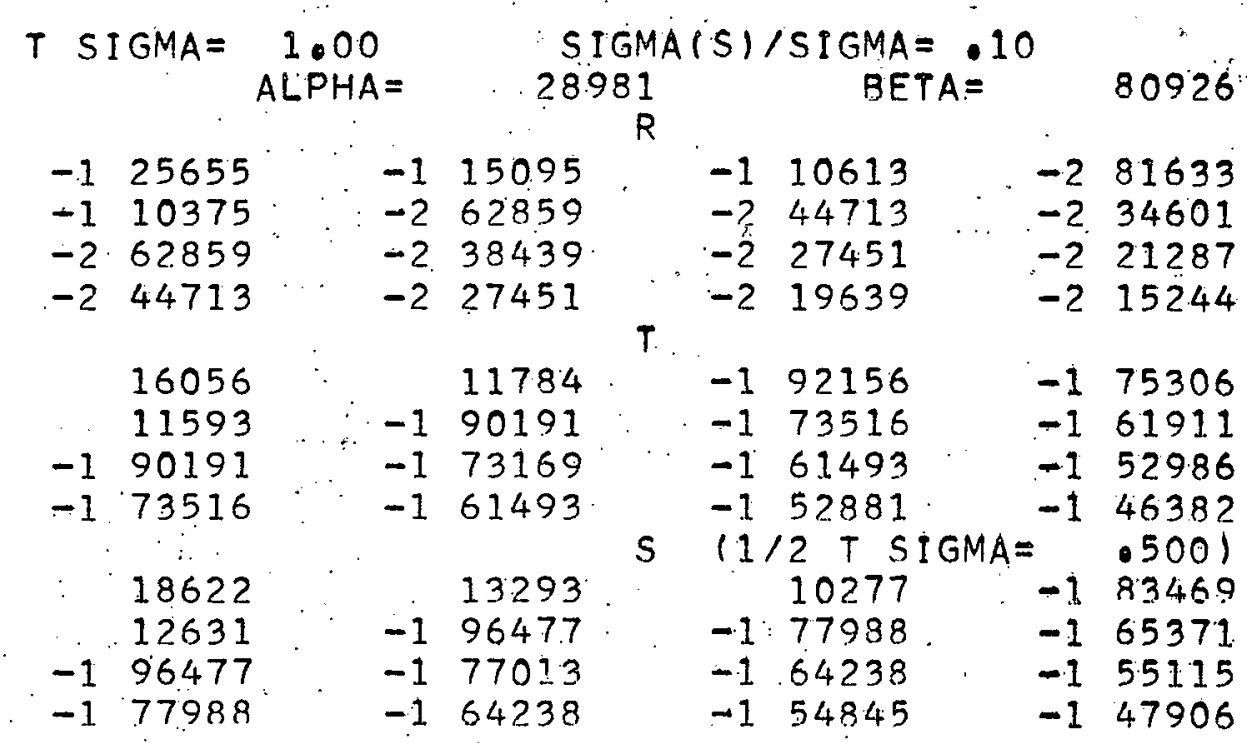

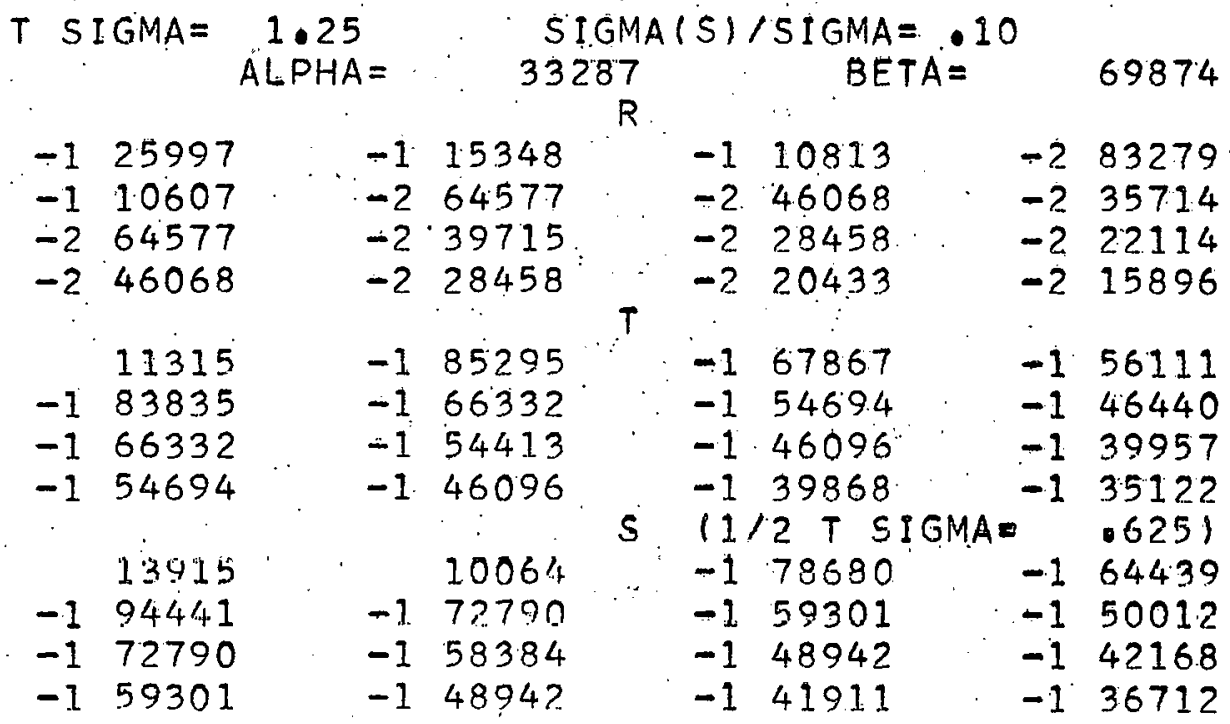

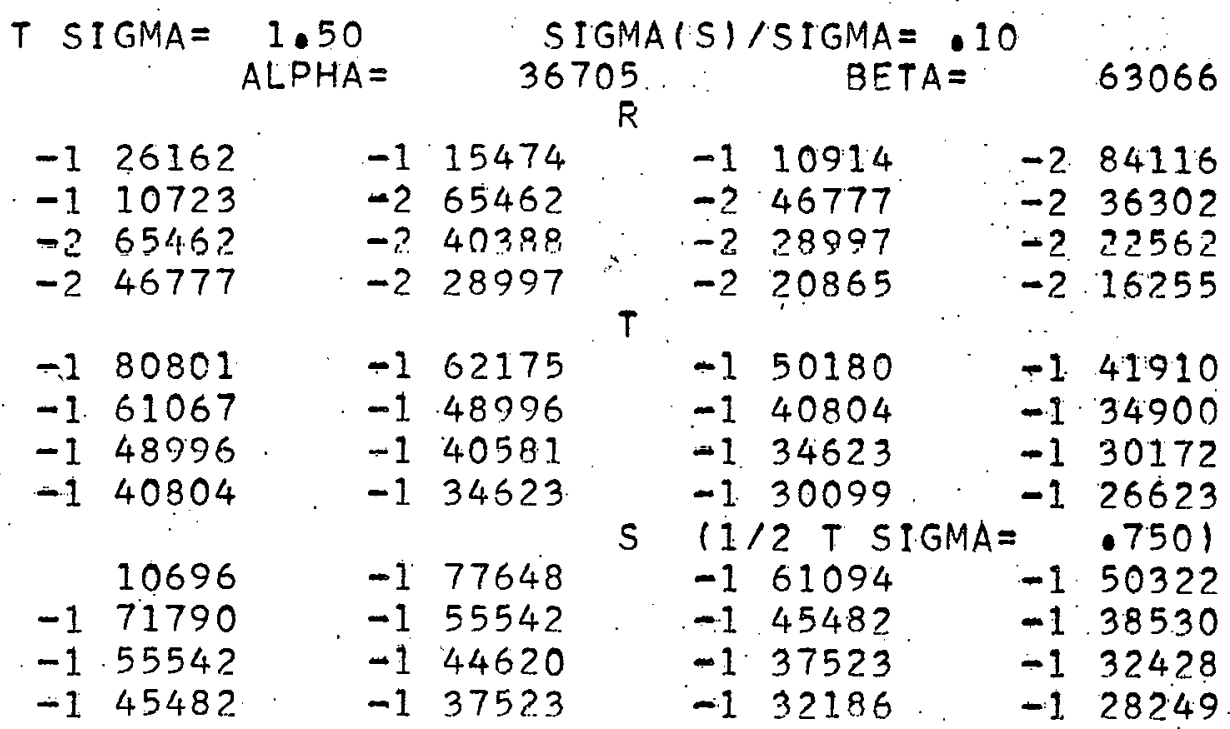




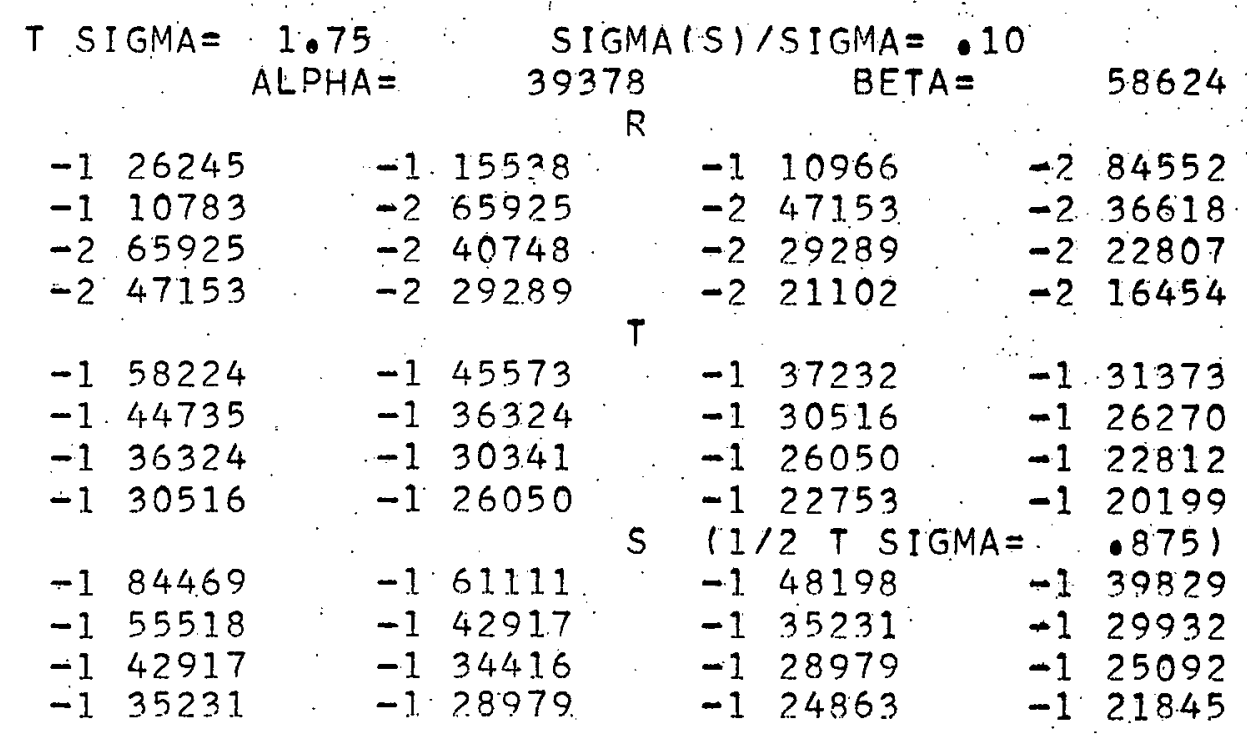

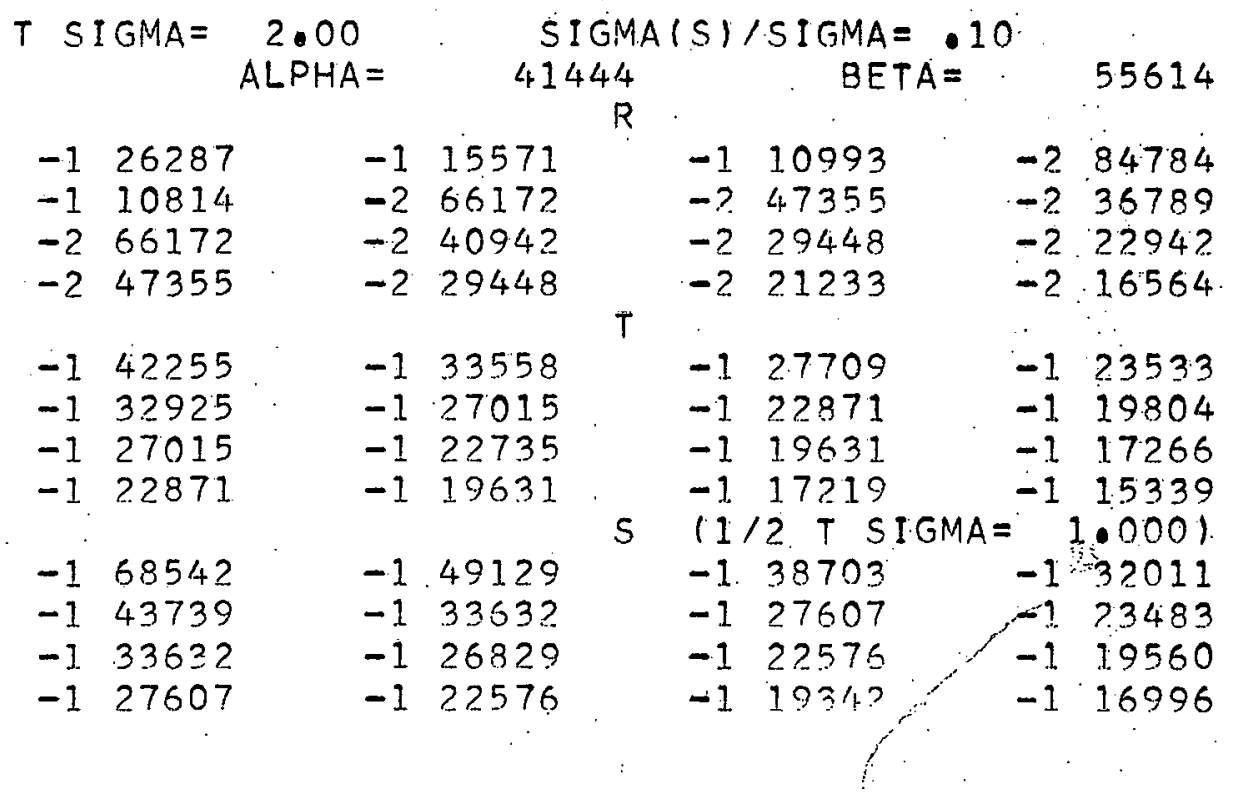

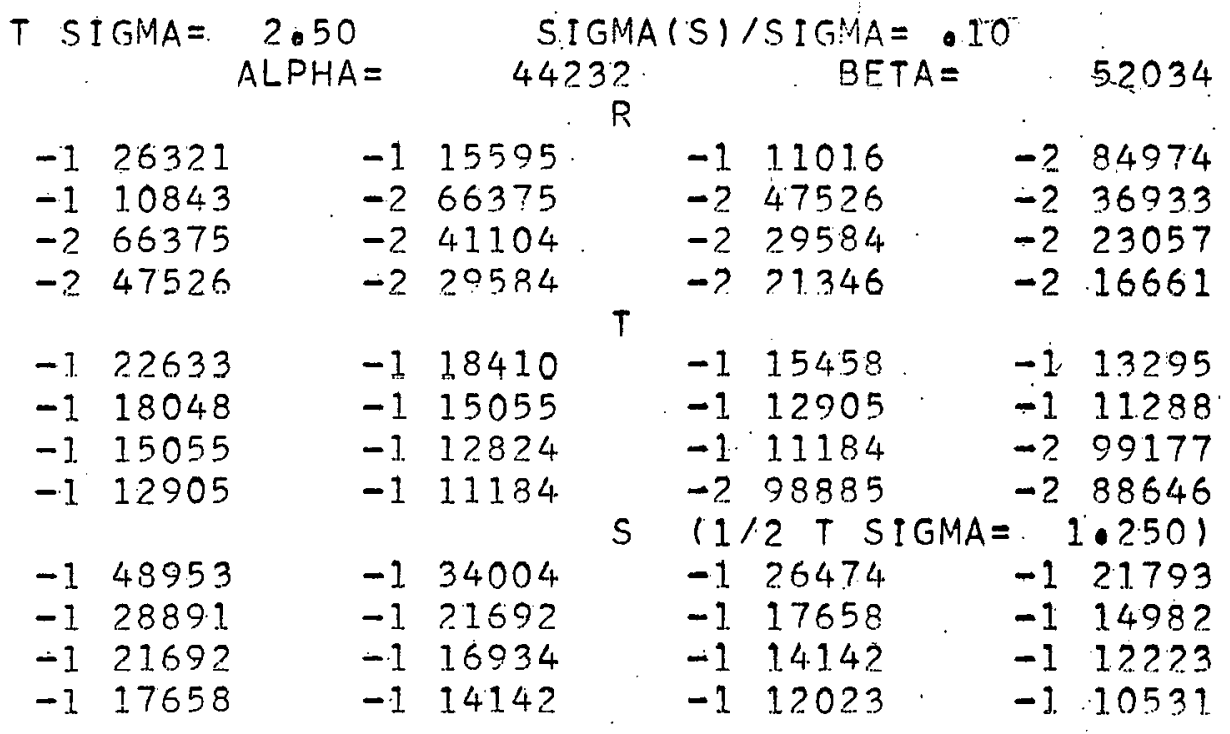




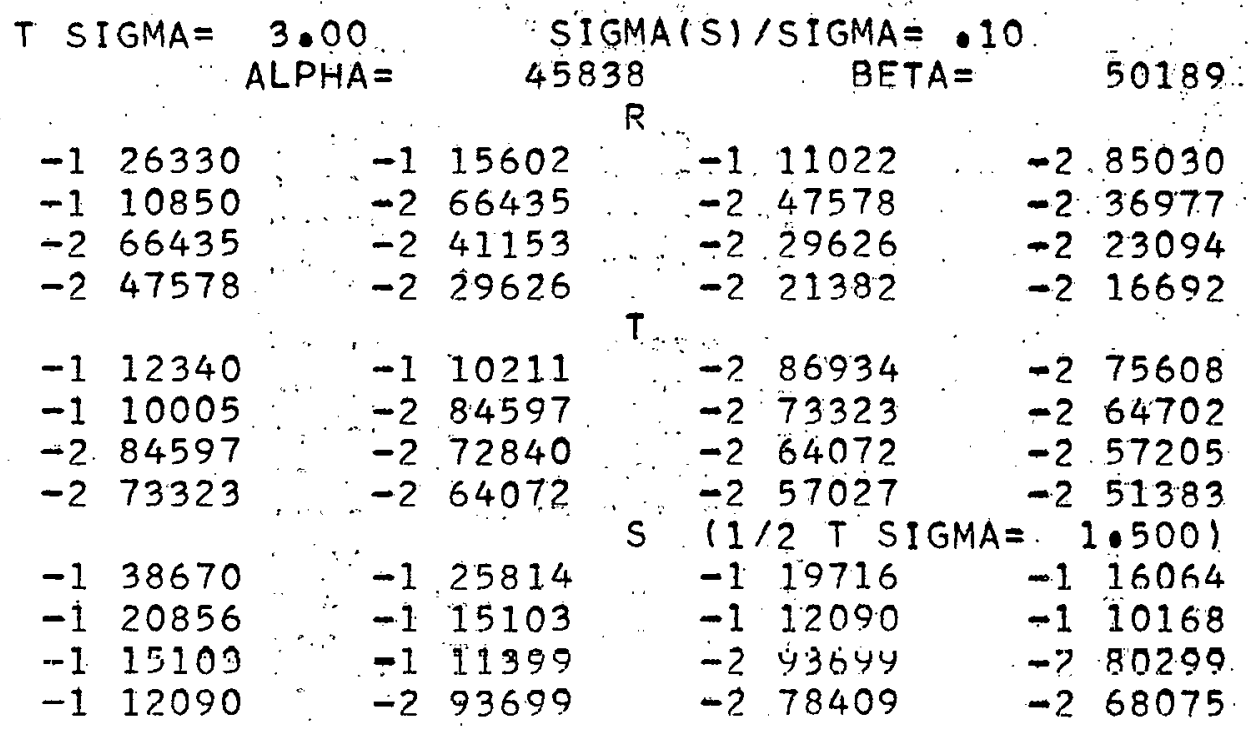

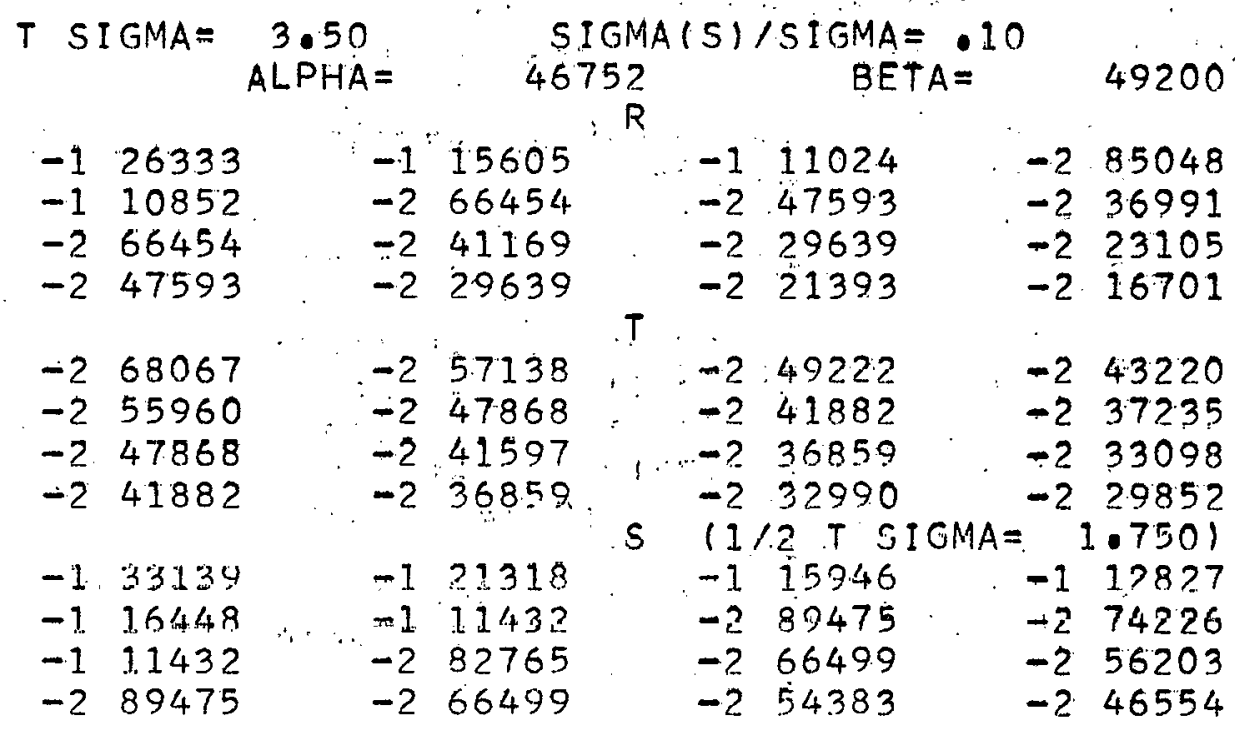

T SIGMA $=4.00 \quad$ SIGMA $(S) /$ SIGMA $=.10$ ALPHA $=47271 \quad$ BETA $=48658$

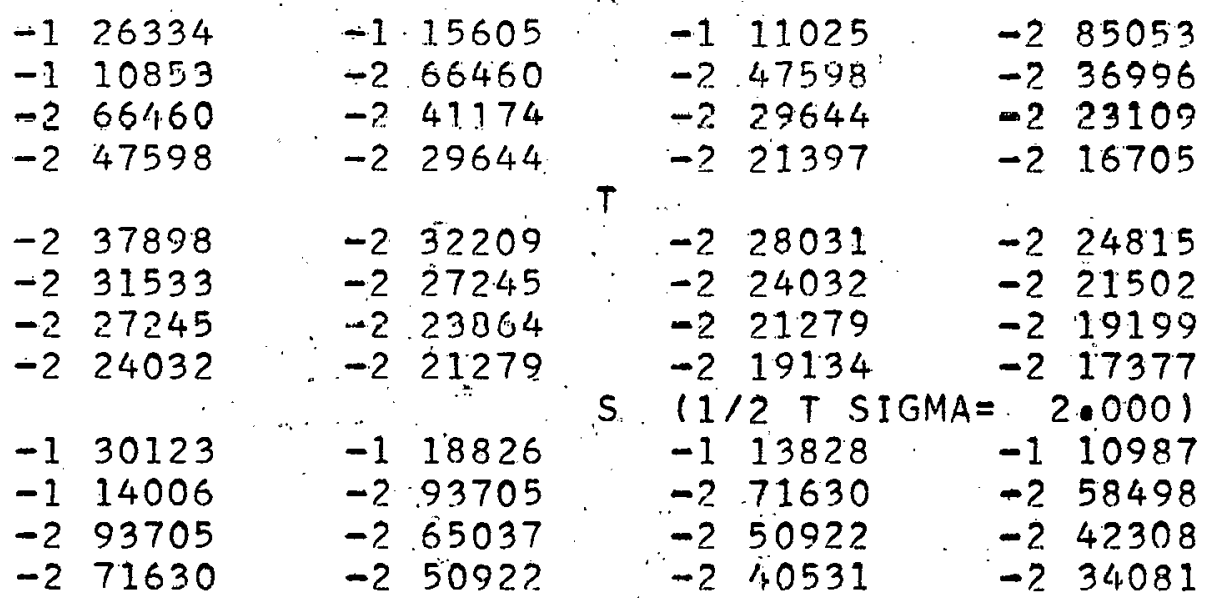




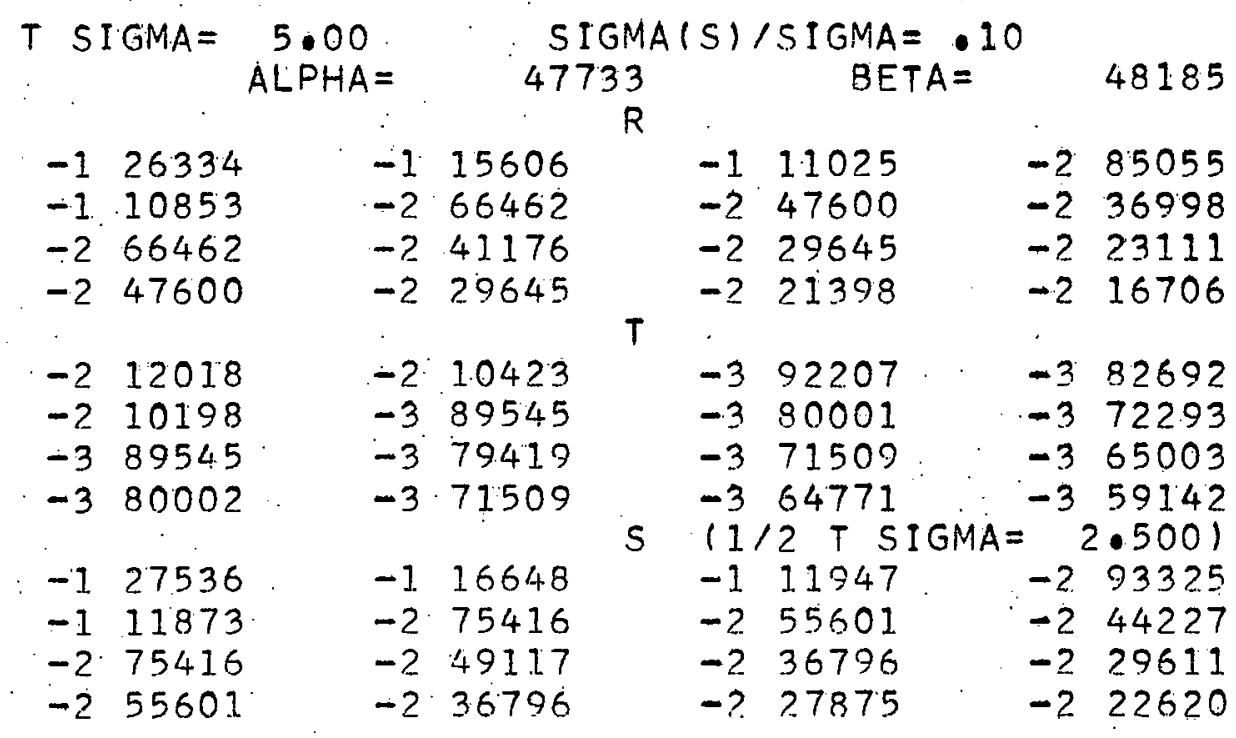

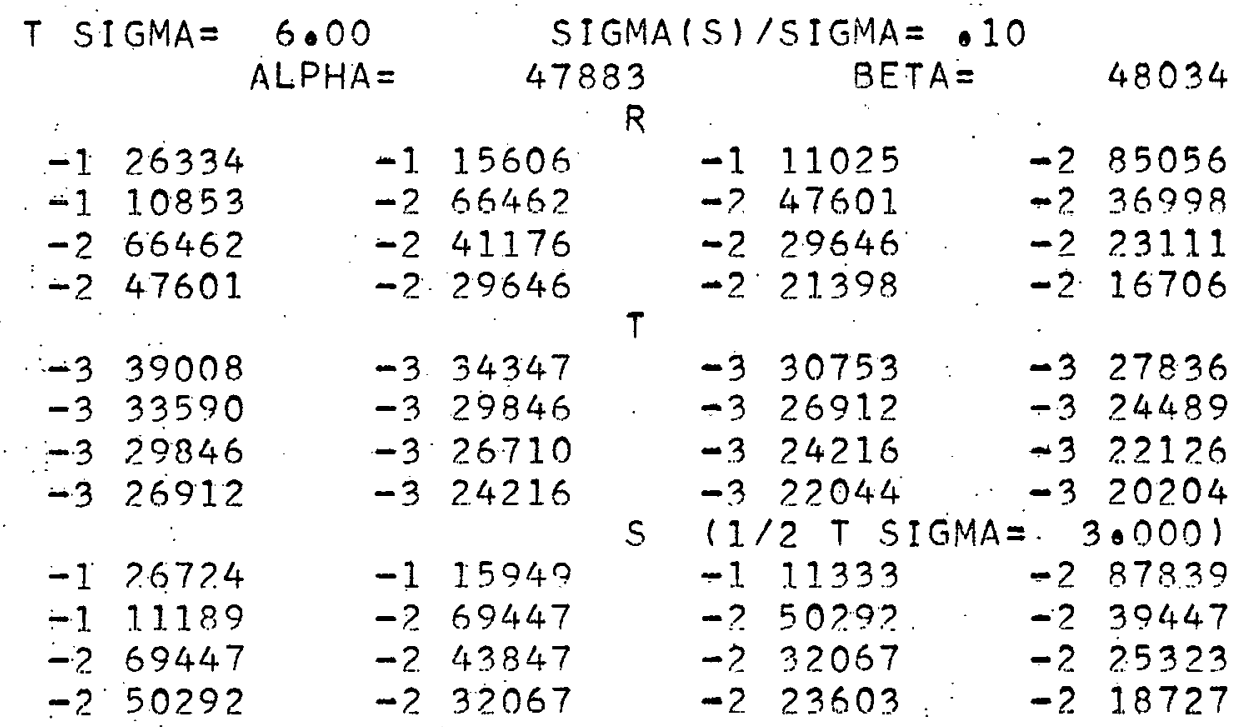

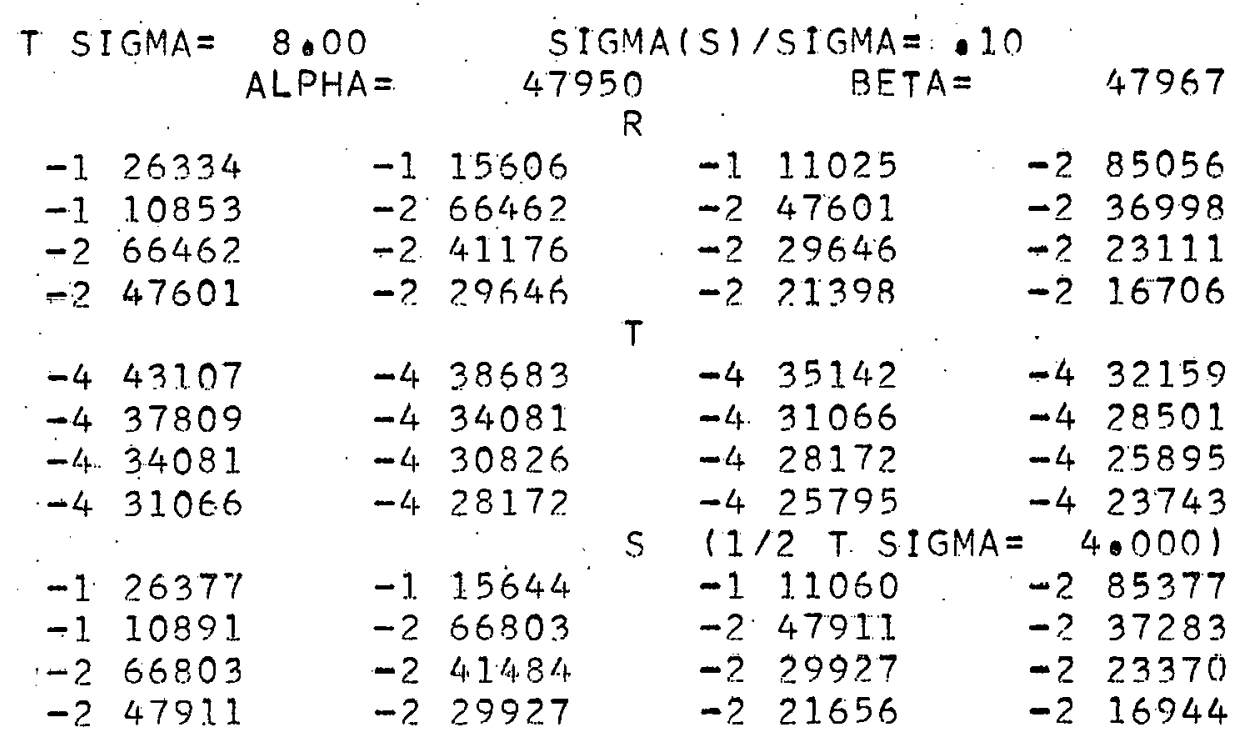




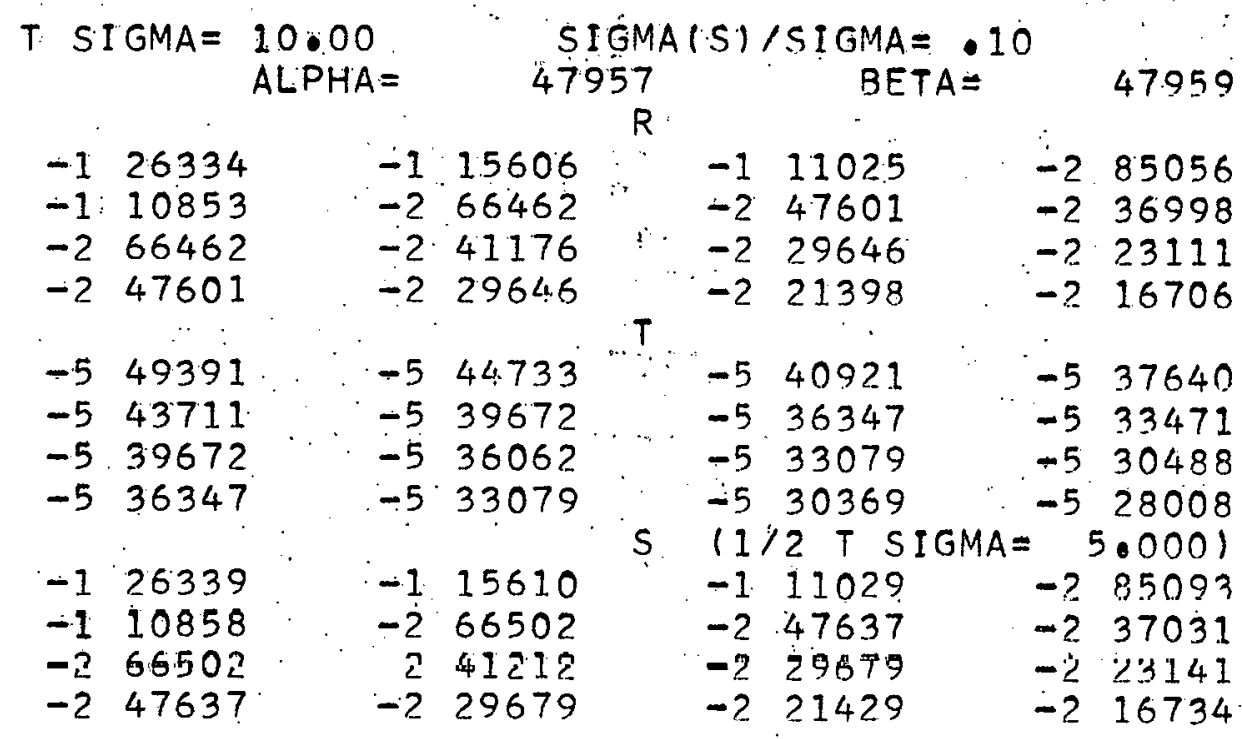

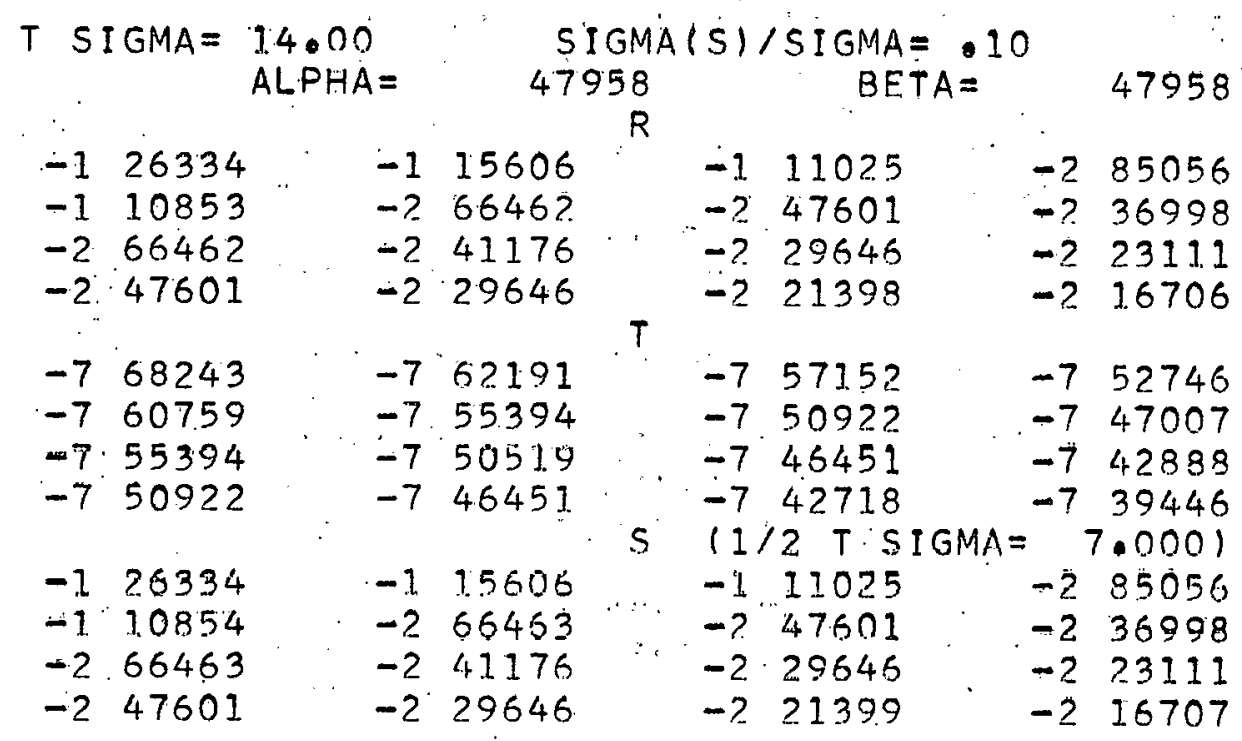

\section{T SIGMA $=20.00$

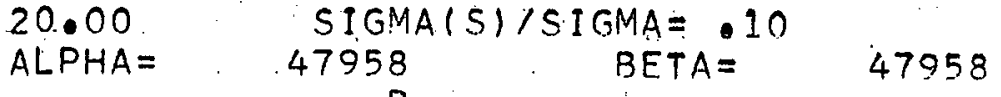

$\begin{array}{llll}-1 & 26334 & -1 & 15606\end{array}$

$-110853 \cdots 2.66462$

$R$

$\rightarrow 6646 ? \quad-241176$

$-247601 \quad \cdots \quad-229646$

$\begin{array}{llll}-9 & 11400 \quad-9 & 10404\end{array}$

$\begin{array}{llll}-9 & 10164 & -10 & 92758\end{array}$

$T$

$-111025 \quad-285056$

$-247601 .-236998$

$-2 ? 2646 \quad-2 \quad 23111$

$\begin{array}{llll}-2 & 21398 & -2 & 16706\end{array}$

$\begin{array}{llll}-10 & 92758 & -10 & 84657\end{array}$

$-10 \quad 85333 \quad-1077883$

$\begin{array}{lllll}-1 & 26334 & -1 & 15606\end{array}$

$\begin{array}{lll}-1095706 & -10 \quad 88396\end{array}$

$\begin{array}{lll}-10 & 85333 \quad-1078817\end{array}$

$\begin{array}{ll}-1077883 & -10.71937\end{array}$

$\begin{array}{llll}-10 & 71652 \quad-1066182\end{array}$

S $11 / 2$ T SIGMA $=10.000)$

$-111025 \quad-285056$

$\begin{array}{llll}-2 & 47601 & -2 & 36998\end{array}$

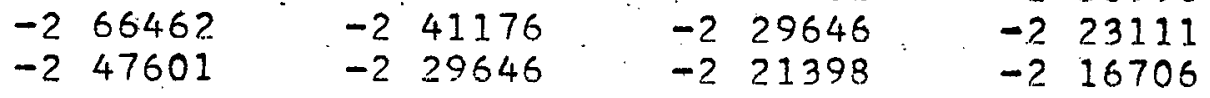

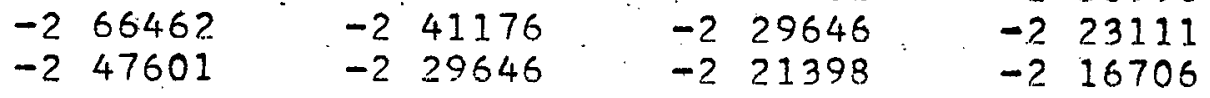


WAPD-TM- 168

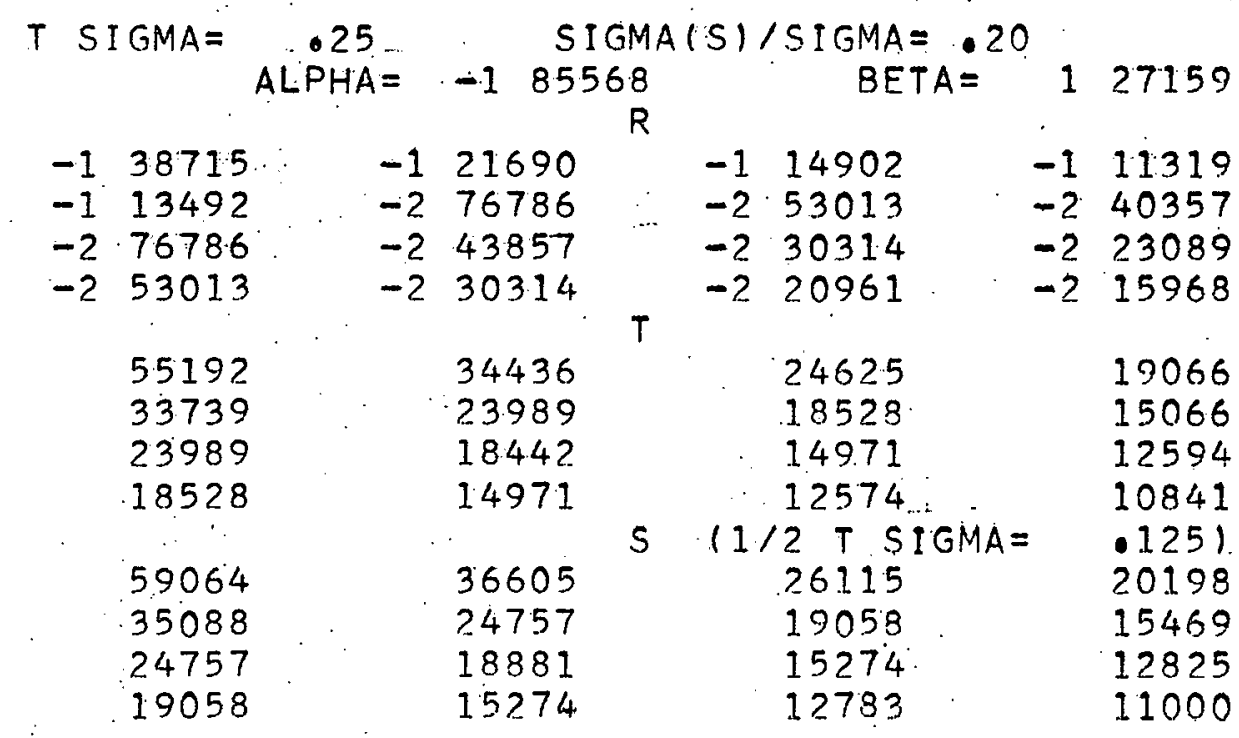

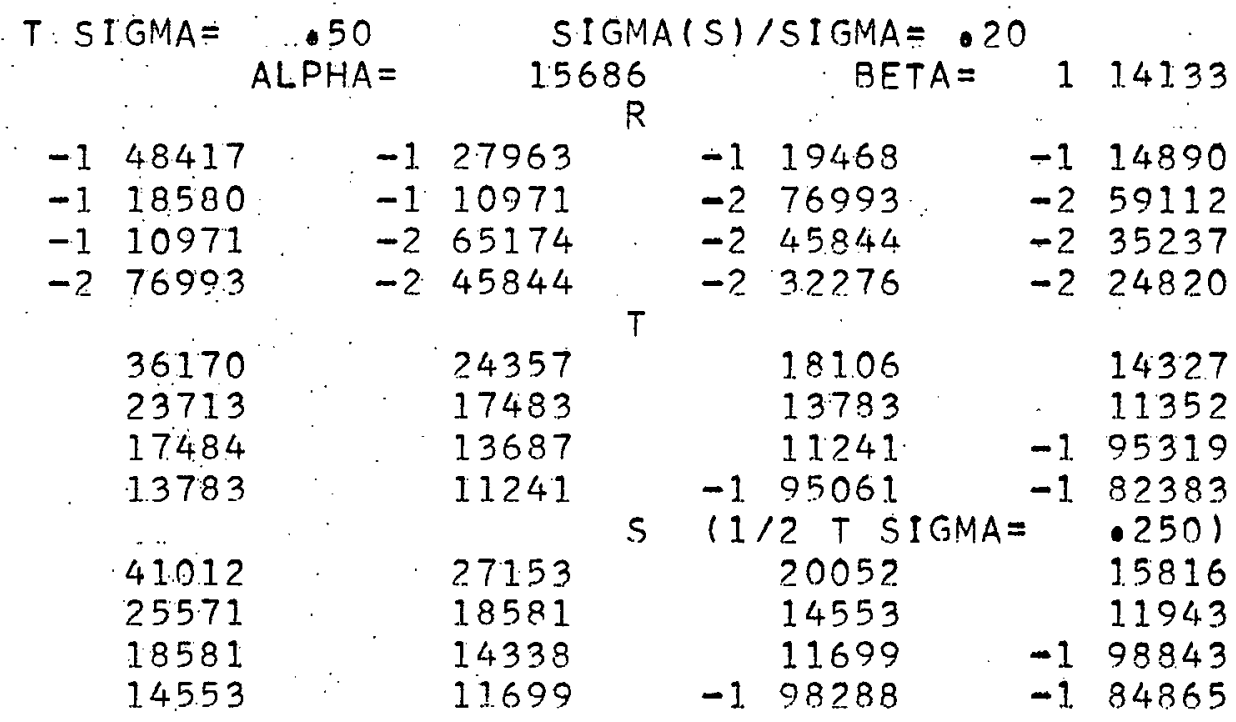

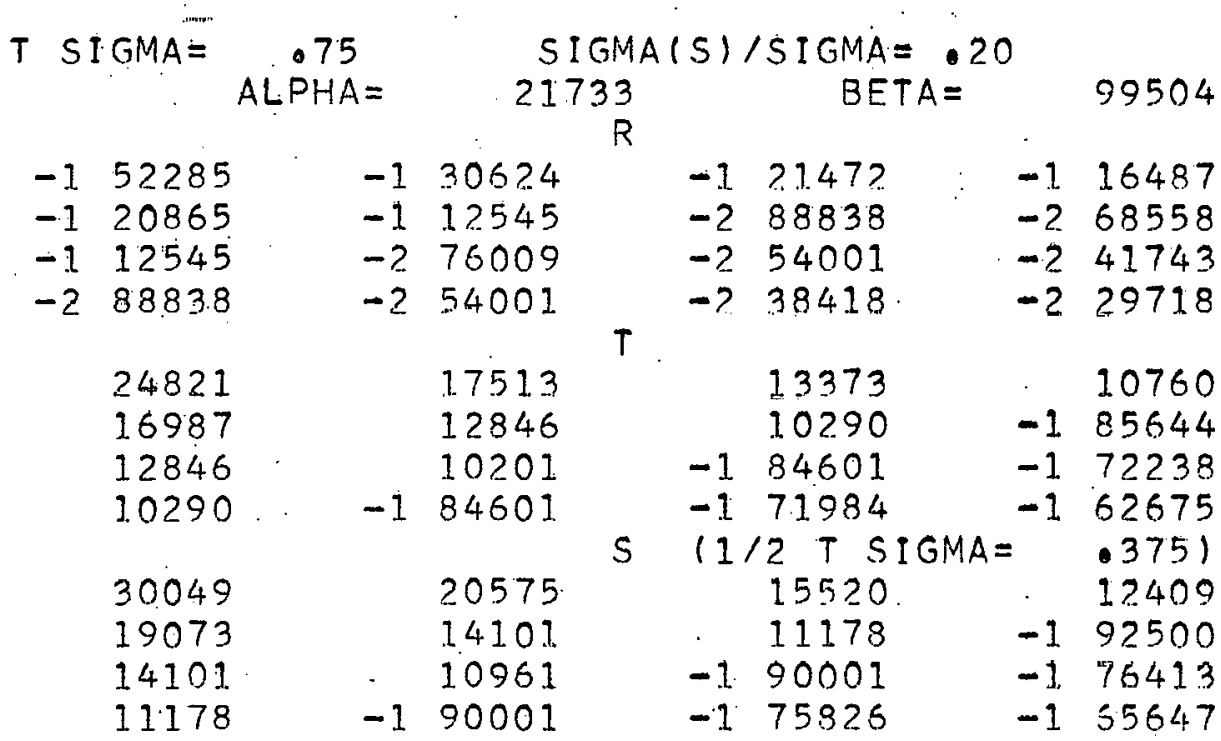




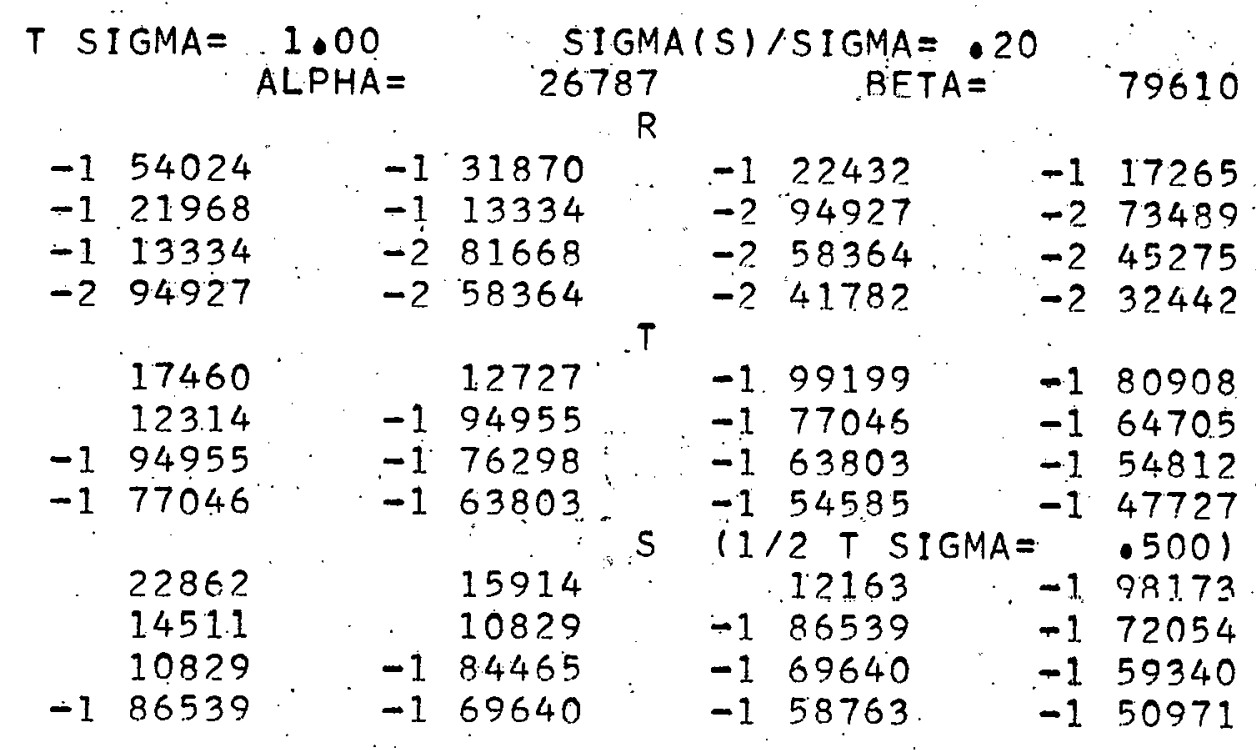

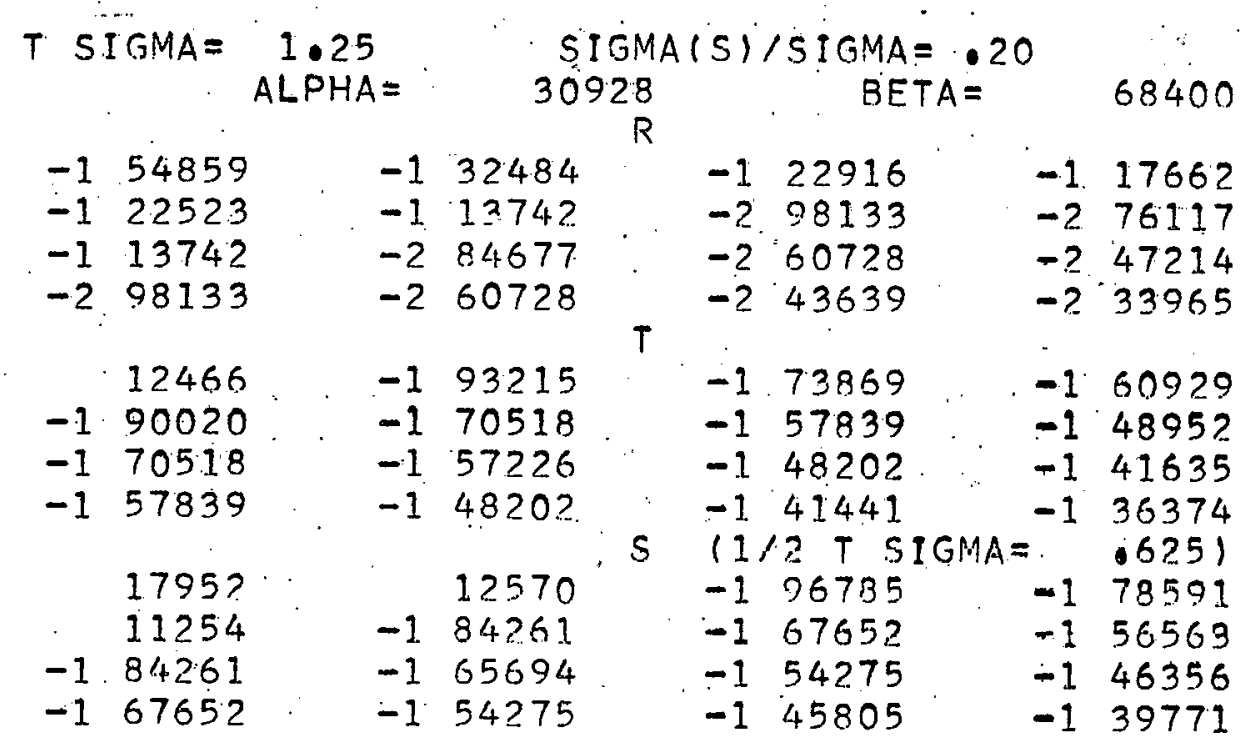

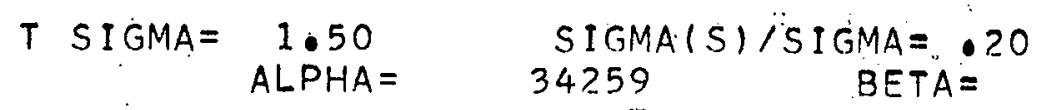

\begin{tabular}{|c|c|c|c|c|c|c|c|c|}
\hline & & & & \multirow[t]{2}{*}{$R$. } & \multicolumn{2}{|r|}{. } & \multicolumn{2}{|r|}{ 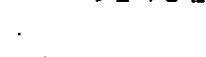 } \\
\hline-1 & 55274 & -1 & 32798 & & -1 & 23166 & -1 & 17868 \\
\hline-1 & 228.08 & -1 & 13958 & & -2 & 99850 & -2 & 7754 \\
\hline-1 & 13958 & -2 & 86301 & & -2 & 62023 & $=?$ & $49 \div 8$ \\
\hline-2 & 99850 & -2 & 62023 & & -2 & 44672 & -2 & 3482 \\
\hline & 90078 & -1 & 686 & & -1 & 55173 & -1 & \\
\hline-1 & 66235 & -1 & $5256 ?$ & & -1 & 43514 & -1 & \\
\hline-1 & 52562 & -1 & 43023 & & -1 & 36472 & -1 & 31 \\
\hline & 43514 & -1 & 36472 & & -1 & 31496 & -1 & 2774 \\
\hline & & & & 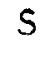 & 11 & $2 T$ SIGMA & & \\
\hline & 14535 & & 10148 & & -1 & 78339 & -1 & \\
\hline & .89043 & -1 & 66520 & & -1 & 53499 & -1 & \\
\hline-1 & 66520 & -1 & 51654 & & -1 & 42675 & -1 & 36 \\
\hline & 53499 & -1 & 42675 & & -1 & 35964 & -1 & $312 ?$ \\
\hline
\end{tabular}




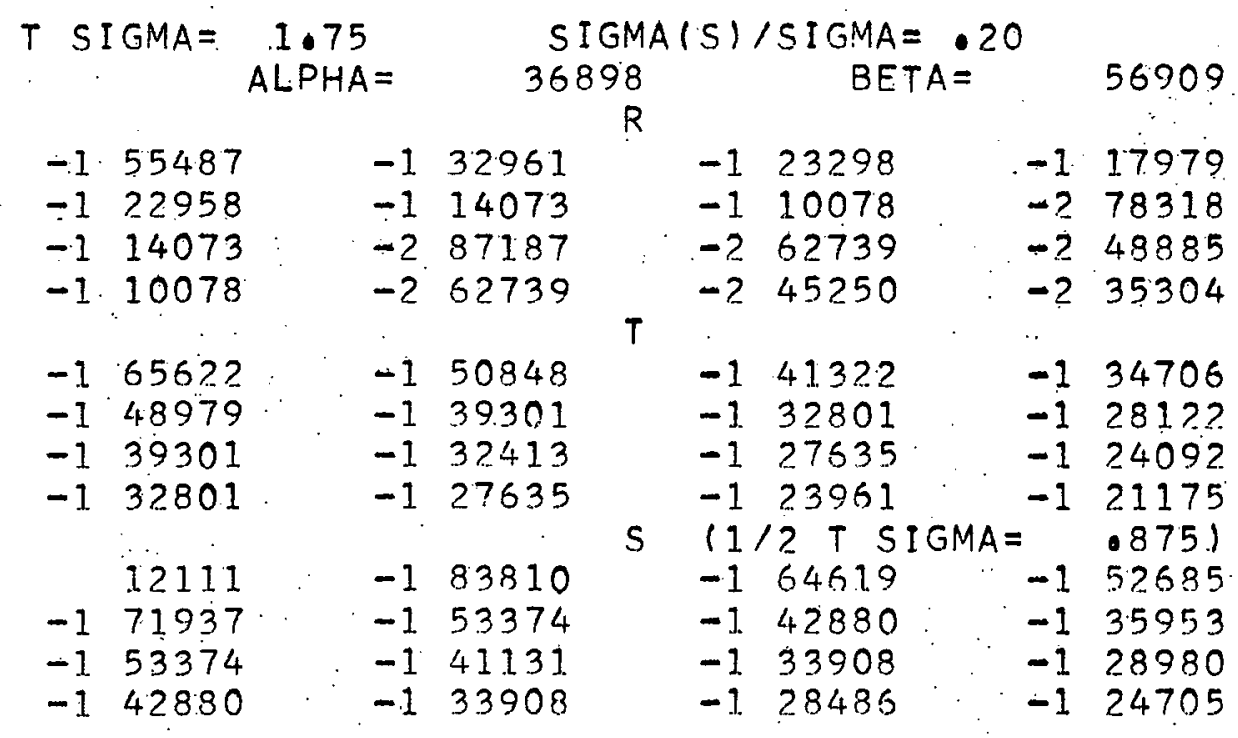

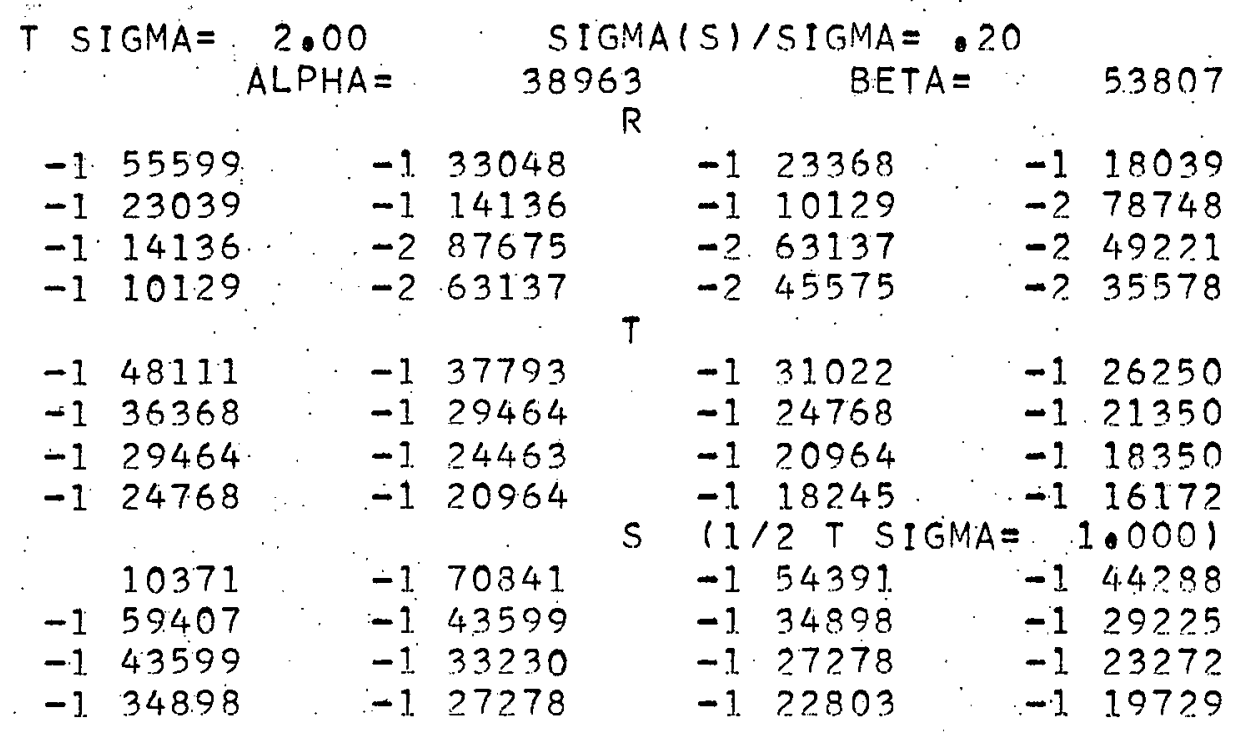

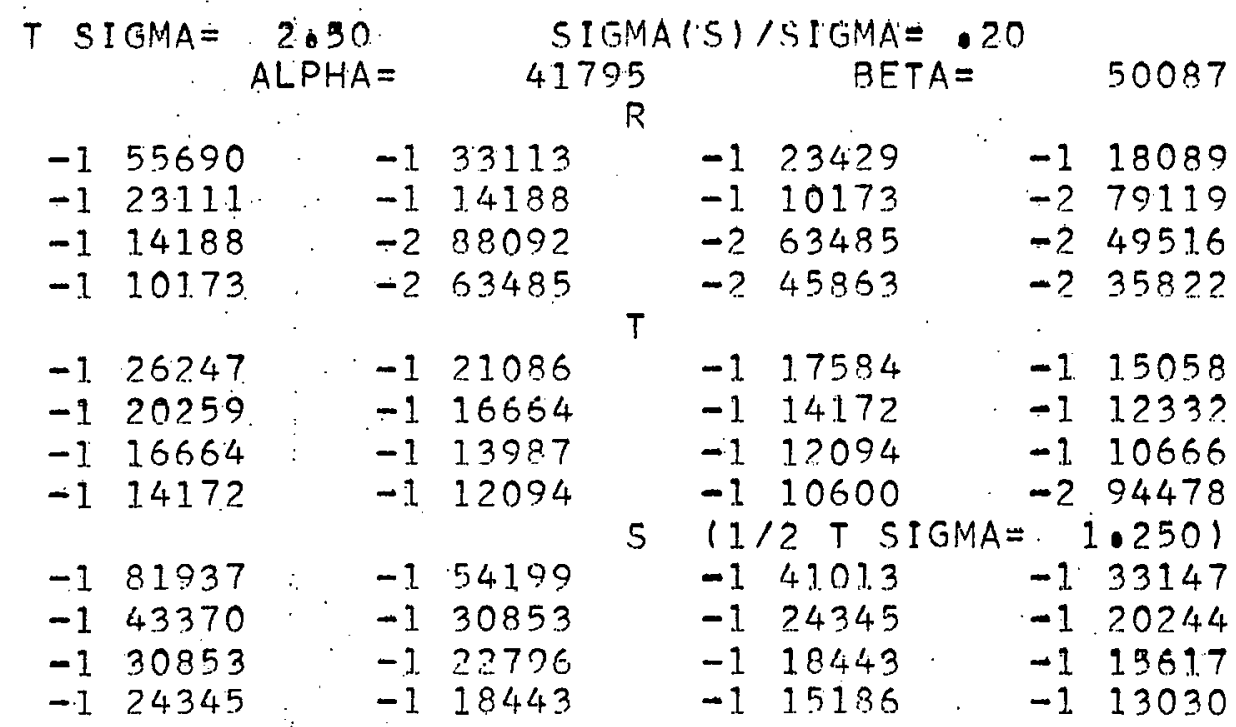




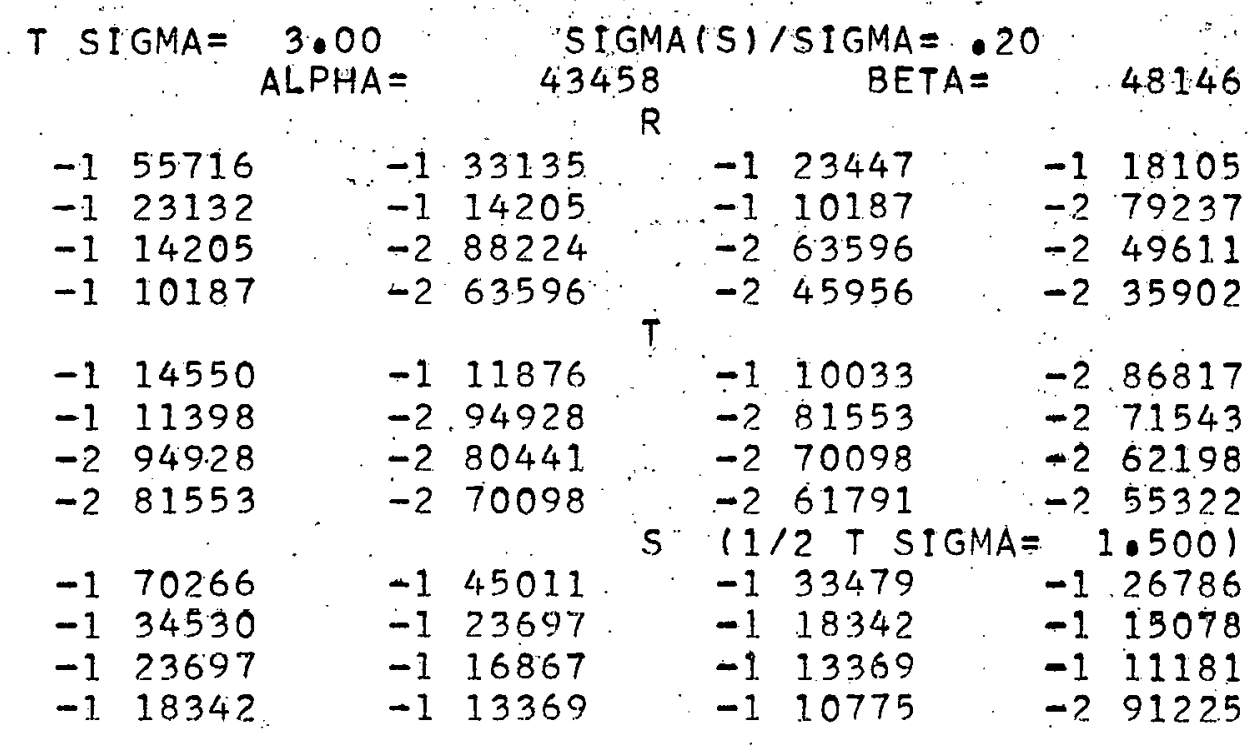

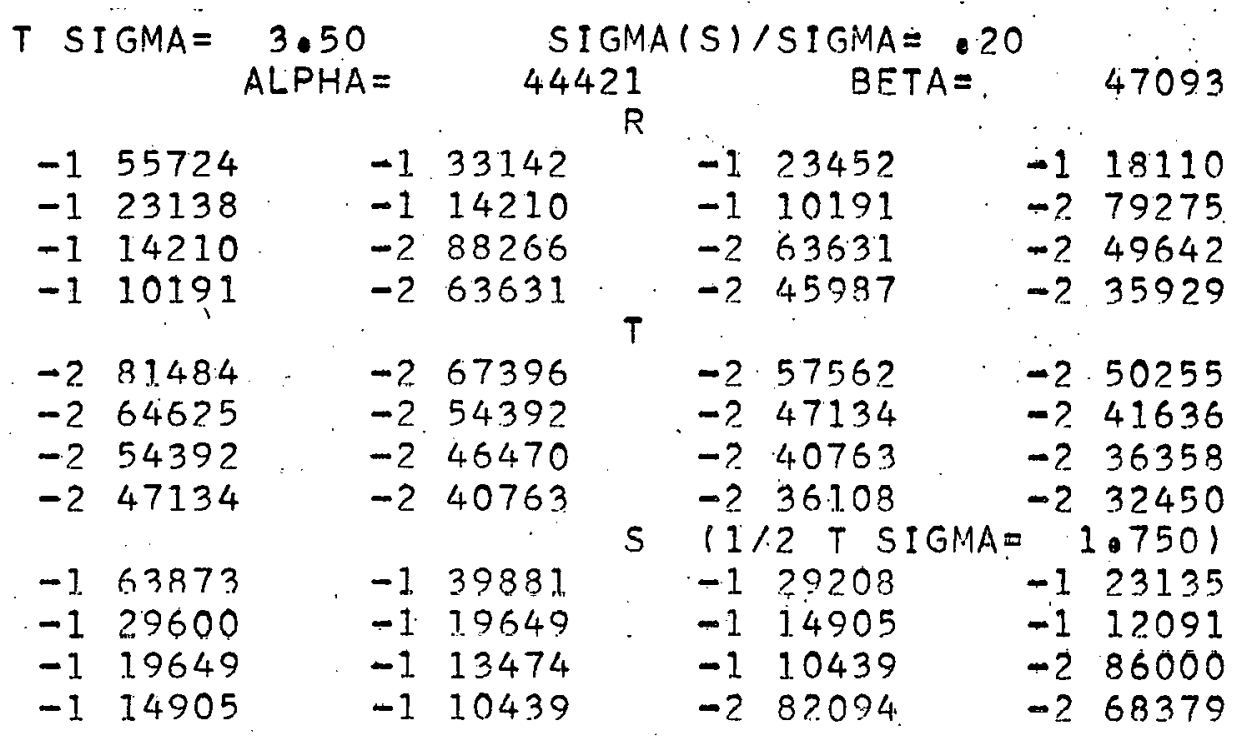

TSIGMA $=4.00 \quad$ SIGMA(S) $/$ SIGMA $=.20$ ALPHA $=\quad \begin{array}{ccc}44977 & B E T A= & 46509\end{array}$

$\begin{array}{ll}-1 & 55727\end{array}$ R

$\begin{array}{ll}-1 & 23140\end{array}$

$-1 \quad 33144$

$-1 \quad 14211$

$-111211$

$-1 \quad 23454$

$\begin{array}{ll}-1 & 18111\end{array}$

$-110193$

$\rightarrow$ 88ว80

$-1 \quad 10193$.

$\begin{array}{ll}-2 & 79287\end{array}$

$-263643$

-2 63643

$\begin{array}{ll}-2 & 49652\end{array}$

$-246010$

$-2 \quad 38488$

$T$

-? 45997

$-2.35938$

$\begin{array}{ll}-2 & 36878\end{array}$

-7 31321

$\begin{array}{ll}-2 & 33182\end{array}$

-2
-29191

$-2 \quad 31321$

$-2.26947$

$\begin{array}{ll}-2 & 27343\end{array}$

$\begin{array}{ll}-2 & 24296\end{array}$

$\begin{array}{ll}-2 & 27343\end{array}$

$\begin{array}{ll}-2 & 23771\end{array}$

$\begin{array}{ll}-1 & 60328\end{array}$

-1. 36993

$-7.73771$

-2 21143

$-2 \quad 21295$

S $11 / 2$ T SIGMA $=$

$-2 \quad 19062$

$-126828$

- 117343

$\begin{array}{ll}-1 & 26772\end{array}$

$\begin{array}{ll}-1 & 12927\end{array}$

-1 17343

-1 11523

$\begin{array}{ll}-2 & 87414\end{array}$

-2 67140

$-121030$

$-110358$

-2 70947

-2. 87414

-2 54999 


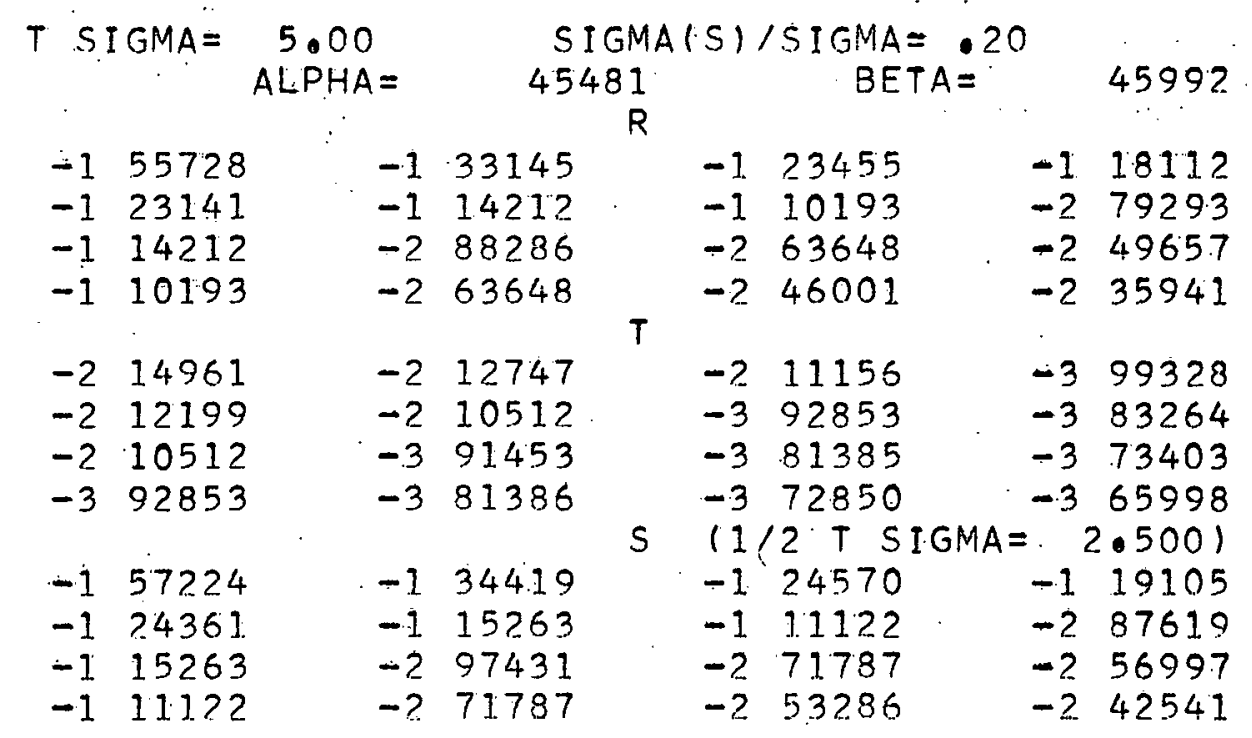

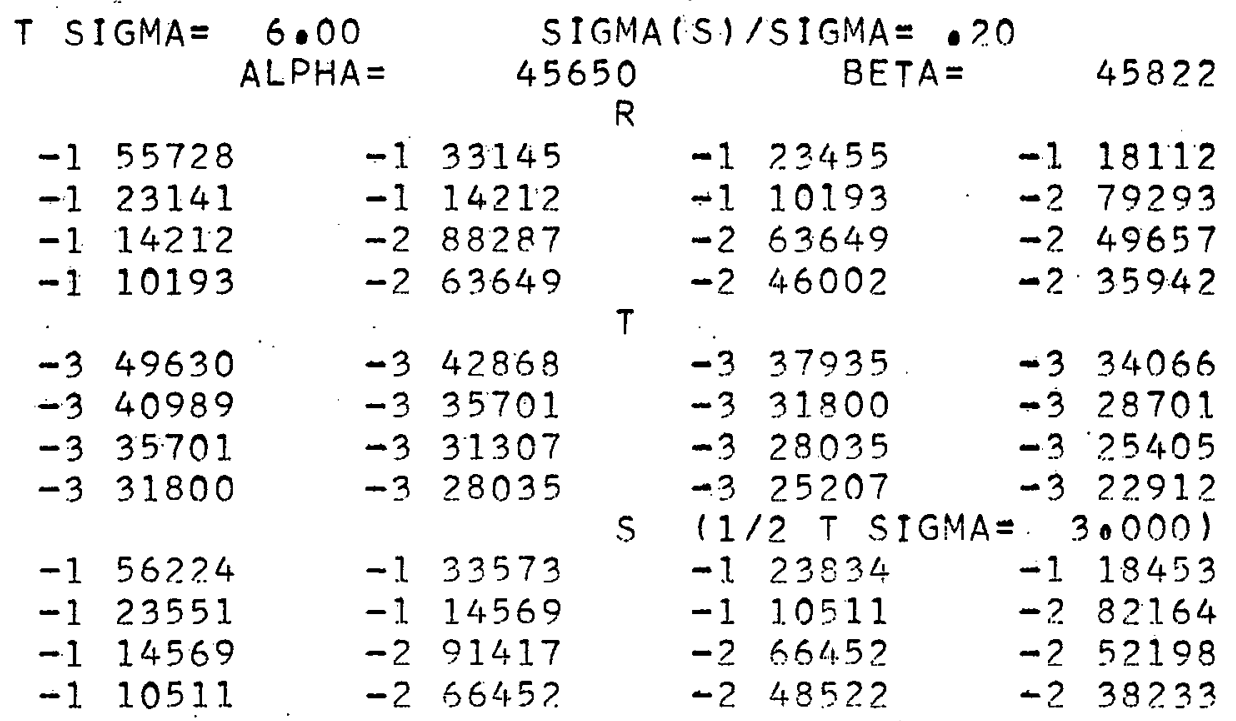

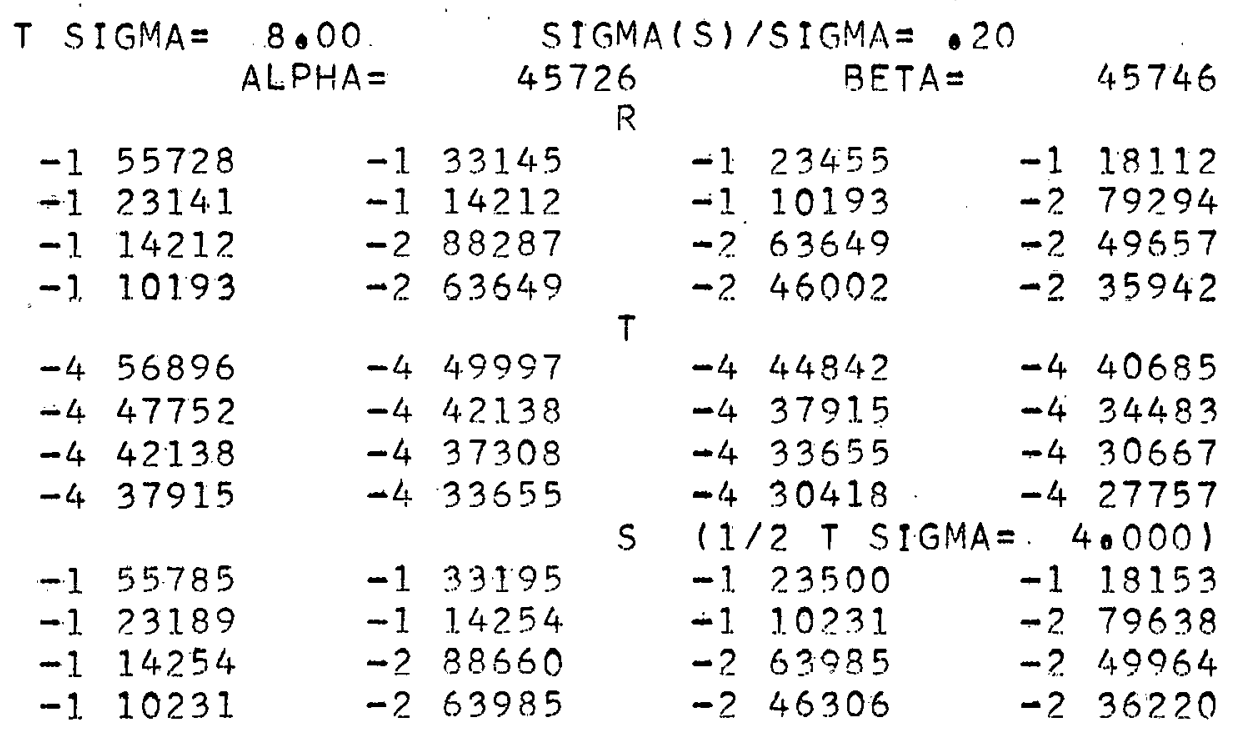

41 


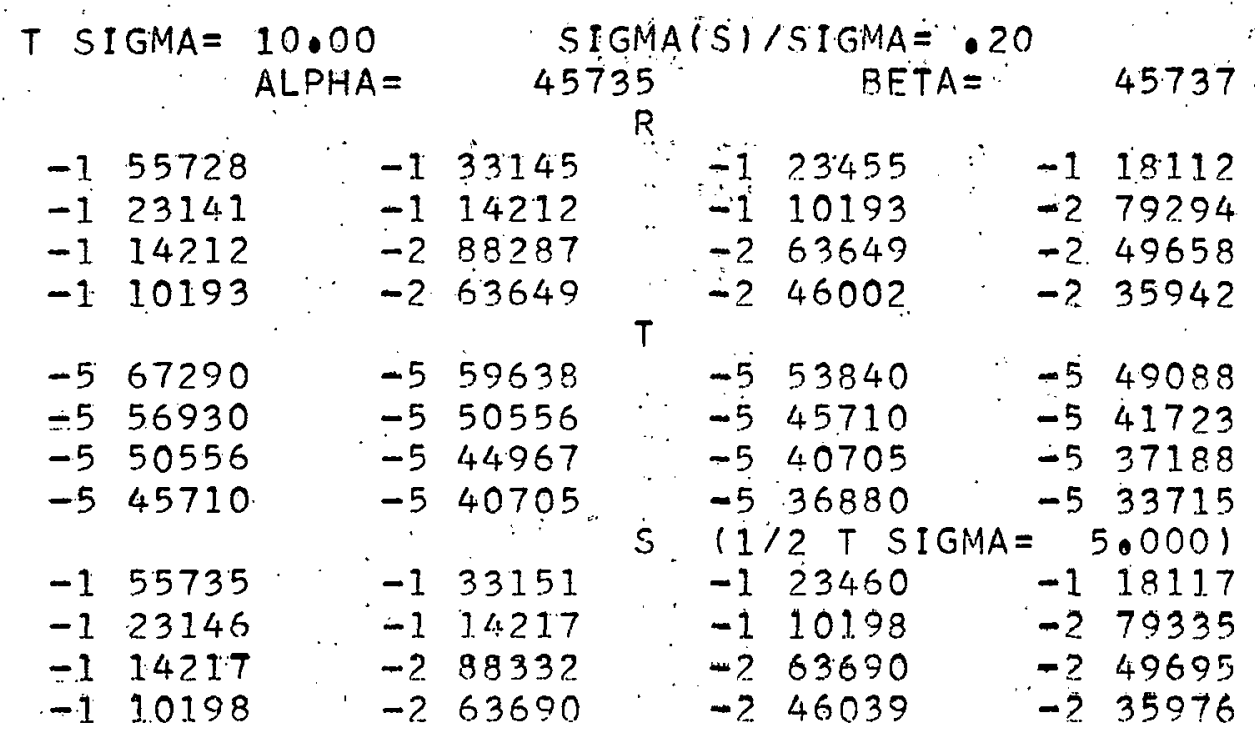

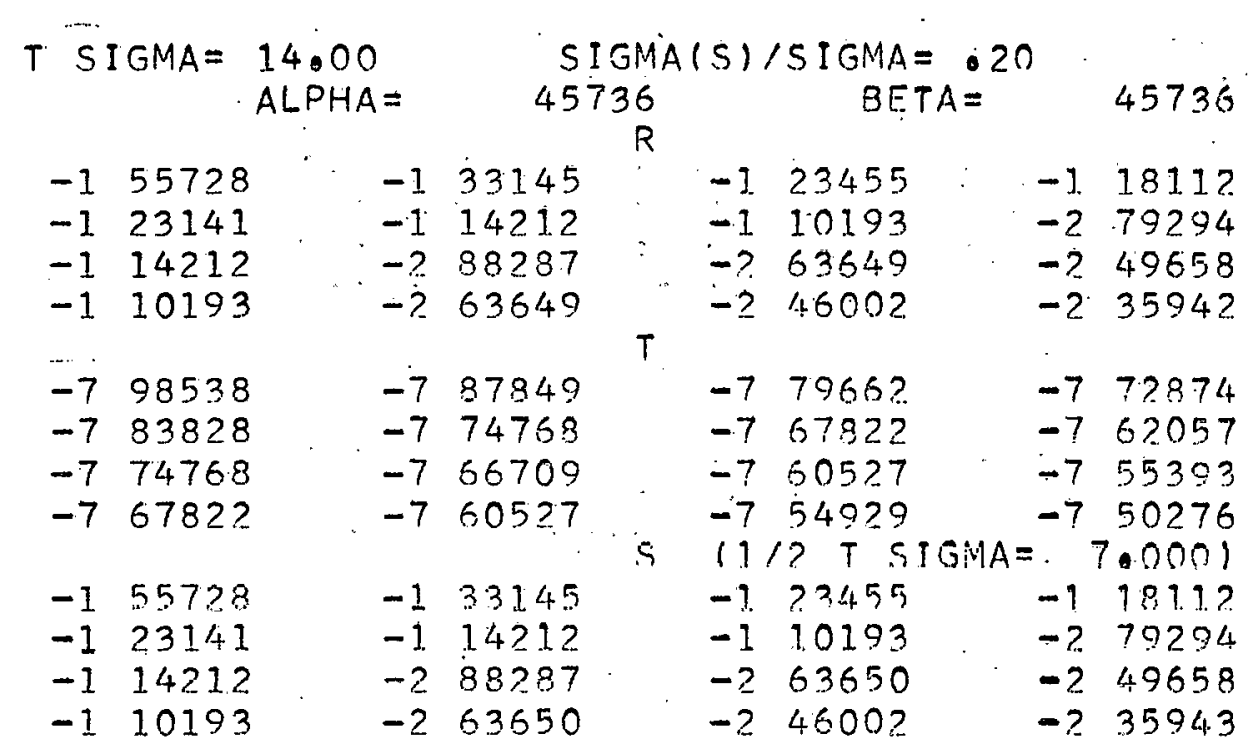

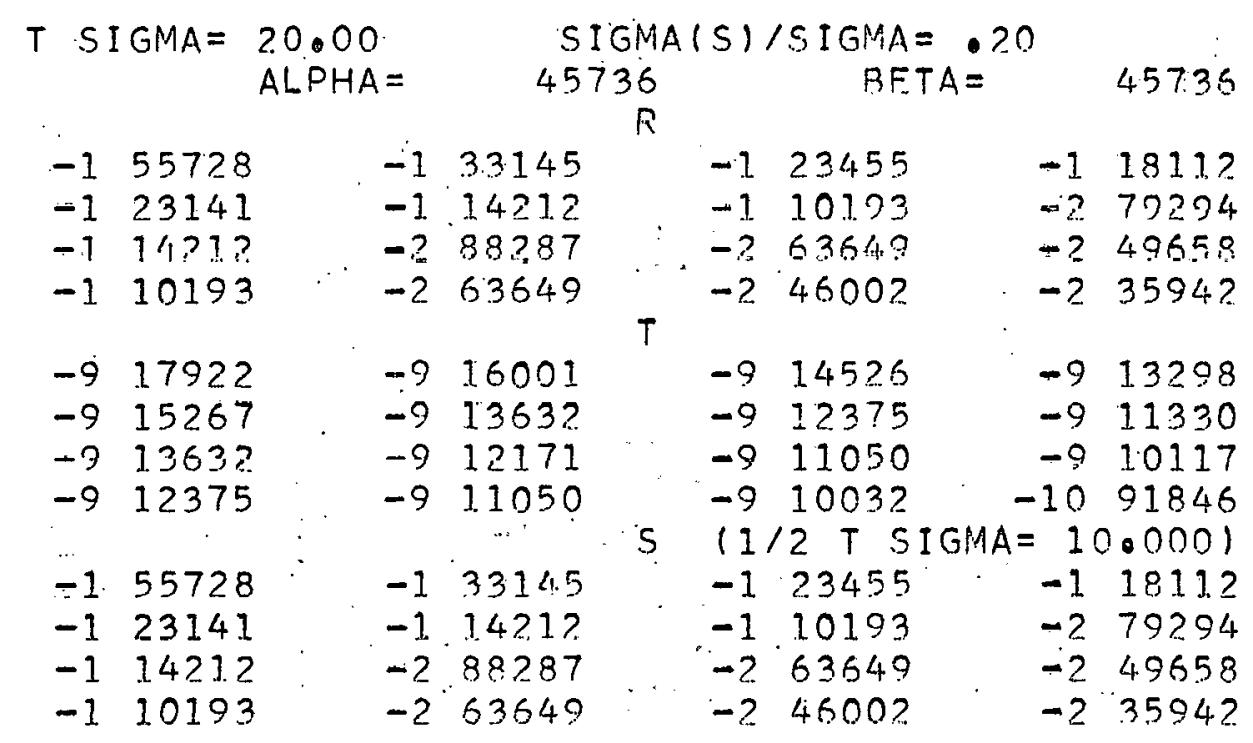

$428 \mathrm{~J} \% ?: 4$ 


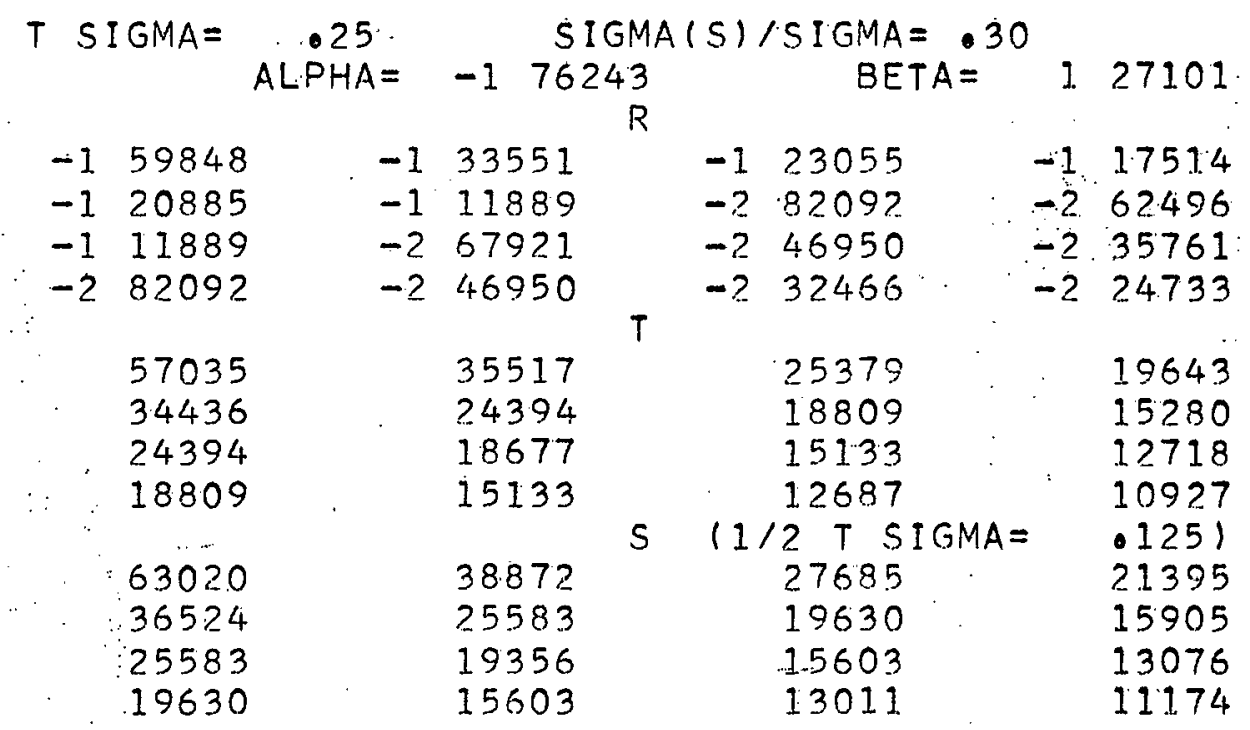

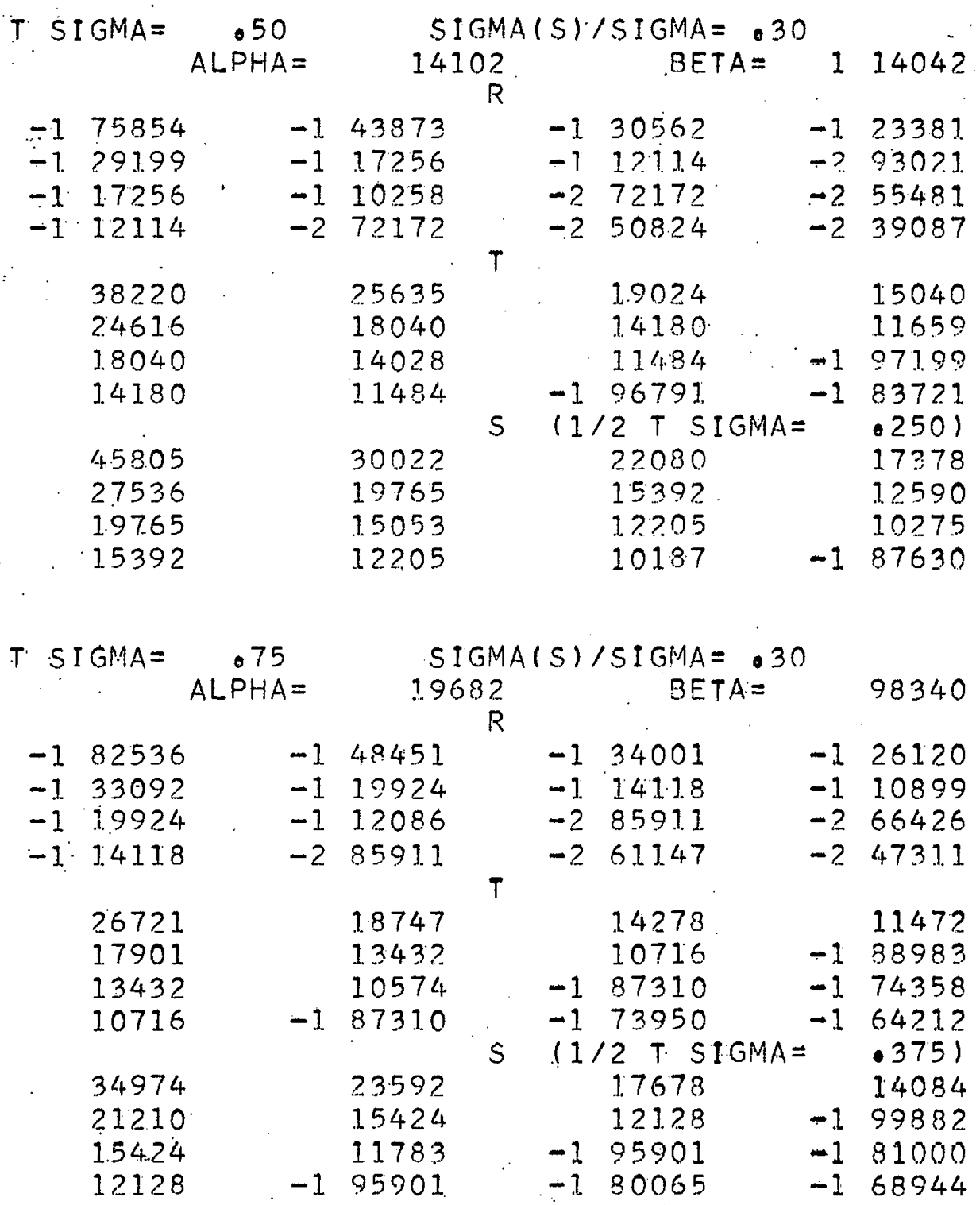




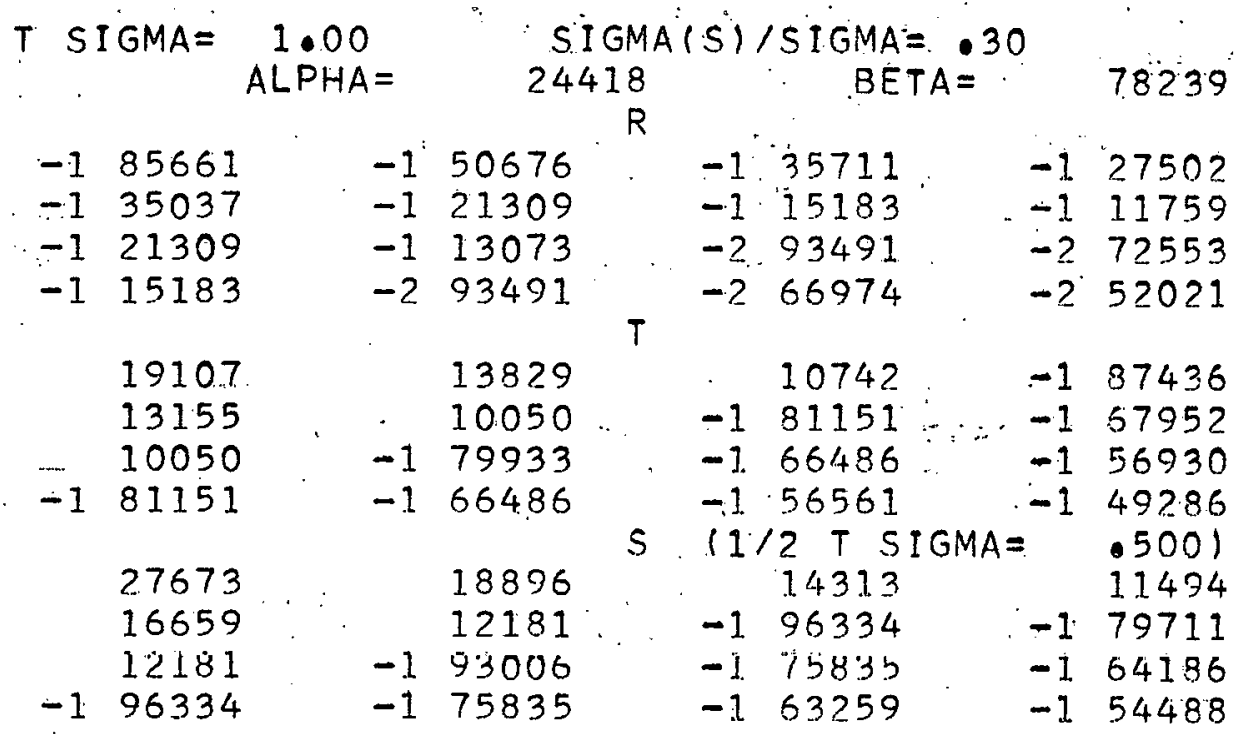

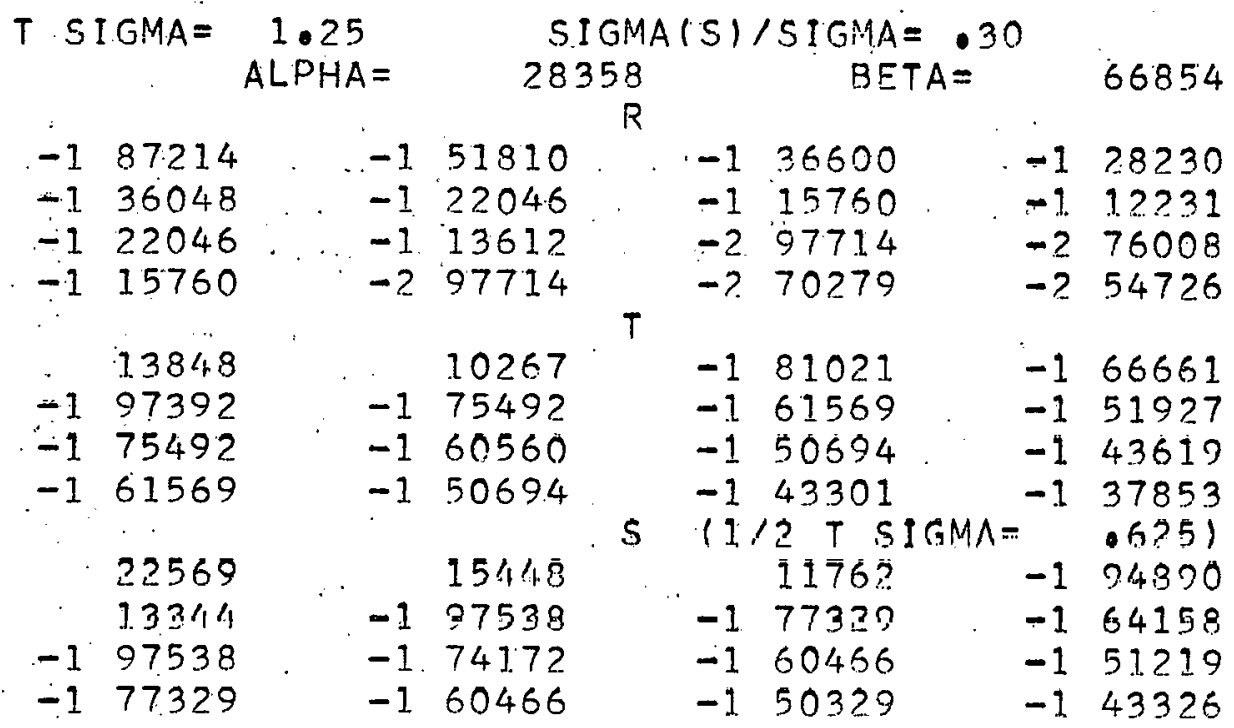

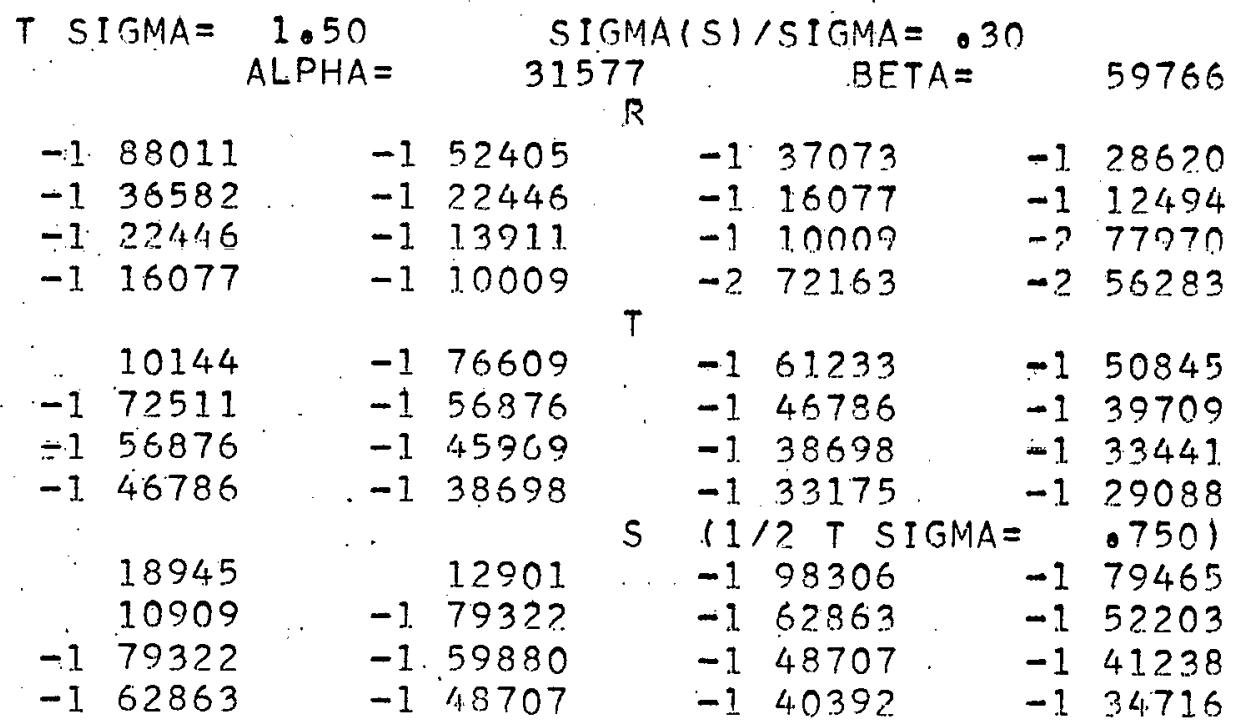




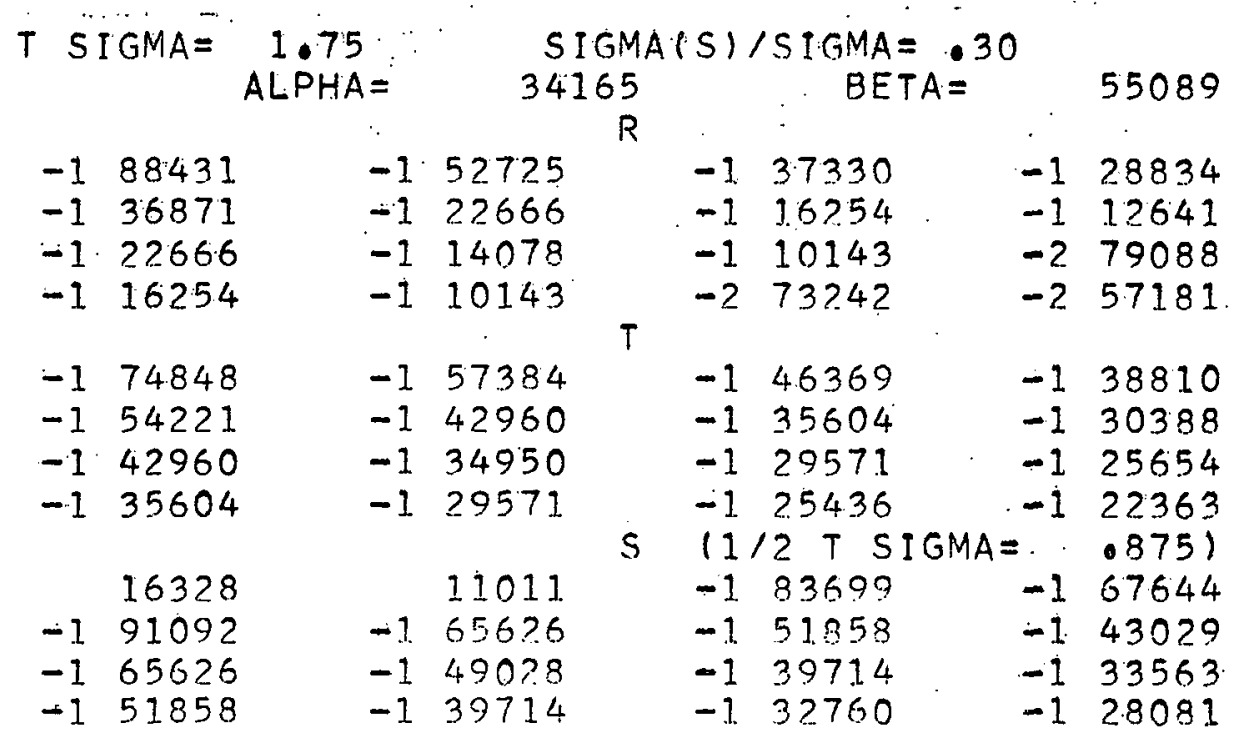

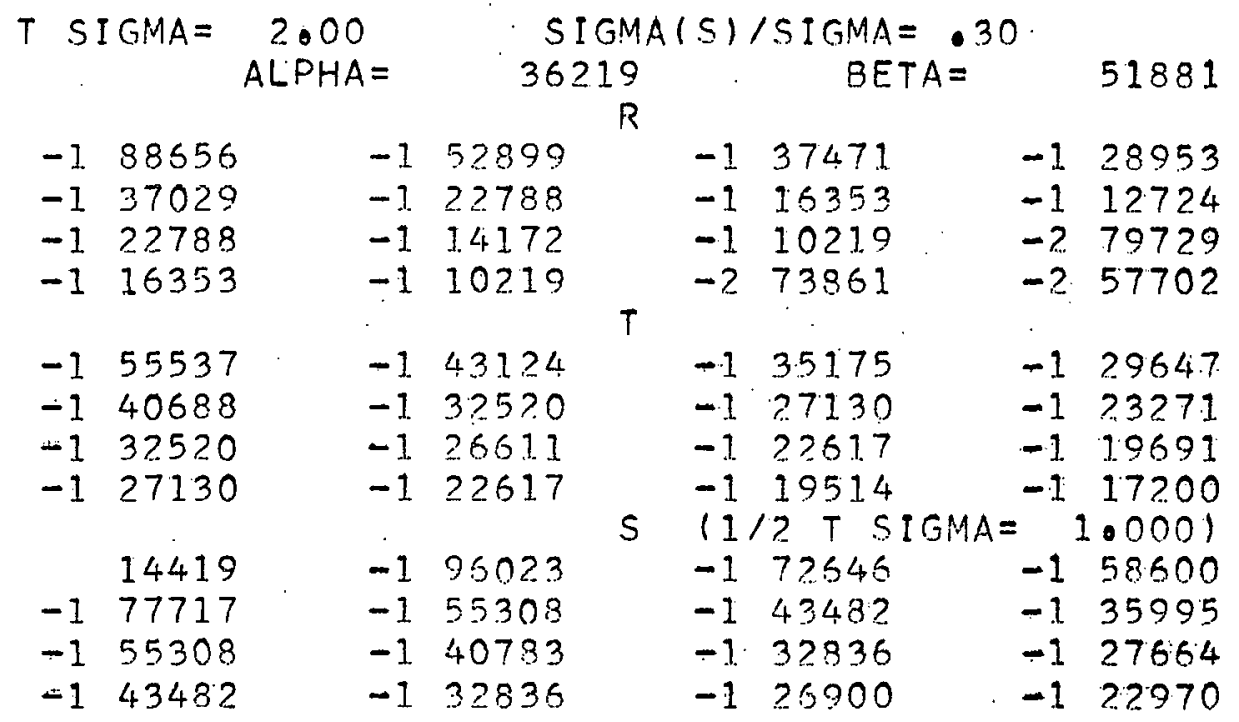

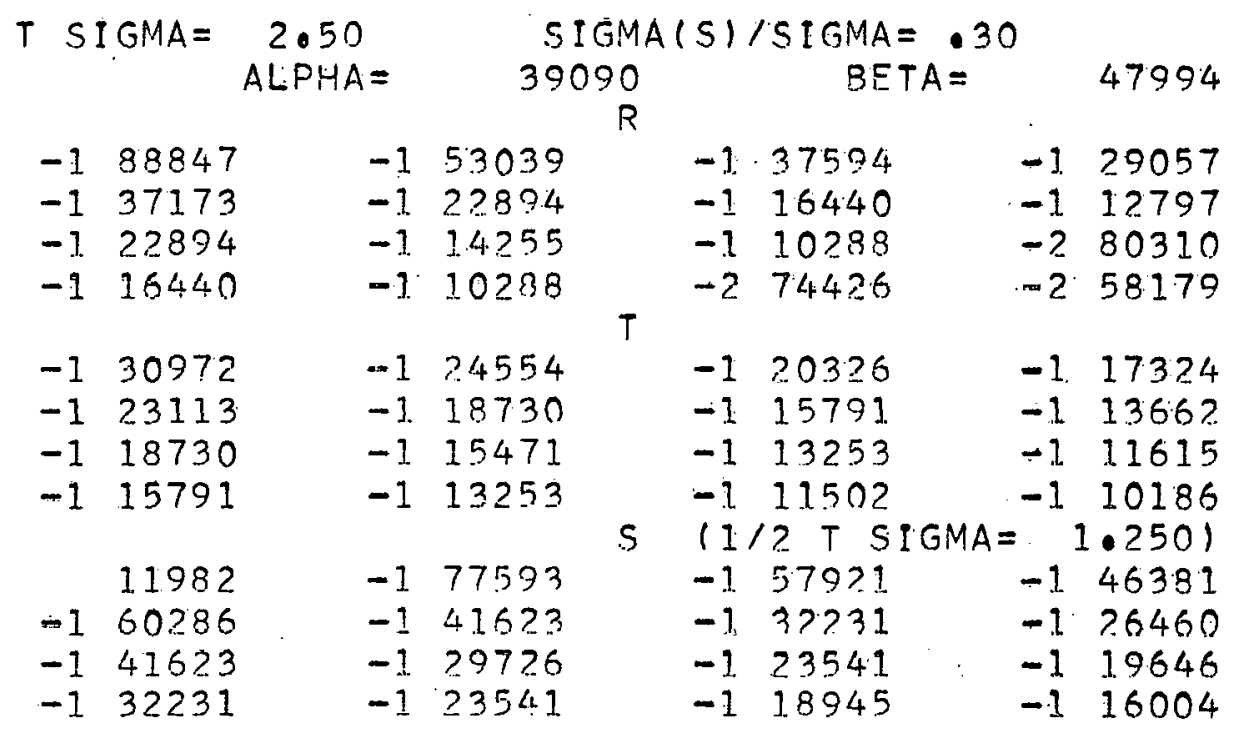




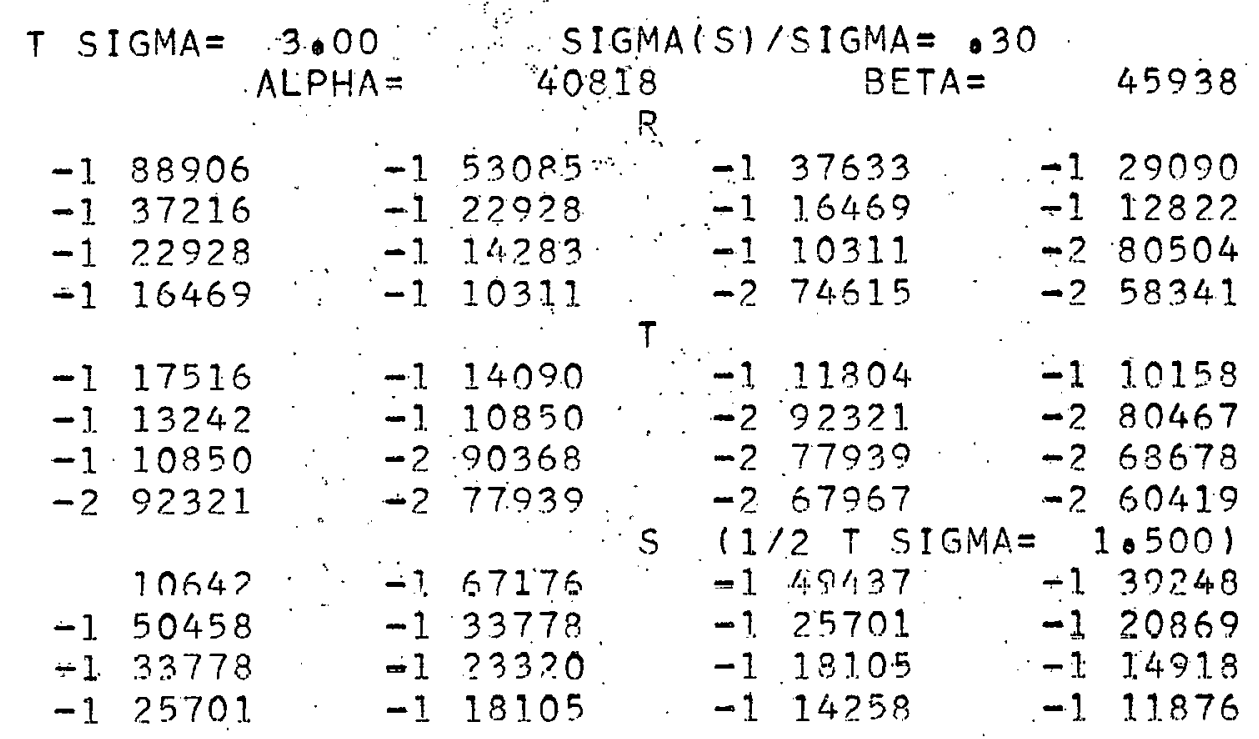

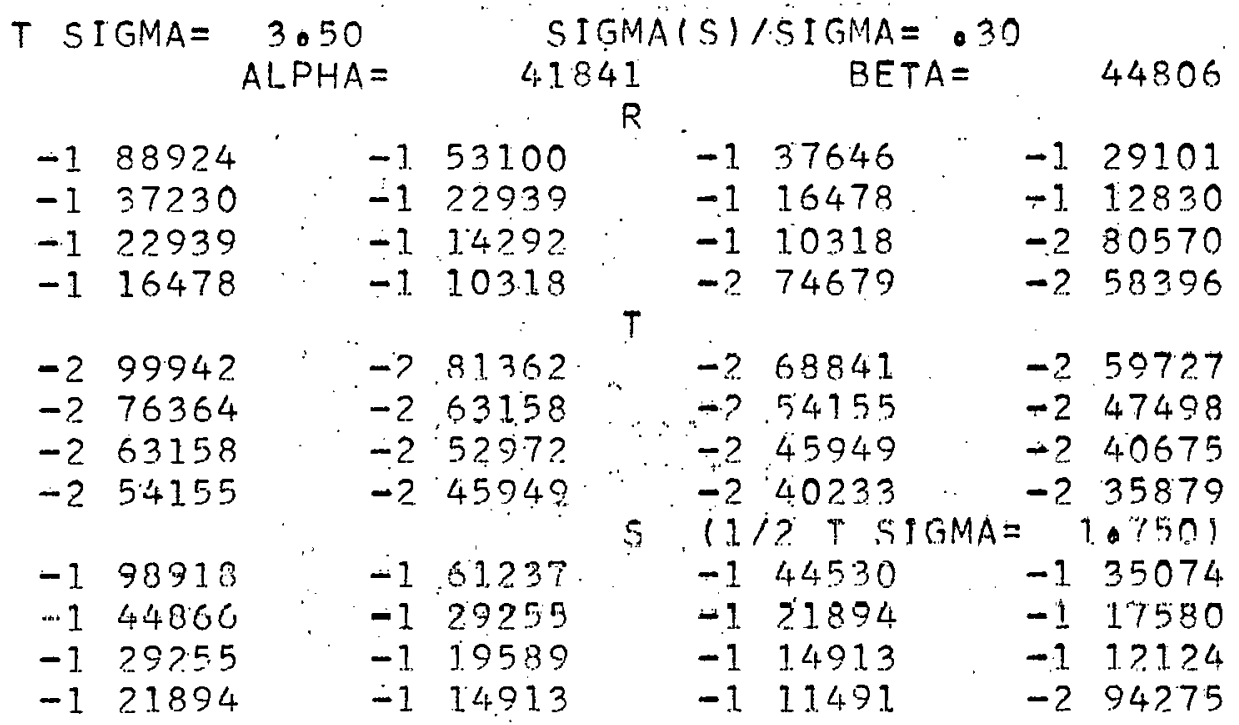

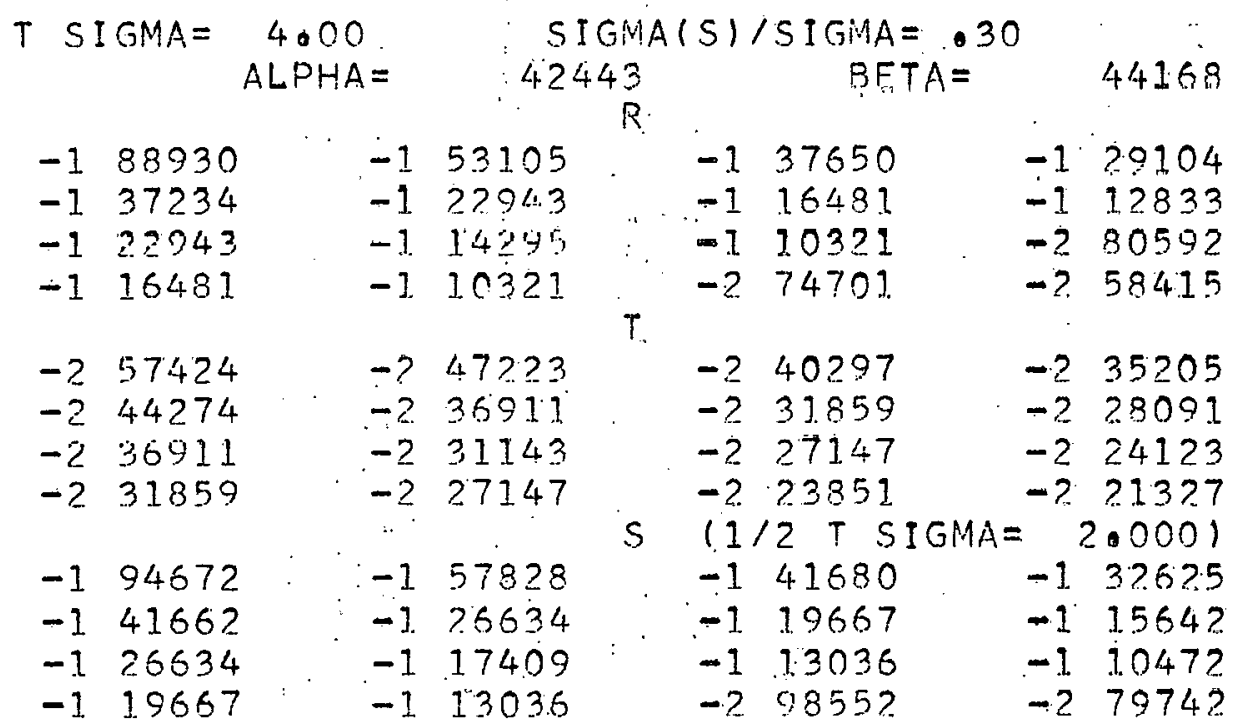




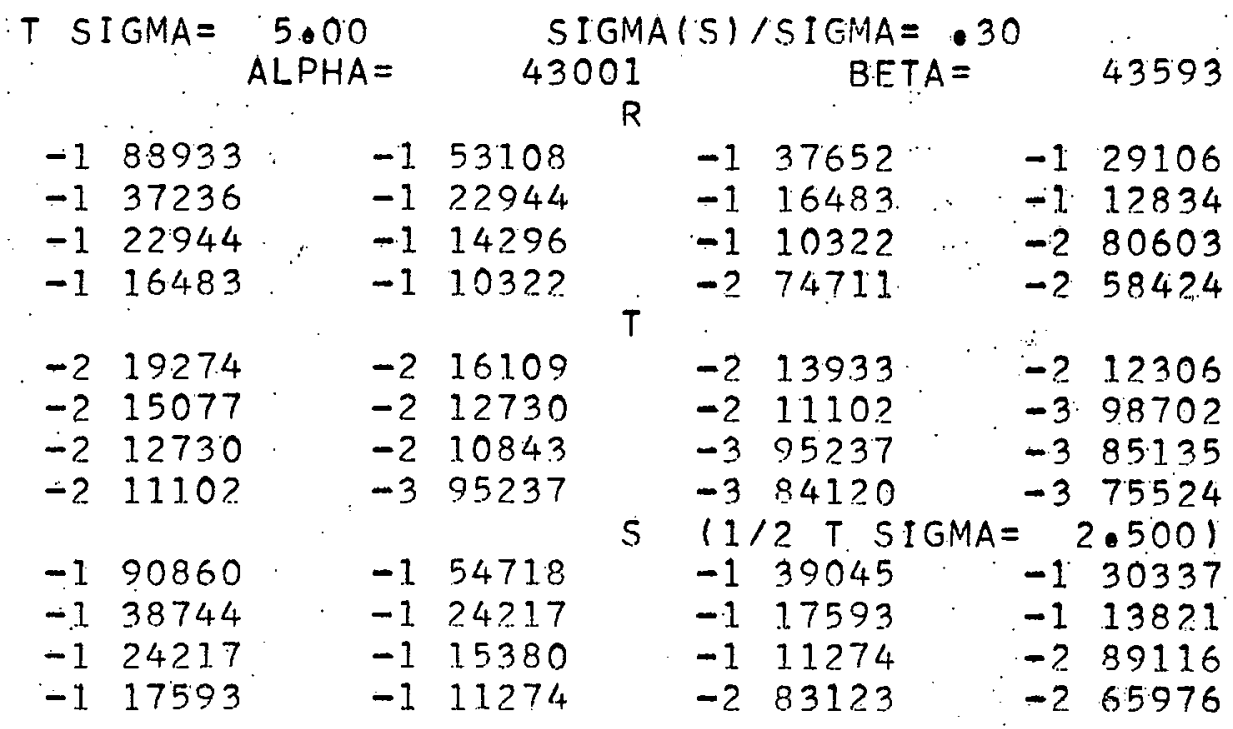

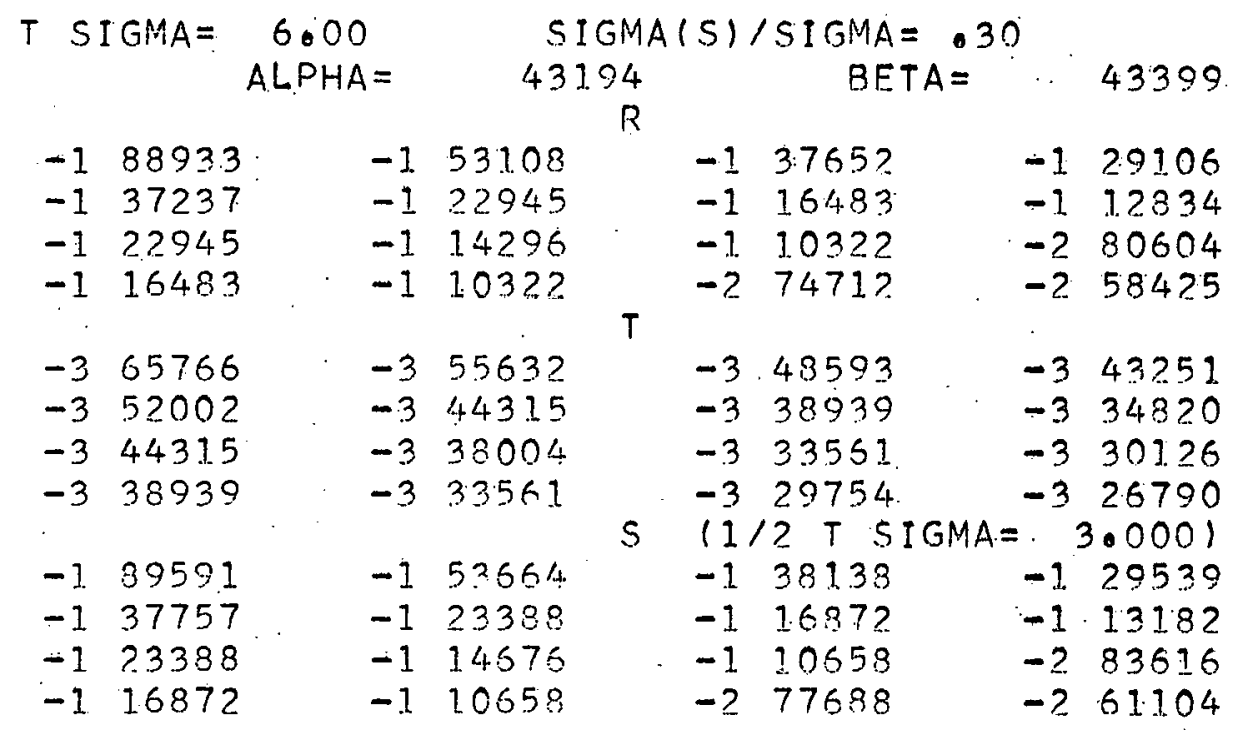

\begin{tabular}{|c|c|c|c|c|c|c|c|c|}
\hline$T S$ & GMA $=$ & 00 & & 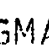 & $(s)$ & SIGMA & & \\
\hline & & $H A=$ & & & & $B E$ & & 43309 \\
\hline$-I$ & 88933 & -1 & 53108 & & -1 & 37652 & -1 & 29106 \\
\hline-1 & 37237 & -1 & 22945 & & -1 & 16483 & -1 & 12834 \\
\hline & 22945 & -1 & 14296 & & -1 & 10322 & -2 & 80604 \\
\hline-1 & 16483 & $=1$ & 1.0322 & & -2 & $7471 ?$ & -2 & 584.25 \\
\hline & & & & $T$ & & & & \\
\hline-4 & 79187 & -4 & 67999 & & -4 & 60112 & -4 & 54005 \\
\hline-4 & 63462 & -4 & 54700 & & -4 & 48499 & -4 & 43669 \\
\hline-4 & 54700 & -4 & 47295 & & -4 & 42036 & -4 & $379 ? 0$ \\
\hline-4 & 48499 & -4 & 42036 & & -4 & 37431 & -4 & 33815 \\
\hline & & & & $\mathrm{S}$ & $11)$ & $2 T S$ & & .0001 \\
\hline-1 & 89012 & -1 & 53176 & & -1 & 37712 & -1 & 29160 \\
\hline-1 & 37300 & -1 & 22999 & & -1 & 16531 & -1 & 12878 \\
\hline-1 & 22999 & -1 & I 4344 & & -1 & 10364 & -2 & 80983 \\
\hline-1 & 16531 & -1 & 10364 & & -2 & 75087 & -2 & 58763 \\
\hline
\end{tabular}




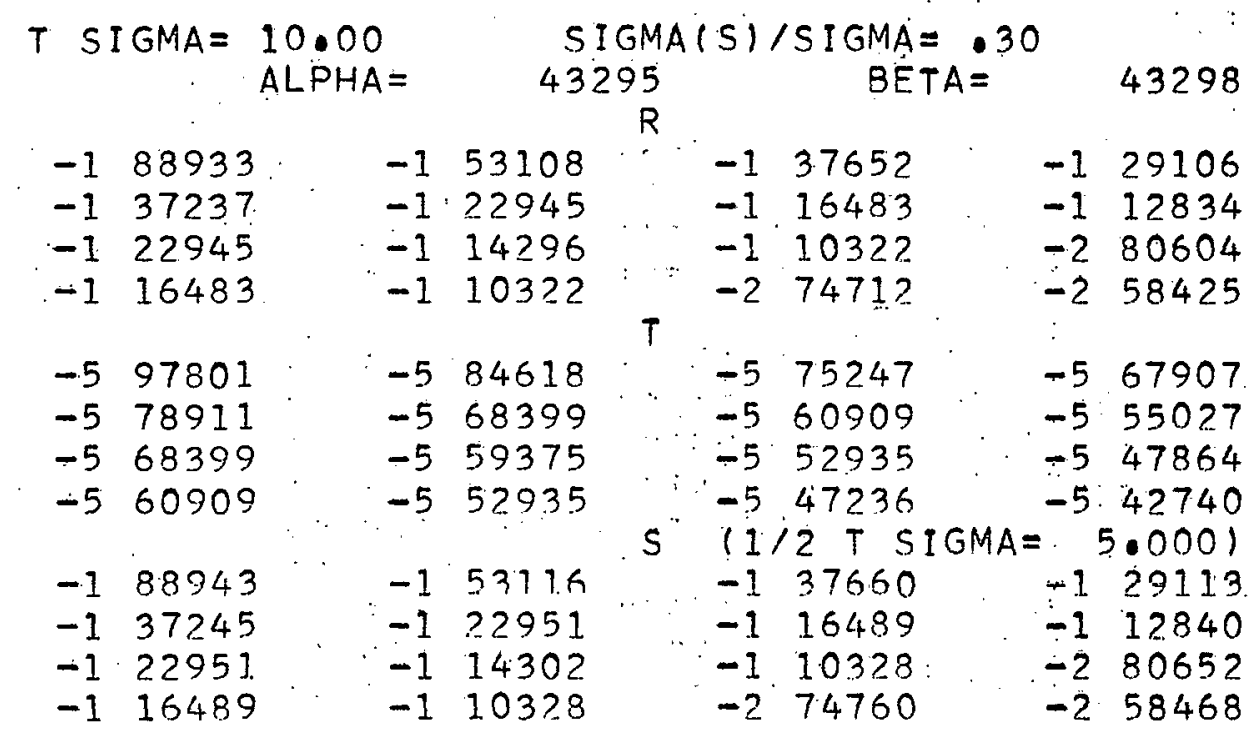

\begin{tabular}{|c|c|c|c|c|c|c|c|c|}
\hline S & GMA $=$ & 14.00 & ${ }^{3} \mathrm{~S}$ & GMA & & SIGMA = & & \\
\hline & & ALPHA = & 43 & $\begin{array}{r}96 \\
R\end{array}$ & & $B \dot{E} T A=$ & & 432.96 \\
\hline-1 & 88933 & -1 & 53108 & & -1 & 37652 & -1 & 29106 \\
\hline-1 & 37237 & -1 & 22.945 & & -1 & 16483 & -1 & 12834 \\
\hline-1 & 22945 & -1 & 14296 & & -1 & $103 ? ?$ & -2 & 80604 \\
\hline-1 & 16483 & -1 & $103 ? 2$ & $T$ & -2 & 74712 & $-?$ & 58425 \\
\hline-6 & 15511 & -6 & $1349 ?$ & & -6 & 12047 & -6 & 10906 \\
\hline-6 & 12575 & -6 & 10943 & & -7 & 9.7741 & -7 & 88504 \\
\hline-6 & 10943 & -7 & 95254 & & -7 & 85104 & -7 & 77076 \\
\hline-7 & 97741 & -7 & 85104 & $s$ & -7 & $\begin{array}{l}76050 \\
2 T 5 I G M A=\end{array}$ & $=-7$ & $\begin{array}{l}68887 \\
7.0001\end{array}$ \\
\hline-1 & 88933 & -1 & 53108 & & -1 & 37652 & -1 & 29106 \\
\hline-1 & 37237 & -1 & 2294.5 & & -1 & 16483 & -1 & 12834 \\
\hline-1 & 22945 & -1 & 14296 & & -1 & $103 ? ?$ & -2 & 80605 \\
\hline-1 & 15483 & -1 & $1032 ?$ & & -2 & 74713 & -2 & 58426 \\
\hline
\end{tabular}

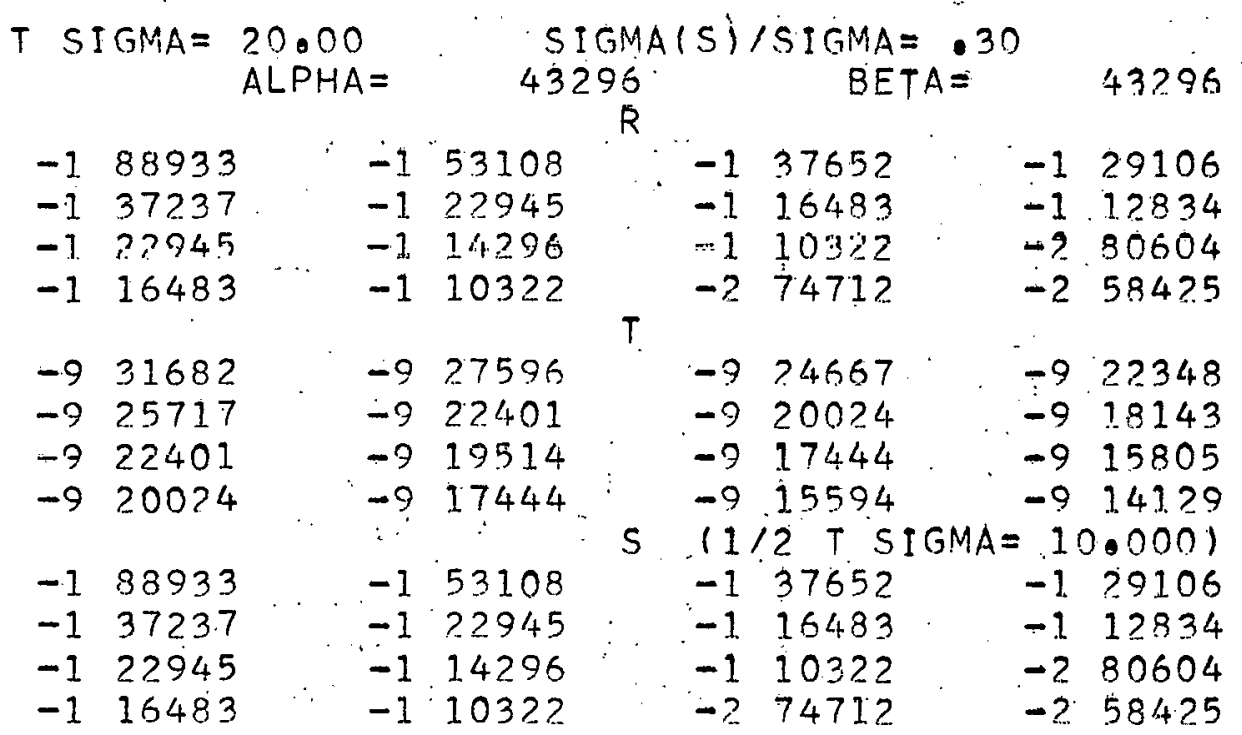




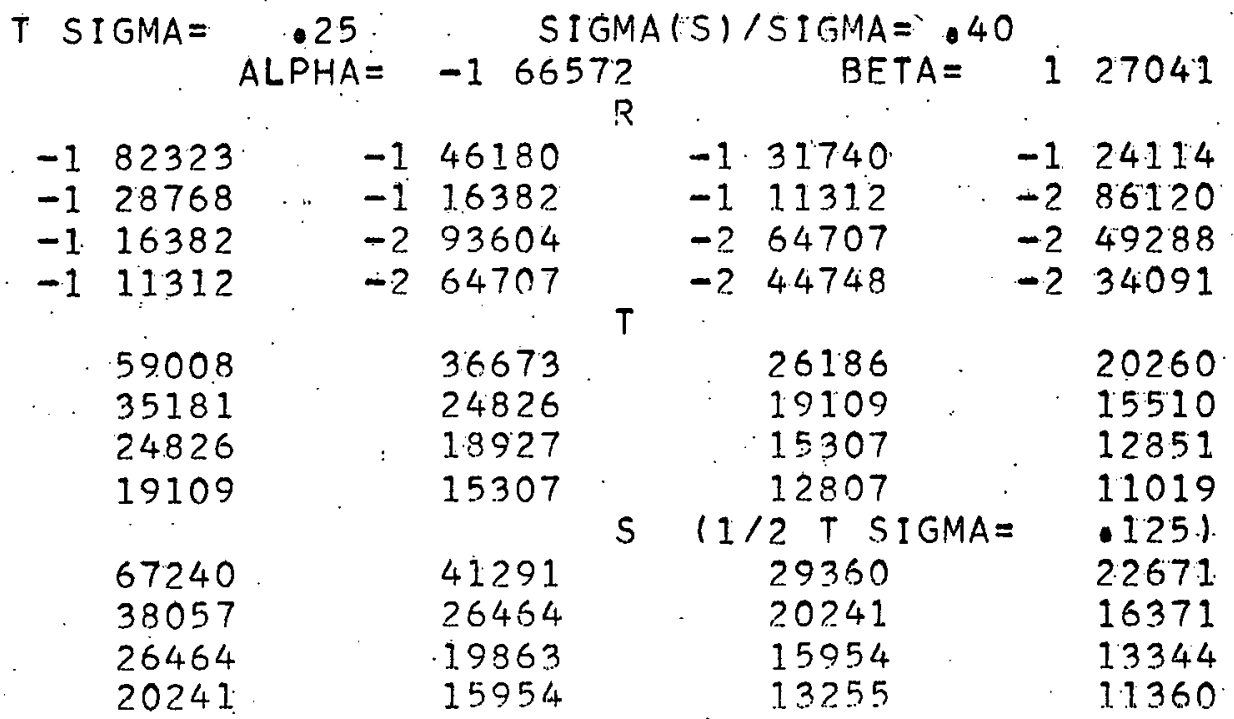

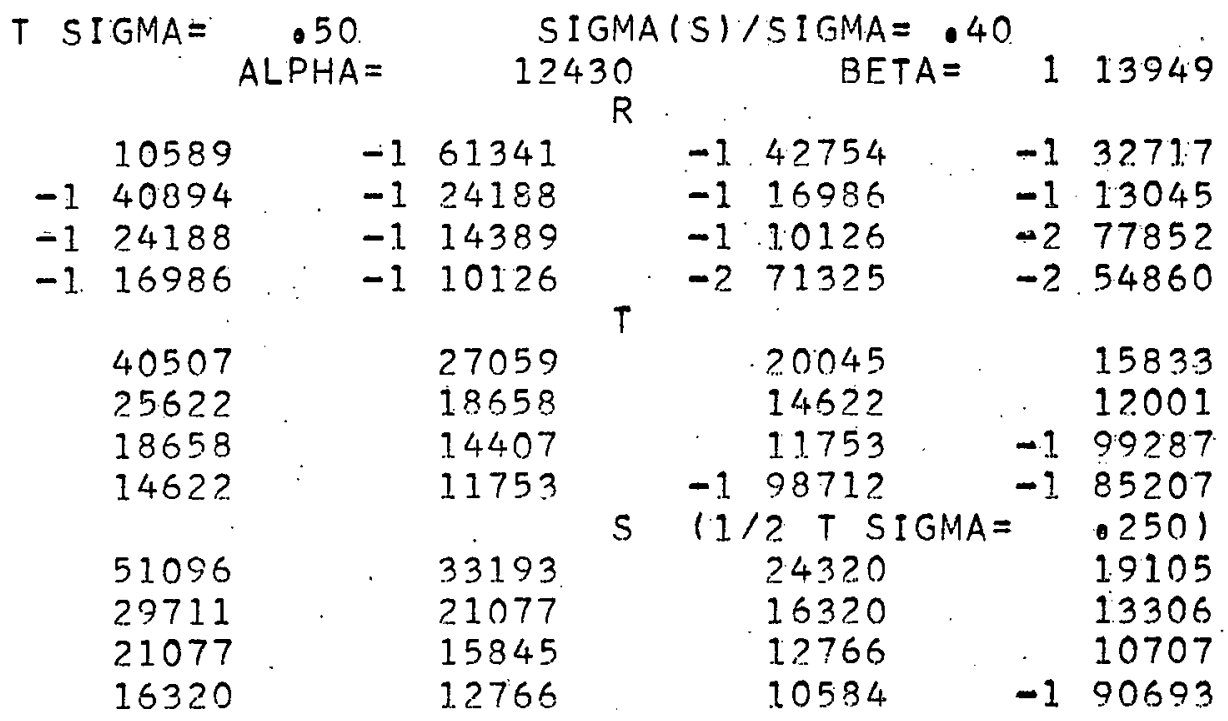

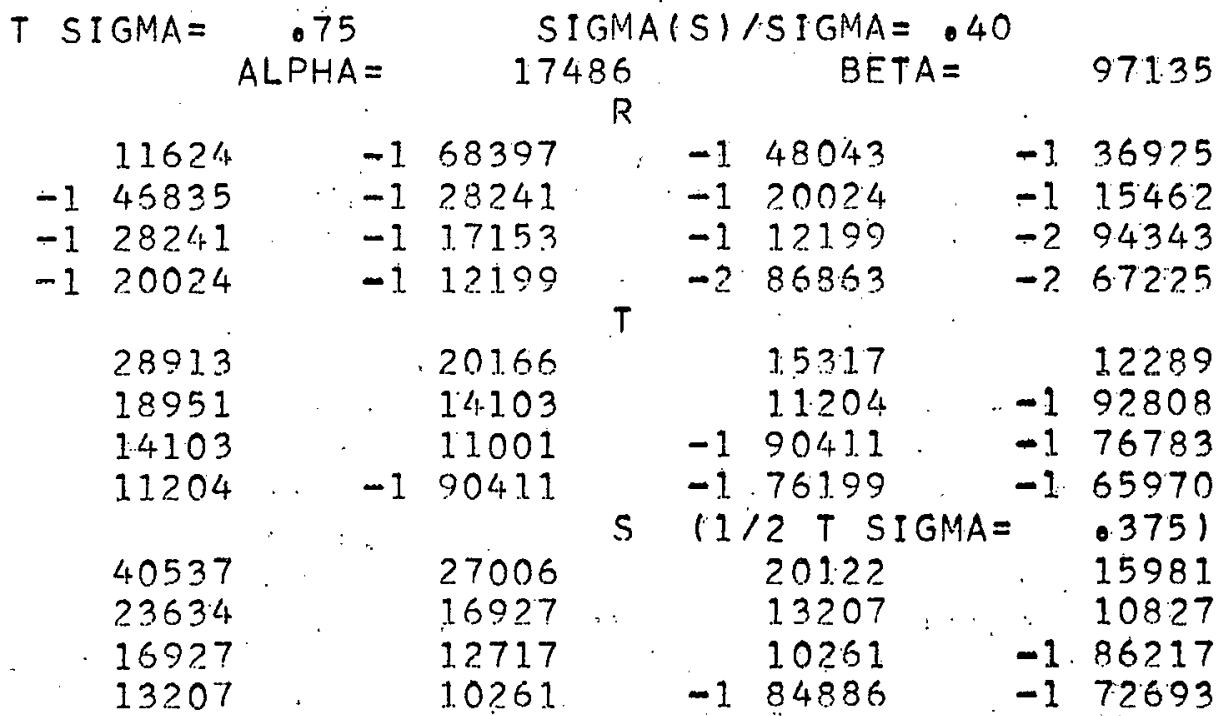


WAPD-TM-168

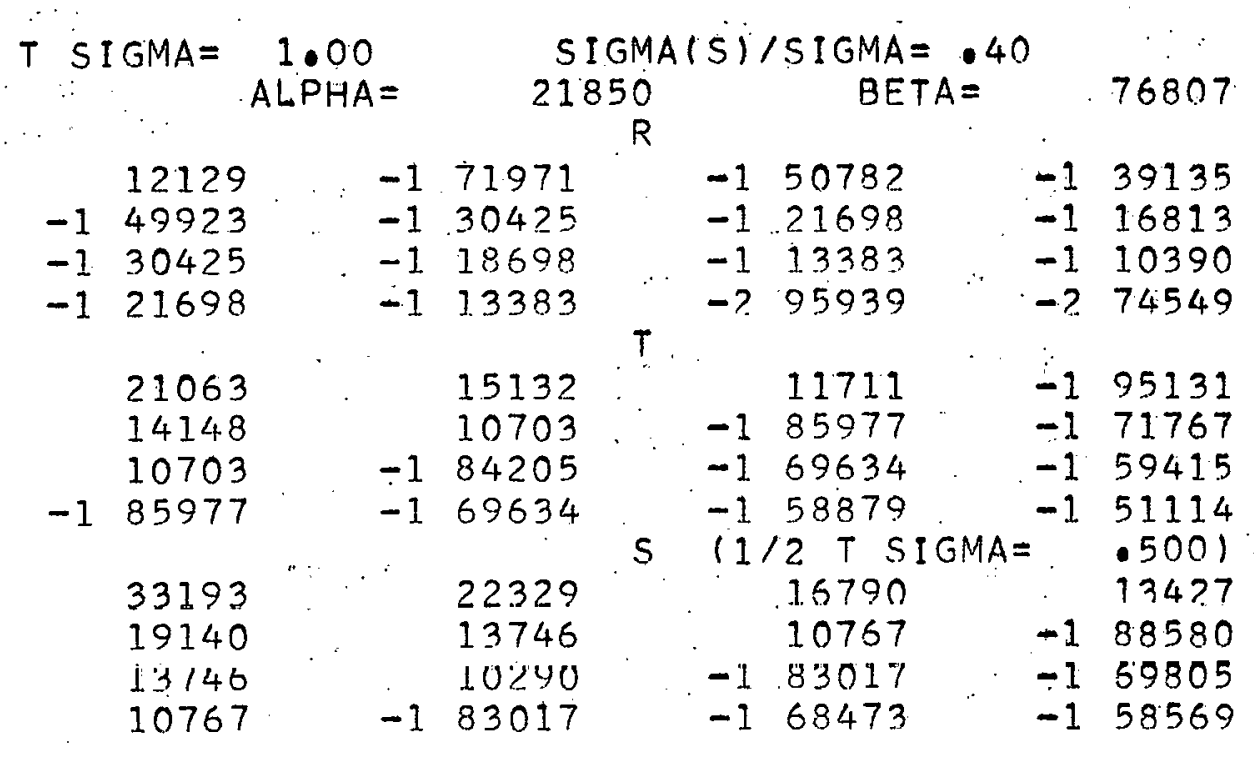

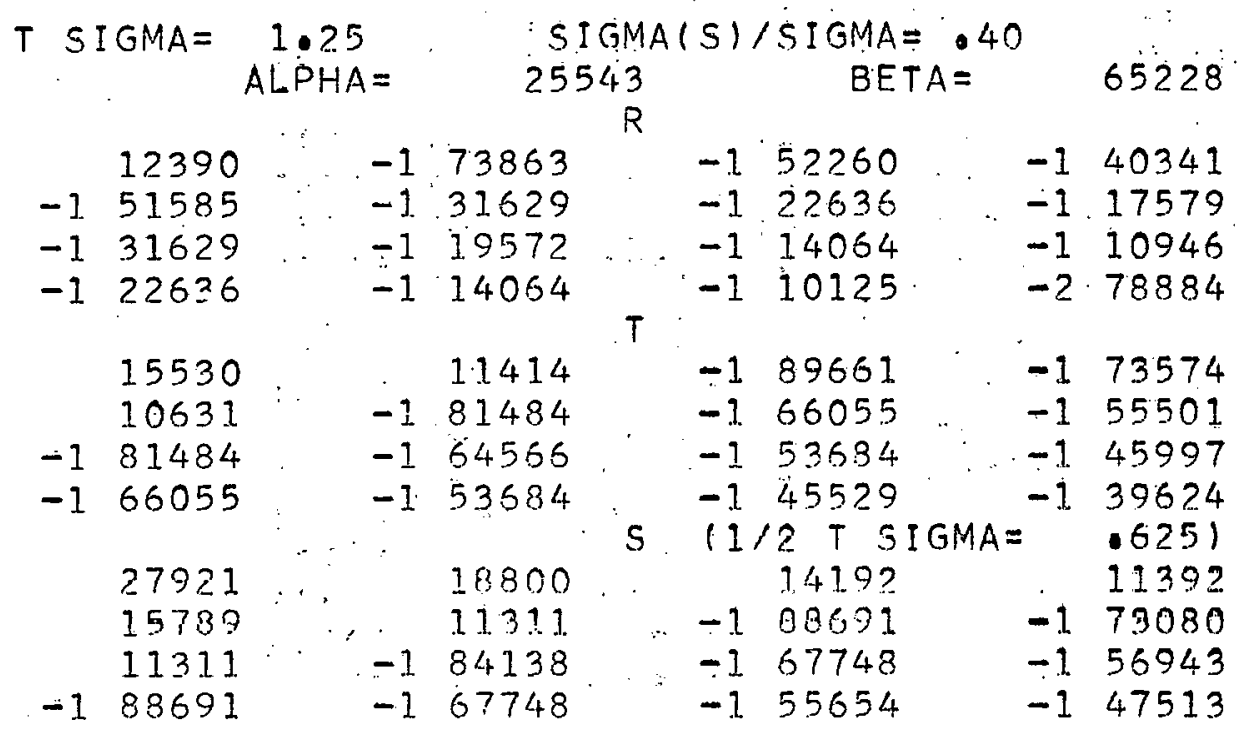

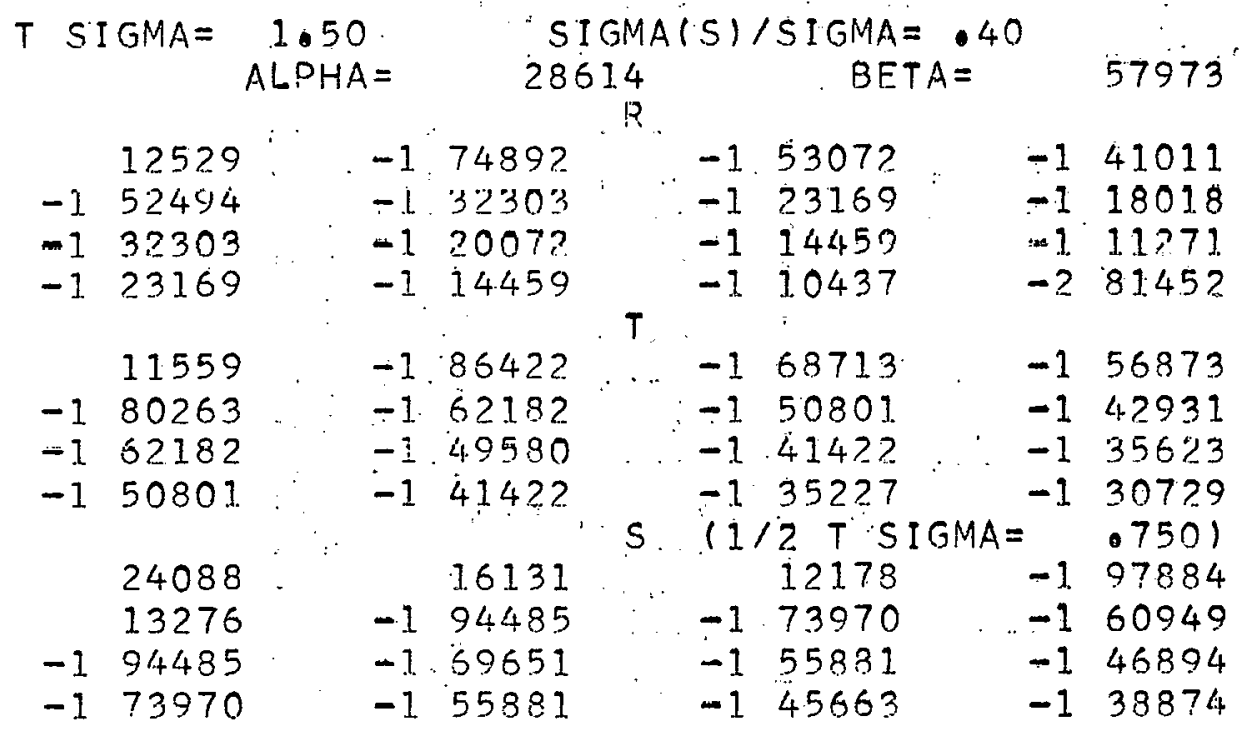




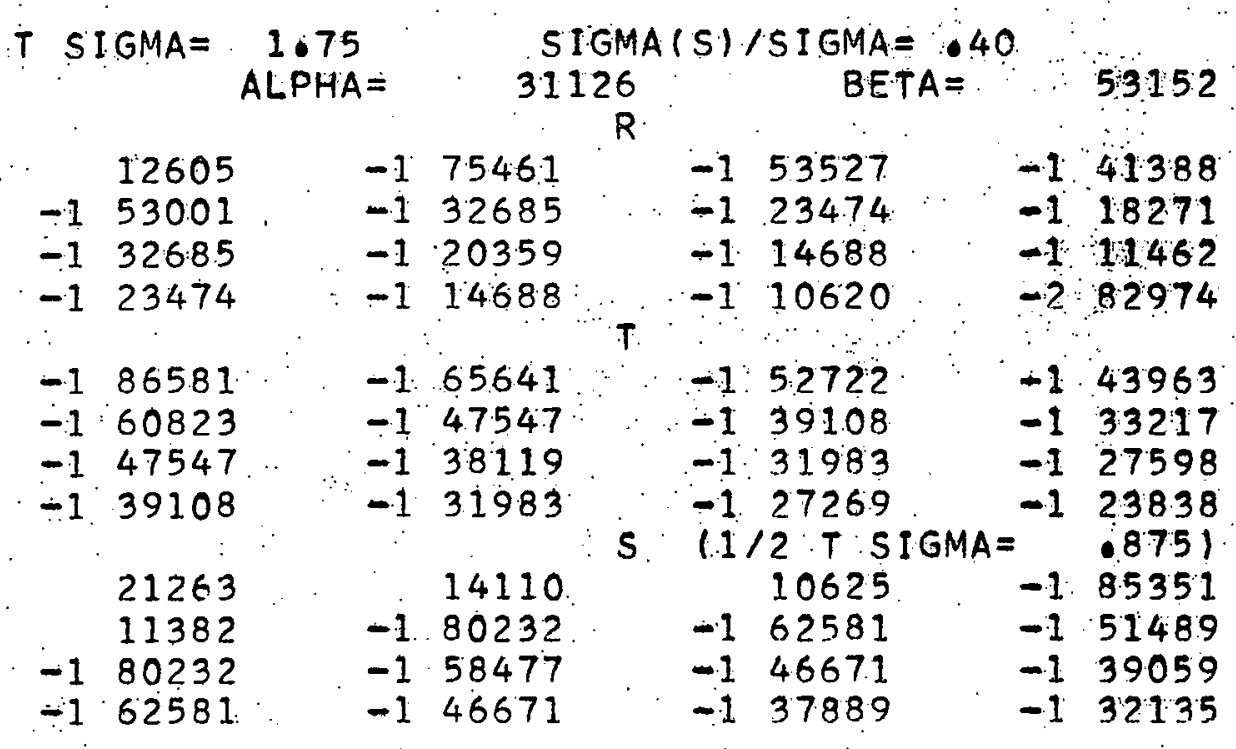

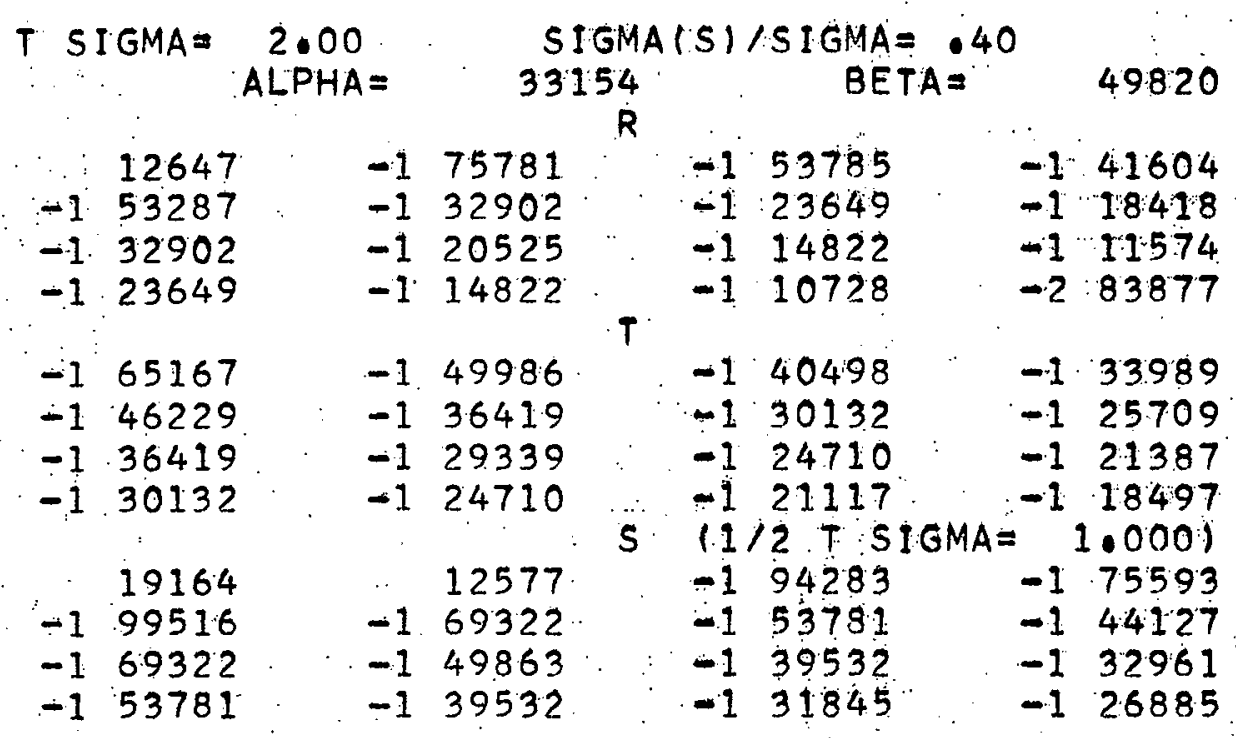

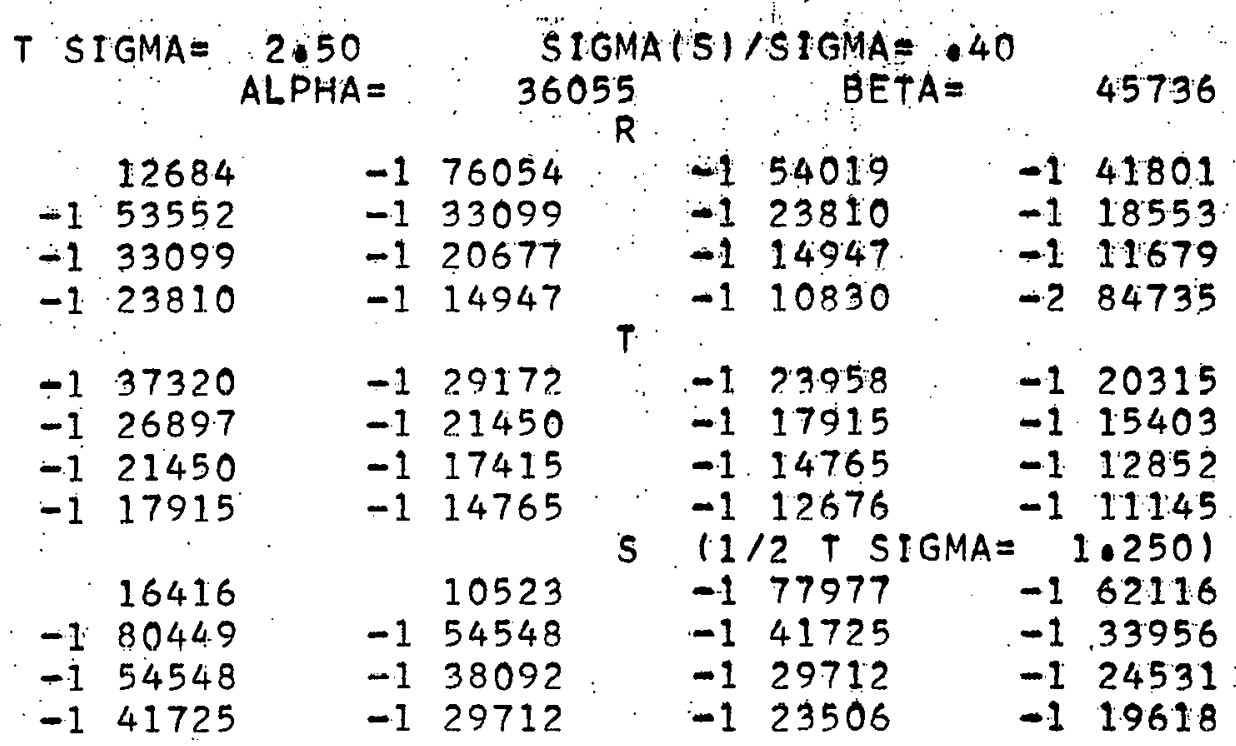




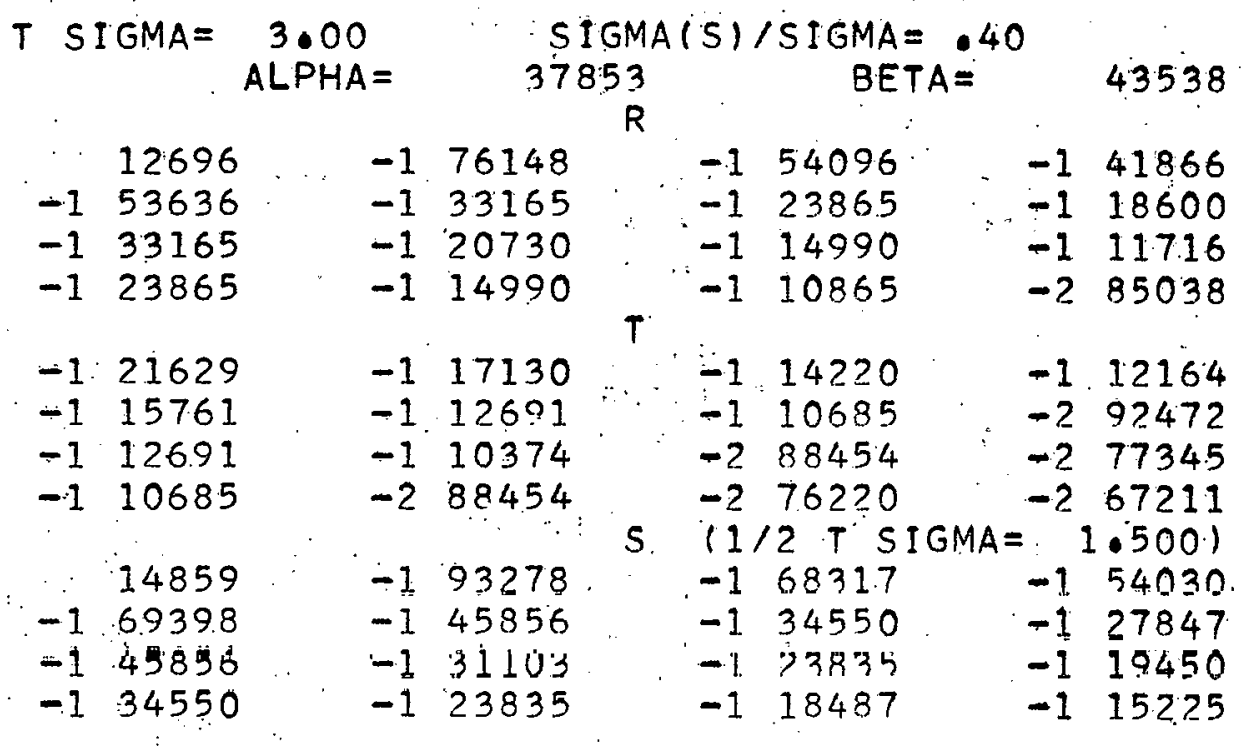

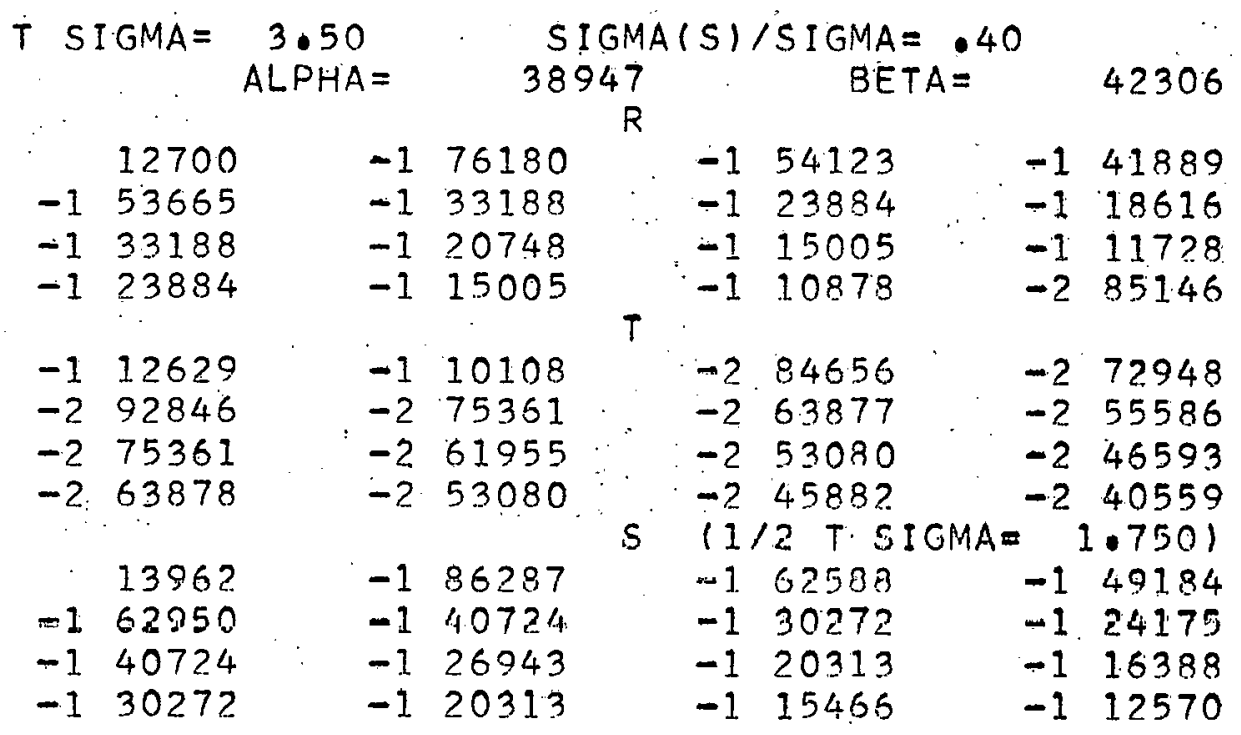

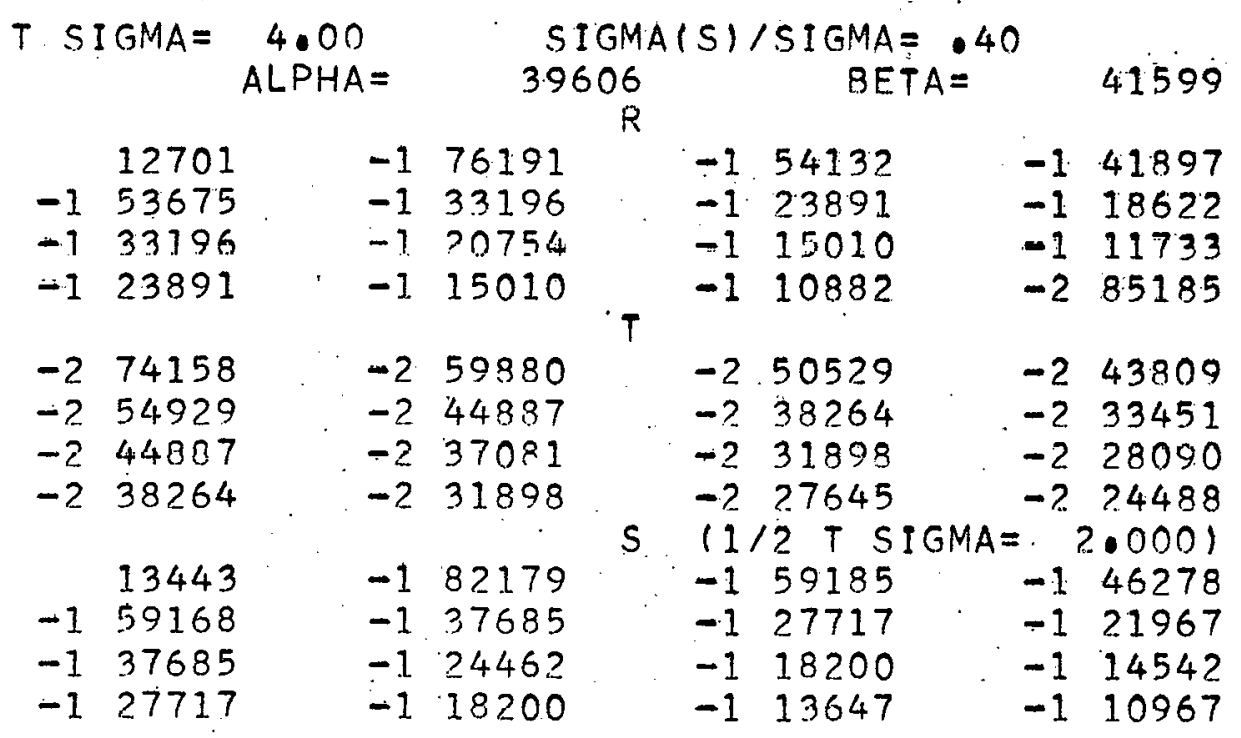




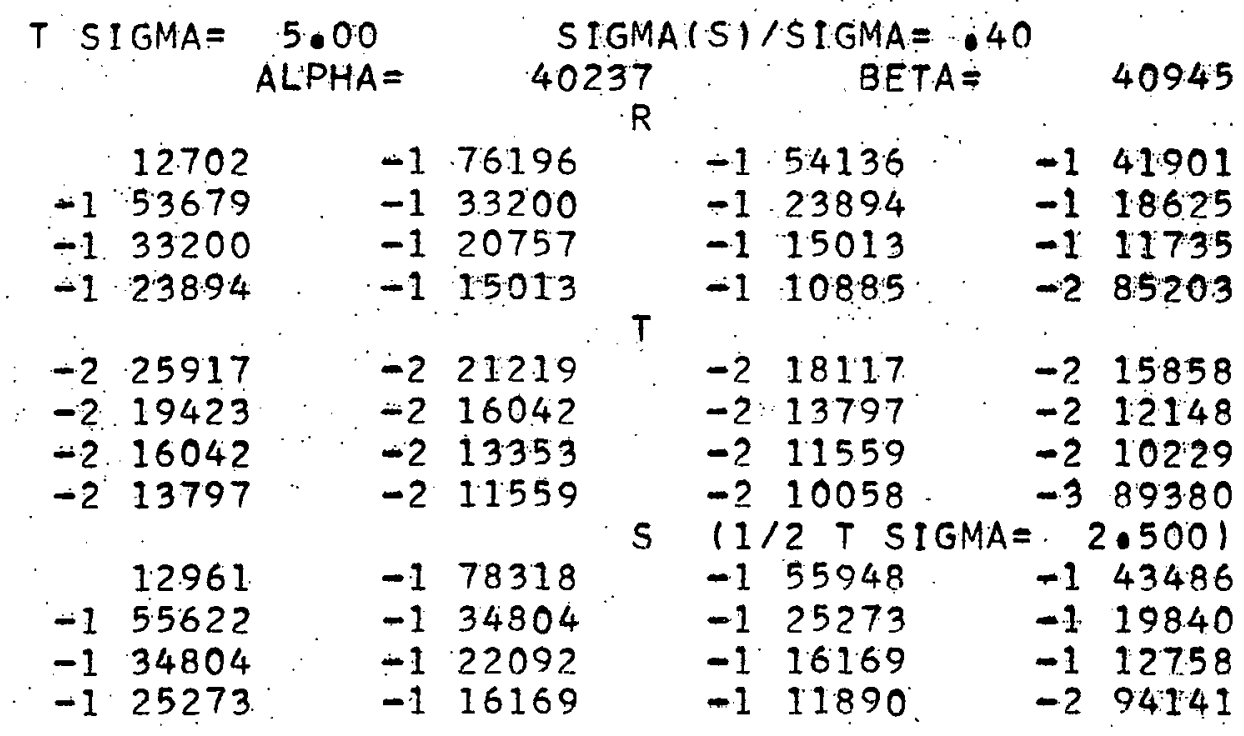

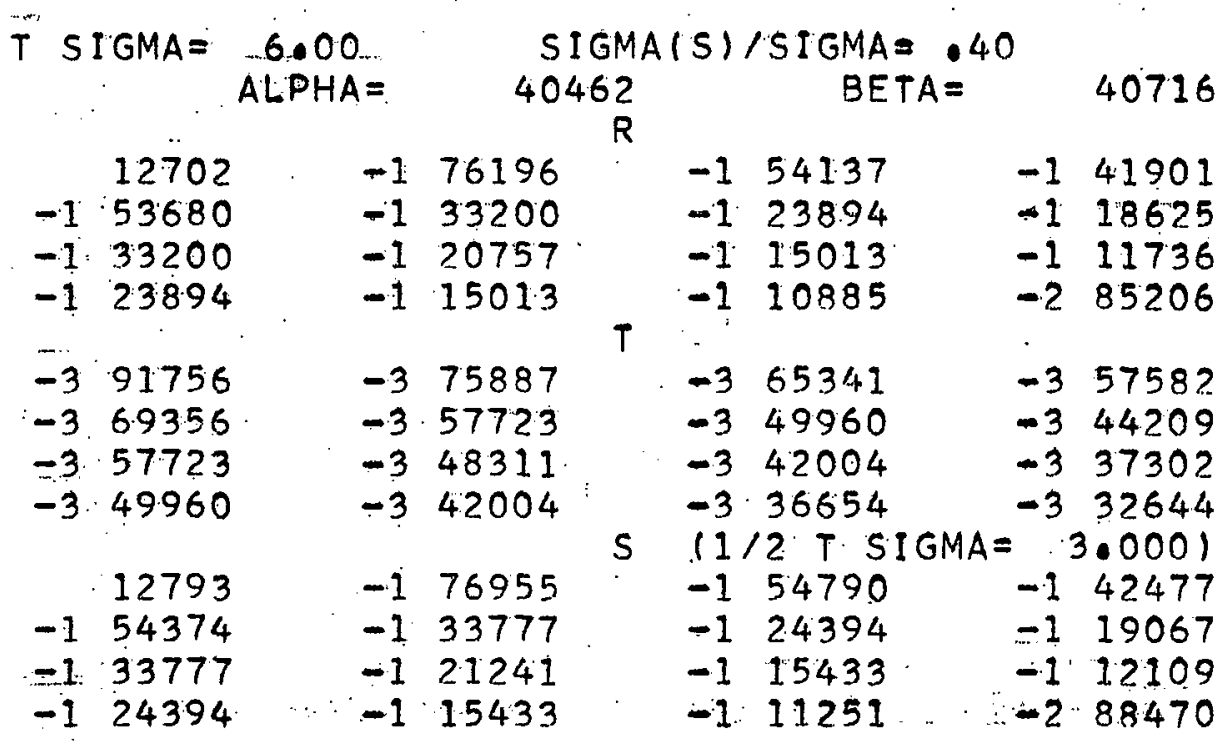

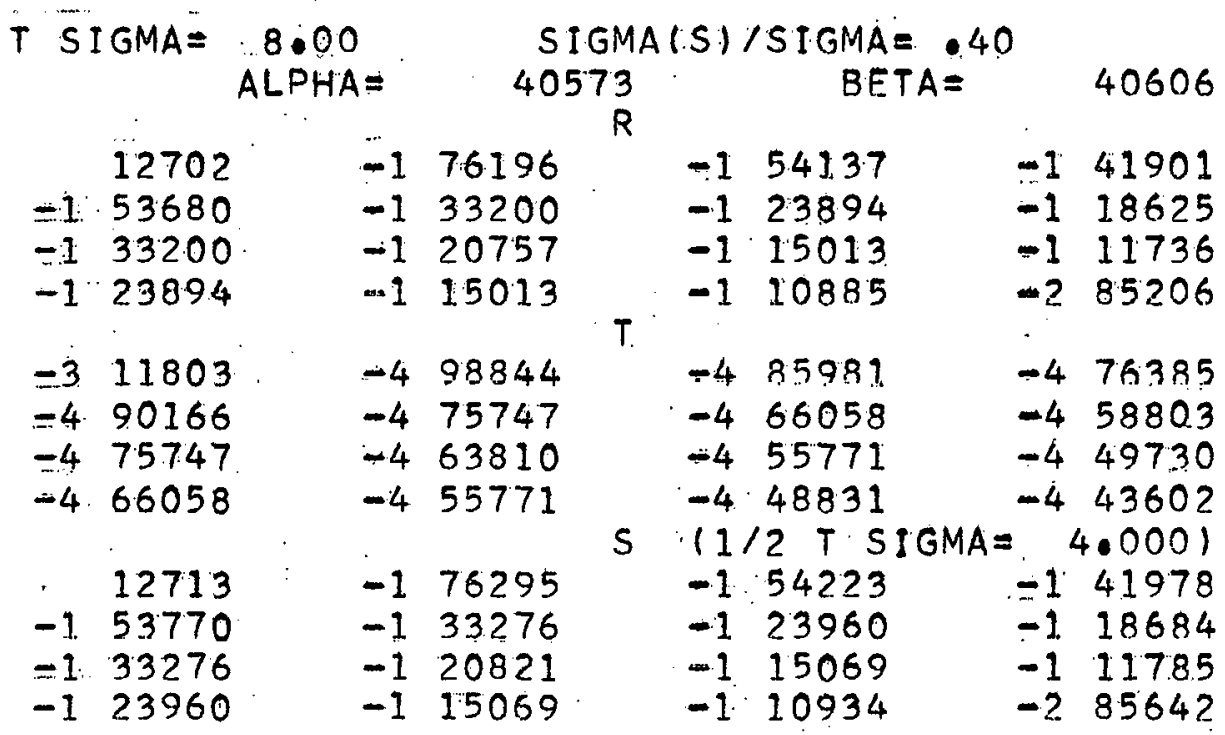




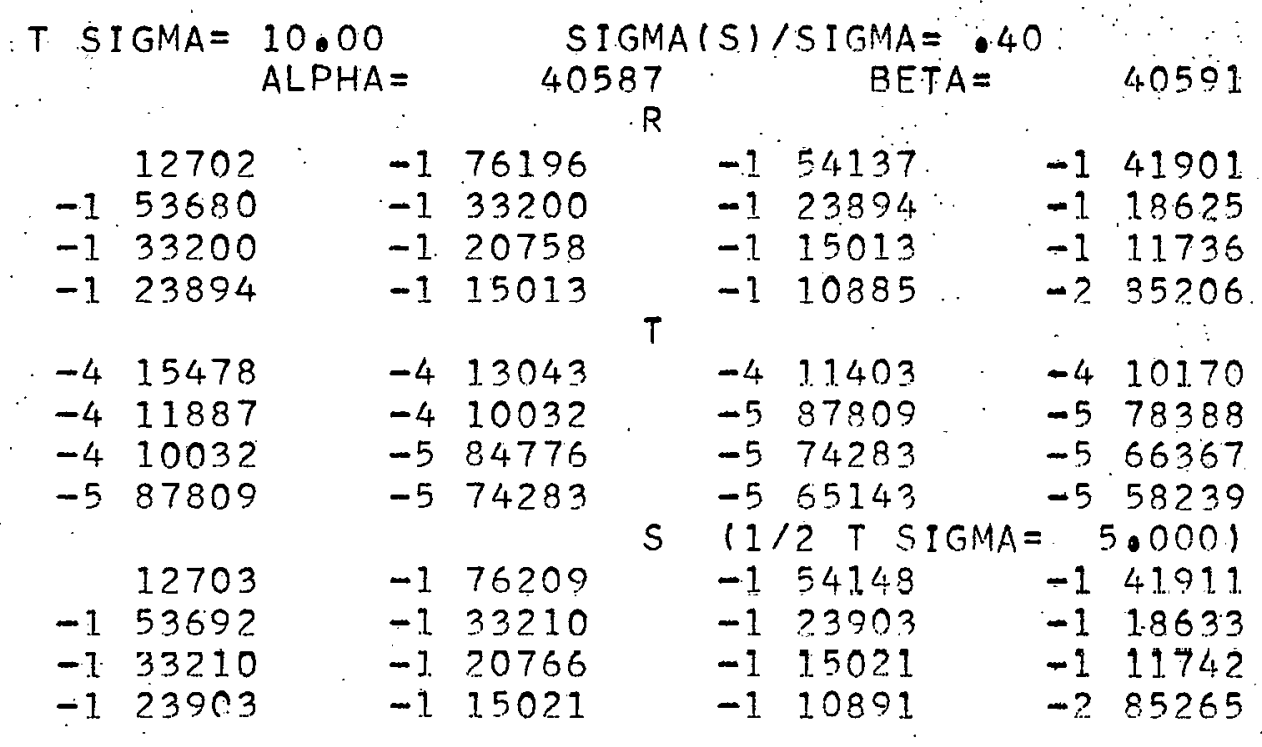

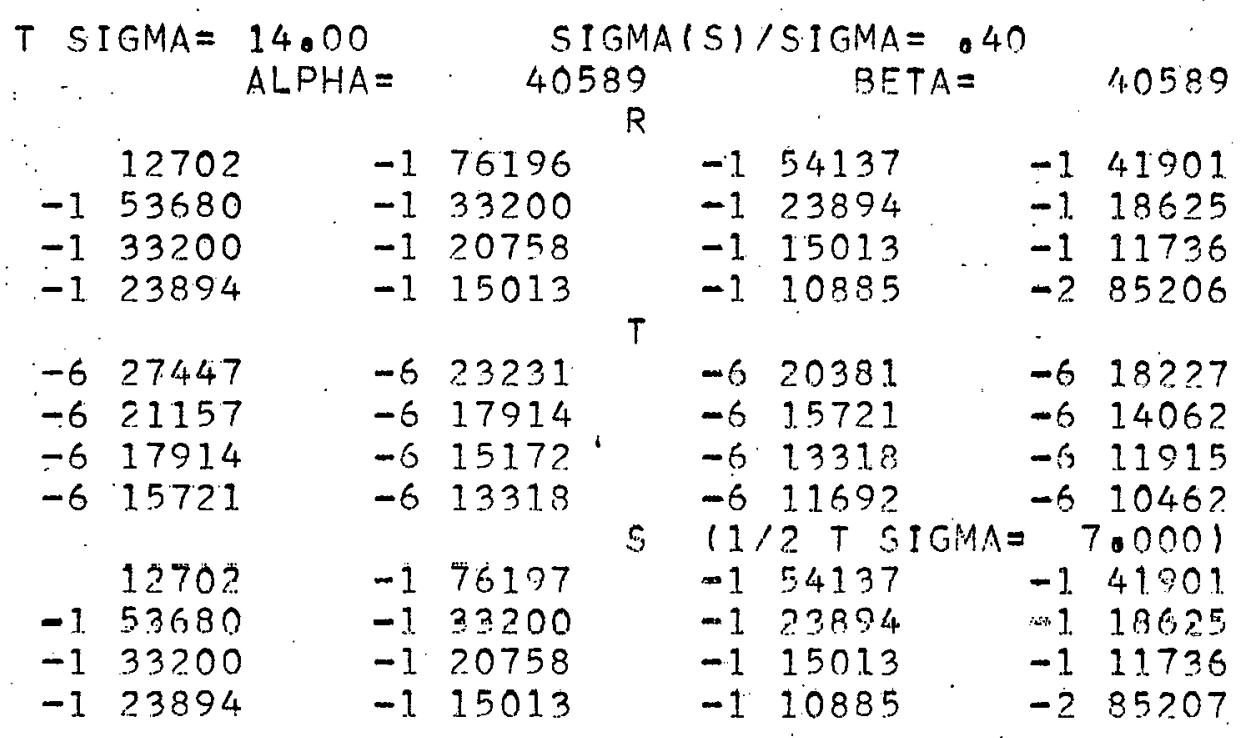

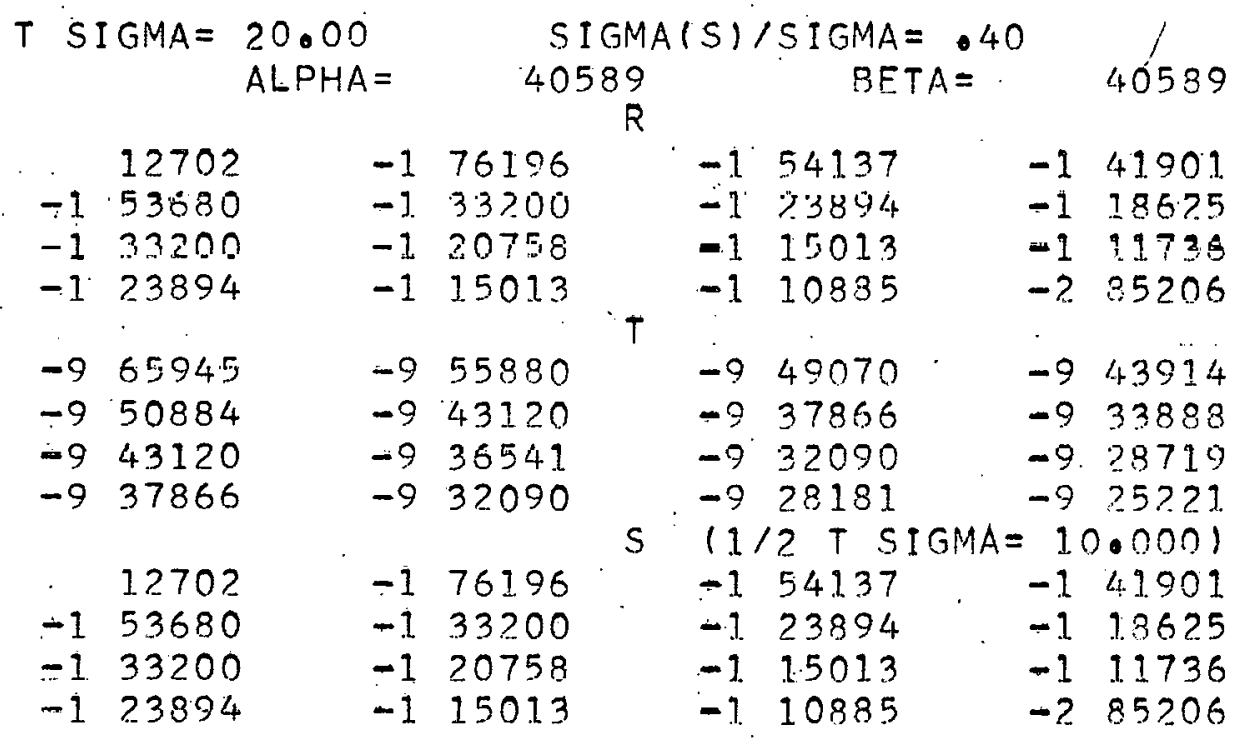




$$
\text { WAPD-TM-168 }
$$

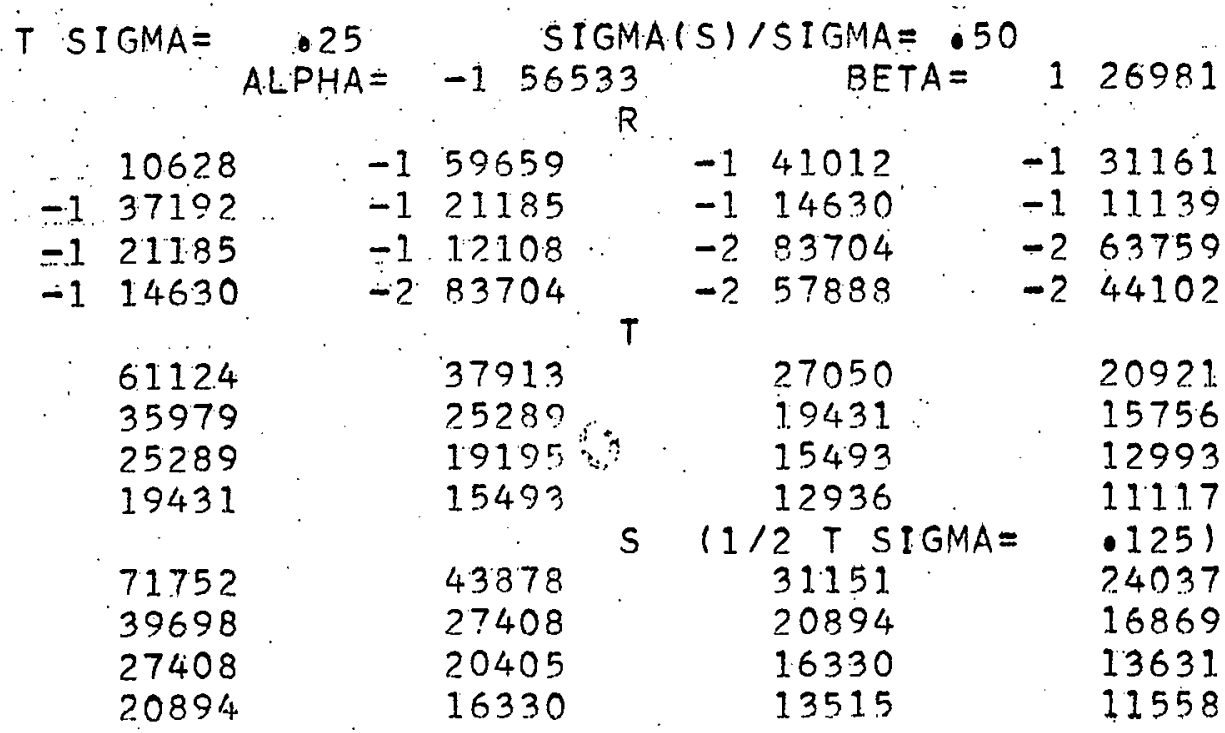

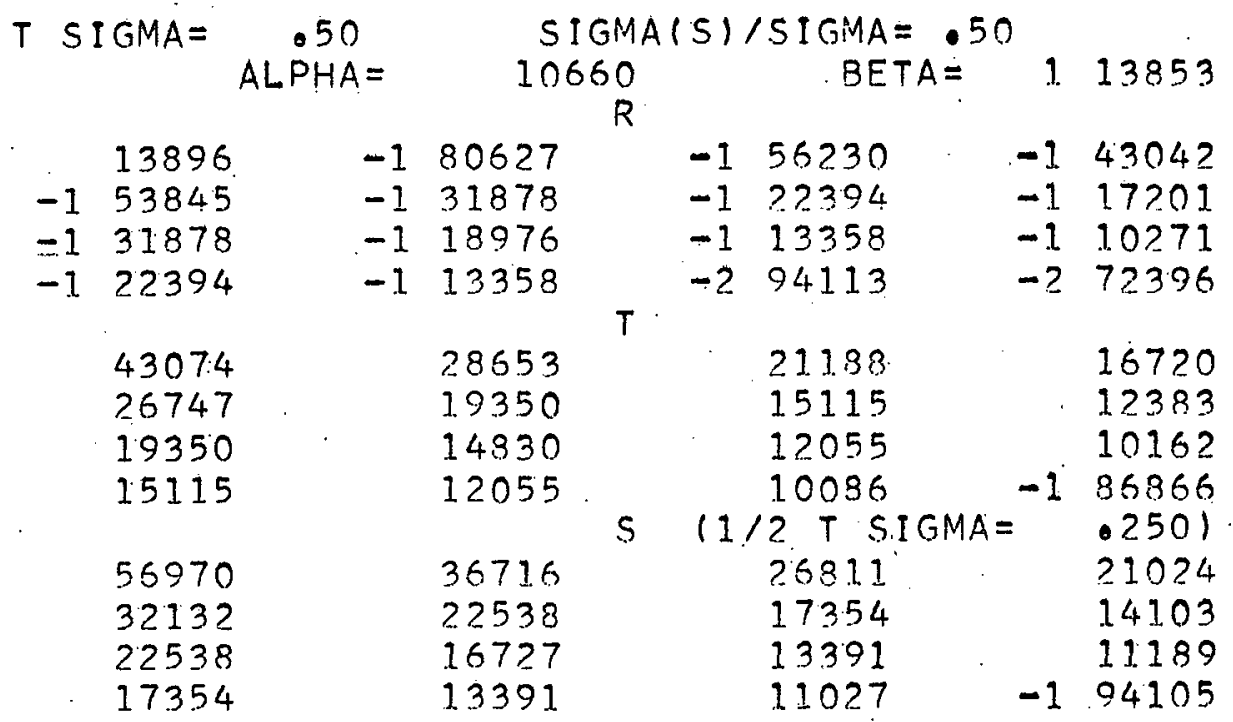

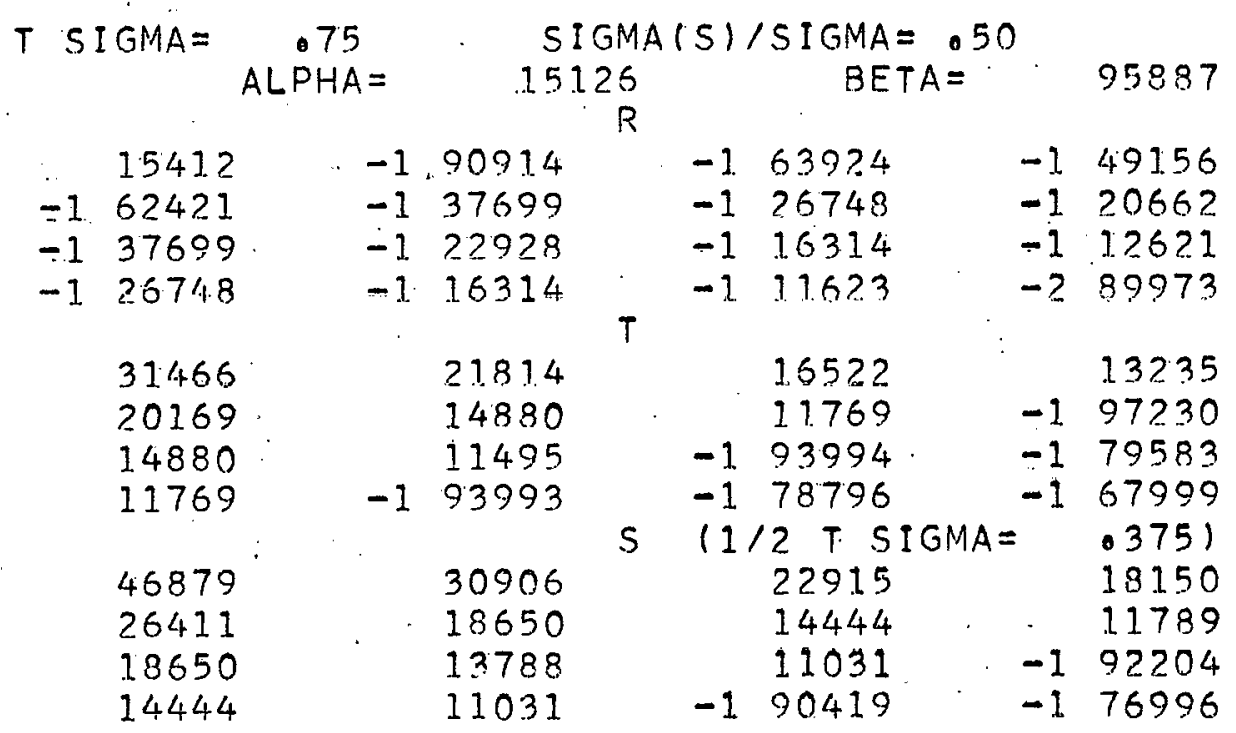




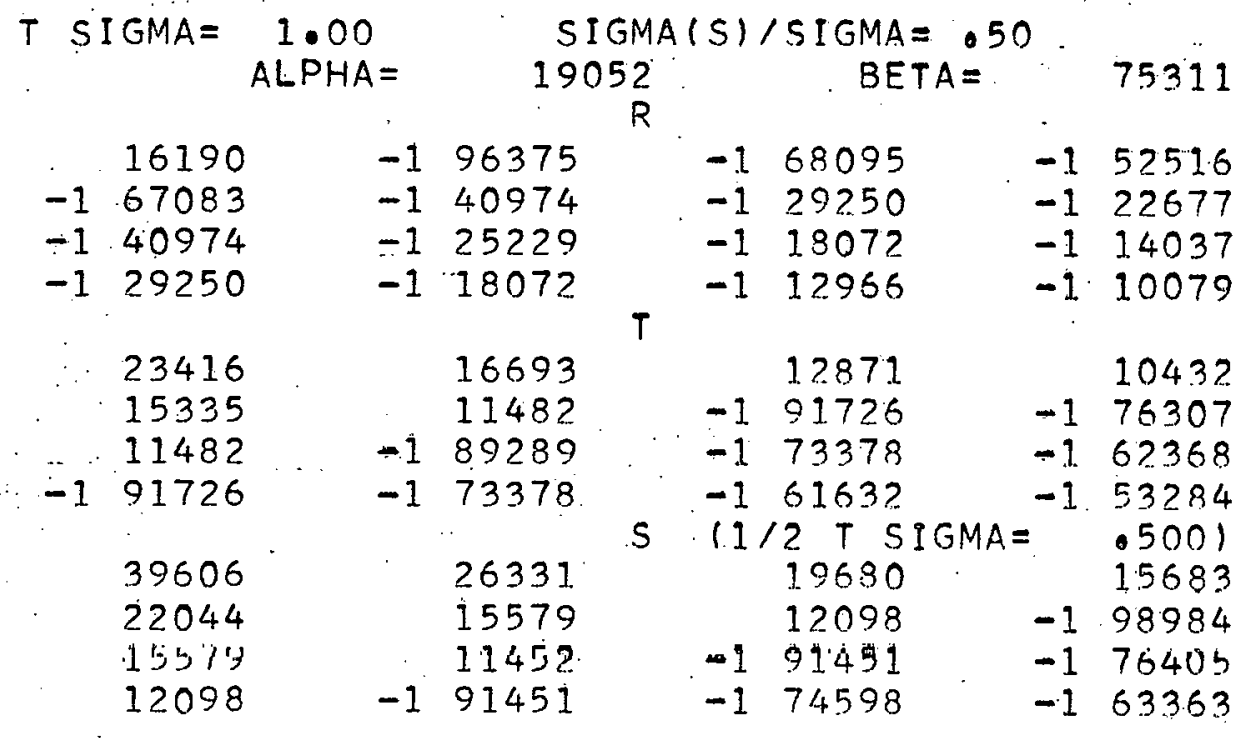

\begin{tabular}{|c|c|c|c|c|c|c|}
\hline T SIGMA = & $1 \cdot 25$ & & jMA (S) & $\angle I G M A=.50$ & & \\
\hline & $A L P H A=$ & 22 & & $B E T A=$ & & 63516 \\
\hline 16609 & -1 & 99393 & -1 & 70441 & -1 & 54426 \\
\hline-169696 & -1 & 42853 & -1 & 30708 & -1 & 23864 \\
\hline$-1: 42853$ & -1 & 26582 & -1 & $1912 ?$ & -1 & 14892 \\
\hline-130708 & -1 & $1912 ?$ & -1 & 1.3781 & -1 & 107.43 \\
\hline $\begin{array}{r}1761.3 \\
\because 11726\end{array}$ & -1 & $\begin{array}{l}12825 \\
88823\end{array}$ & -1 & $\begin{array}{l}10028 \\
71.538\end{array}$ & $\begin{array}{l}-1 \\
-1\end{array}$ & $\begin{array}{l}82054 \\
59866\end{array}$ \\
\hline$-1 \quad 88823$ & -1 & 69459 & -1 & 57331 & -1 & 488.95 \\
\hline-171538 & -1 & 57331. & -1 & $\begin{array}{l}48243 \\
? \quad T \text { SIGMA }=\end{array}$ & $=-1$ & $\begin{array}{l}41779 \\
.6251\end{array}$ \\
\hline 34223 & & 22765 & & $1.707 ?$ & & 13648 \\
\hline 18695 & & 13168 & & 10225 & -1 & 83730 \\
\hline 13168 & -1 & 96040 & -1 & 76453 & -1 & 63787. \\
\hline 10225 & -1 & 76453 & -1 & 62024 & -1 & 5252.2 \\
\hline
\end{tabular}

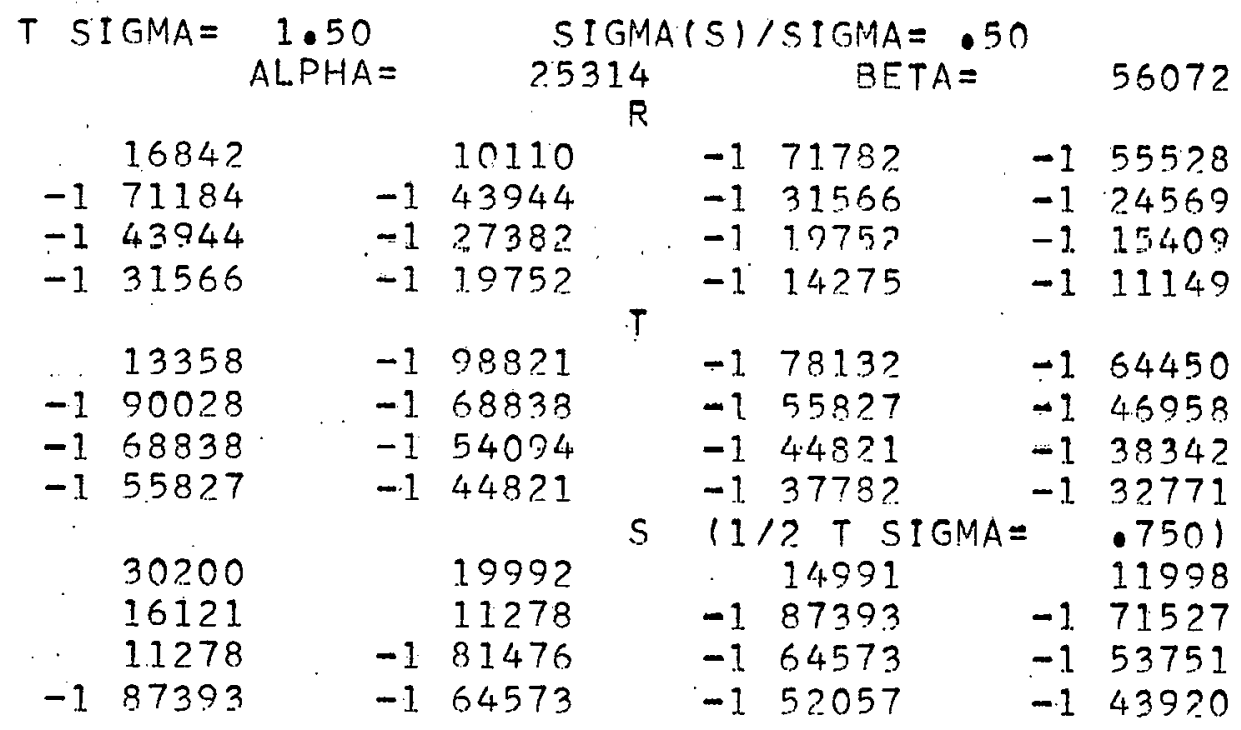




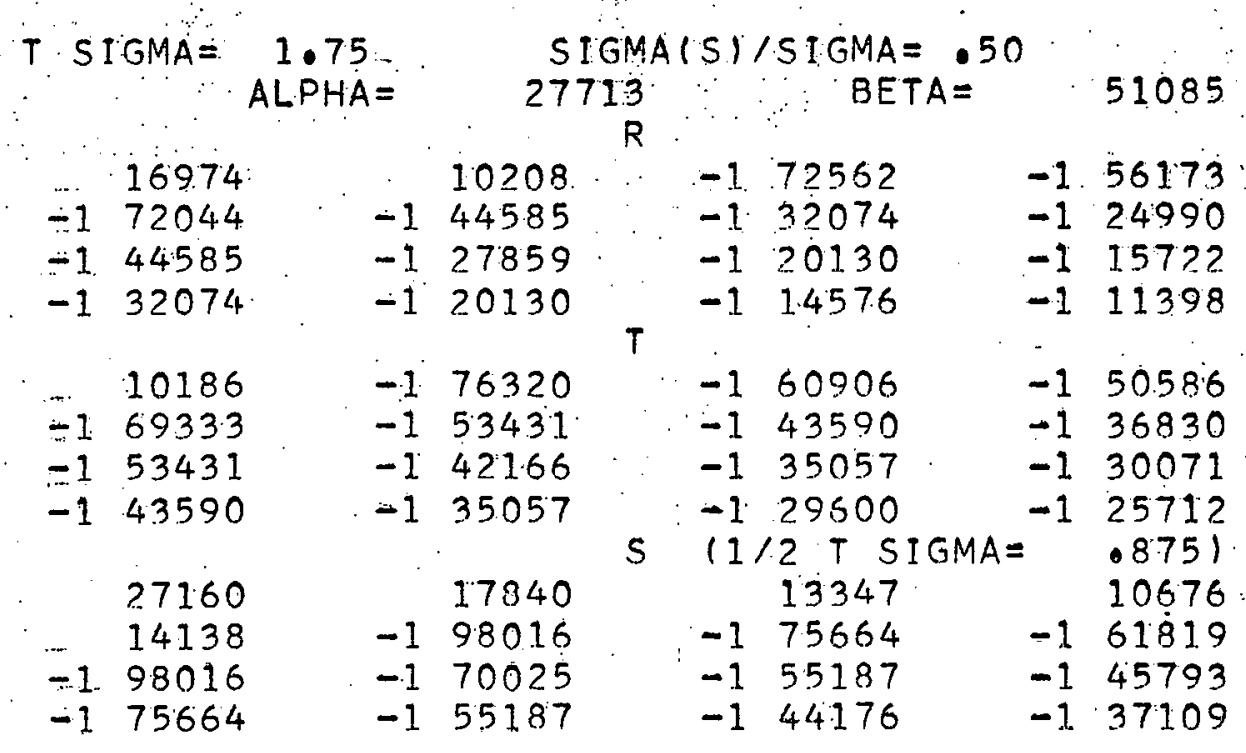

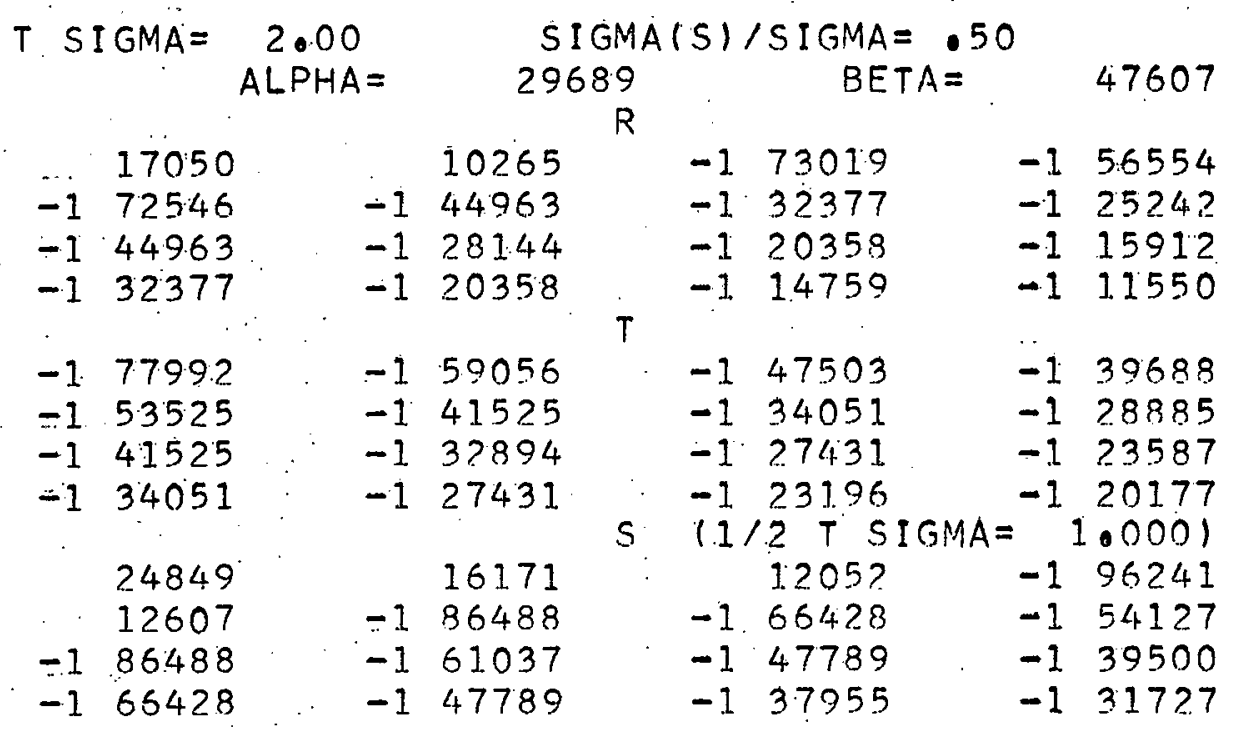

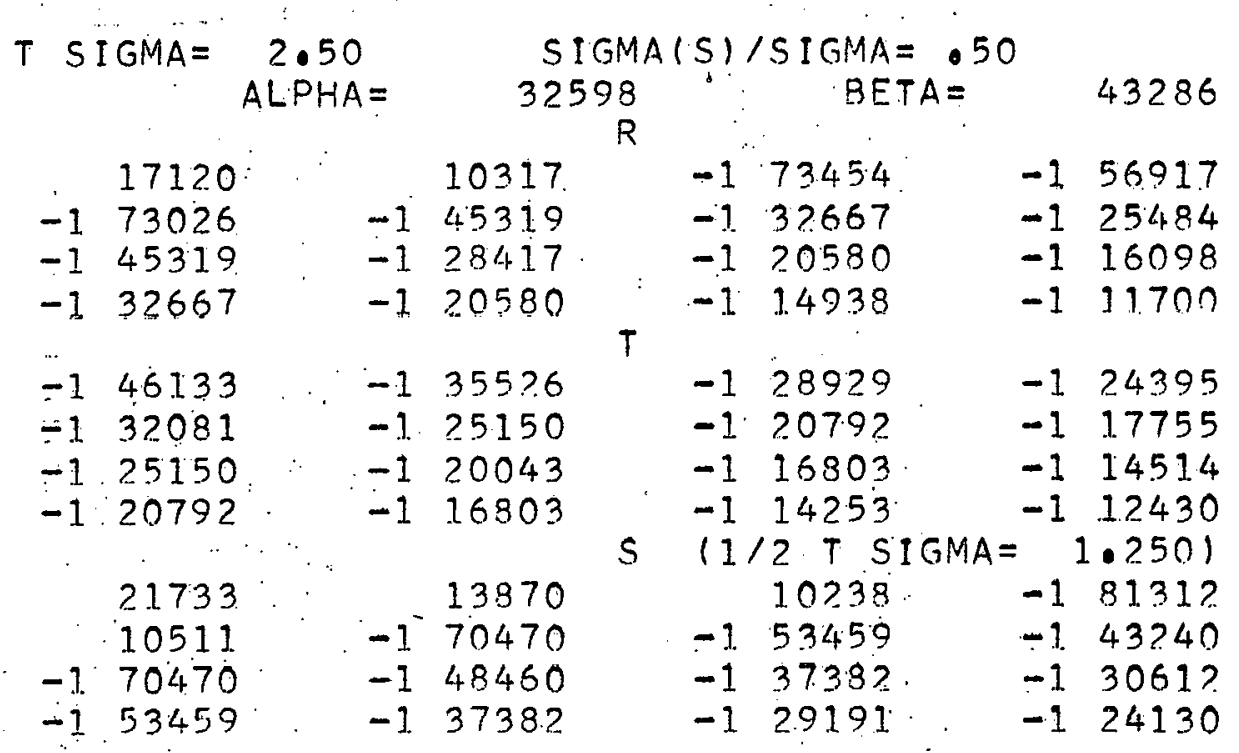


WAPD-TM-168

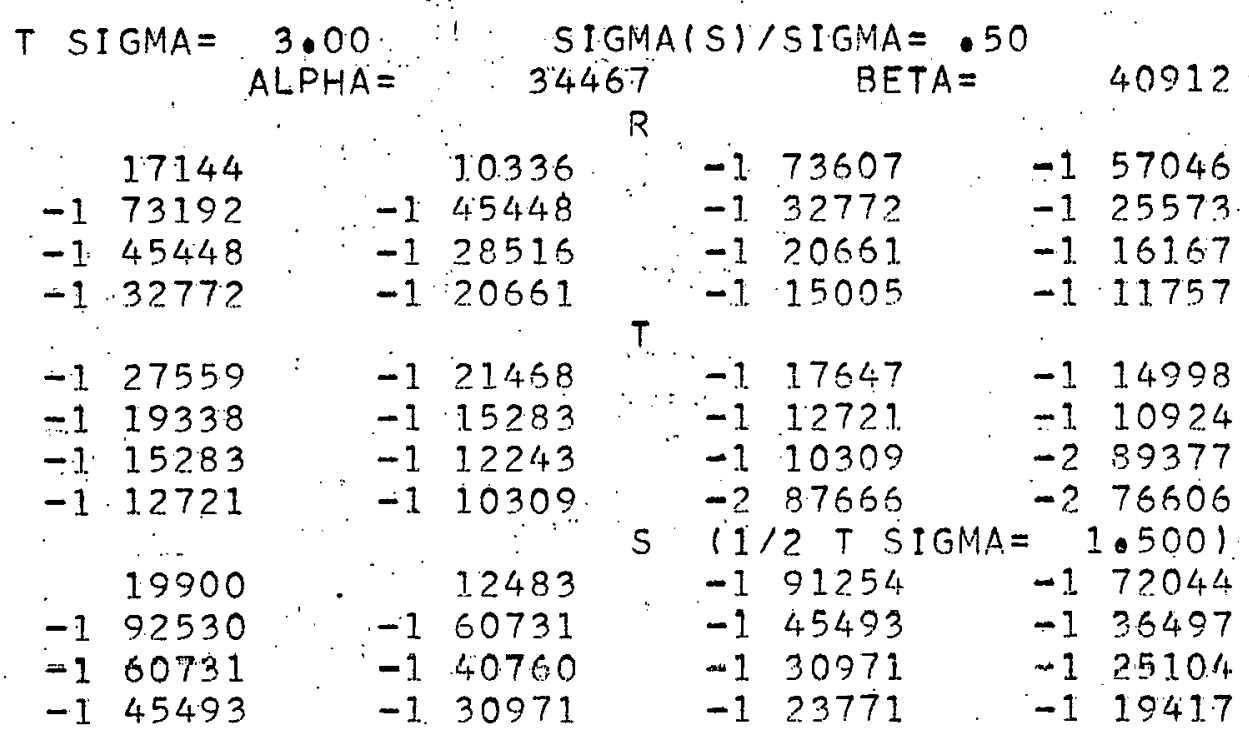

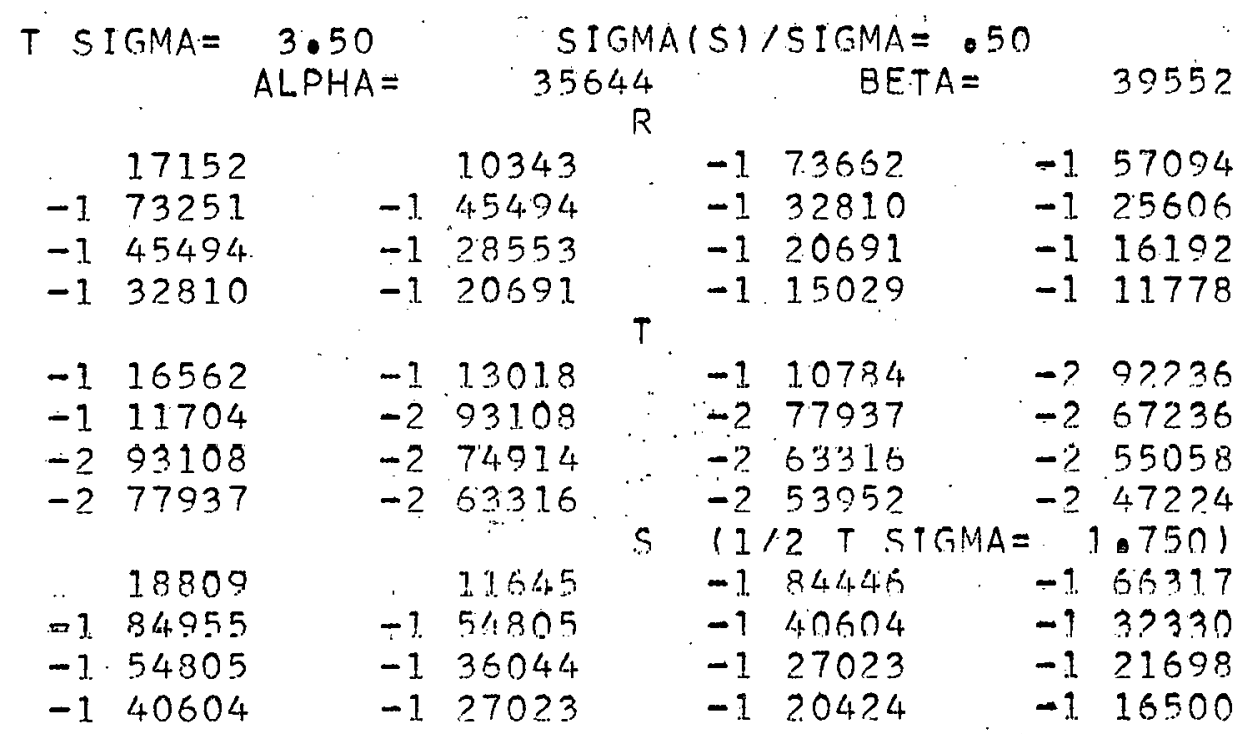

$T$ SIGMA $=4.00 \quad$ SIGMA(S)/SIGMA $=.50$

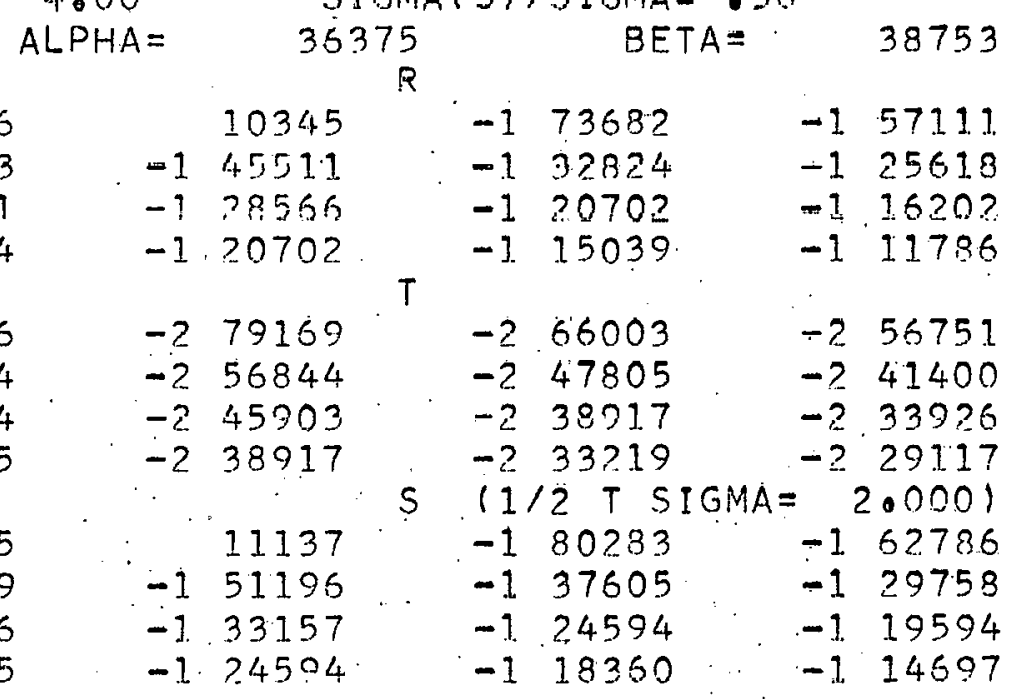




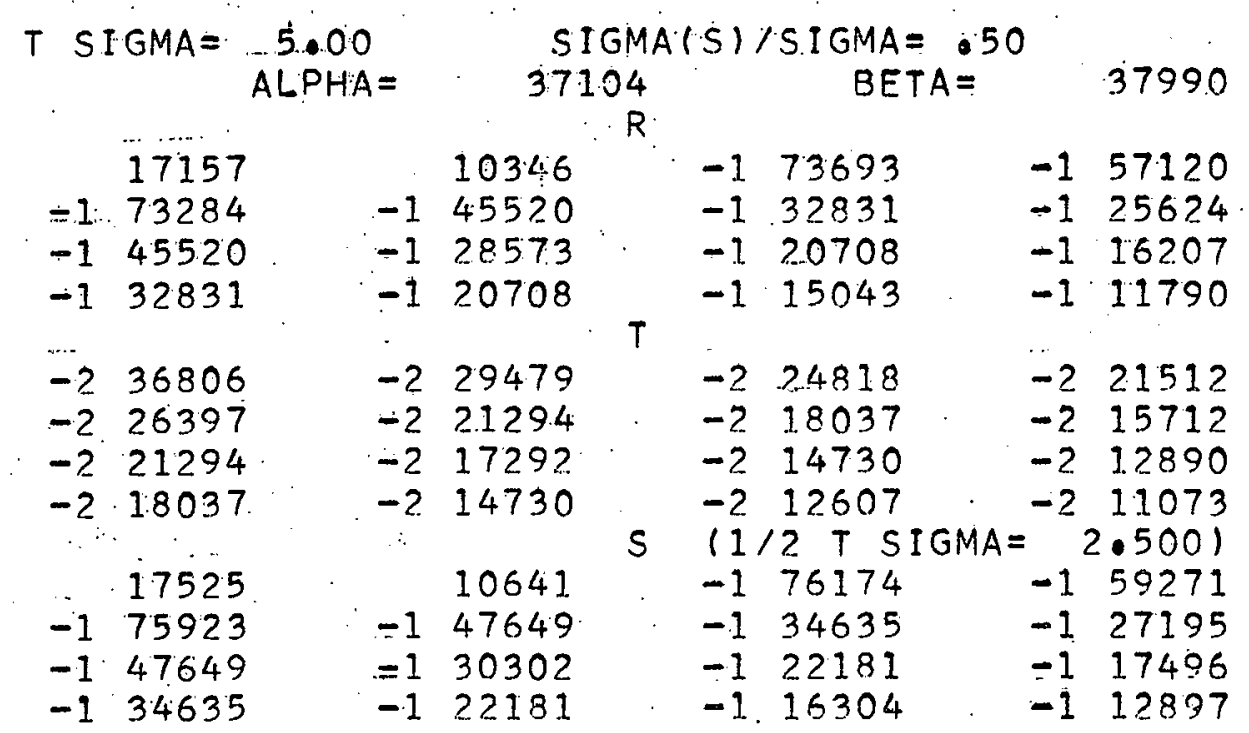

\begin{tabular}{|c|c|c|c|c|c|c|c|c|}
\hline \multirow[t]{2}{*}{ T } & GMA $=$ & \multirow{2}{*}{$\begin{array}{l}6.000 \\
\text { AL.PHA }=\end{array}$} & \multirow{2}{*}{\multicolumn{5}{|c|}{$\begin{array}{cc}\text { SIGMA (S)/SIGMA }=: 50 \\
37378\end{array}$}} & \multirow[b]{2}{*}{37711} \\
\hline & & & & & & & & \\
\hline & 17157 & 7 & 10.347 & & -1 & 73694 & -1 & 57121 \\
\hline-1 & 73285 & -1 & 45521 & & -1 & 32832 & -1 & 25625 \\
\hline-1 & 45521 & -1 & 28574 & & -1 & 20709 & -1 & 16207 \\
\hline-1 & 32832 & -1 & 20709 & & -1 & 15044 & -1 & 790 \\
\hline-2 & 13680 & -2 & 11045 & & -3 & 93629 & -3 & 81611 \\
\hline-3 & 98741 & -3 & 80127 & & -3 & 68212 & -3 & \\
\hline-3 & 80127 & -3 & 65325 & & -3 & 55829 & -3 & \\
\hline-3 & 68212 & -3 & 55829 & $\mathrm{~S}$ & & $\begin{array}{l}47858 \\
2 T \text { SIGMA }=\end{array}$ & $=-3$ & $\begin{array}{r}42.107 \\
3.0001\end{array}$ \\
\hline & 17294 & & 10457 & & -1 & 74630 & -1 & 57937 \\
\hline-1 & 74273 & -1 & $4632 ?$ & & -1 & 33514 & -1 & 26222 \\
\hline-1 & 46322 & & 29227 & & - & 21267 & -1 & 16697 \\
\hline-1 & 33514 & -1 & 21267 & & -1 & 15523 & -1 & 12211 \\
\hline
\end{tabular}

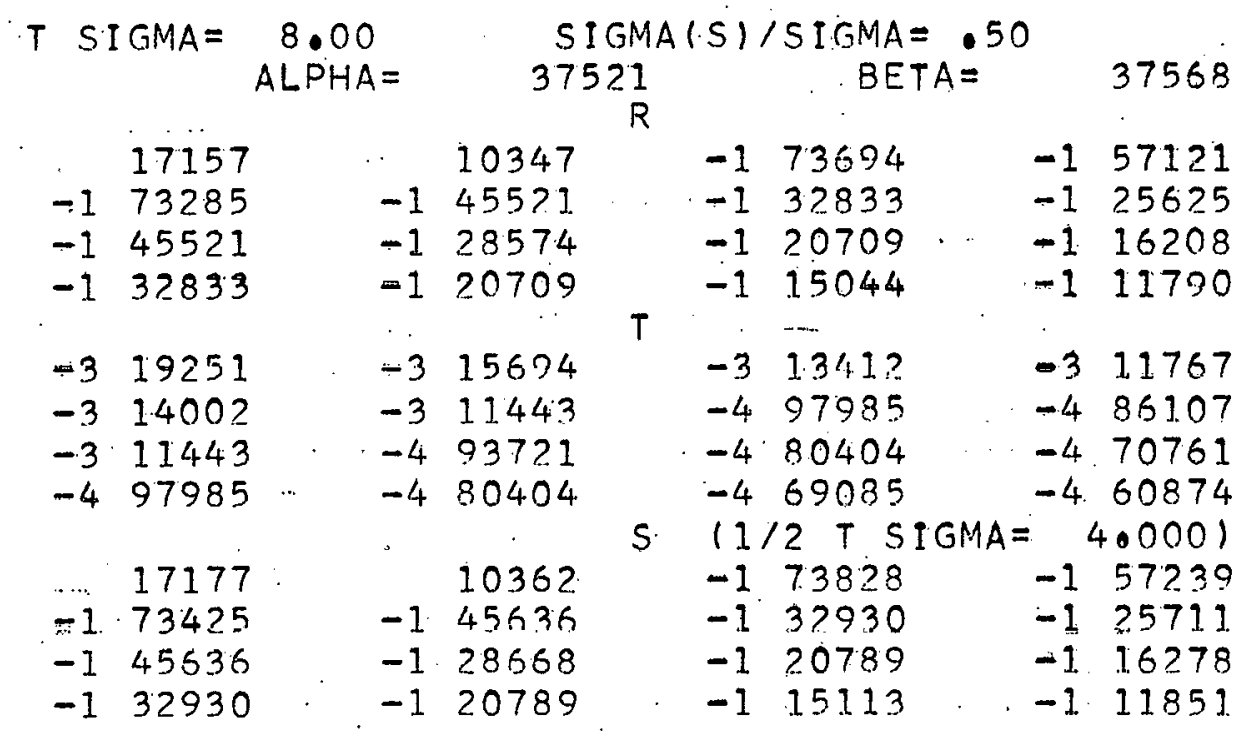


WAPD -TM-168

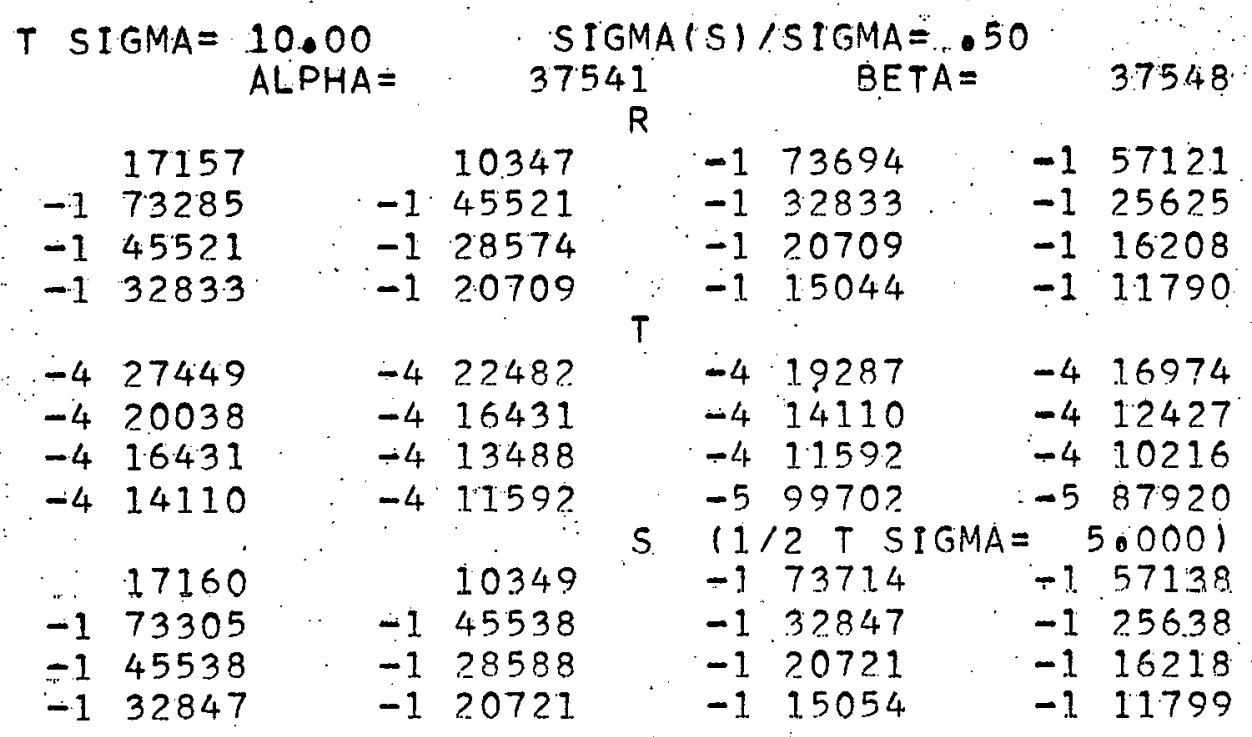

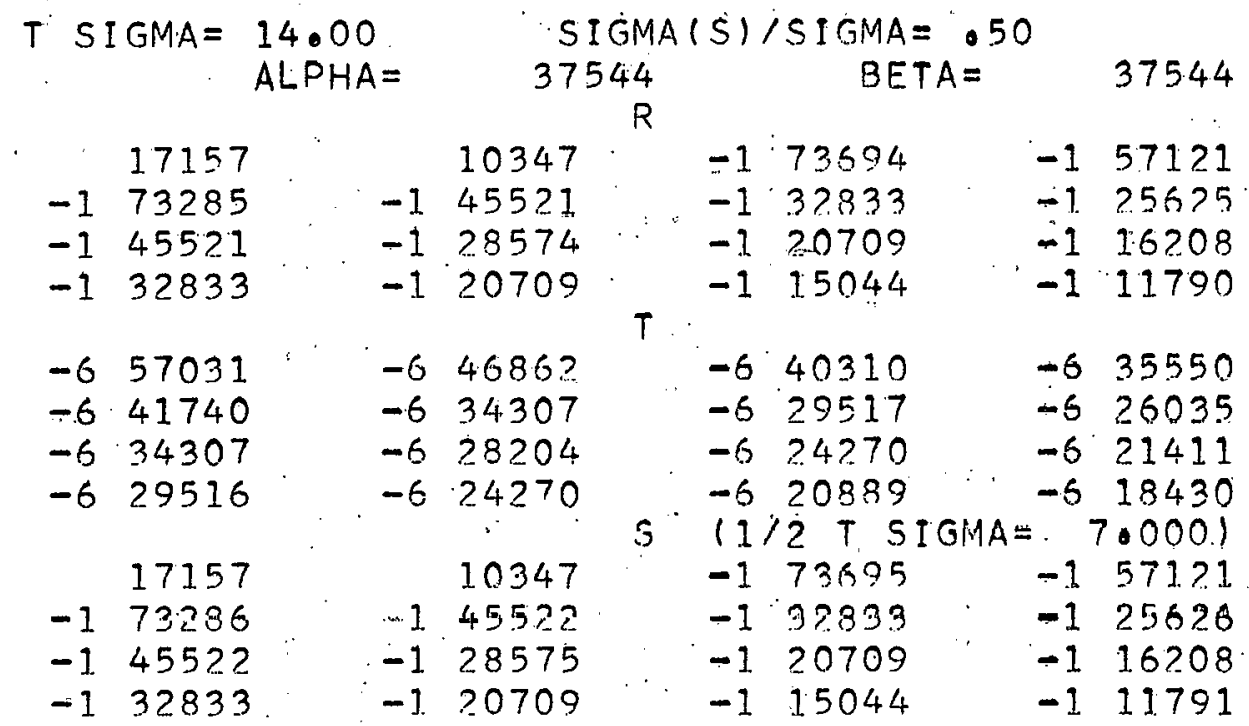

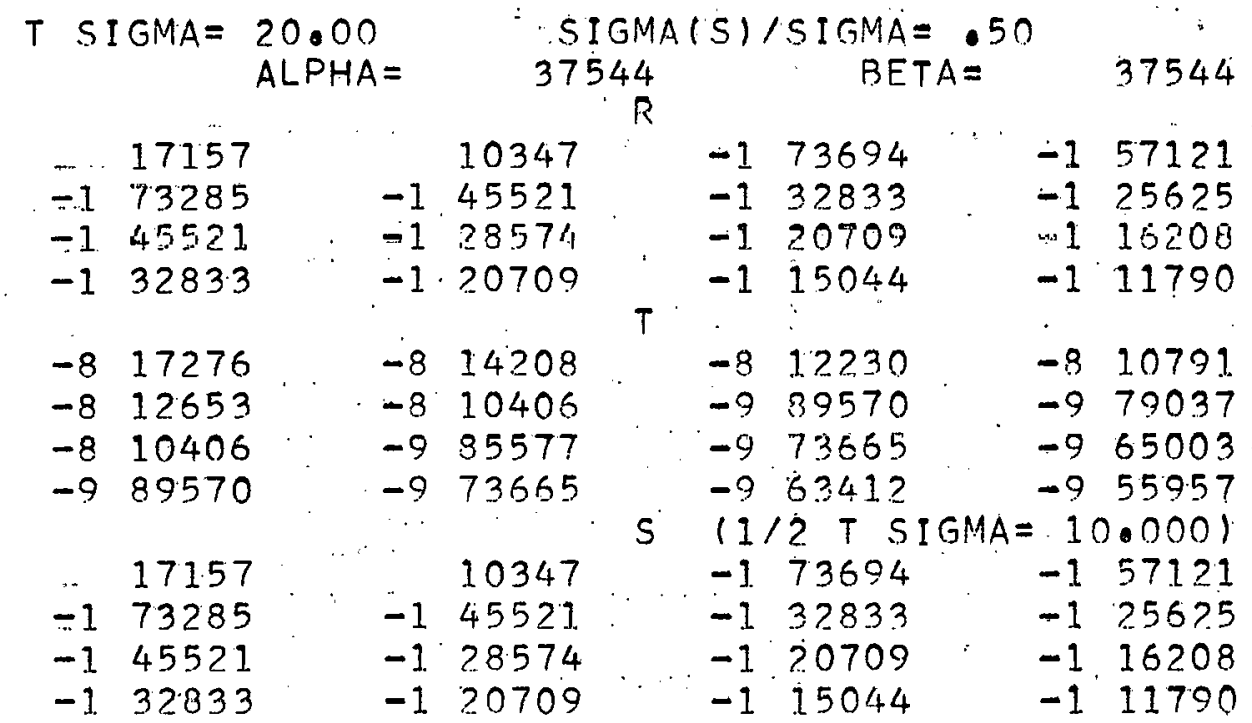


WAPD - TM- 168

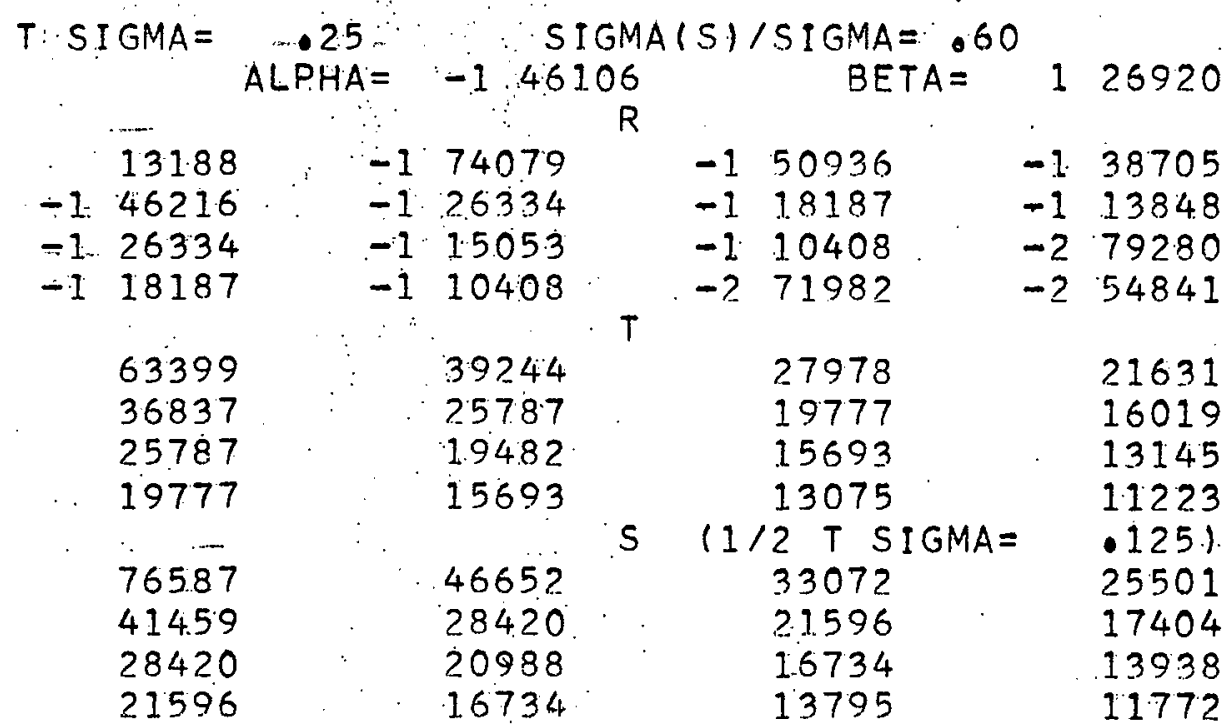

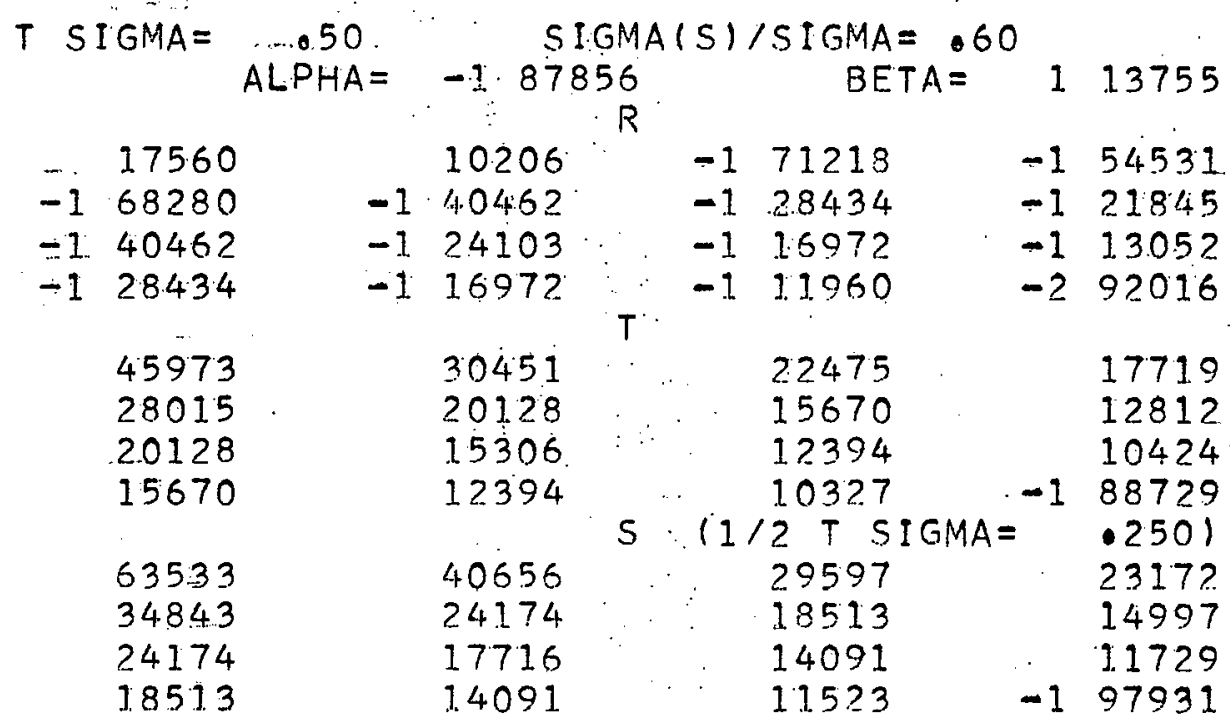

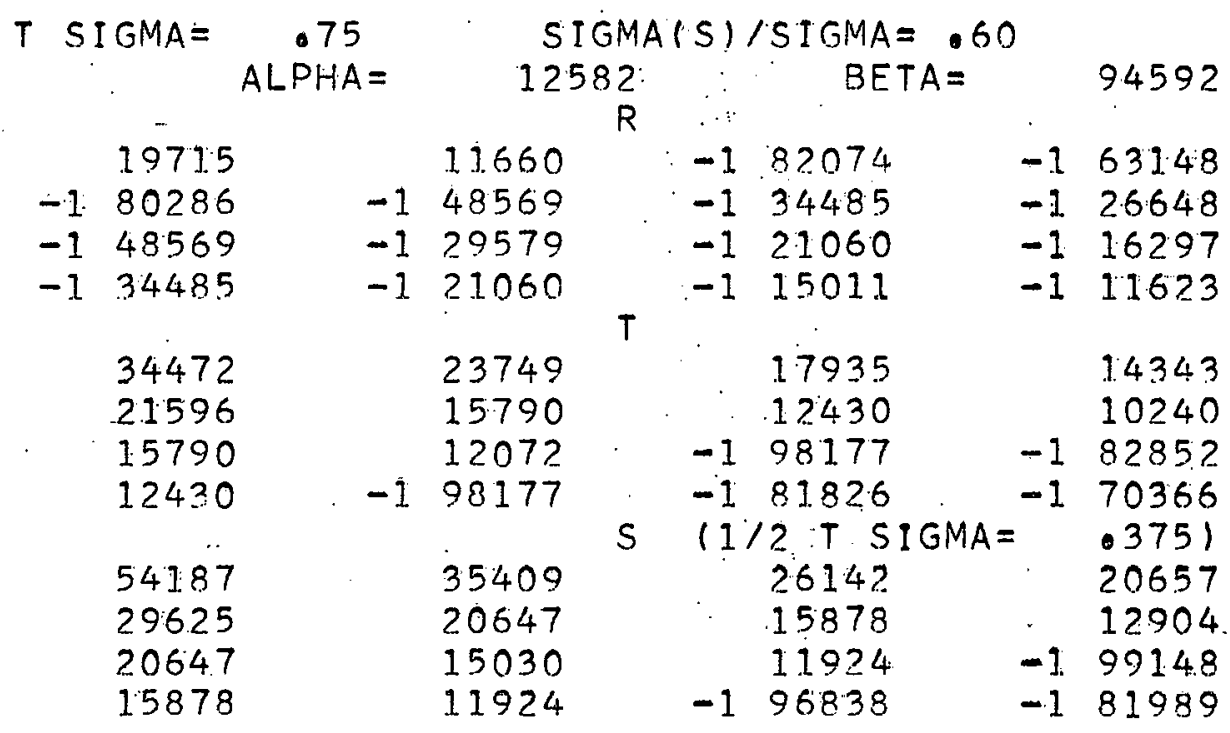


WAPD-TM- 168

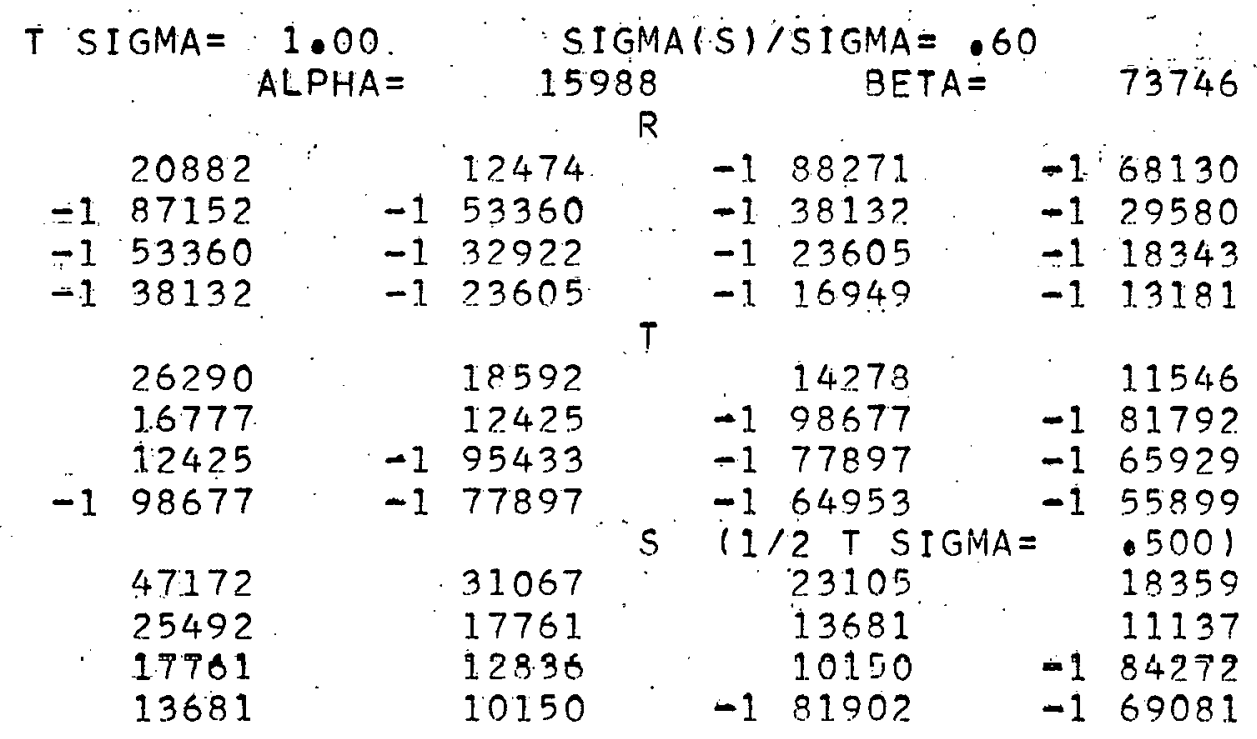

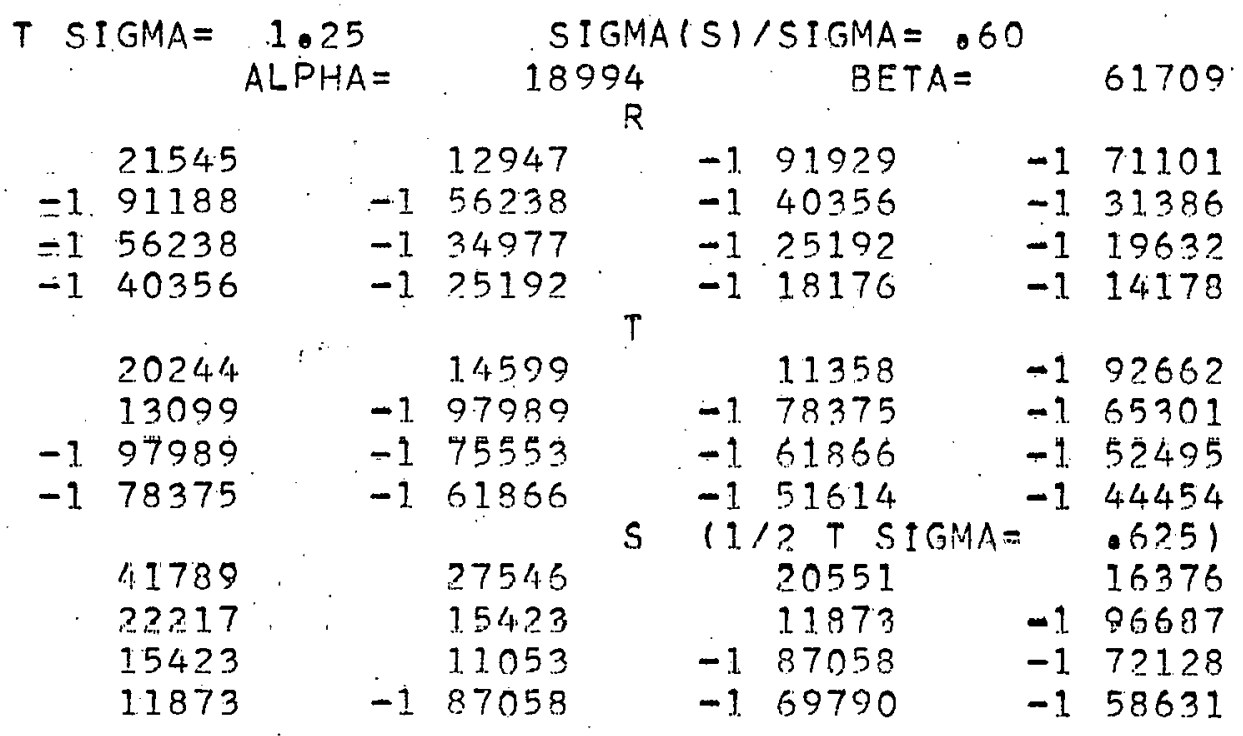

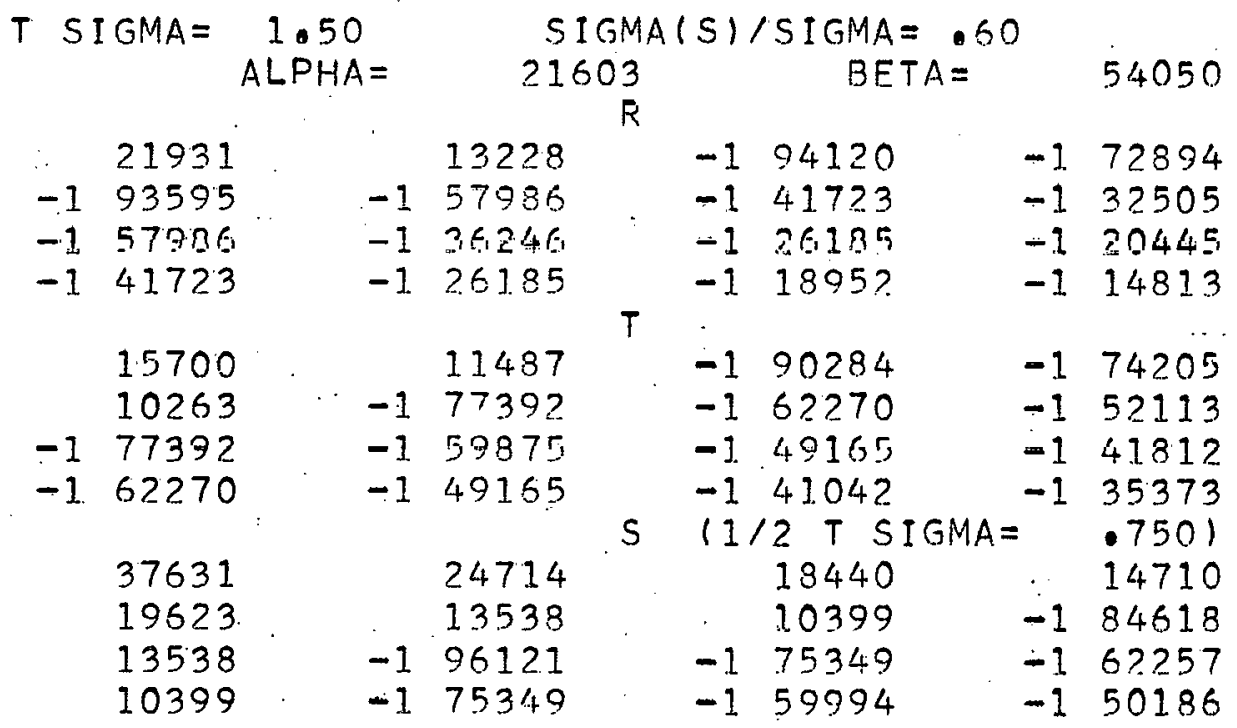

62 


\section{WAPD-TM-168}

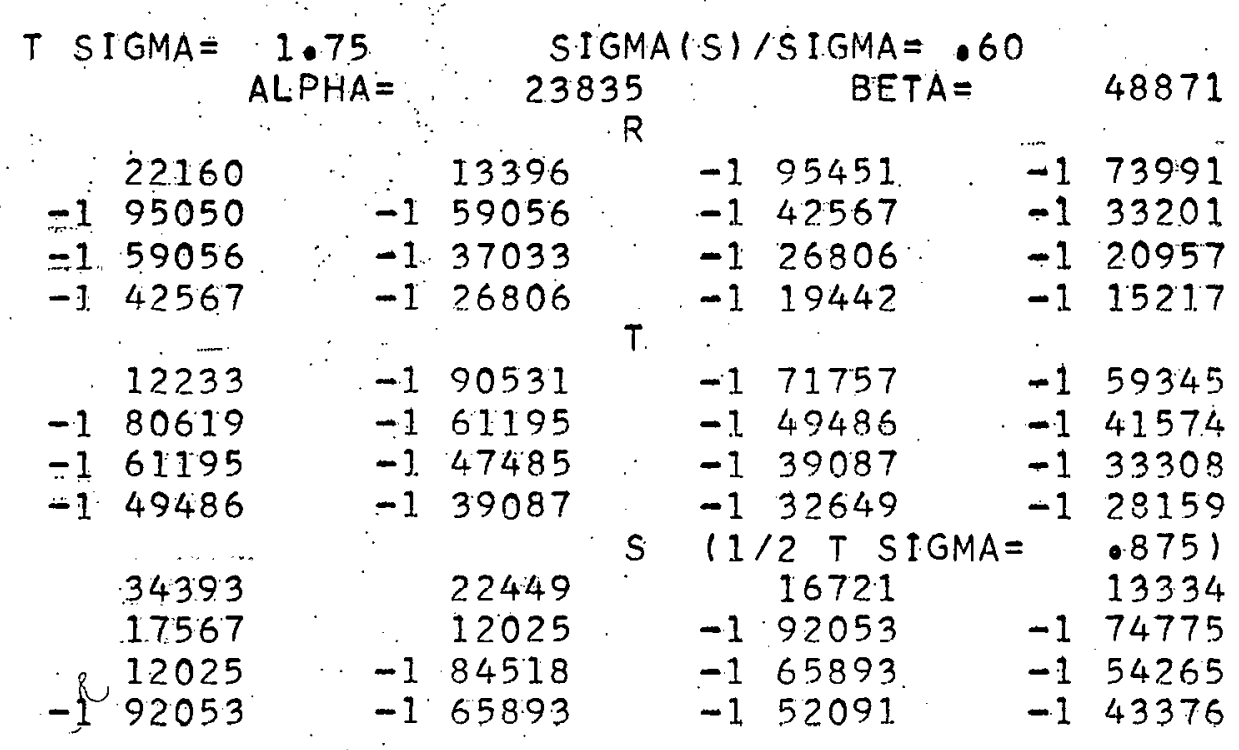

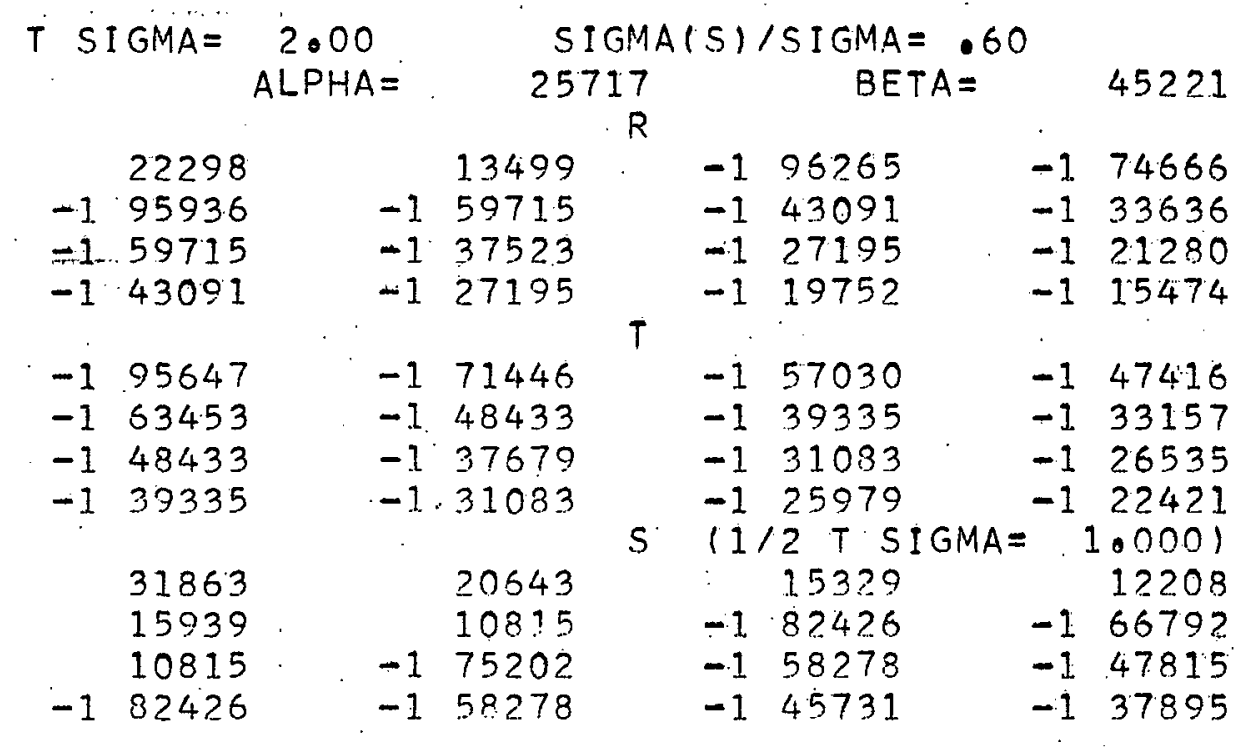

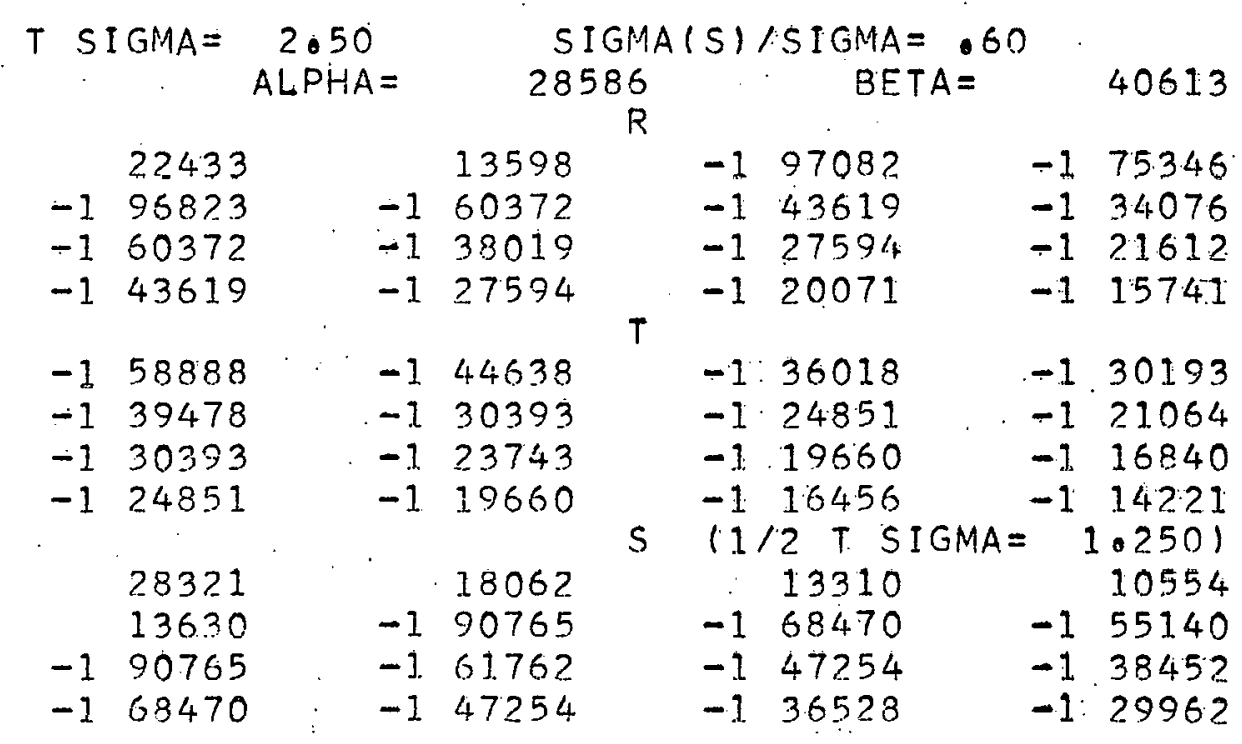


WAPD-TM- 168

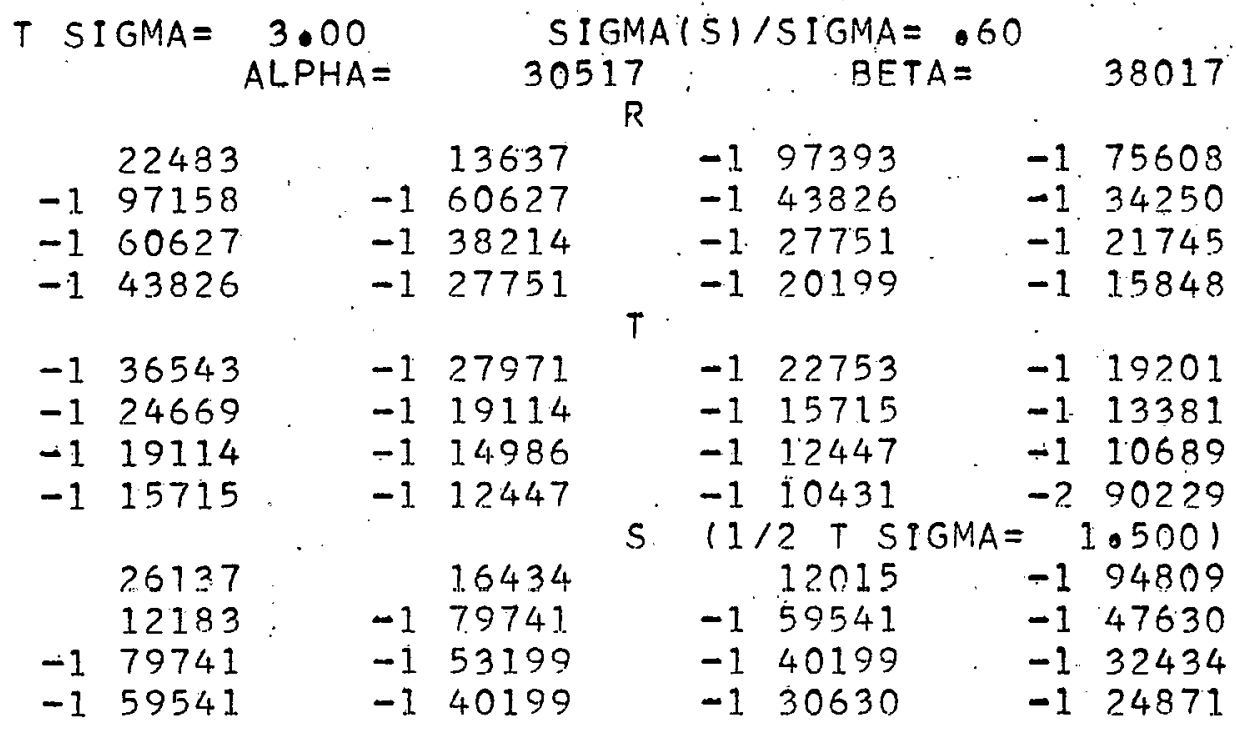

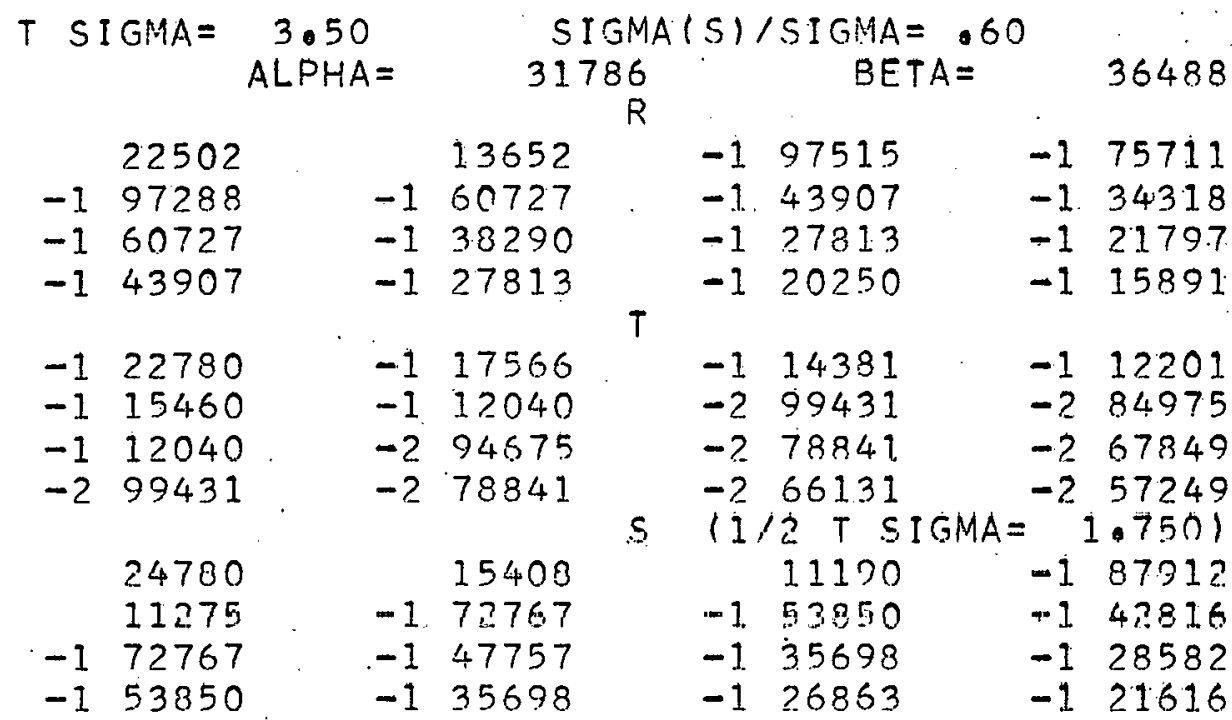

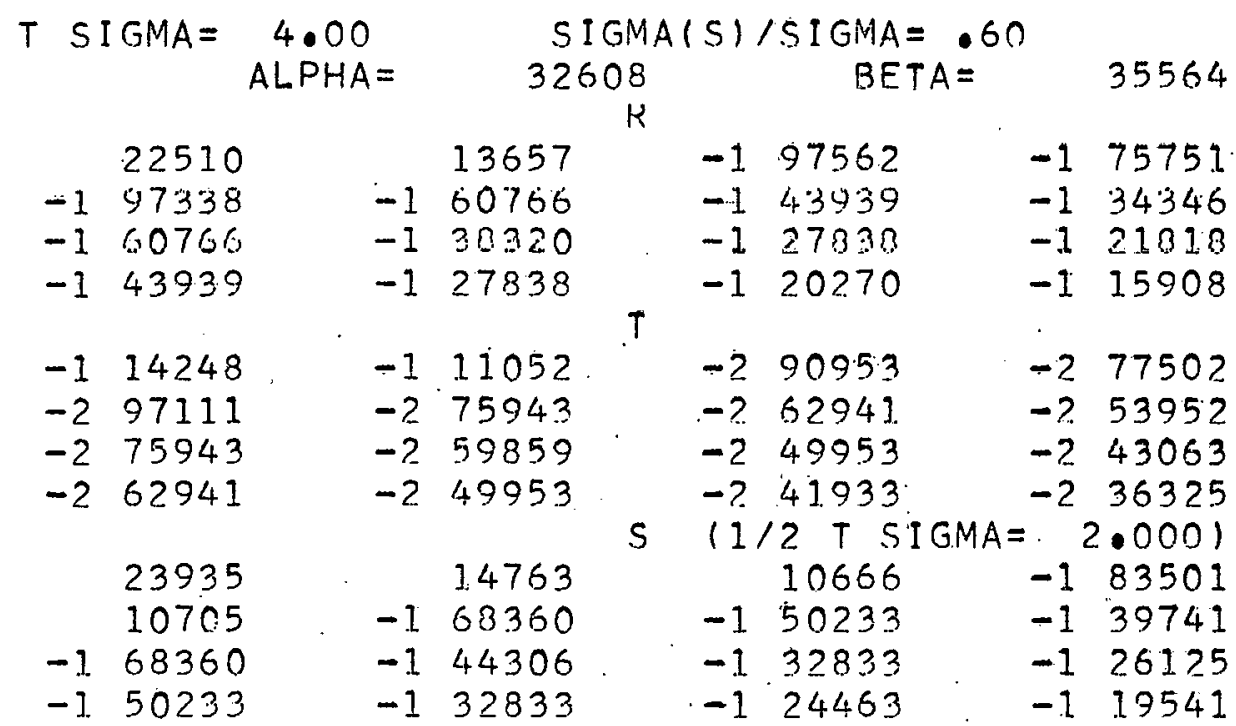




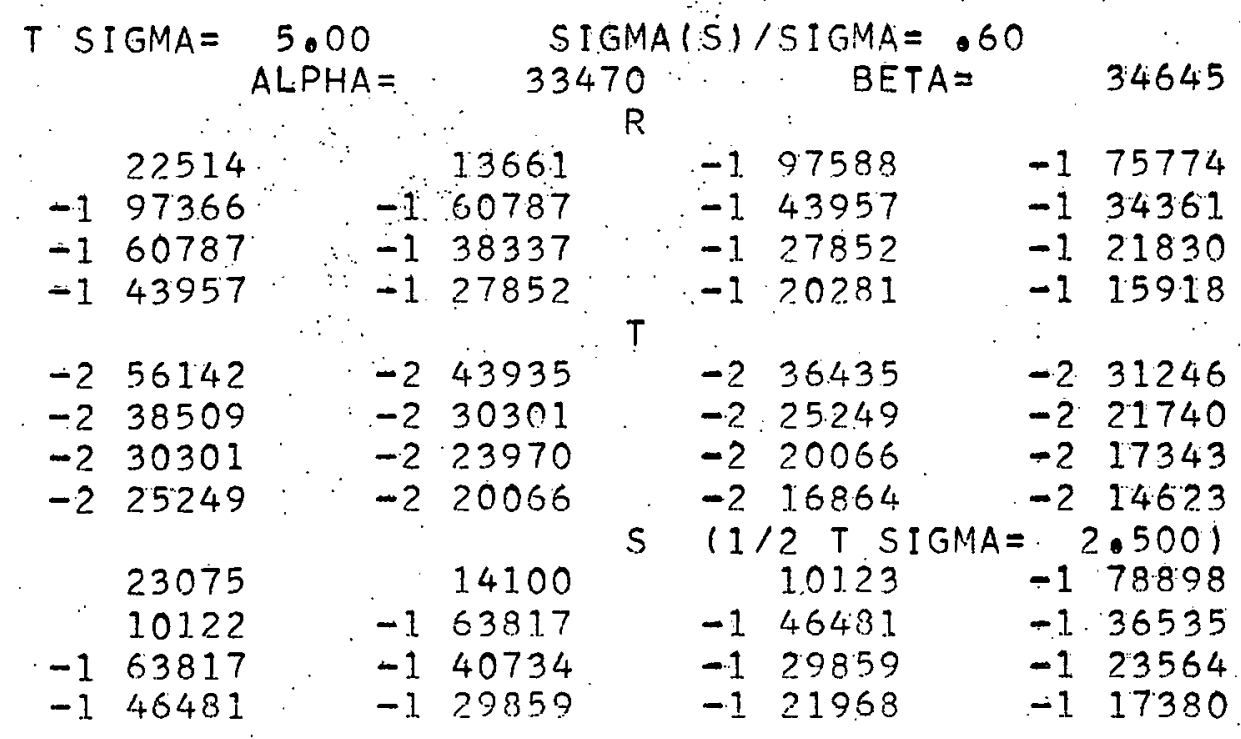

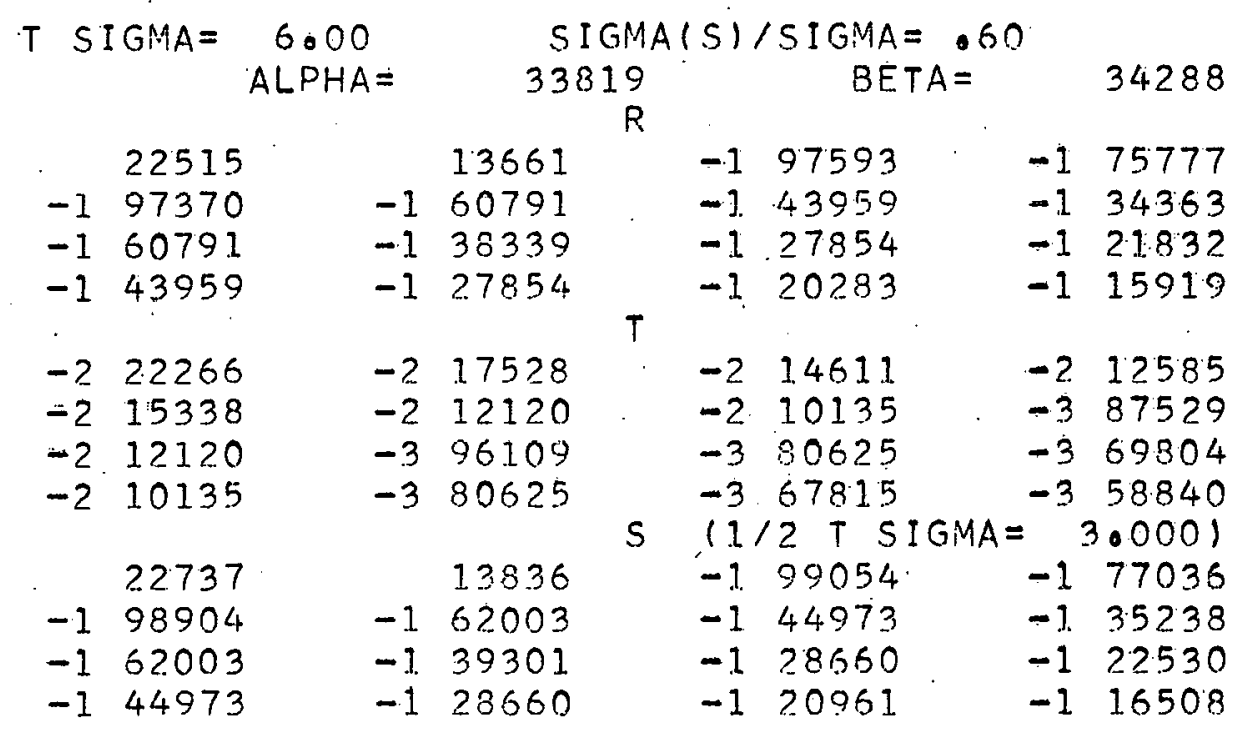

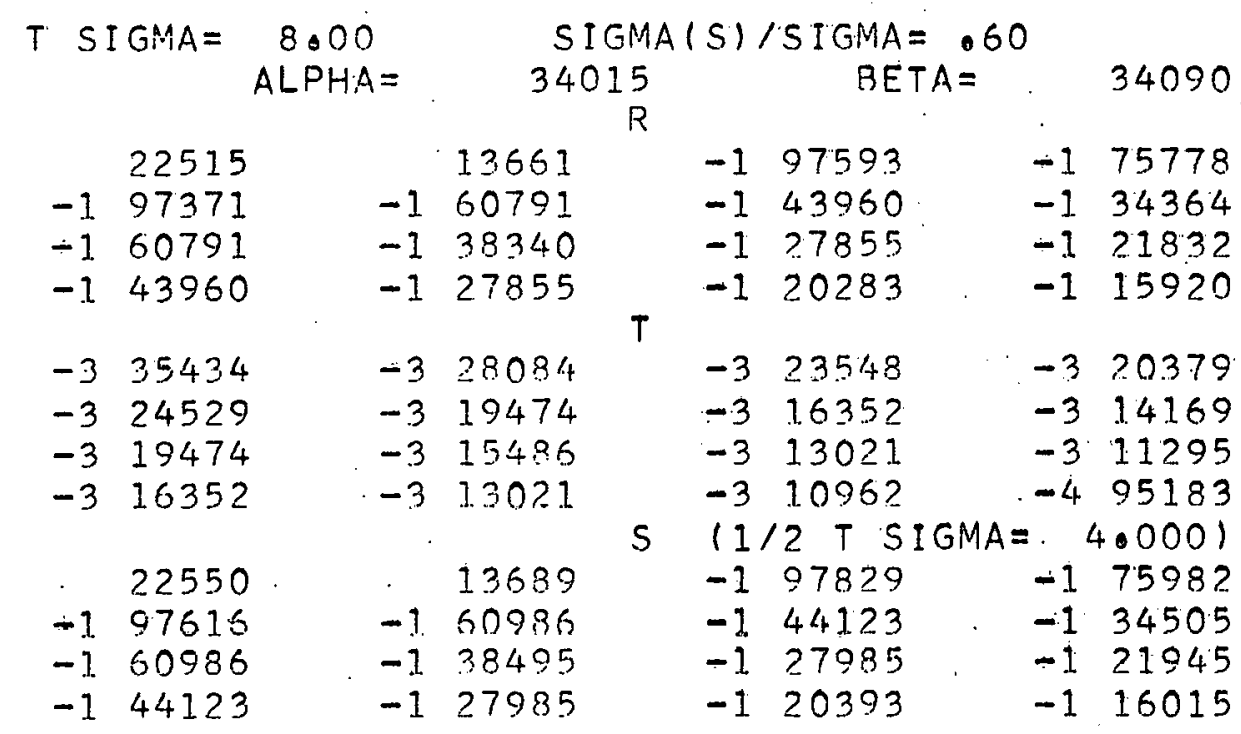




\section{WIAPD-TM- 168}

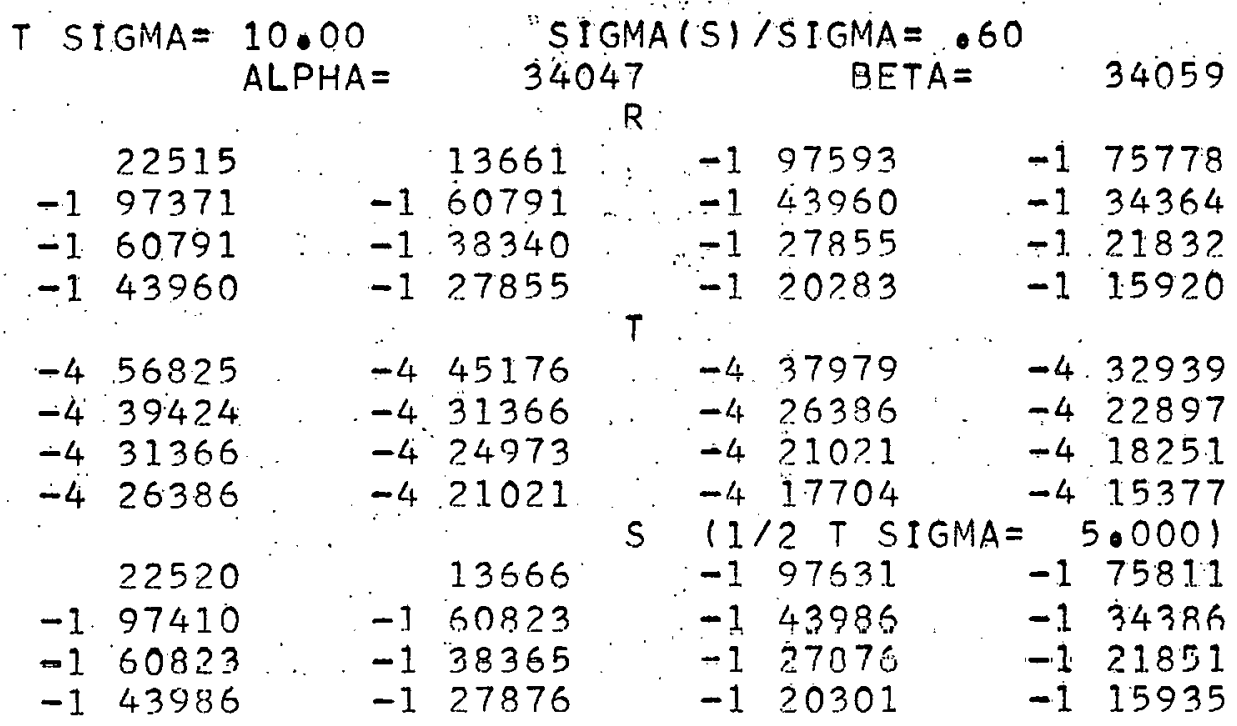

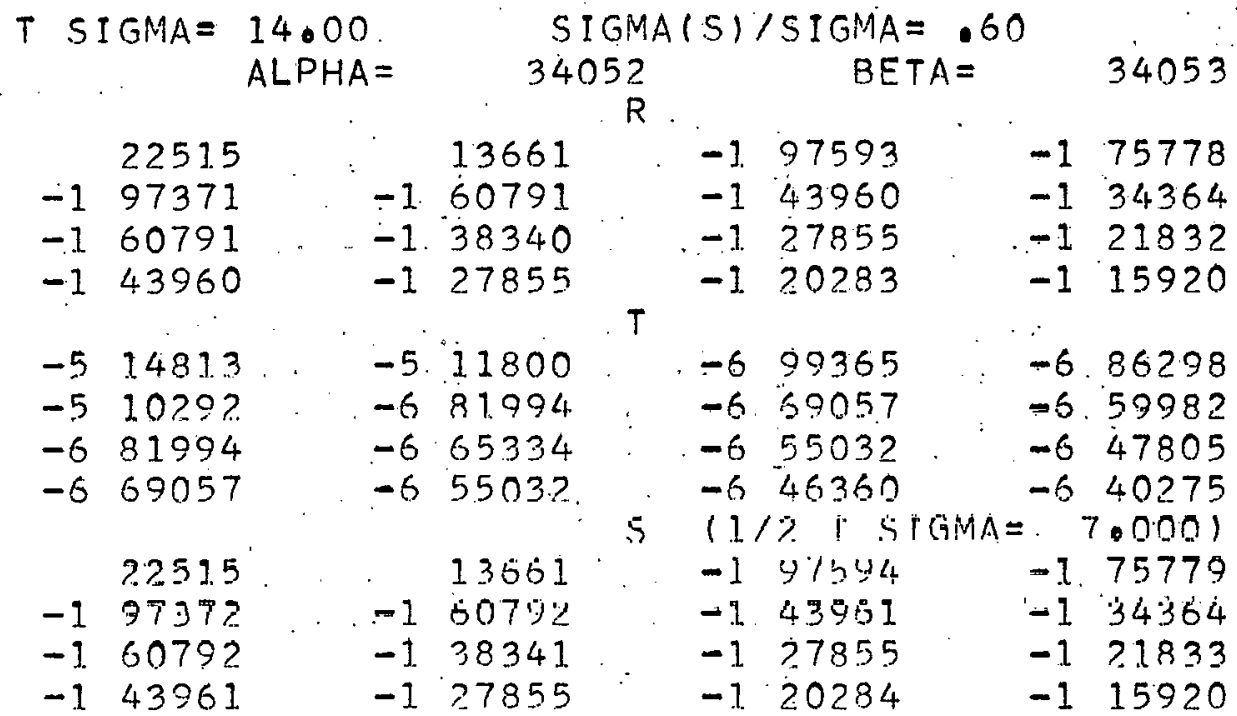

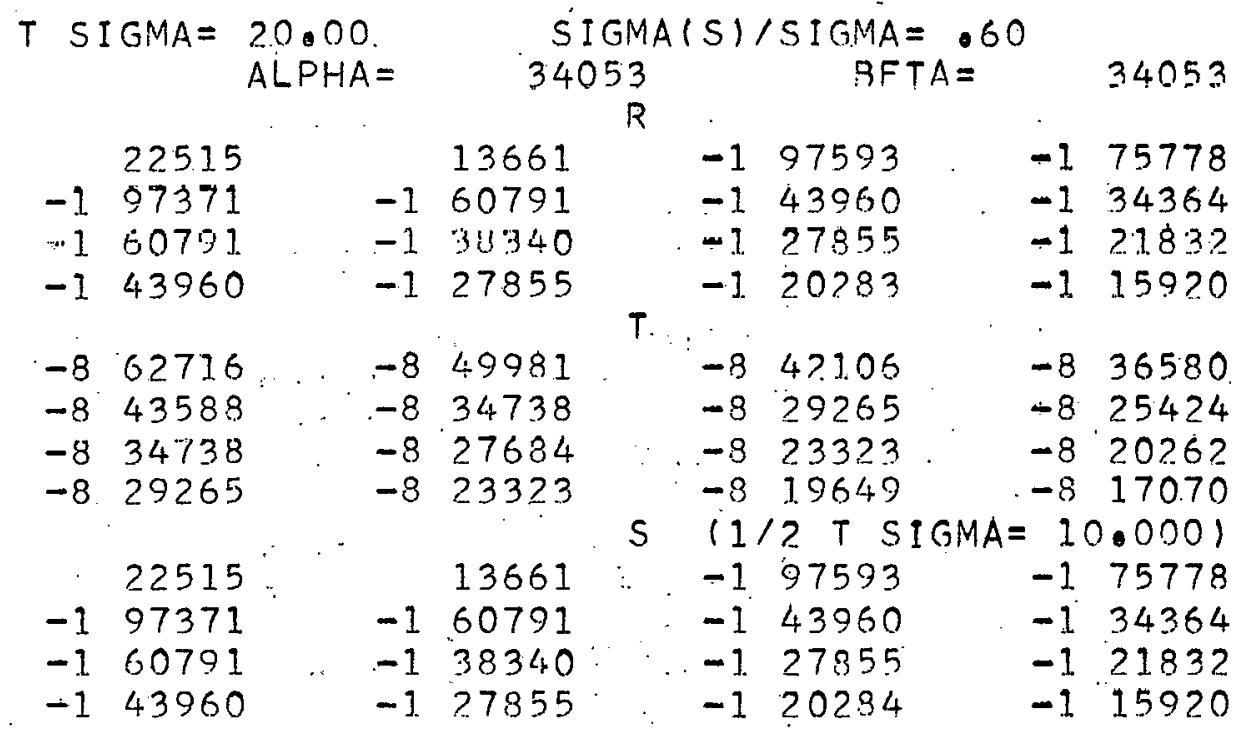




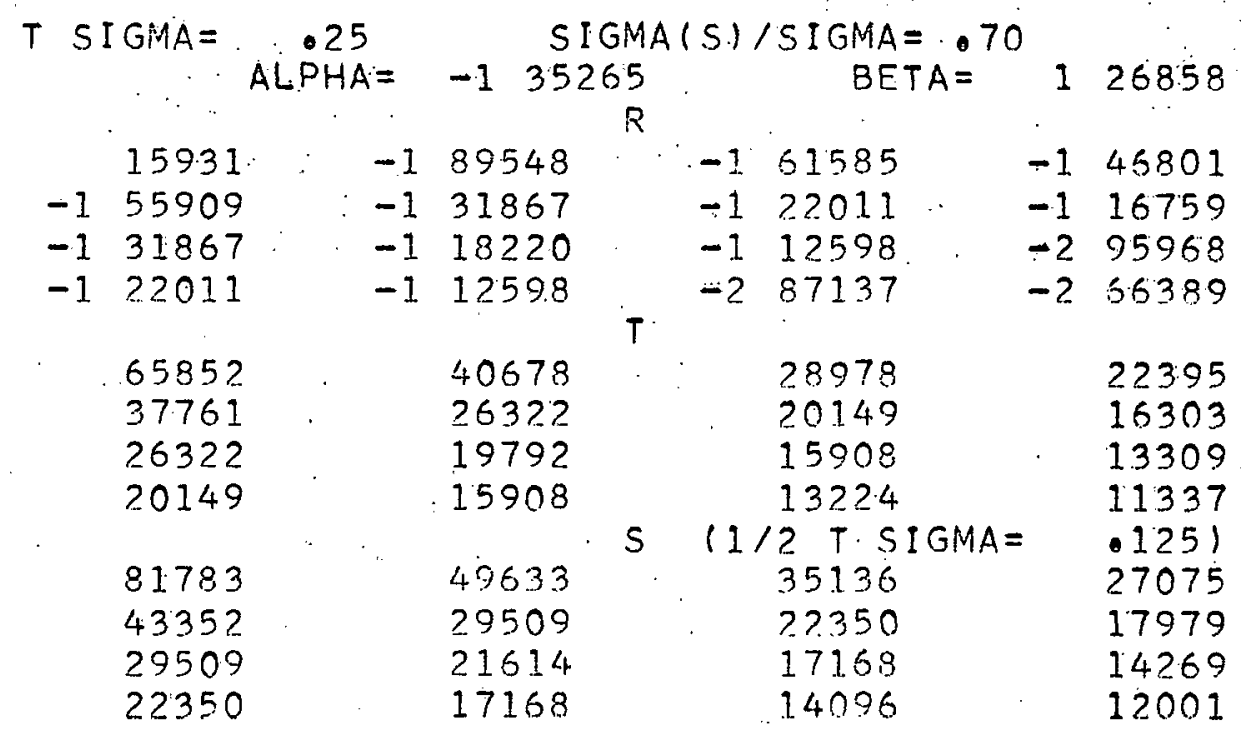

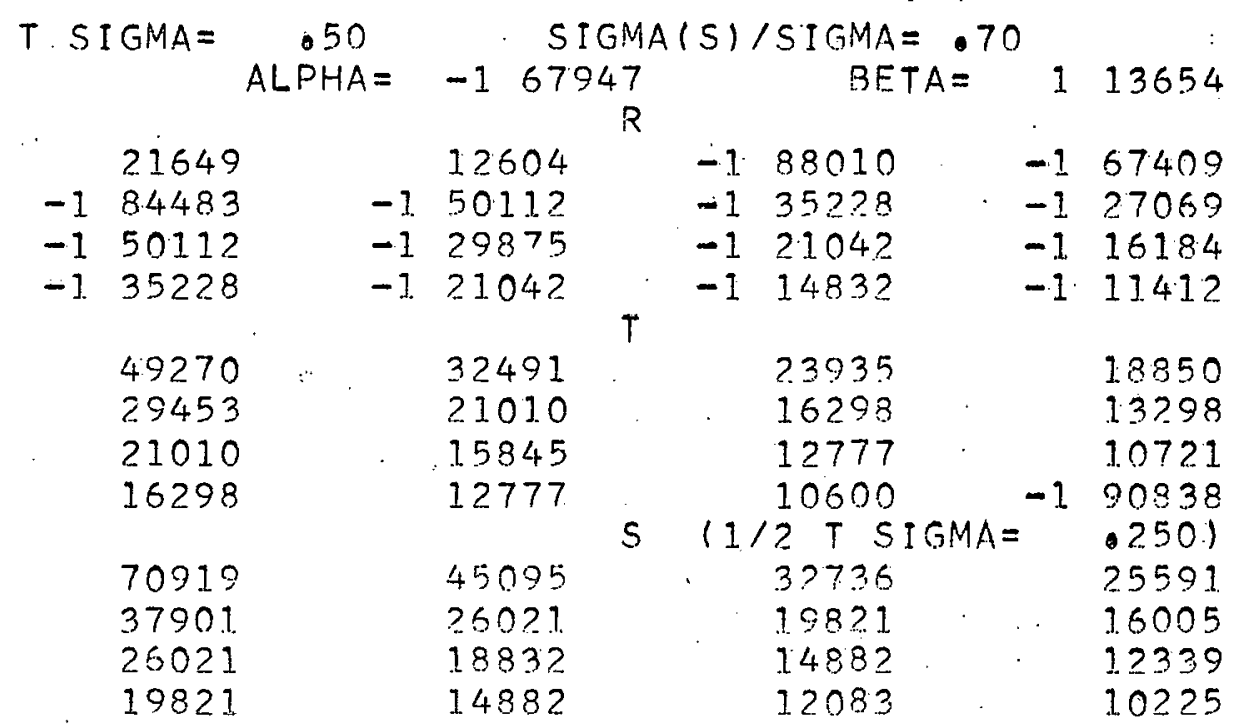

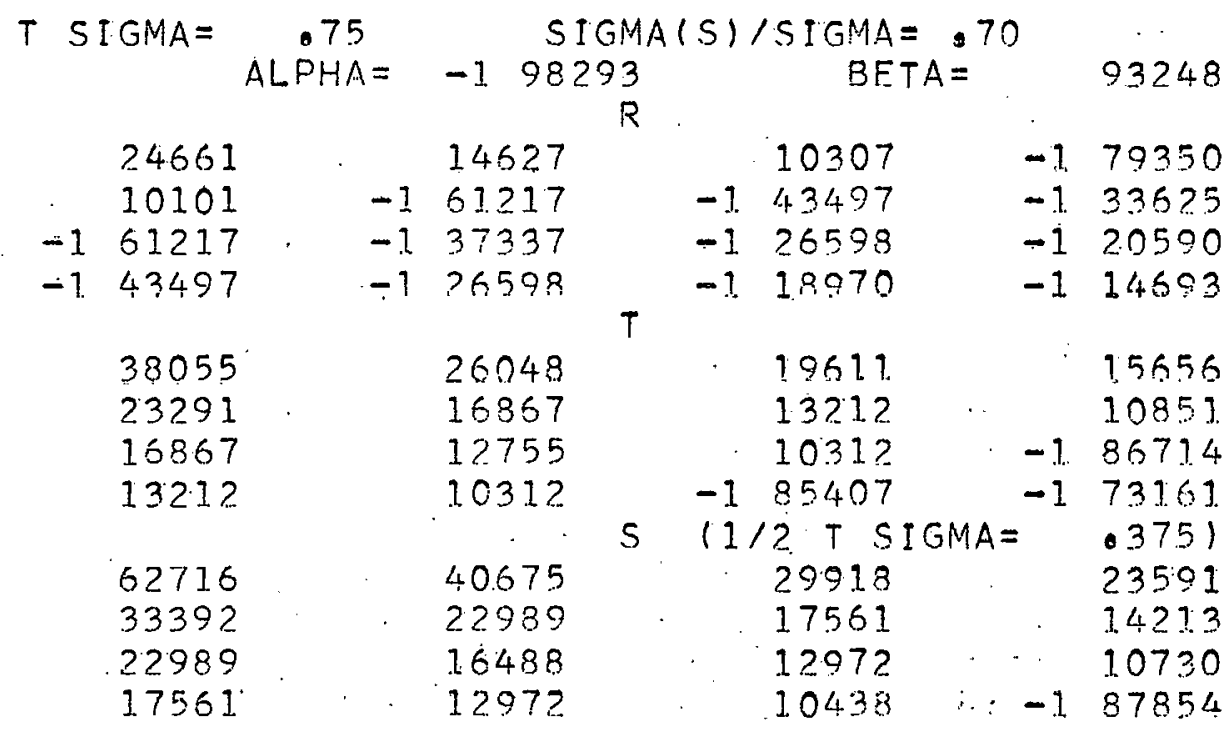




\section{WAPD-TM-168}

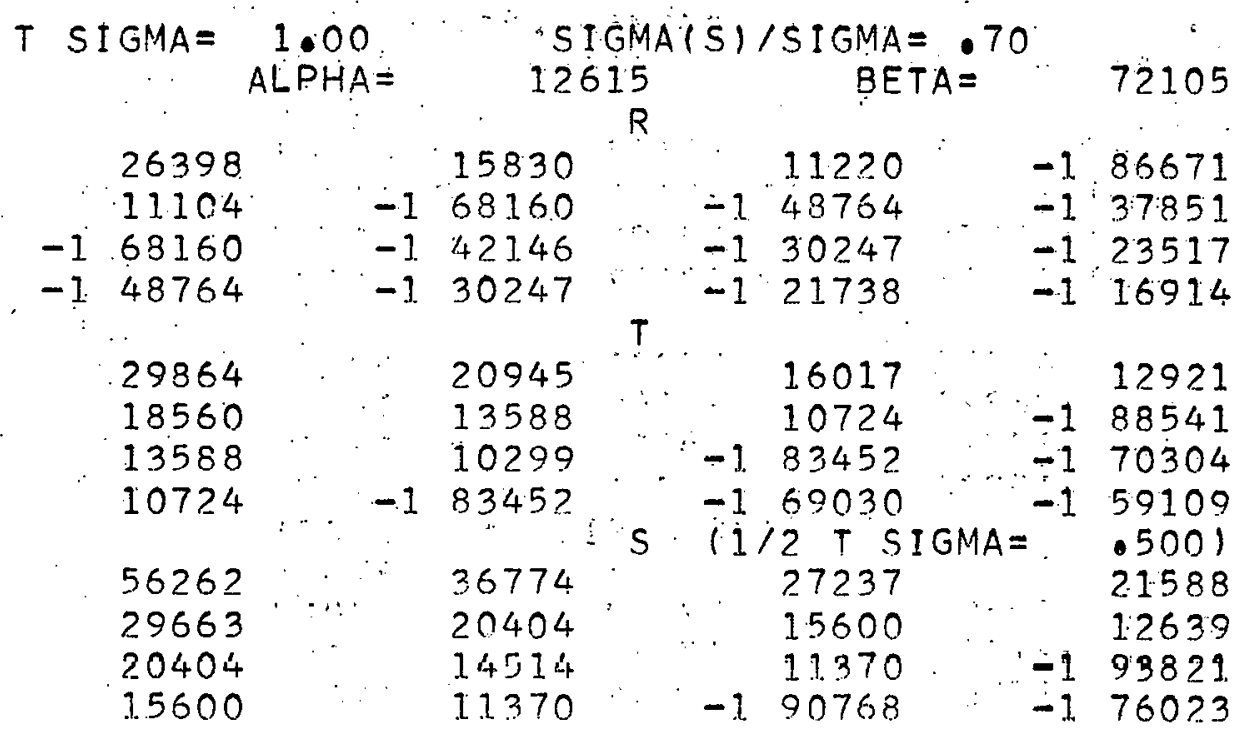

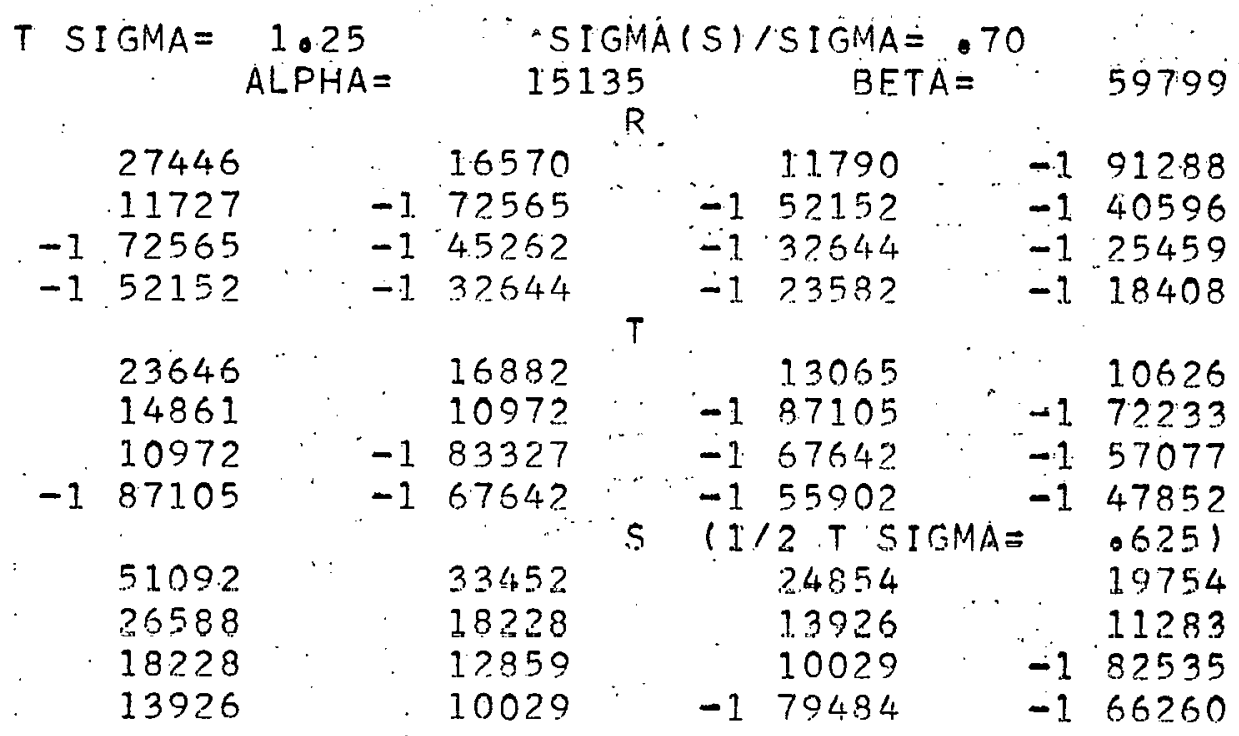

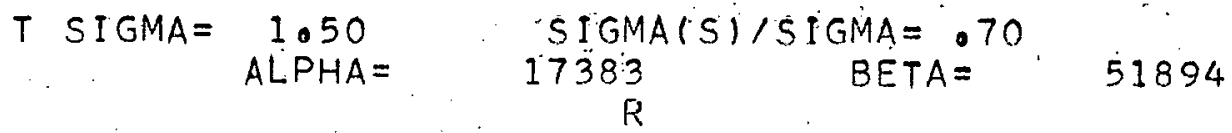

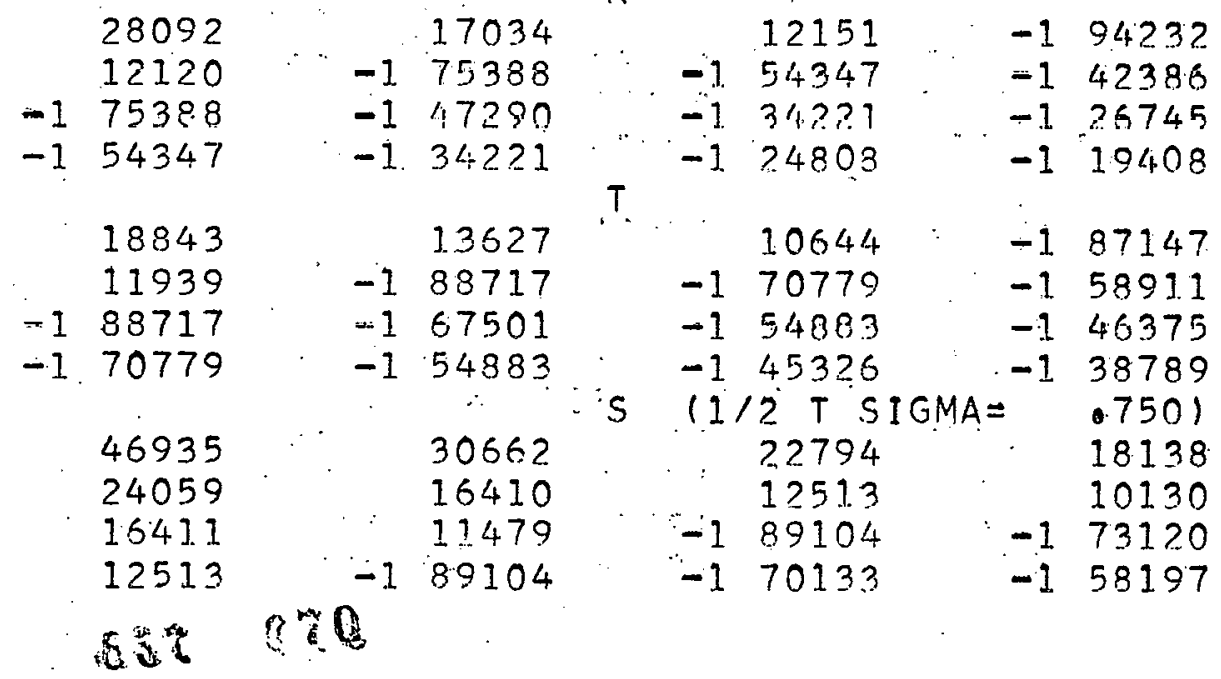




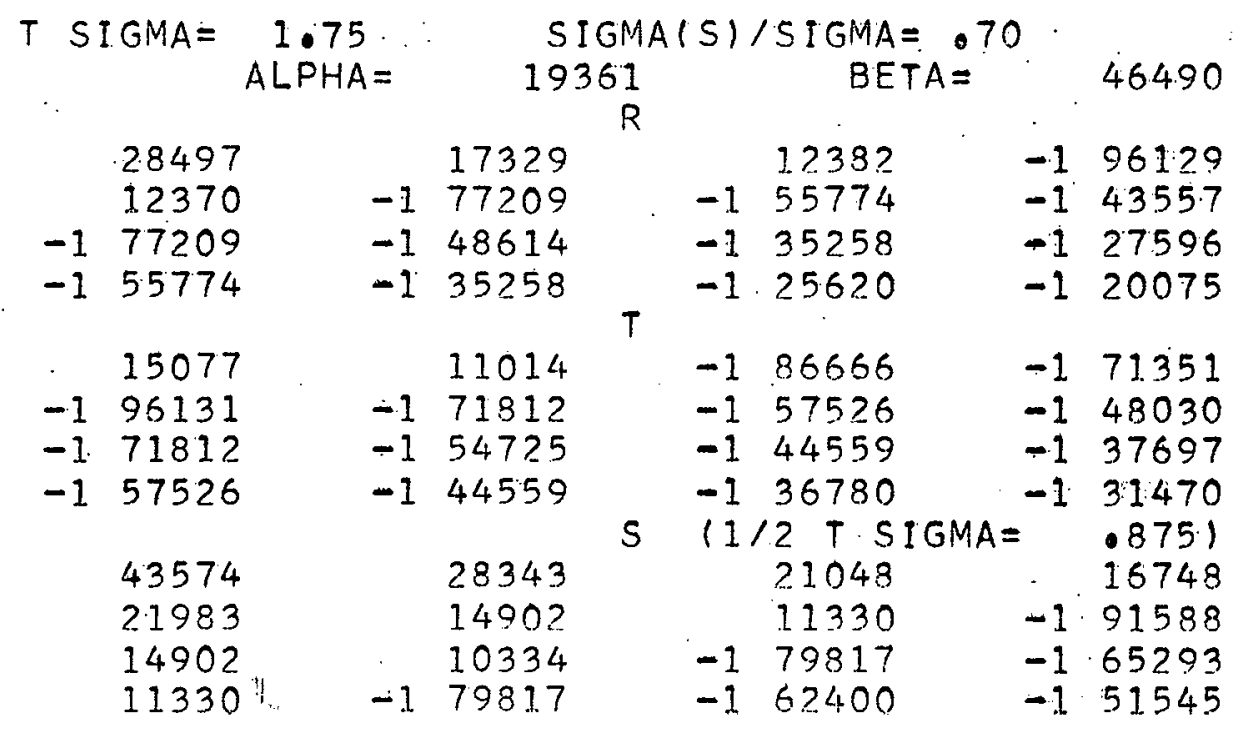

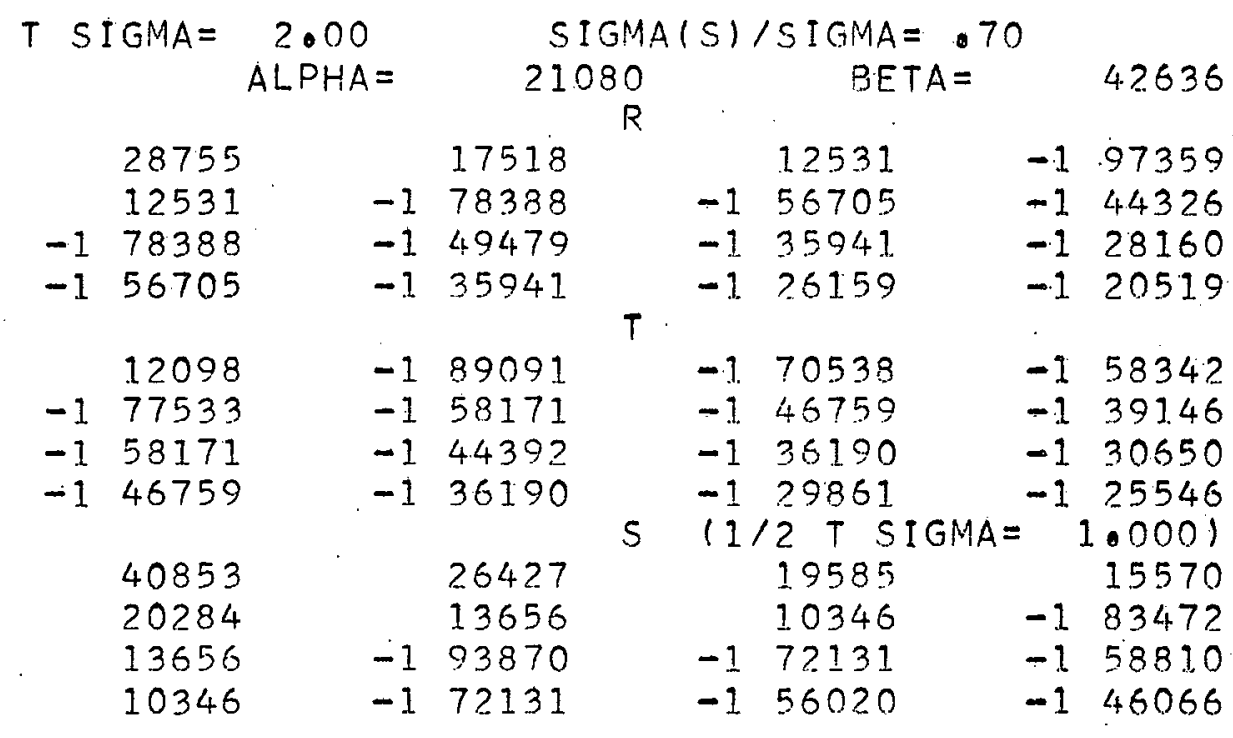

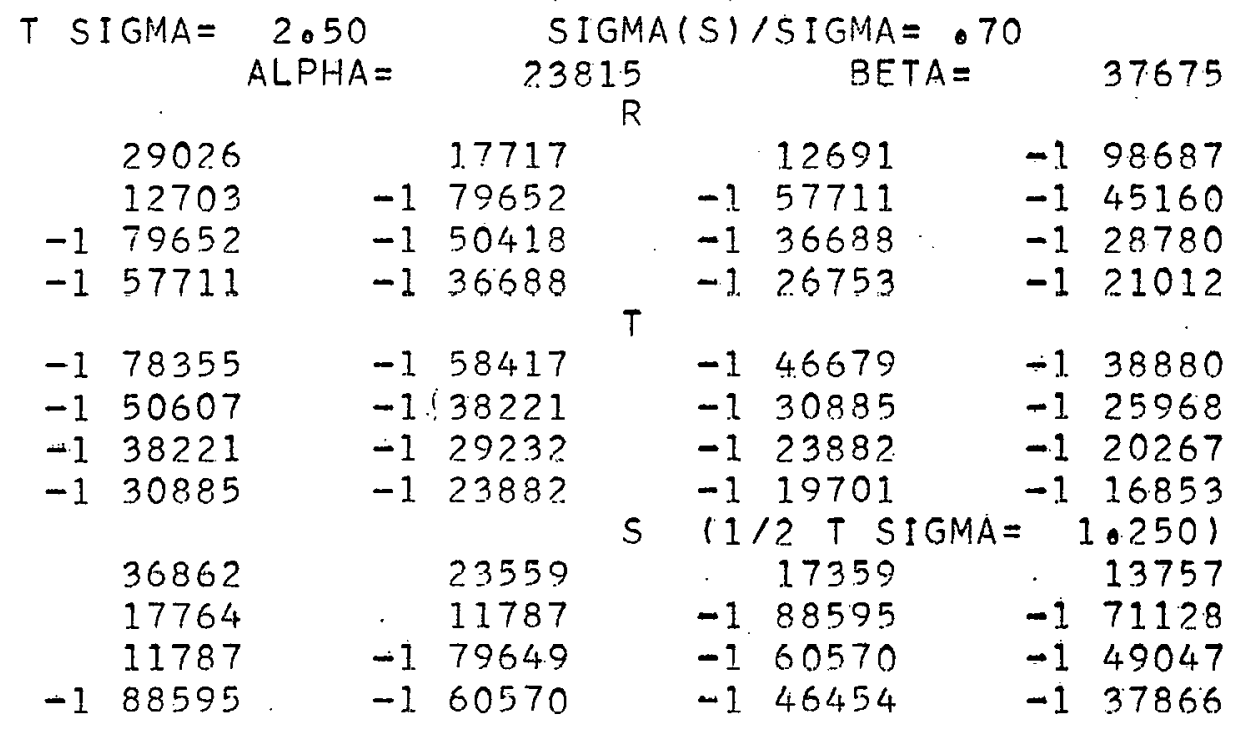




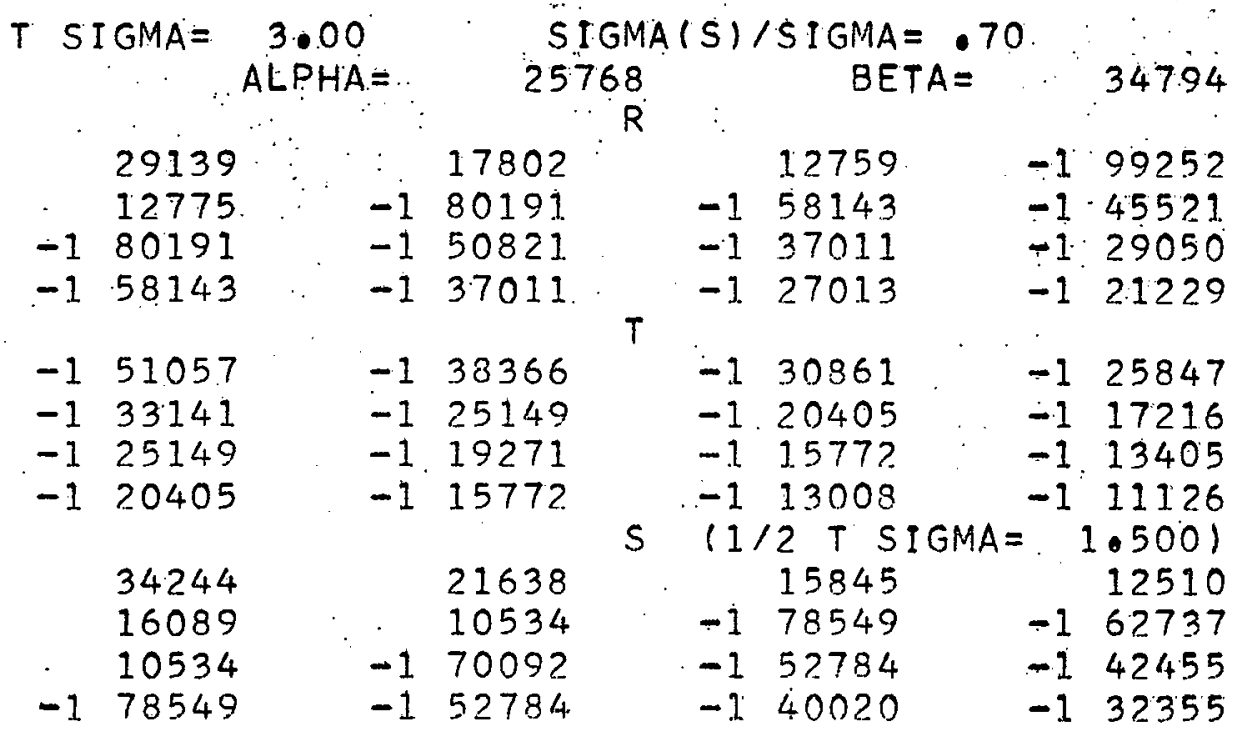

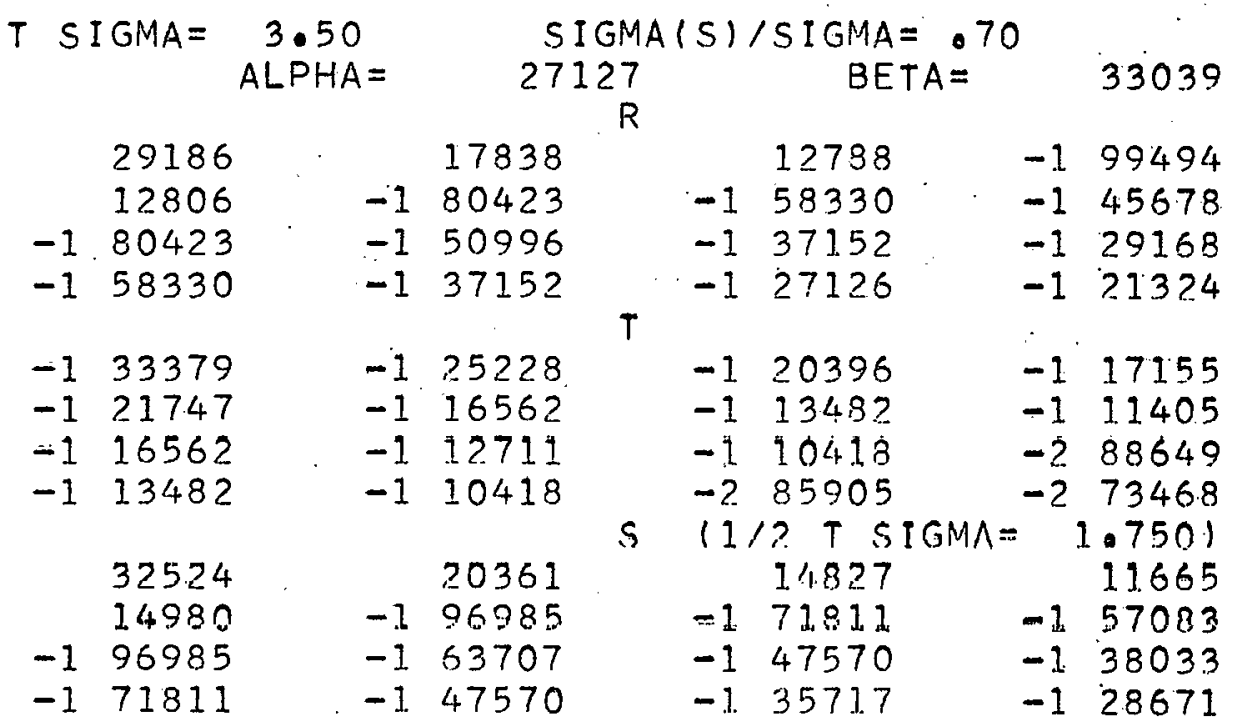

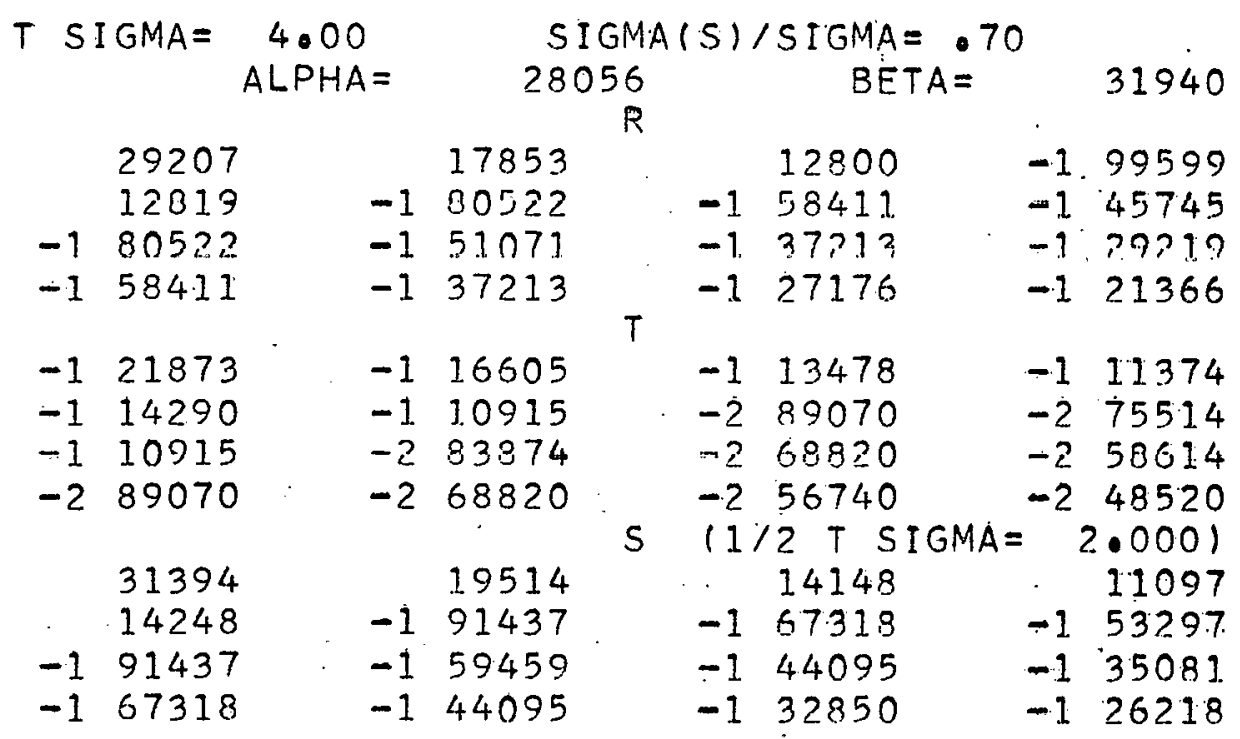




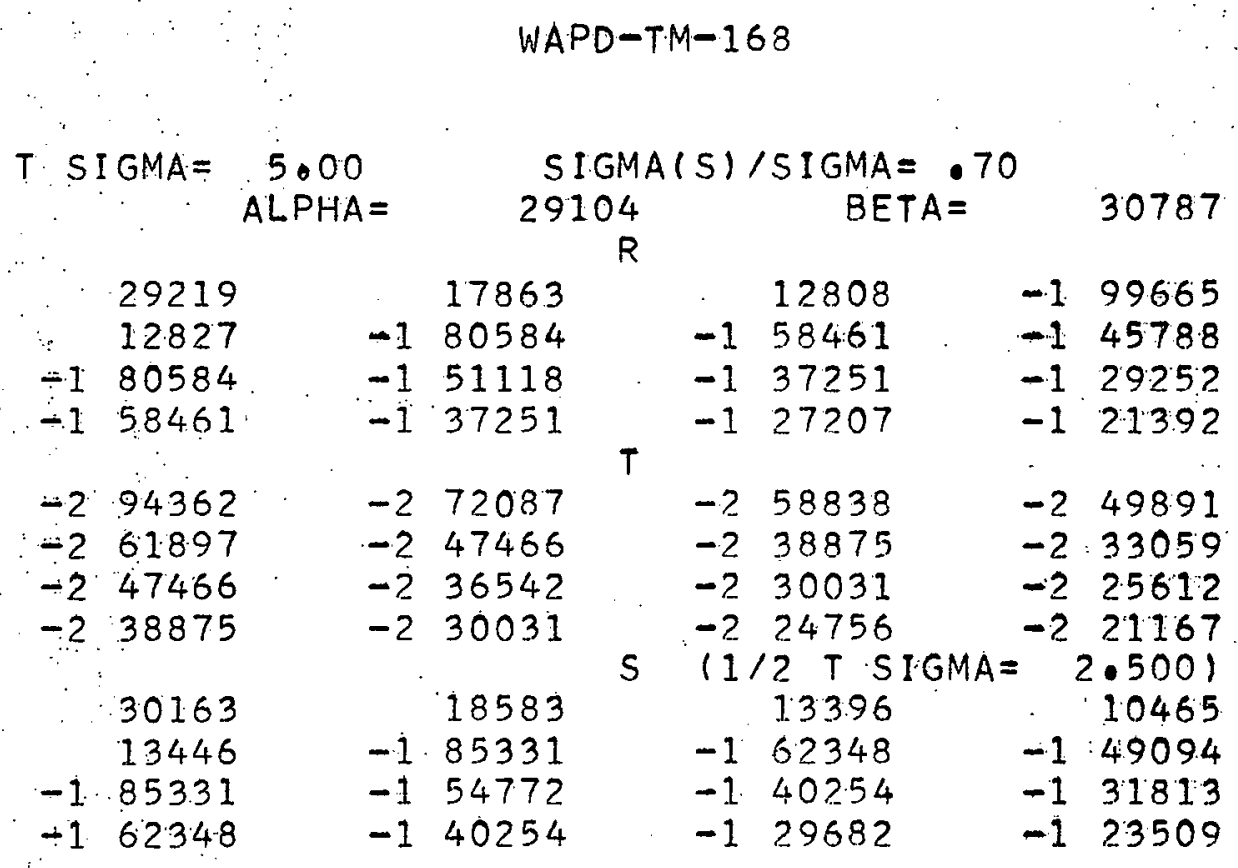

\begin{tabular}{|c|c|c|c|c|c|c|c|c|}
\hline \multicolumn{2}{|c|}{ T. S.I GMA $=$} & \multirow{2}{*}{$\begin{array}{c}6.00 \\
\text { ALPHA }=\end{array}$} & \multicolumn{5}{|c|}{ SIGMA $(S) / S I G M A=.70$} & \multirow[b]{2}{*}{30301} \\
\hline & & & \multicolumn{2}{|c|}{29570} & \multicolumn{3}{|c|}{ BETA $=$} & \\
\hline & 29222 & & 17864 & & & 12809 & -1 & 99677 \\
\hline & 12829 & -1 & 80596 & & -1 & 58470 & -1 & 45796 \\
\hline & 80596 & -1 & 51127 & & -1 & 37259 & -1 & 29258 \\
\hline & 58470 & -1 & 37259 & & -1 & 27213 & -1 & 21397 \\
\hline- & 408.66 & -2 & 31343 & & -2 & 25673 & $-?$ & 21834 \\
\hline 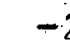 & 26874 & -2 & 20661 & & -2 & 16960 & -2 & 14451 \\
\hline-2 & 20661 & -2 & 15924 & & $-?$ & 13100 & -2 & 11182 \\
\hline & 16960 & -2 & 13100 & & -2 & 10798 & -3 & 92320 \\
\hline & & & & $S$ & 12 & $2 T S I G M A=$ & & .0001 \\
\hline & 29630 & & 18173 & & & 13066 & & 10186 \\
\hline & 13097 & 1 & 82662 & & -1 & 50166 & -1 & 47241 \\
\hline & 82662 & -1 & 52719 & & -1 & 38559 & -1 & 30376 \\
\hline 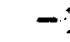 & 60166 & -1 & 38569 & & -1 & 28292 & -1 & 22320 \\
\hline
\end{tabular}

\begin{tabular}{|c|c|c|c|c|c|c|c|c|}
\hline \multirow[t]{2}{*}{$\mathrm{T}$} & SI:GMA = & \multirow{2}{*}{$\begin{array}{c}8.00 \\
\text { ALPHA }=\end{array}$} & \multicolumn{6}{|c|}{ SIGMA(S)/SIGMA $=.70$} \\
\hline & & & 29 & & & $B E T A=$ & & 30003 \\
\hline & 29222 & & 17865 & & & 12810 & -1 & 99680 \\
\hline & 12829 & -1 & 80598 & & -1 & 58472 & -1 & 457.98 \\
\hline-1 & 80598 & -1 & 51129 & & -1 & 37260 & -1 & 29259 \\
\hline-1 & 58472 & -1 & 37260 & & -1 & $27 ? 14$ & -1 & 21398 \\
\hline$\cdot$ & & & & $T$ & & & $\cdot$ & \\
\hline-3 & 77133 & -3 & 594.03 & & -3 & 48835 & -3 & 41.661 \\
\hline-3 & 50857 & -3 & 39205 & & -3 & 32259 & -3 & 27540 \\
\hline-3 & 39205 & -3 & 30253 & & -3 & 24914 & -3 & 21.285 \\
\hline-3 & 32259 & -3 & 24914 & & -3 & 20534 & -3 & 17554 \\
\hline & & & & $\mathrm{S}$ & 11 & $2 T S I G M A=$ & & .00001 \\
\hline & 29299 & & 17924 & & & 12858 & & 1.0010 \\
\hline & 12.880 & -1 & 80990 & & -1 & 58795 & -1 & 46073 \\
\hline-1 & 80990 & -1 & 51432 & & -1 & 37509 & -1 & 29472 \\
\hline-1 & 58795 & -1 & 37509 & & -1 & 27419 & -1 & 21574 \\
\hline
\end{tabular}




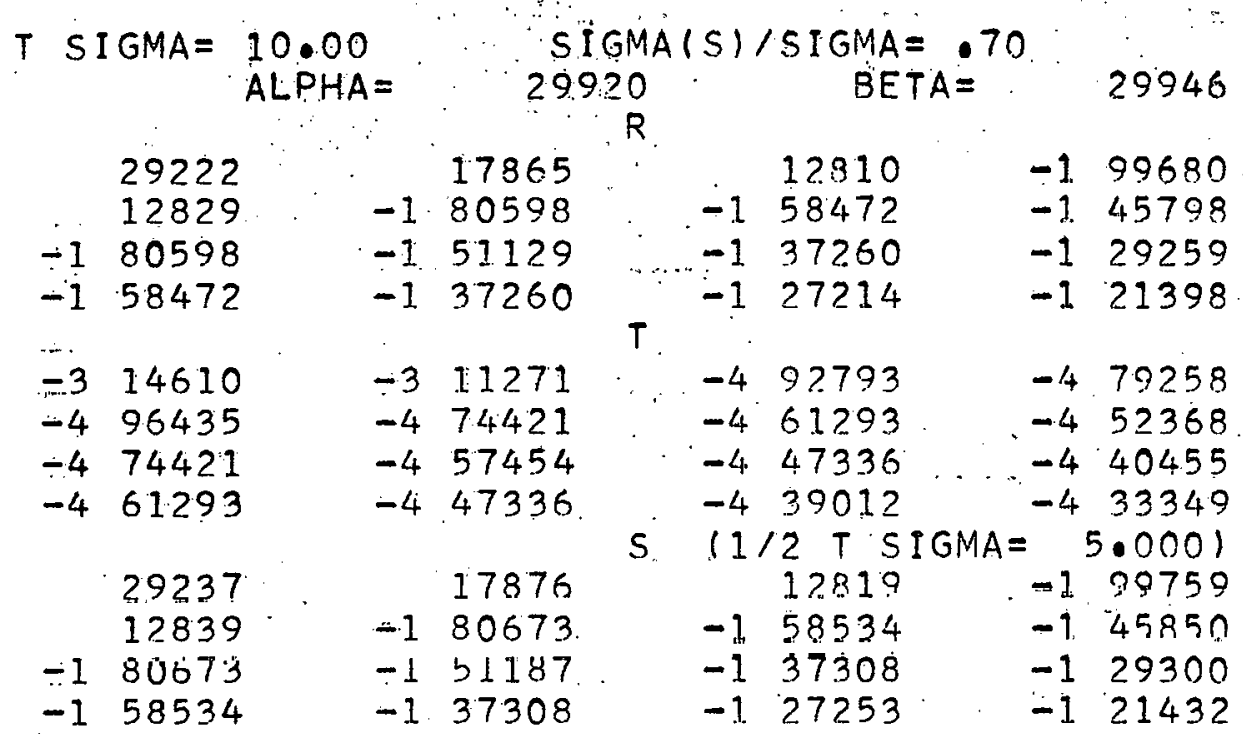

\begin{tabular}{|c|c|c|c|c|c|c|c|c|}
\hline S : & $G M A=$ & $14 \cdot 00$ & & GMA & $(5) 1$ & $51 \mathrm{GMA}=.70$ & & \\
\hline & & $A L P H A=$ & 299 & 33 & & BETA = & & 29934 \\
\hline & 29222 & & 17865 & & & 12810 & -1 & 99680 \\
\hline & 12829 & -1 & 80598 & & -1 & $5847 ?$. & -1 & 45798 \\
\hline-1 & 80598 & -1 & 51129 & & -1 & 37260 & -1 & 29259 \\
\hline-1 & 58472 & -1 & 37260 & & -1 & 272.14 & -1 & 21398 \\
\hline & & & 40763 & & & 32588 & & \\
\hline-5 & 34866 & -5 & 26923 & & -5 & 22186 & -5 & 18964 \\
\hline-5 & 26923 & -5 & 20791 & & -5 & 171.33 & -5 & 14646 \\
\hline-5 & 22186 & -5 & 17133 & & -5 & $141 ? 0$ & -5 & 12070 \\
\hline & & & & 5 & 111 & $2 T S I G M A=$ & & 7.000 \\
\hline & 20223 & 3 & 17865 & & & 12810 & -1 & 99683 \\
\hline & 12829 & -1 & 80601 & & -1 & 58475 & -1 & 45800 \\
\hline-1 & 80601 & -1 & 51131 & & -1 & 37252 & -1 & 29261. \\
\hline-1 & 58475 & -1 & 37262 & & -1 & 27215 & -1 & 21399 \\
\hline
\end{tabular}

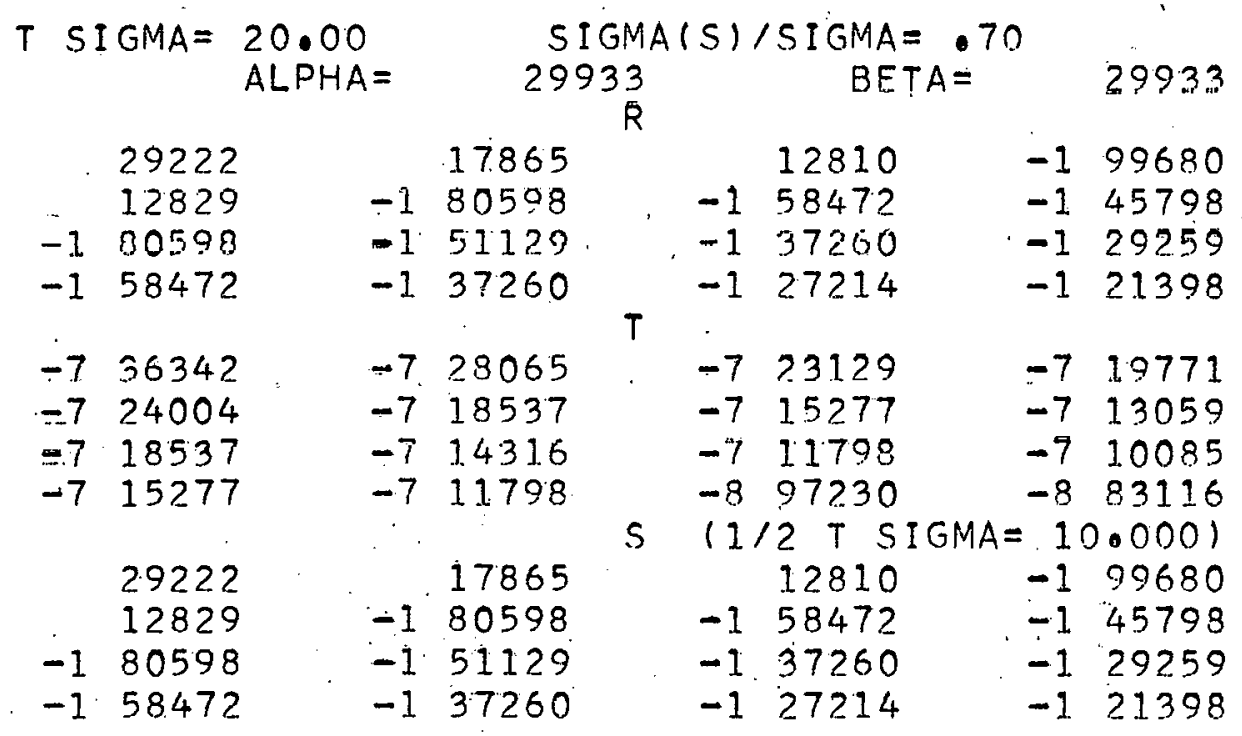




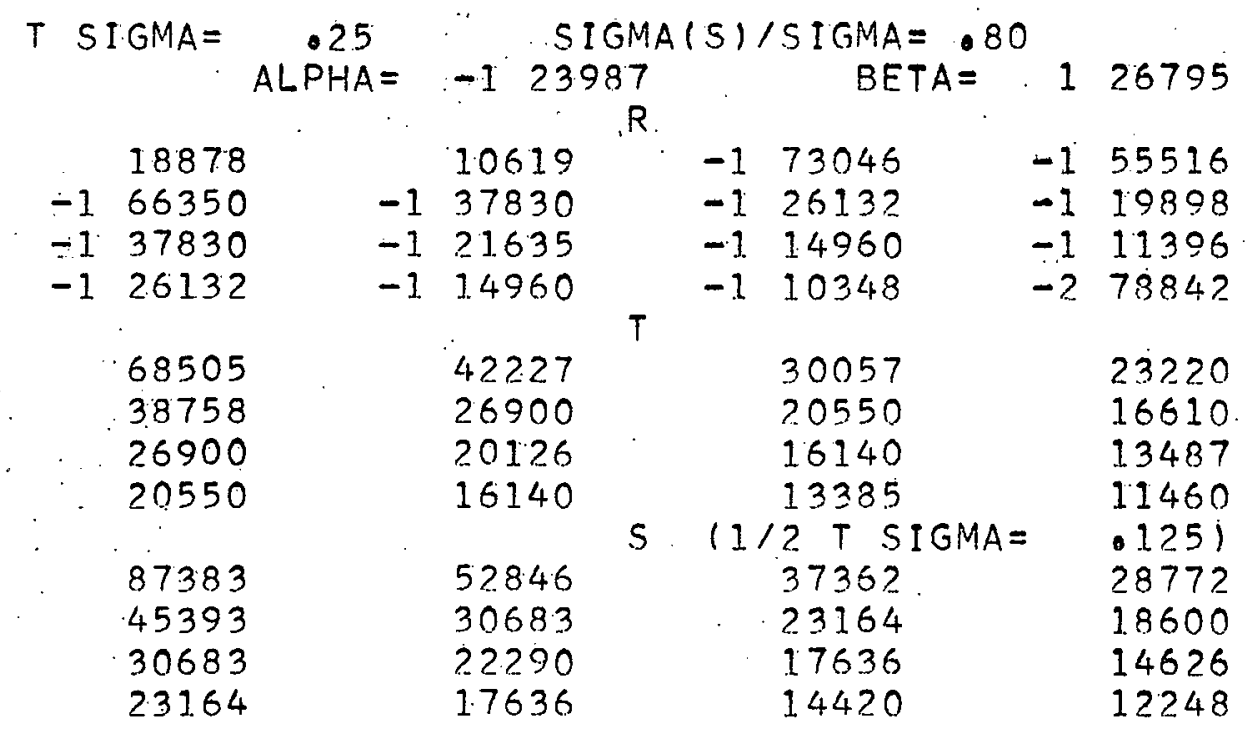

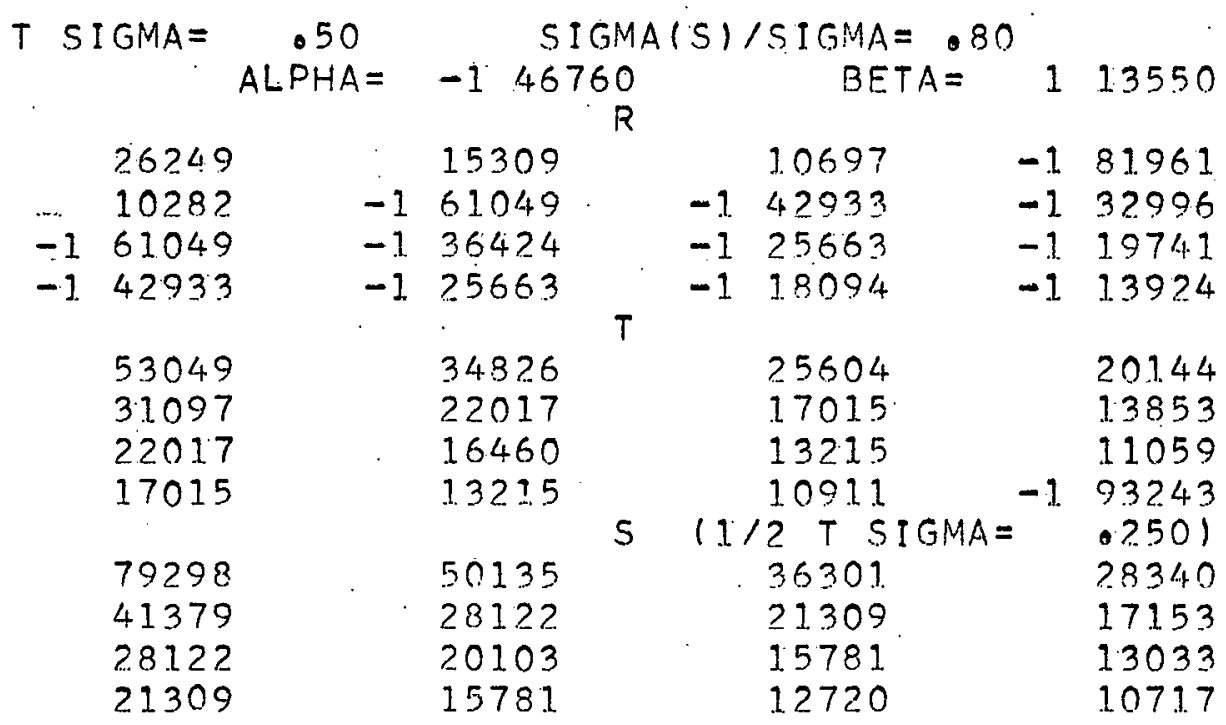

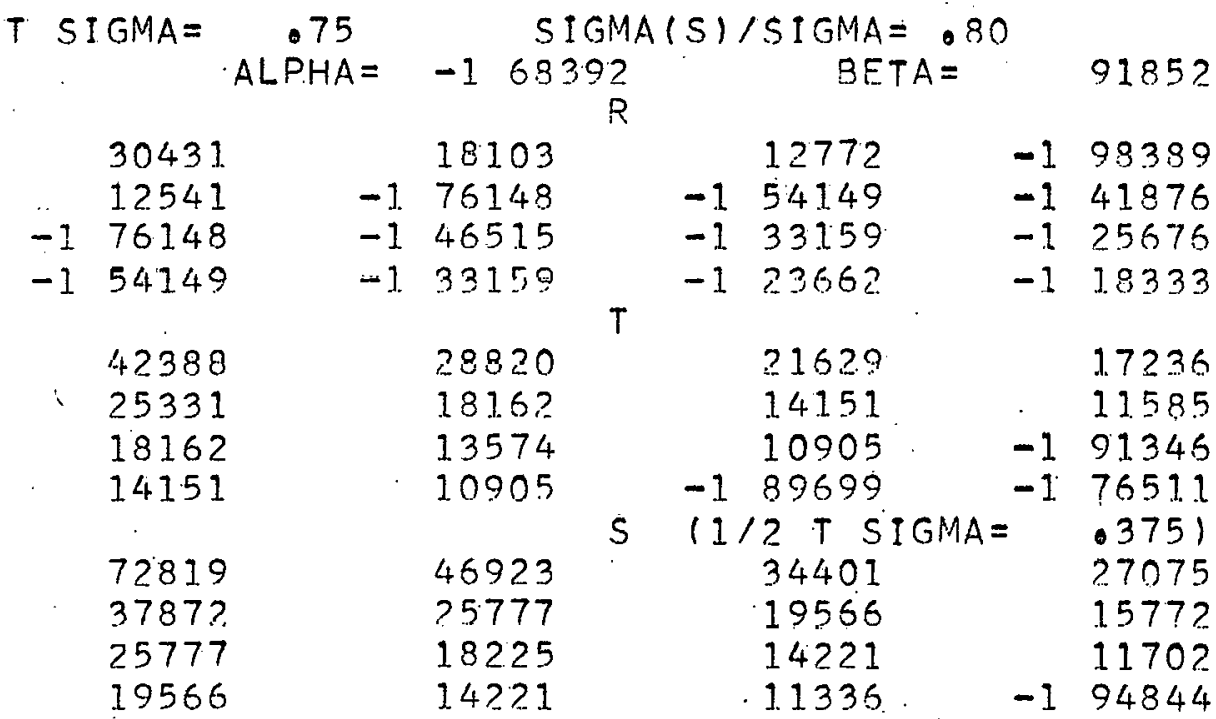




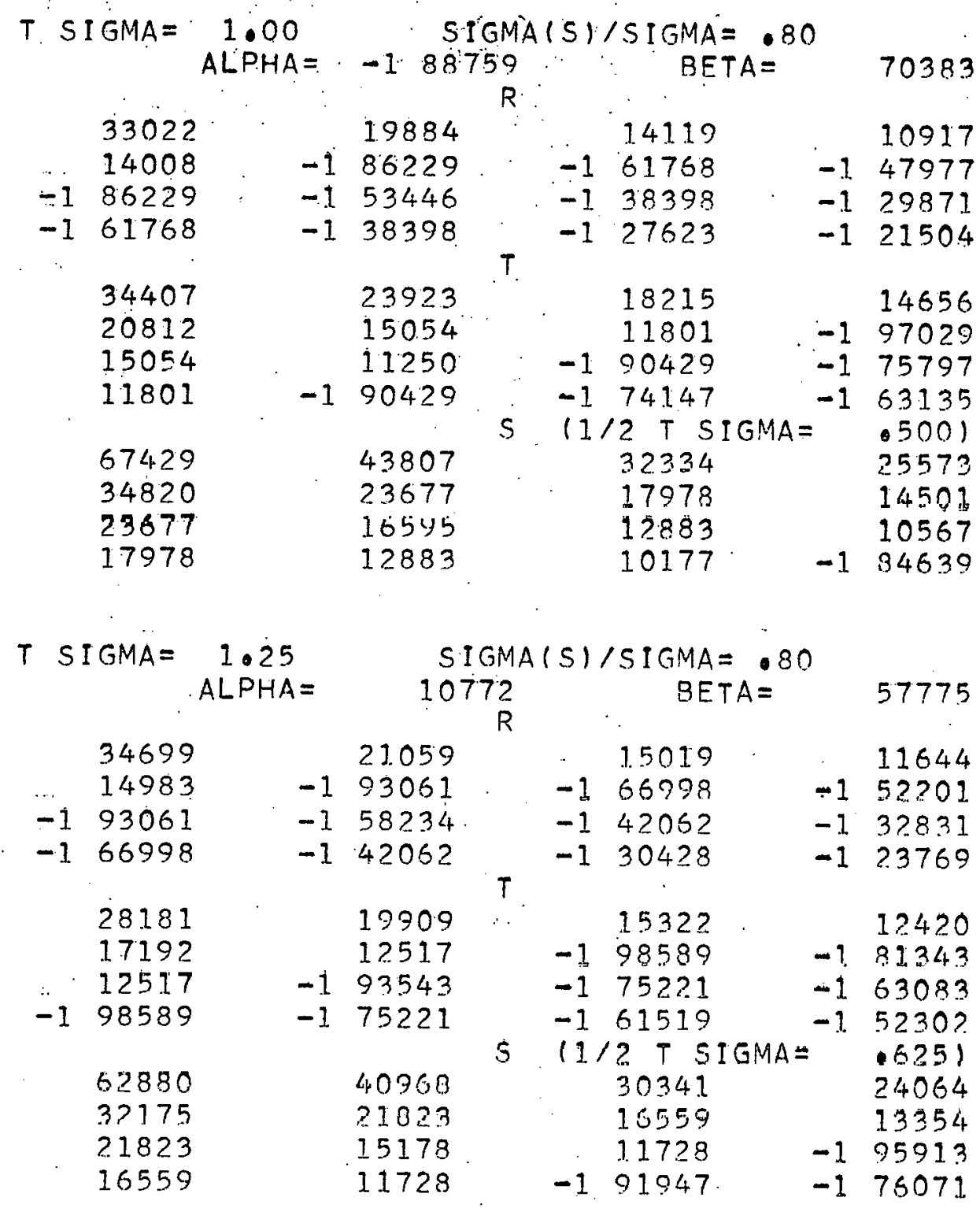

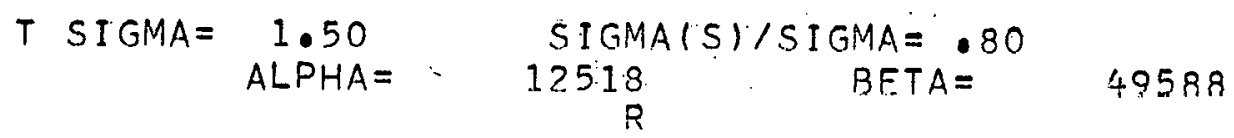

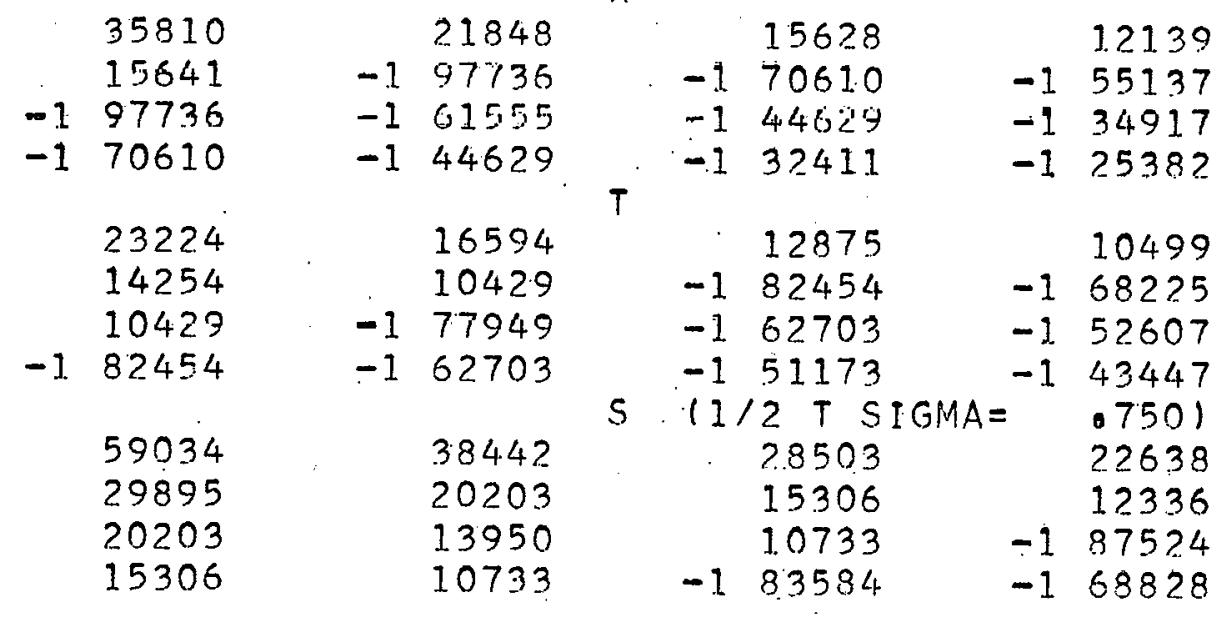

74

837 C 


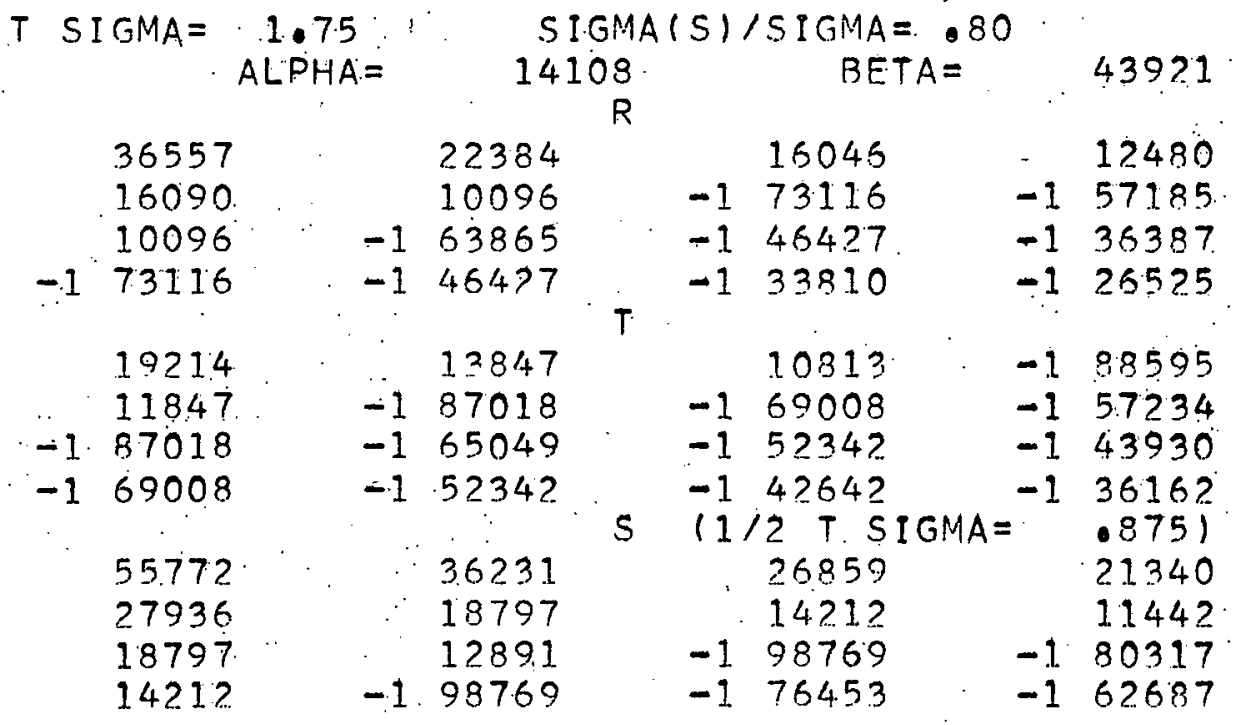

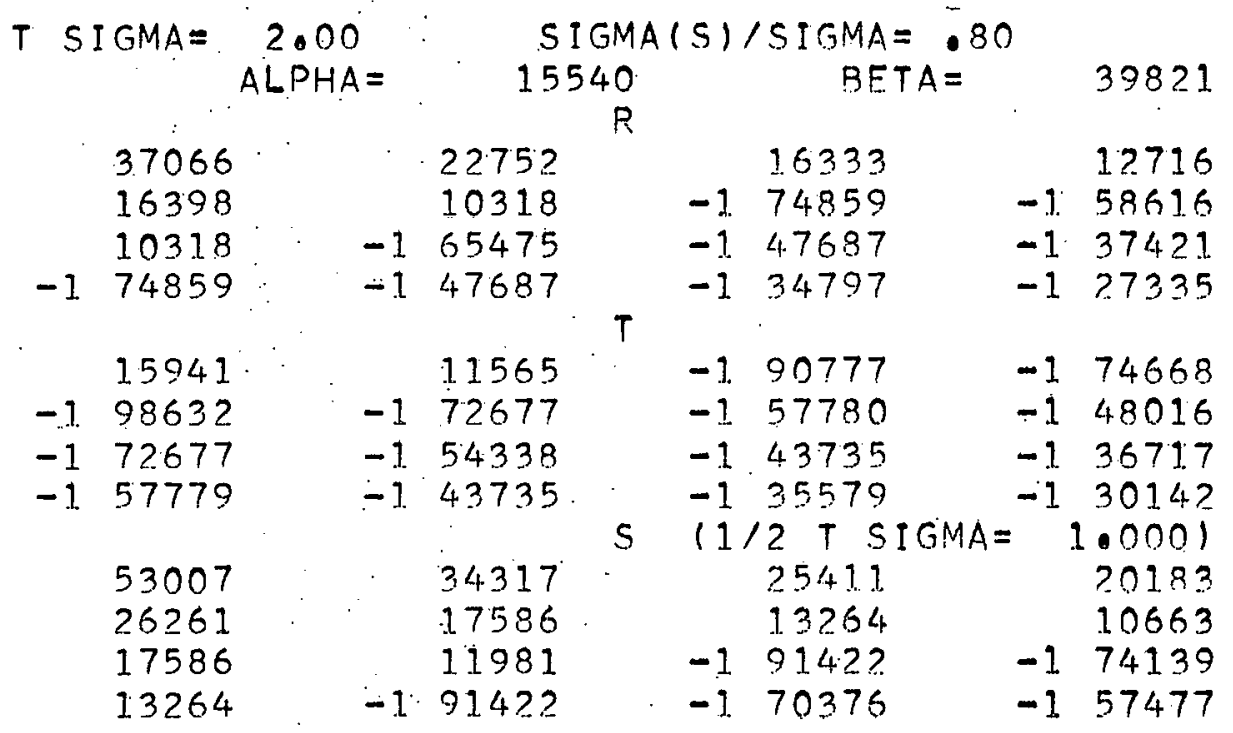

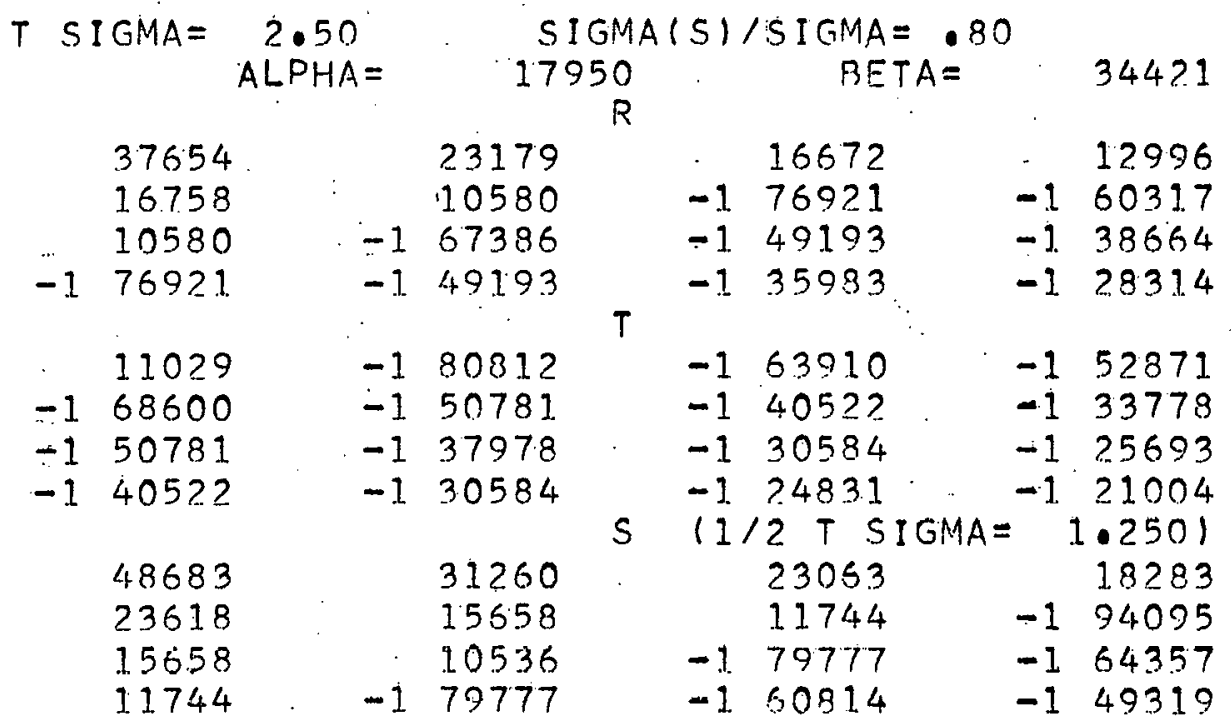




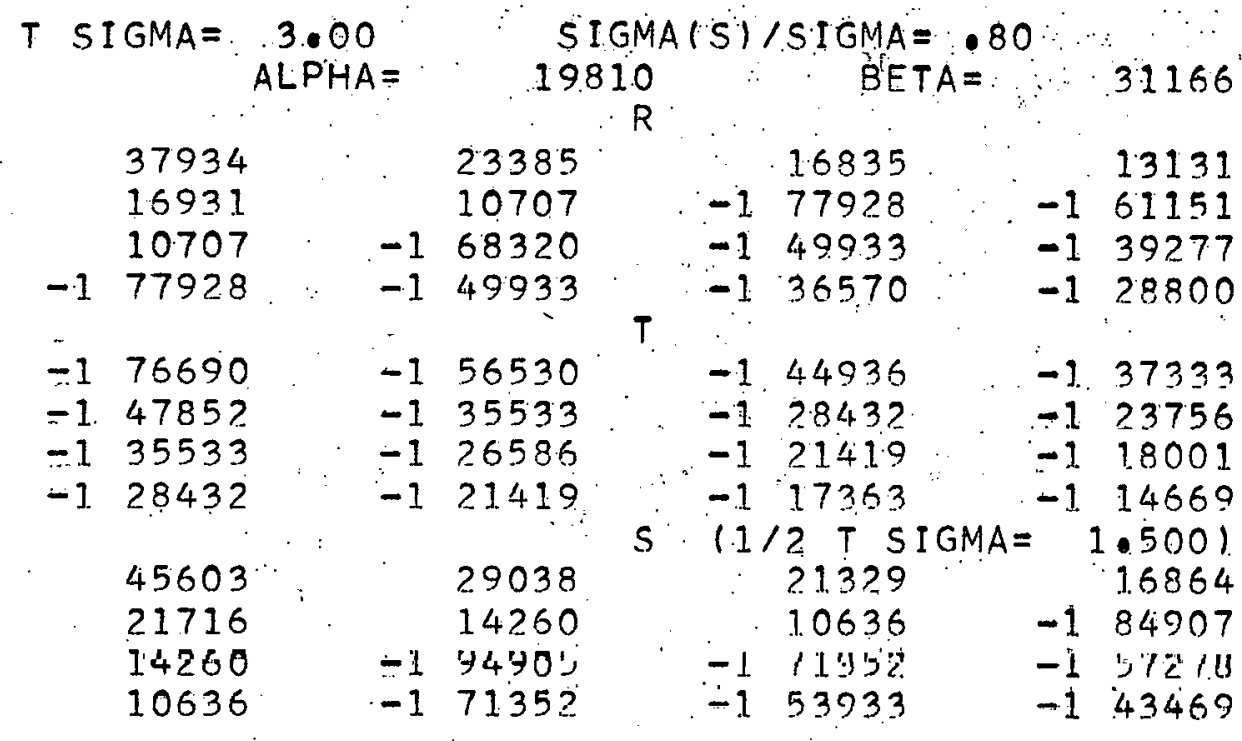

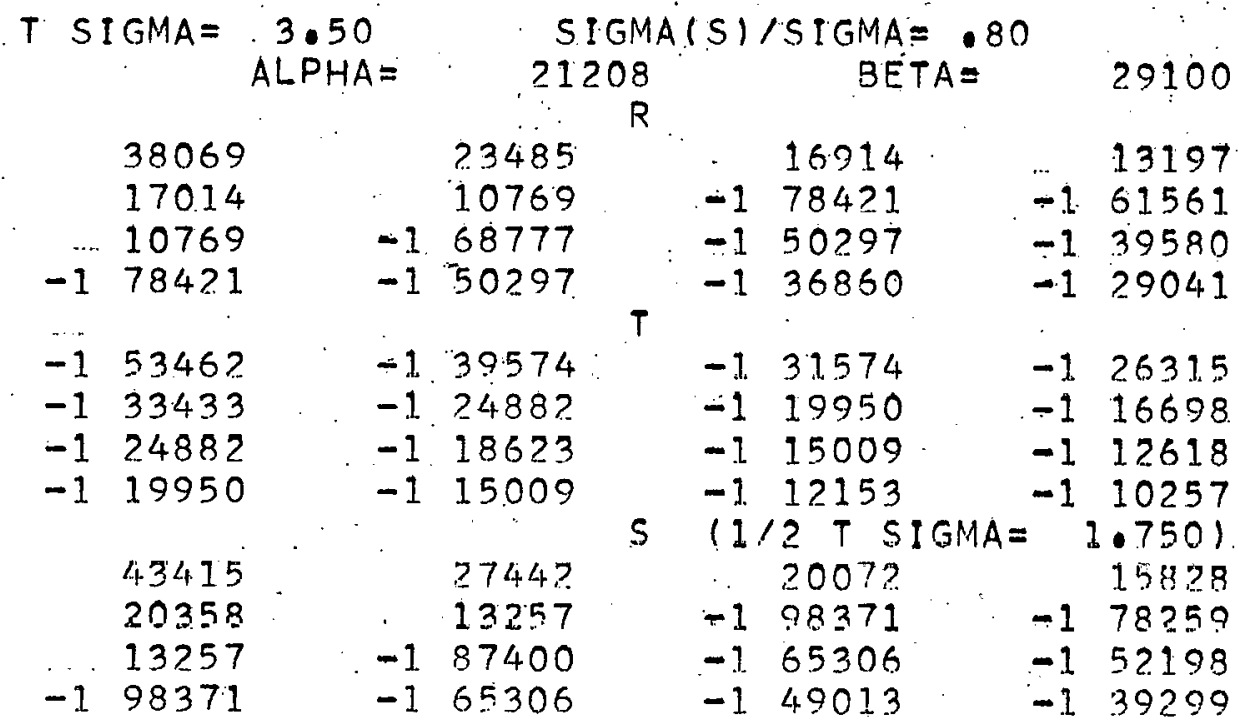

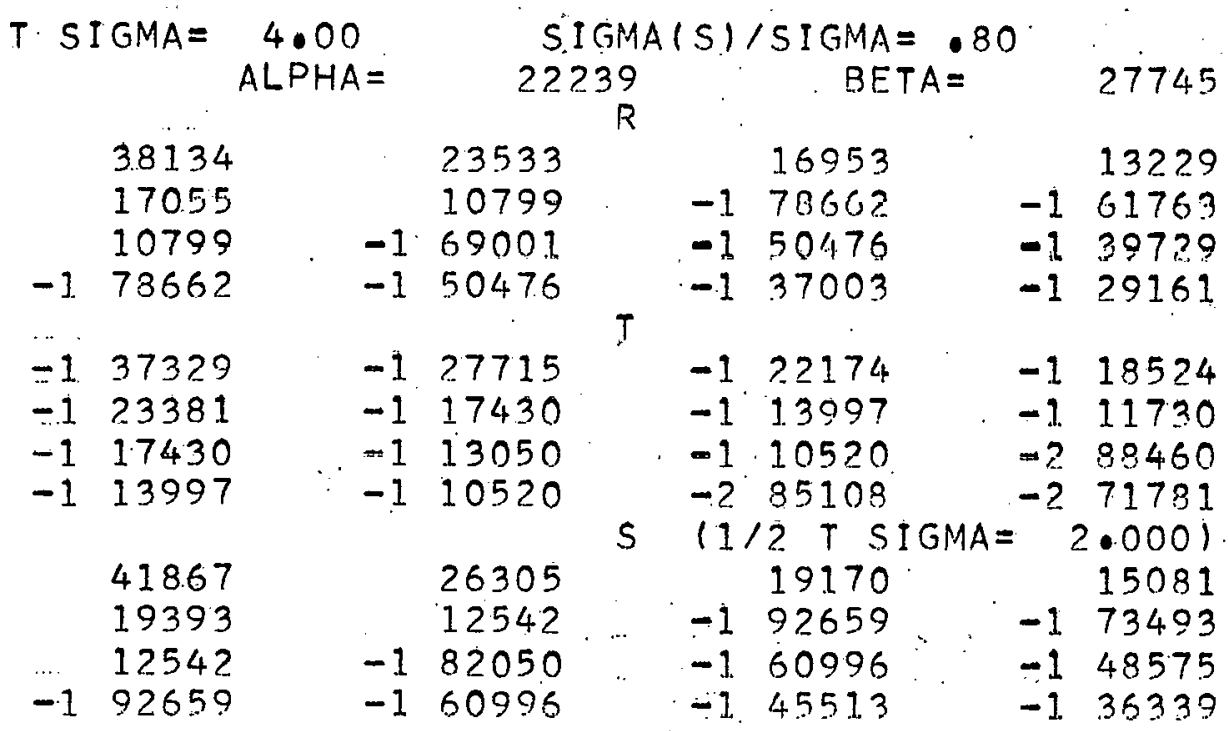




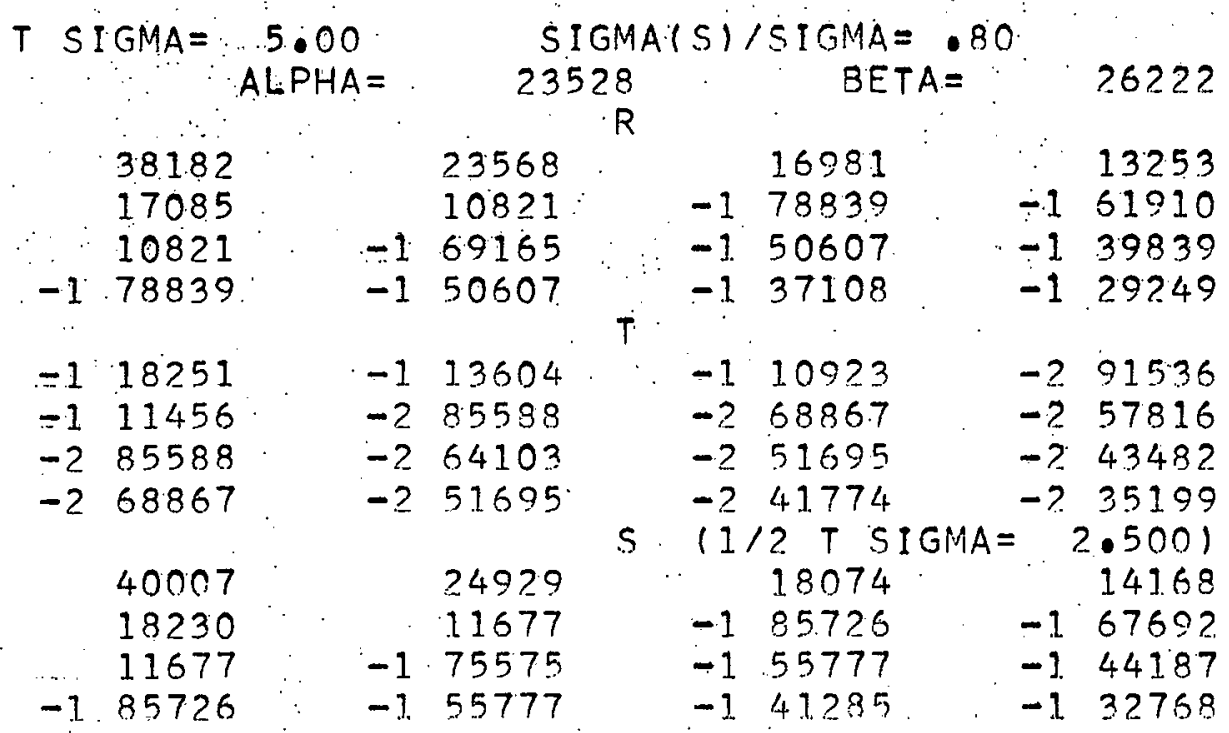

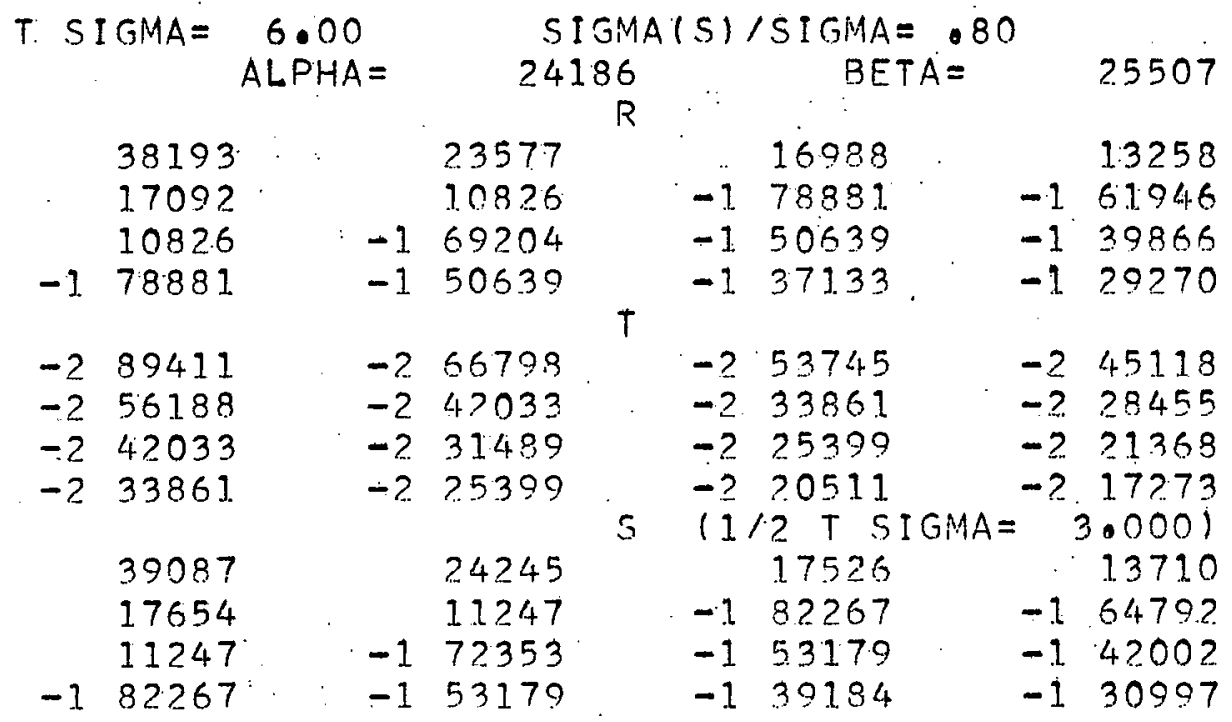

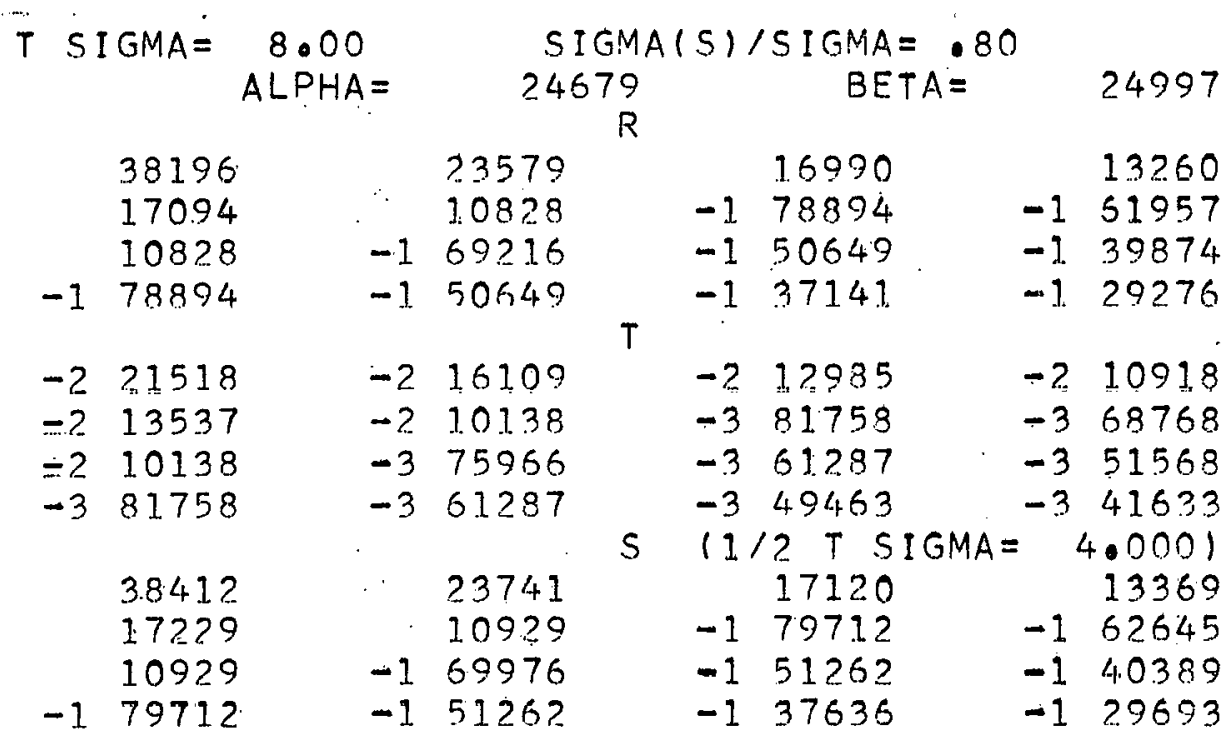




\section{WAPD-TM-168}

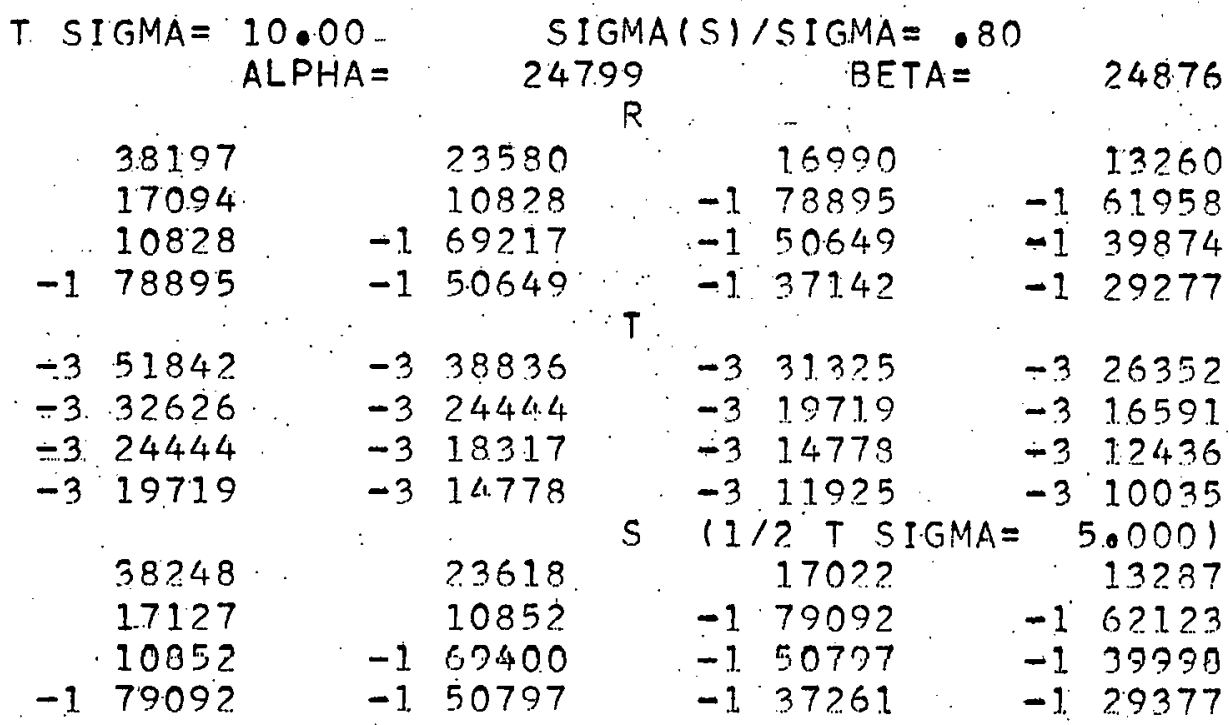

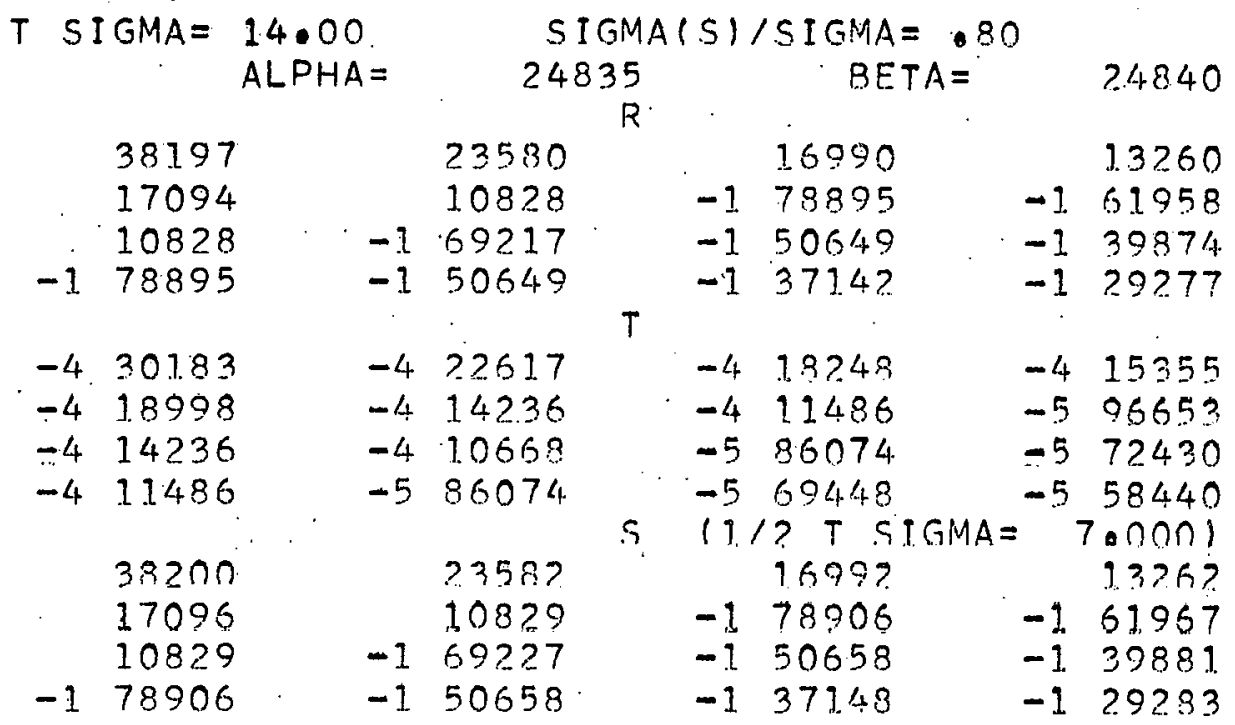

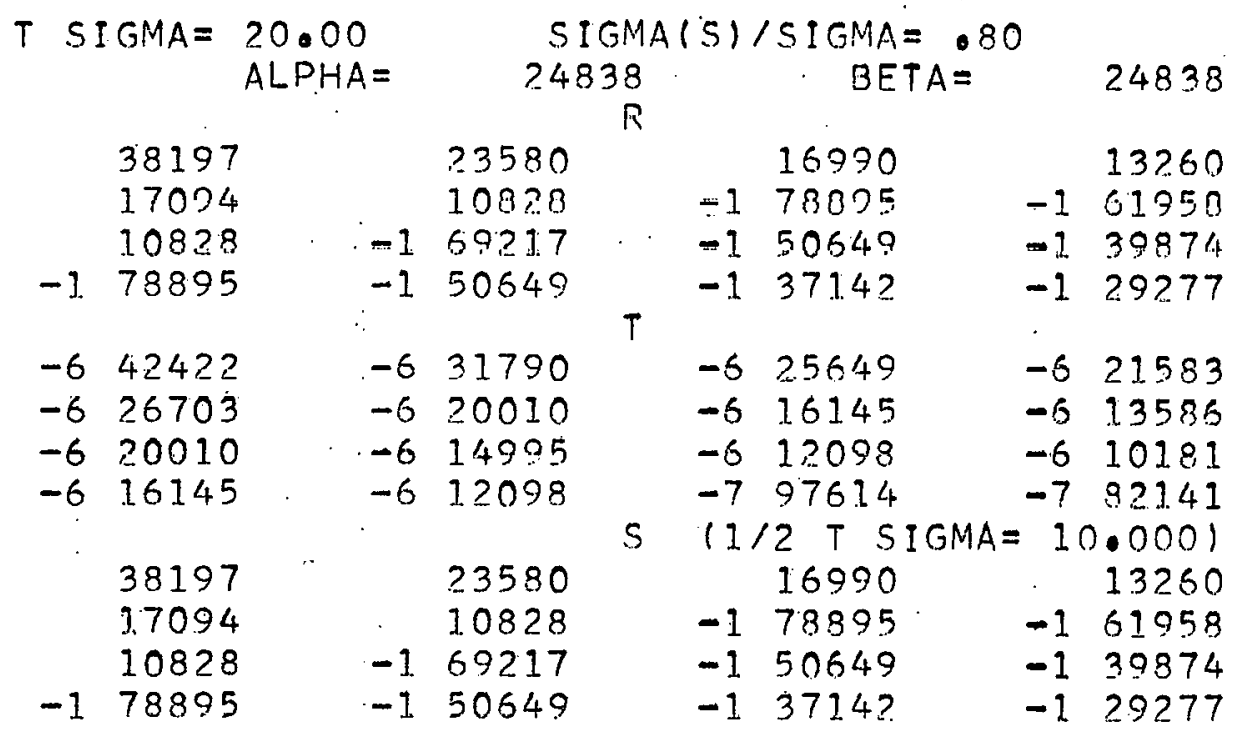




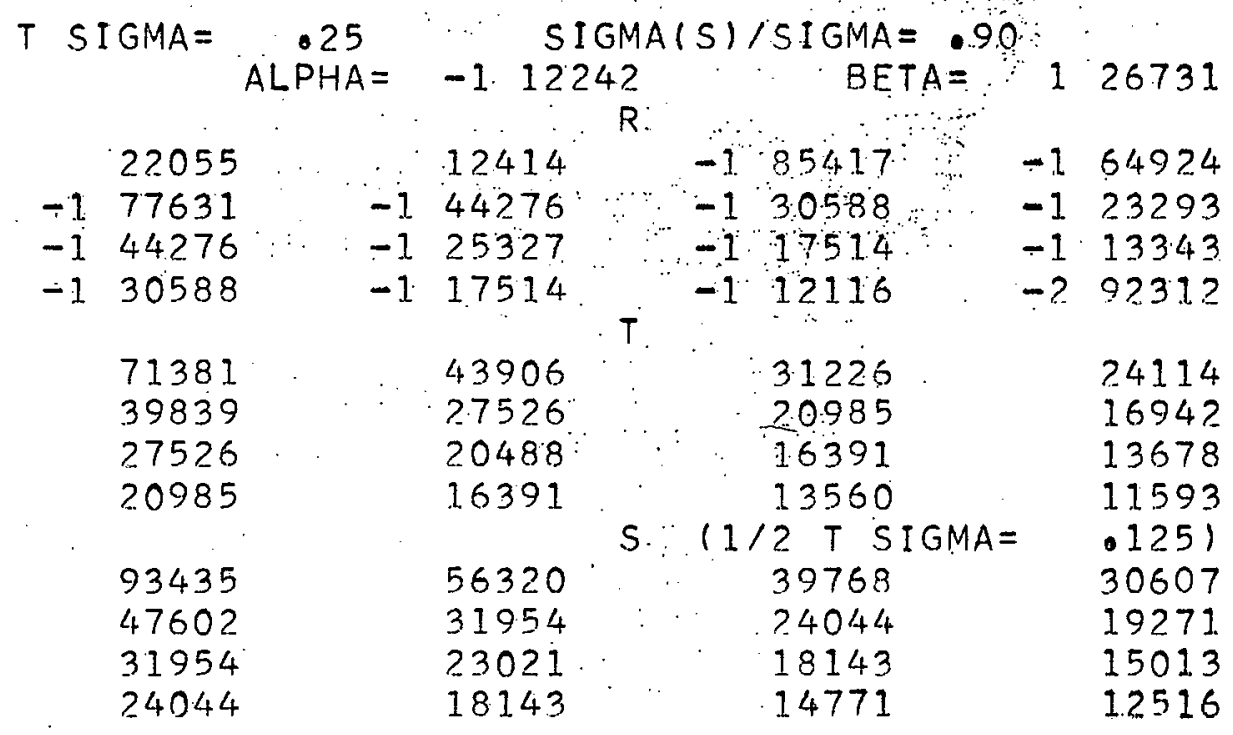

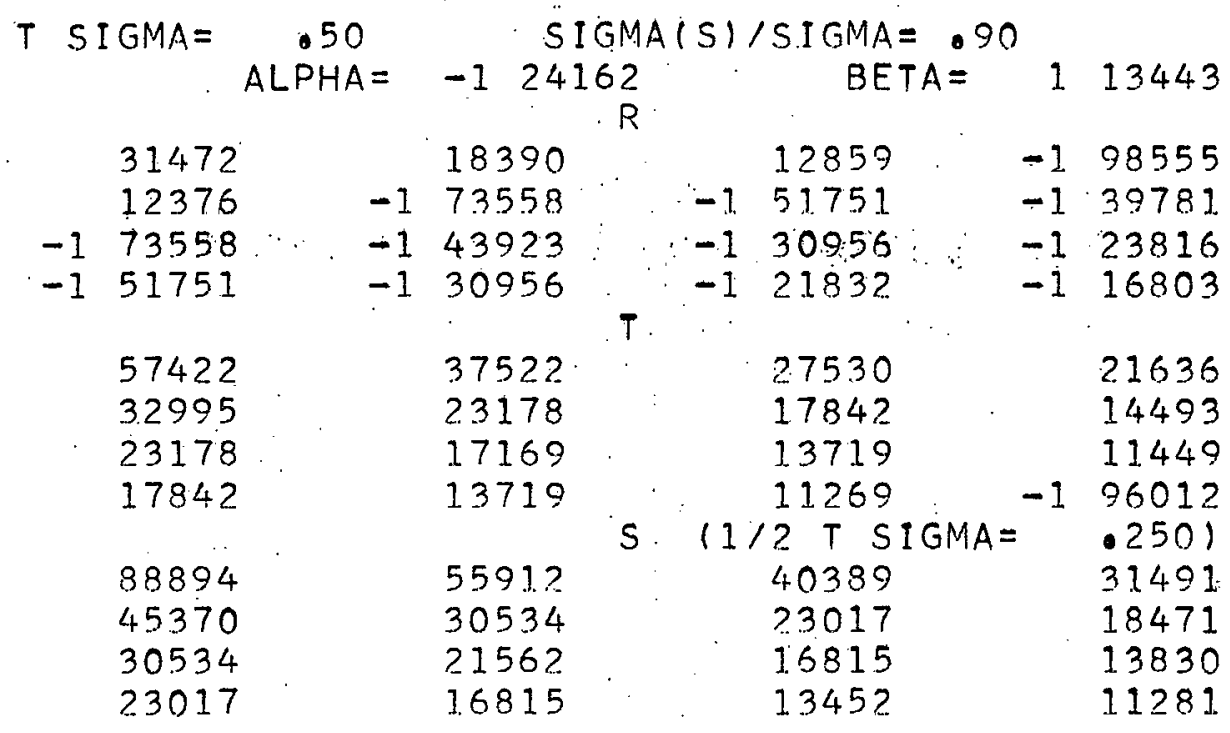

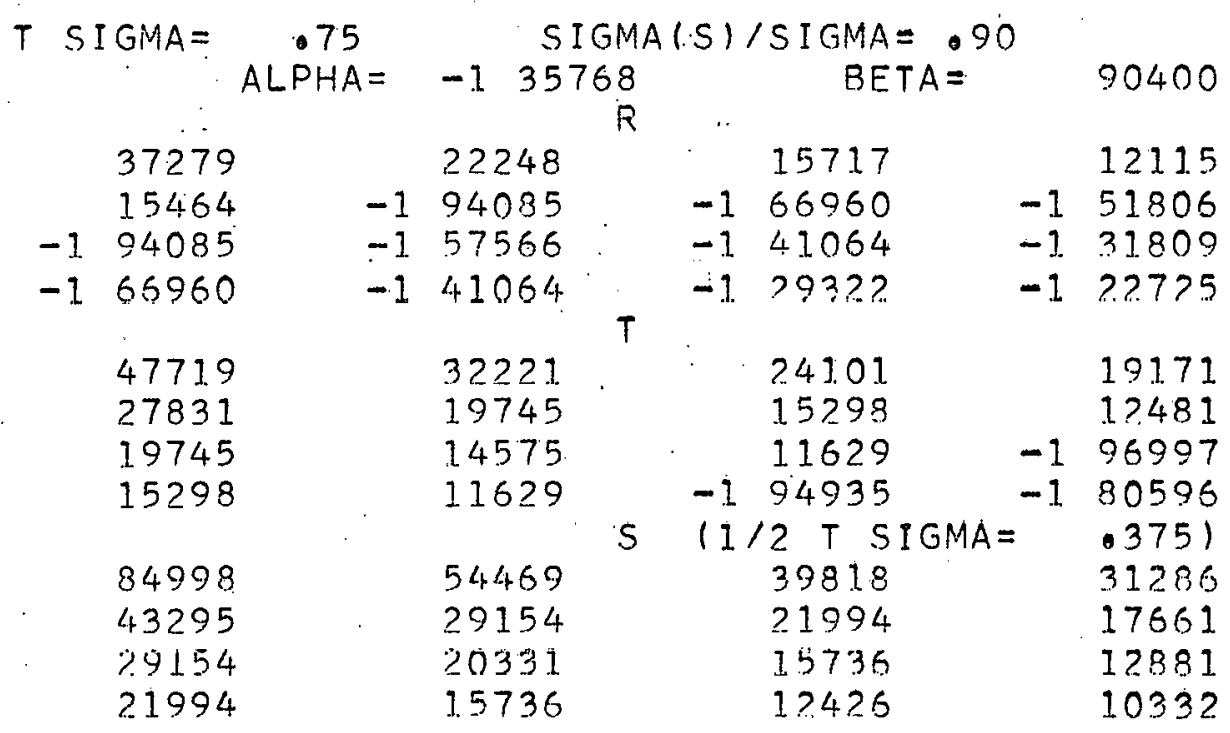


WAPD $-T M-168$

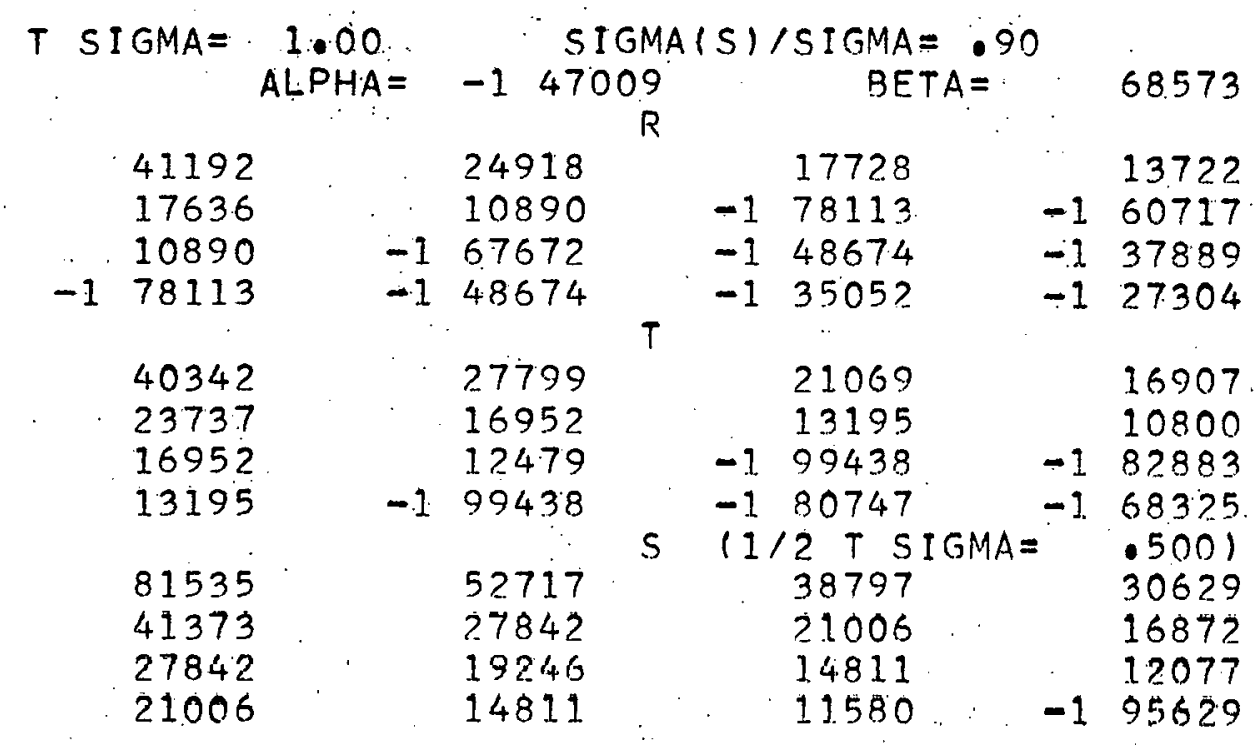

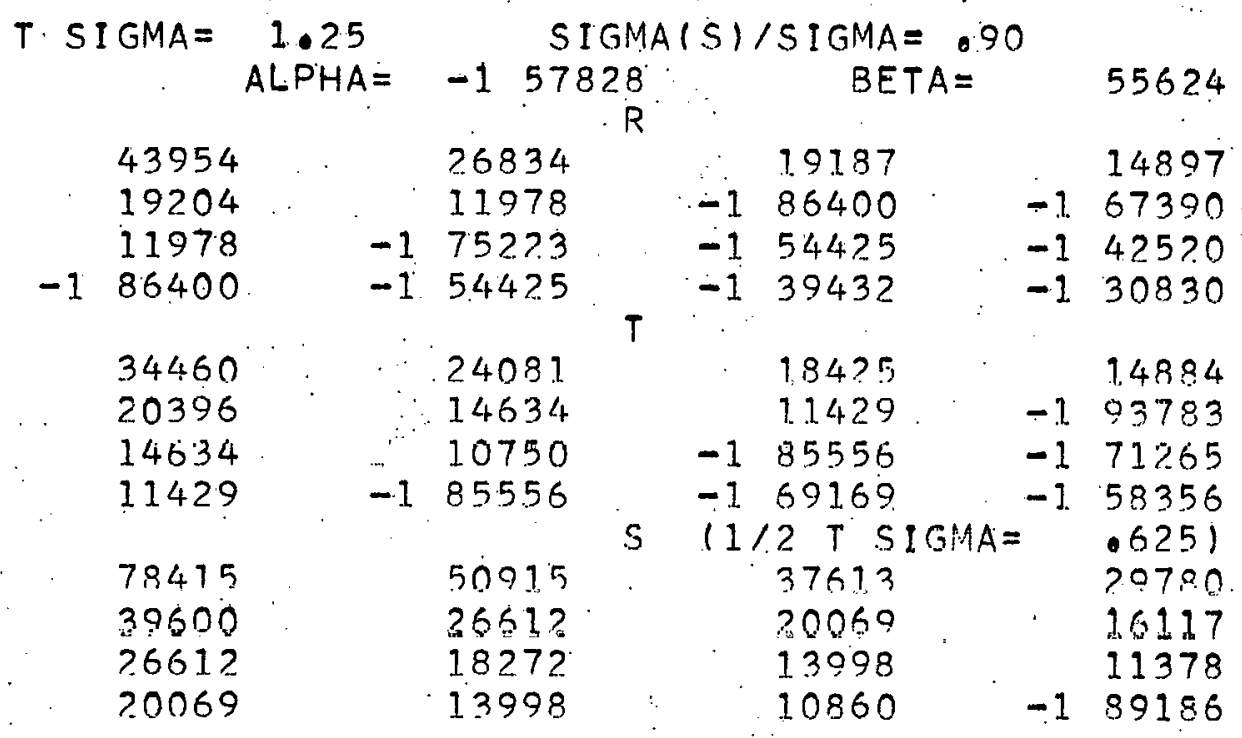

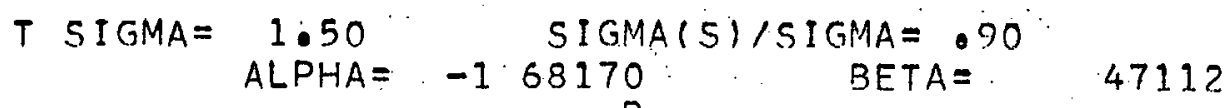
459512020264.15768 $20357 \quad 12787 \quad-122615 \quad-172423$ $12787 \quad-1$ Sก9ก6: $-158789, \quad-146054$

$\begin{array}{lllllll}-1 & 92615 & -1 & 58789 & 42783 & -1 & 33543\end{array}$

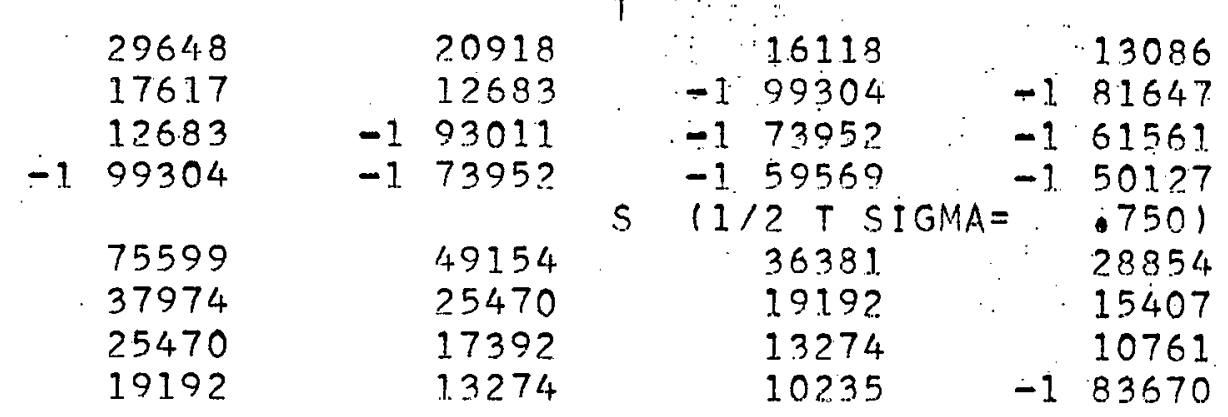




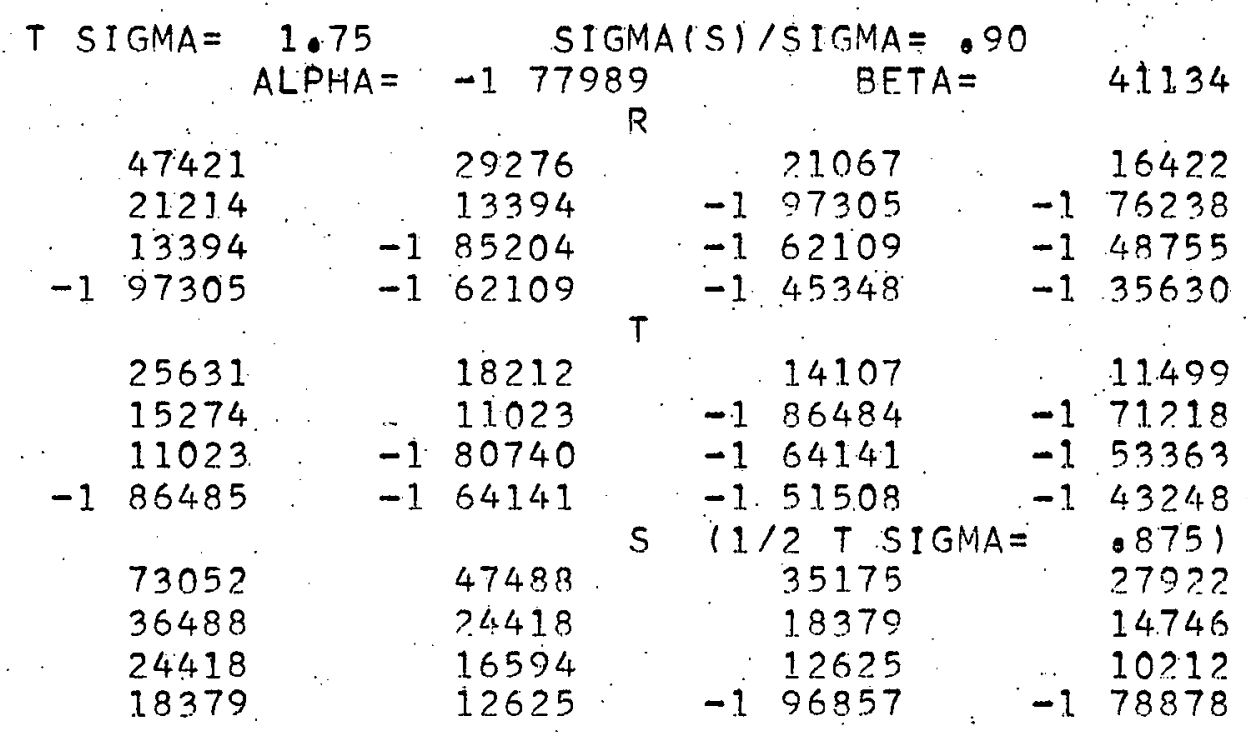

\begin{tabular}{|c|c|c|c|c|c|c|c|c|}
\hline \multicolumn{2}{|c|}{ SI GMA = } & \multirow{2}{*}{$\begin{array}{l}2.00 \\
\text { ALPHA }=\end{array}$} & \multicolumn{6}{|c|}{ SIGMA (S) /SIGMA $=.90$} \\
\hline$T$ & & & $-1 \quad 872$ & $\begin{array}{r}48 \\
R\end{array}$ & & $B E T A=$ & & 36737 \\
\hline & 4851.5 & & 30056 & & & 2.1673 & & 16916 \\
\hline & 2.1857 & & 13853 & & & 90086 & -1 & 79141 \\
\hline & 13853 & -1 & 88468 & & -1 & 64643 & -1 & 50823 \\
\hline & 10086 & -1 & 64643 & & -1 & 47315 & -1 & 372.36 \\
\hline & & & & $\mathrm{T}$ & & & & \\
\hline & $\begin{array}{l}22236 \\
13279\end{array}$ & -1 & $\begin{array}{l}1.5883 \\
96018\end{array}$ & . & -1 & $\begin{array}{l}1.2354 \\
75459\end{array}$ & -1 & $\begin{array}{l}101.02 \\
62209\end{array}$ \\
\hline-1 & 96018 & -1 & 70259 & & -1 & 55774 & -1 & 46.380 \\
\hline-1 & 7.5451 & -1 & 55774 & & -1 & 44677 & -1 & 37441 \\
\hline & & & & $S$ & 111 & $12 T$ SIGMA $=$ & & 1.0001 \\
\hline & 70 & & 45939 & & & $340 ? 77$ & & 27019 \\
\hline & 35136 & & 23454 & & & 17631 & & 14135 \\
\hline & 23454 & & 15873 & & & 12042 & -1 & 97203 \\
\hline & 17631 & & 12042 & & -1 & $9199 ?$ & -1 & 74677 \\
\hline
\end{tabular}

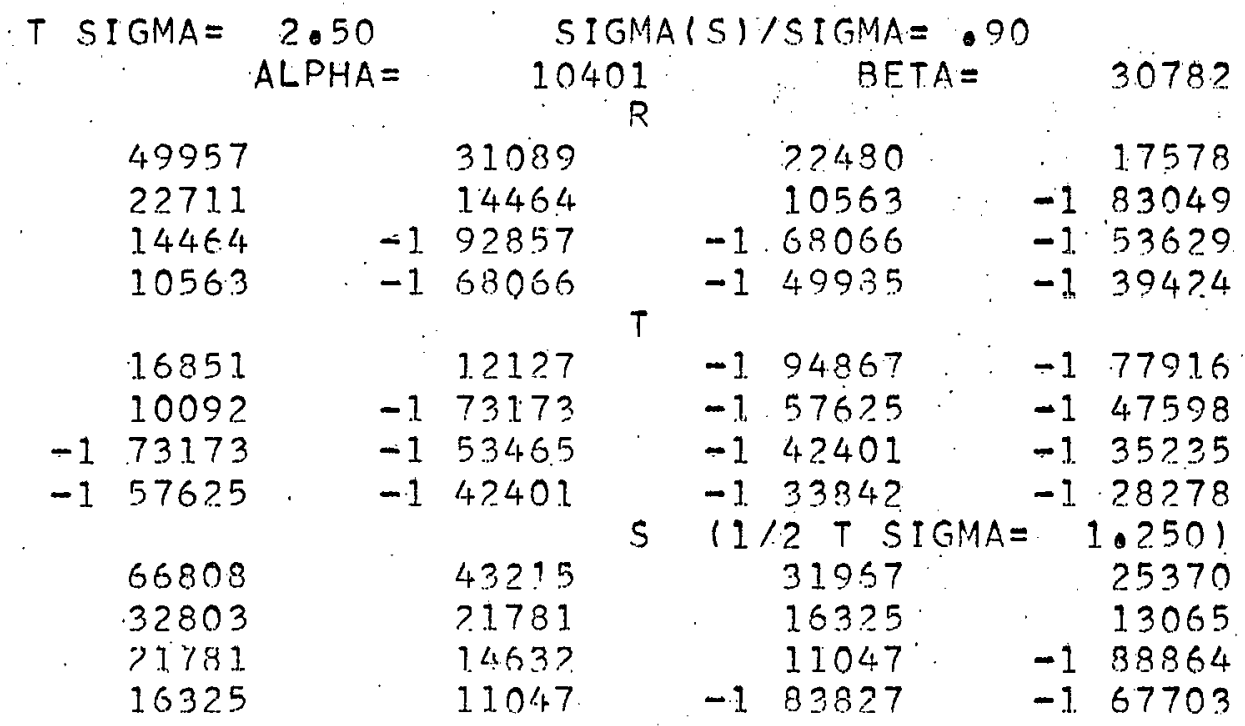




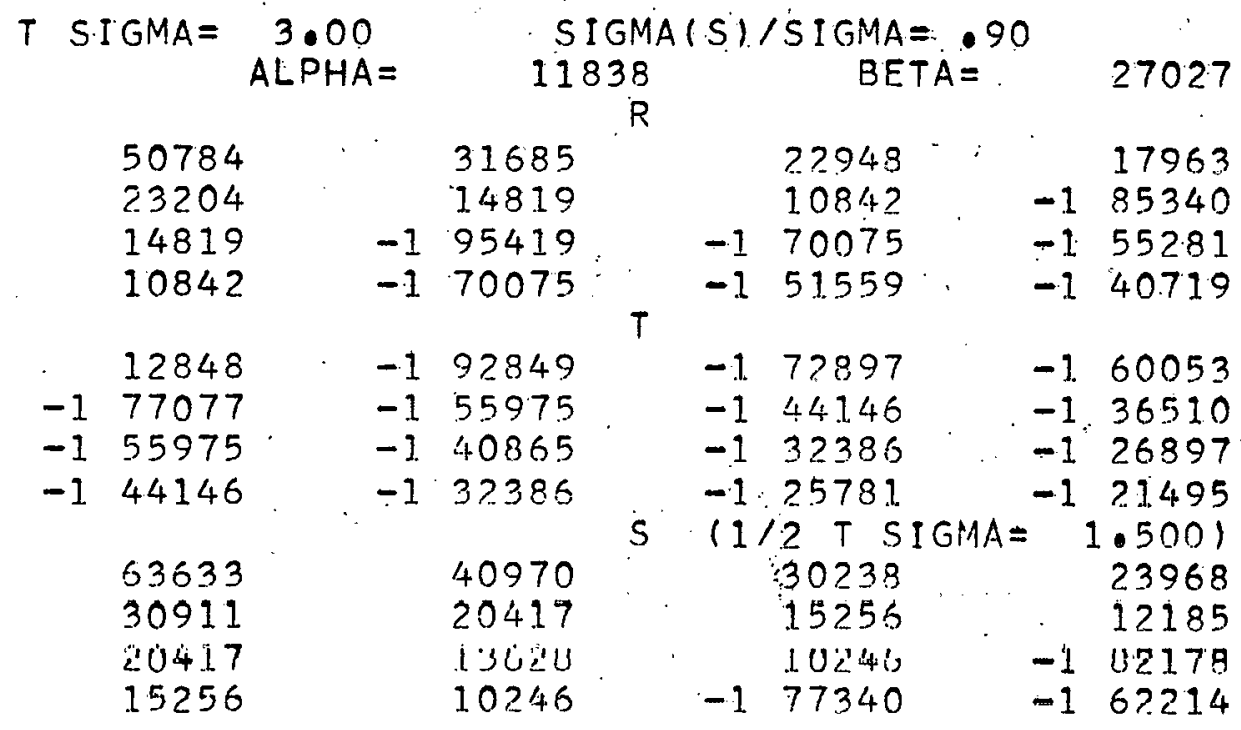

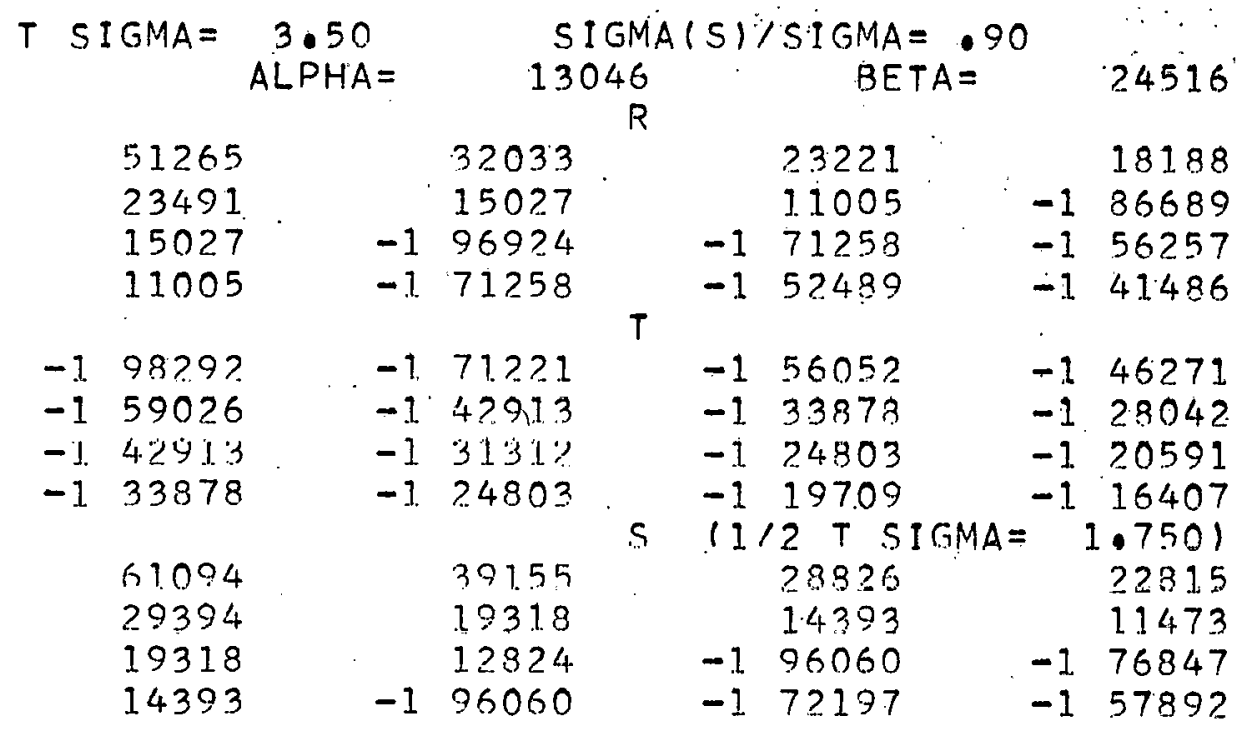

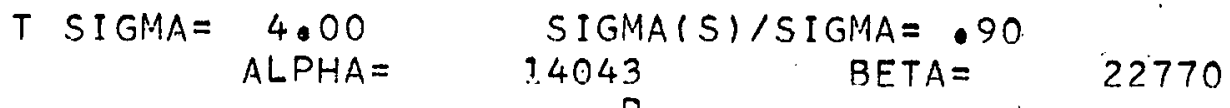

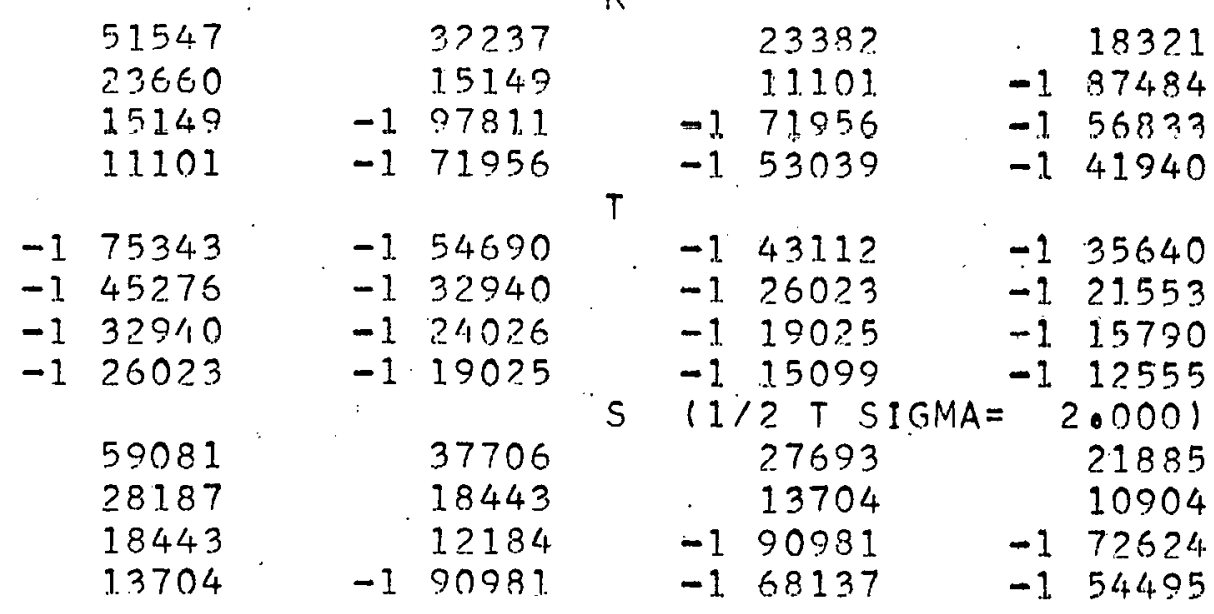

82 
WAPOD-TM-168

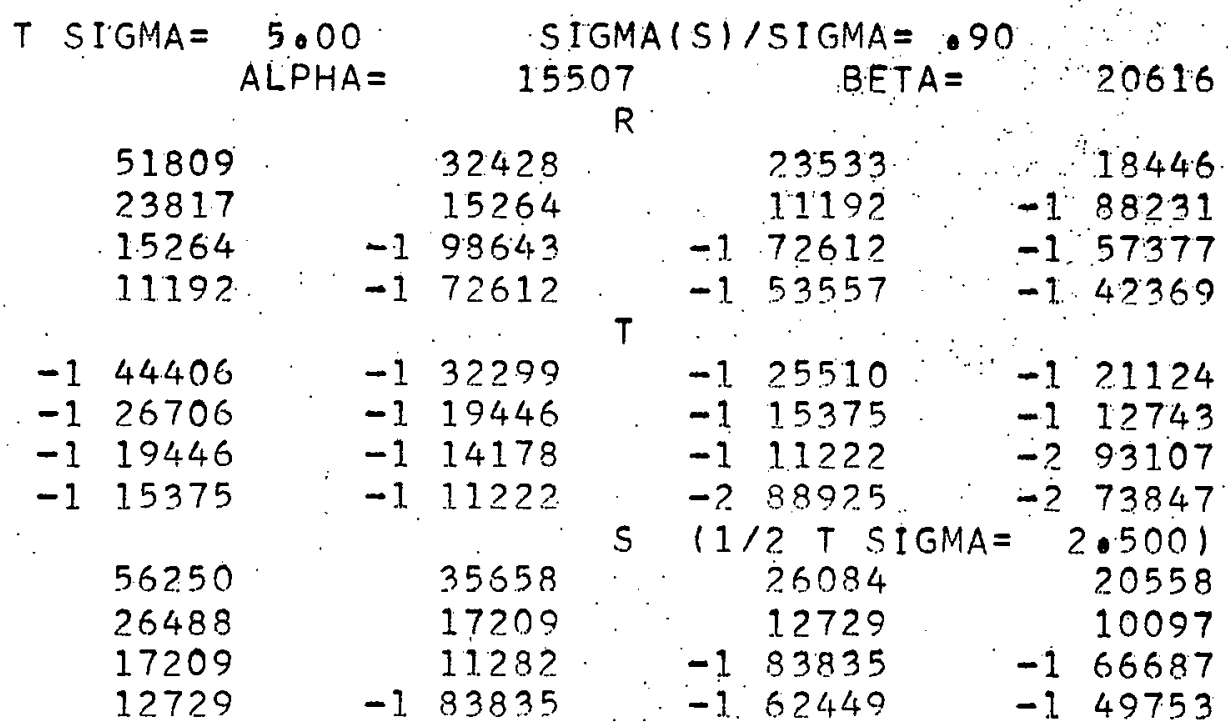

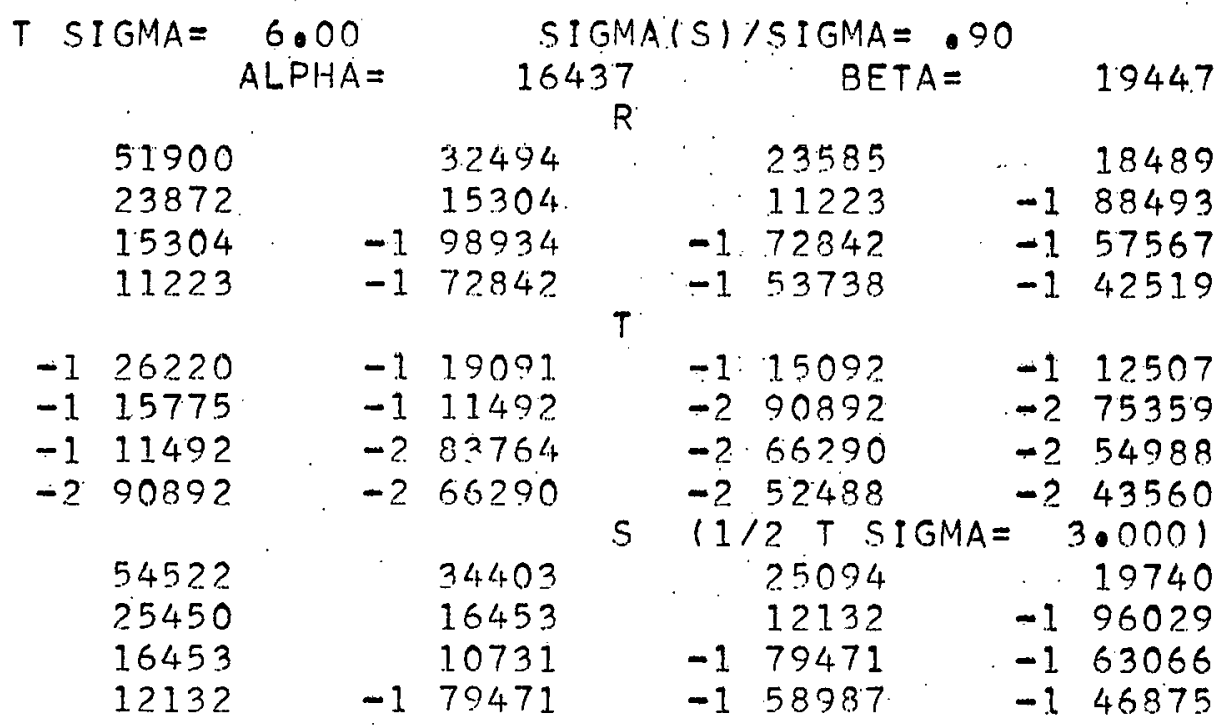

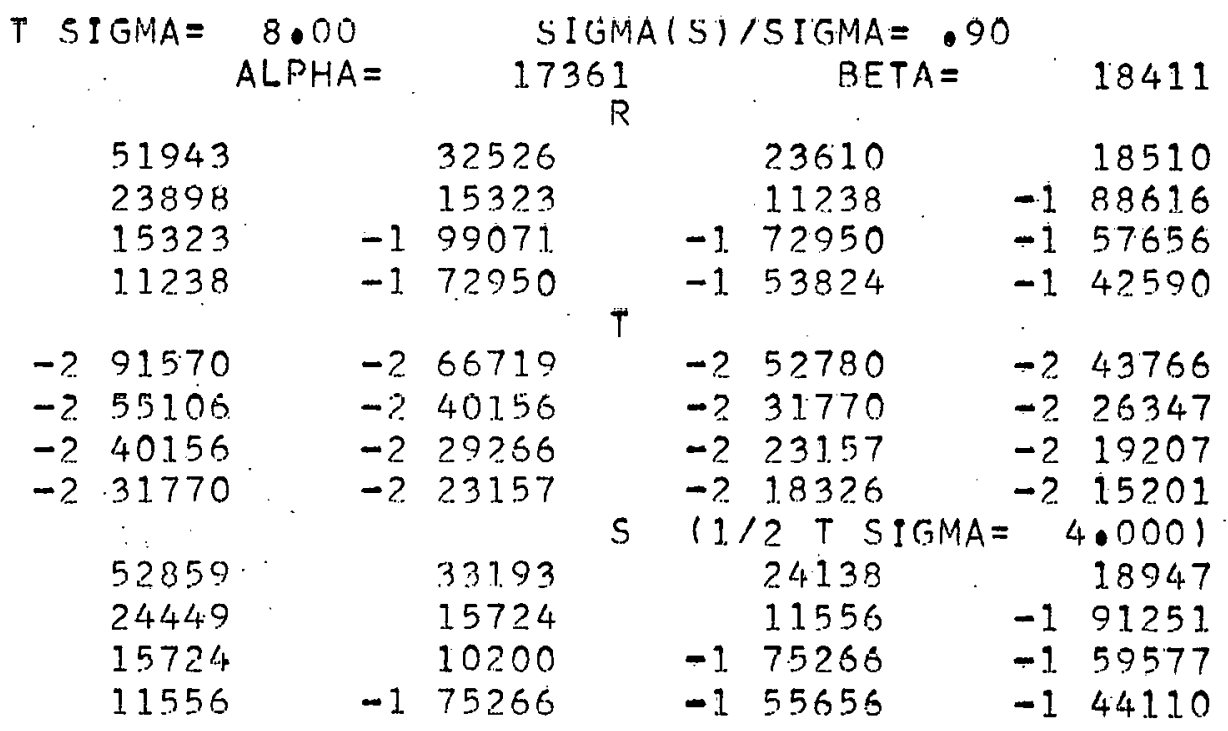




\section{WAPD-TM-168}

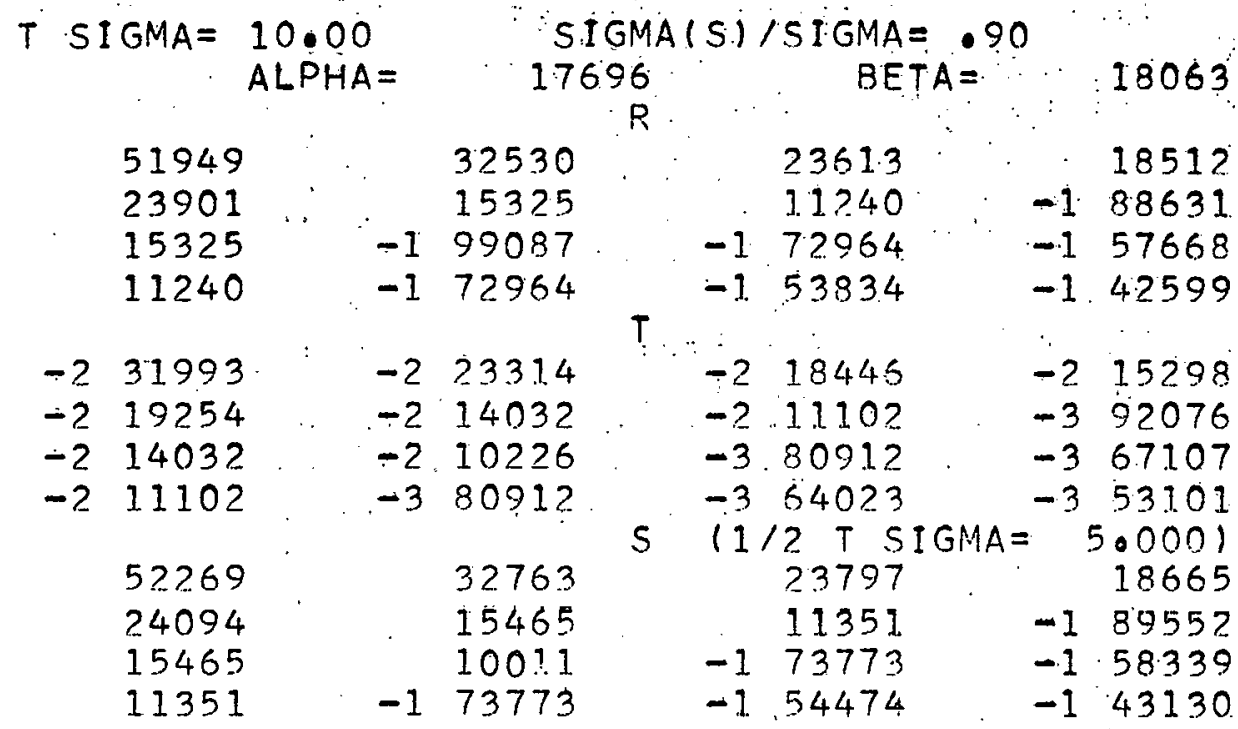

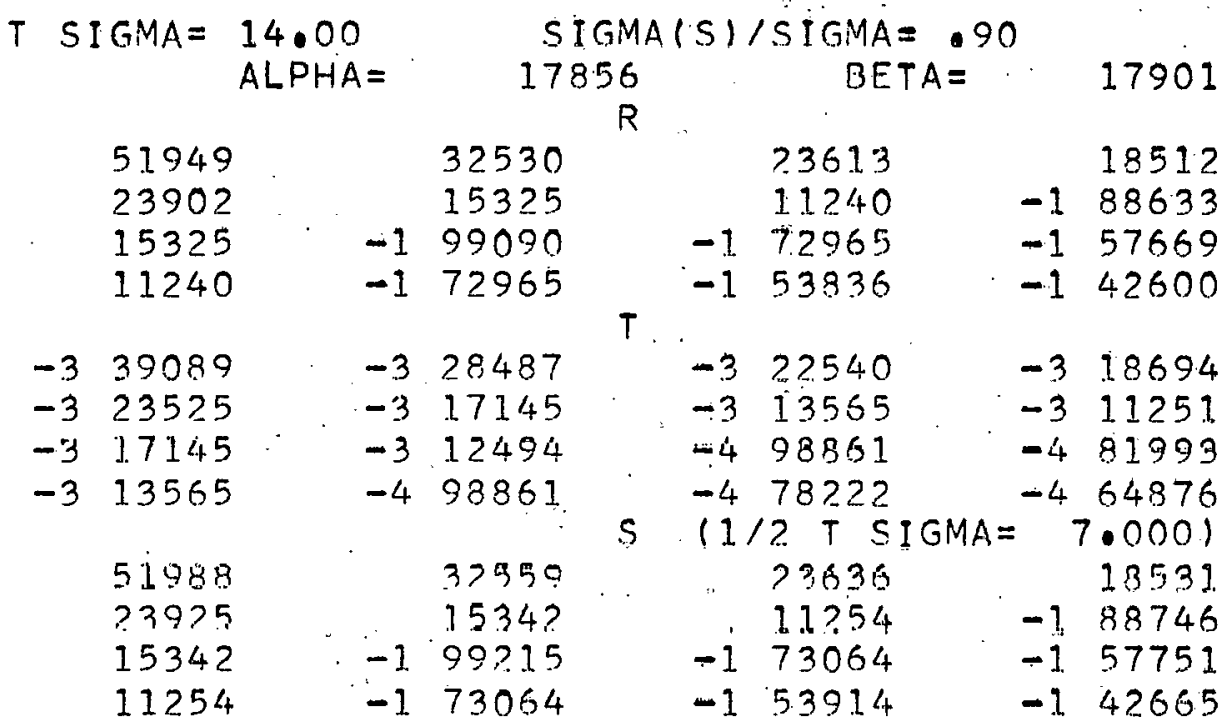

\begin{tabular}{|c|c|c|c|c|c|c|c|c|}
\hline $\mathrm{S}$ & GMA $=$ & 20.00 & & GMA & $(5)$ & $151 G M A=.90$ & & \\
\hline & & ALPHA $=$ & & $\begin{array}{r}78 \\
\text { 月 }\end{array}$ & & $B E T A=$ & & 17880 \\
\hline & 51949 & & 32530 & & & 23613 & & 18512 \\
\hline & 23902 & & 15325 & & & $112 \% 0$ & -1 & 88633 \\
\hline & 15325 & -7 & 99090 & & -1 & 72.965 & -1 & 57669 \\
\hline & 11240 & -1 & 72965 & & -1 & 53836 & -1 & 42600 \\
\hline & & & & $T$ & & & & \\
\hline-4 & $166 ? 5$ & - & 12167 & & -5 & 96267 & -5 & 79842 \\
\hline-4 & 10048 & -5 & $732 ? .4$ & & -5 & 57938 & -5 & 48052 \\
\hline$\cdots 5$ & 73224 & -5 & 53364 & & -5 & 42223 & -5 & 35019 \\
\hline-5 & 57938 & -5 & 42223 & & -5 & 33409 & -5 & 27708 \\
\hline & & & & $S$ & 11 & $12 T$ SIGMA $=$ & $=10$ & 0.0001 \\
\hline & 51951 & & 32531 & & & 23614 & & 18523 \\
\hline & 23903 & & 15326 & & & 11241 & -1 & 8863 \\
\hline & 15326 & - & 99095 & & -1 & 72970 & -1 & 57673 \\
\hline & 1.1241 & - & 72970 & & -1 & 5.3839 & -1 & 42603 \\
\hline
\end{tabular}




\section{WAPD-TM-168}

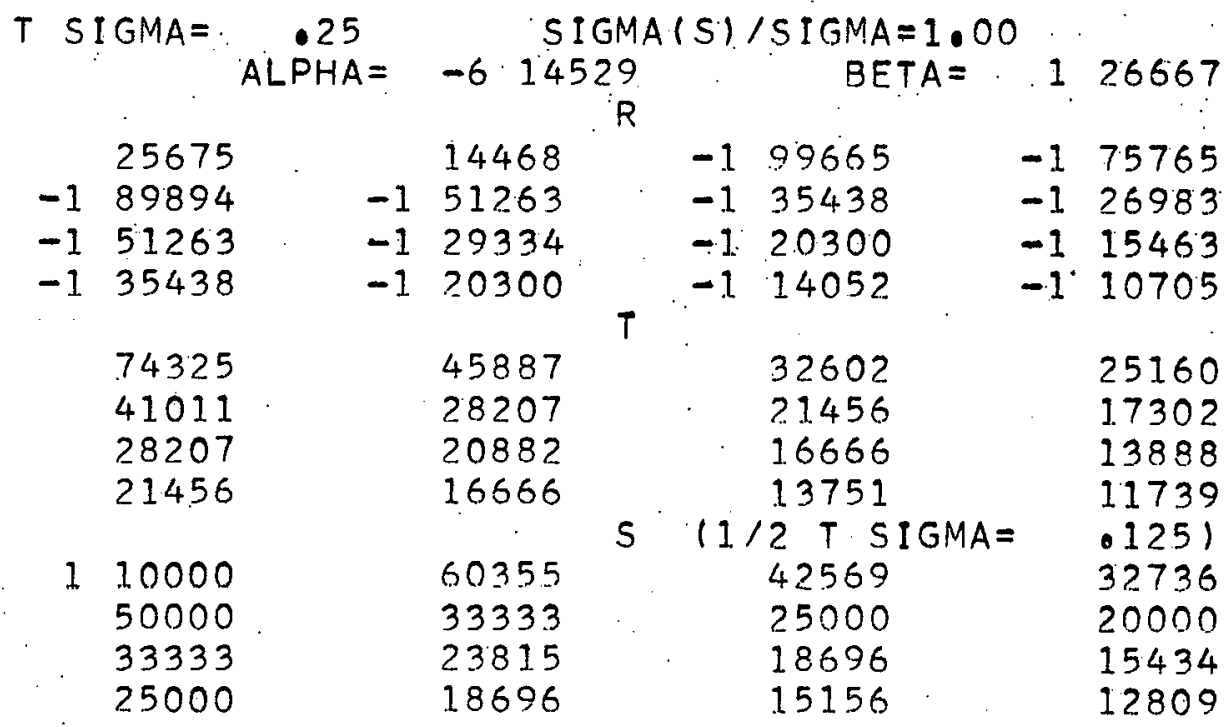

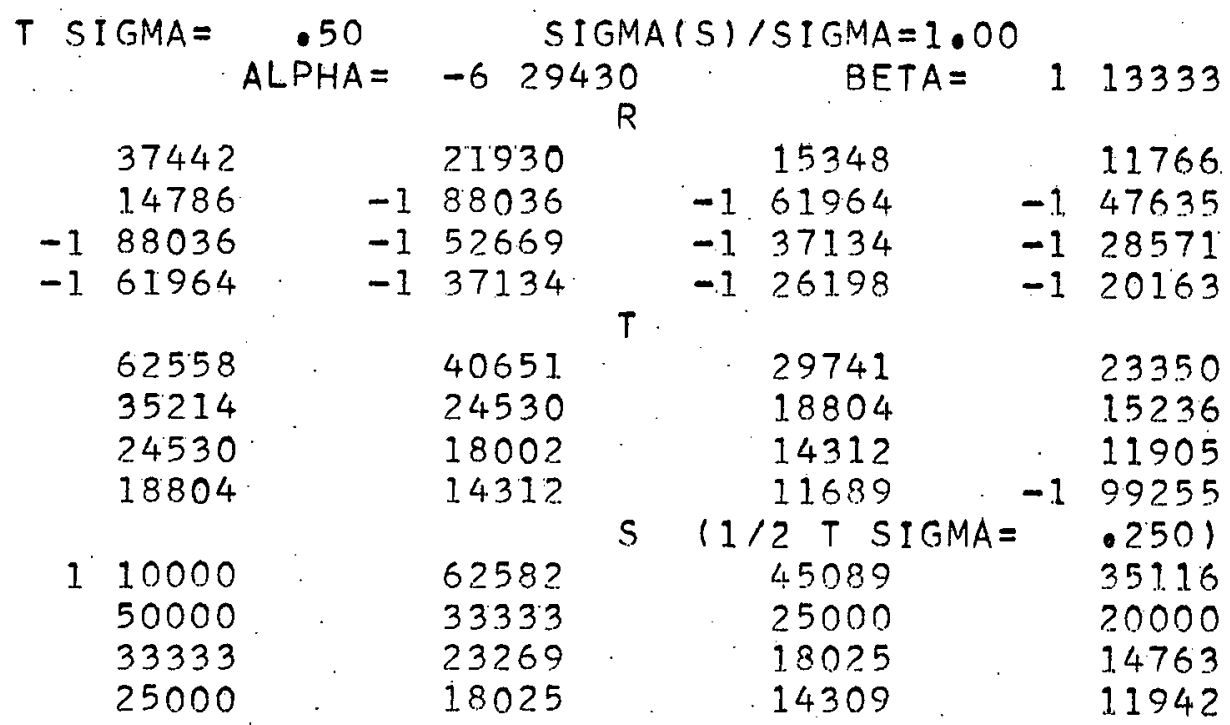

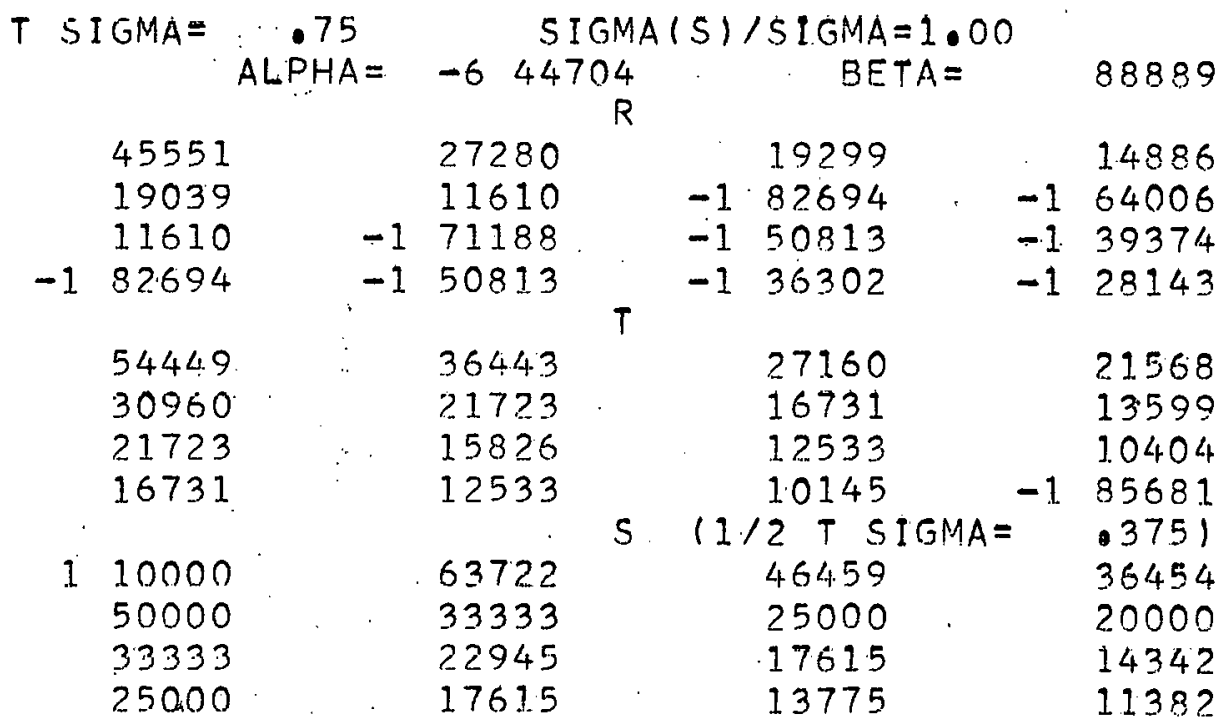




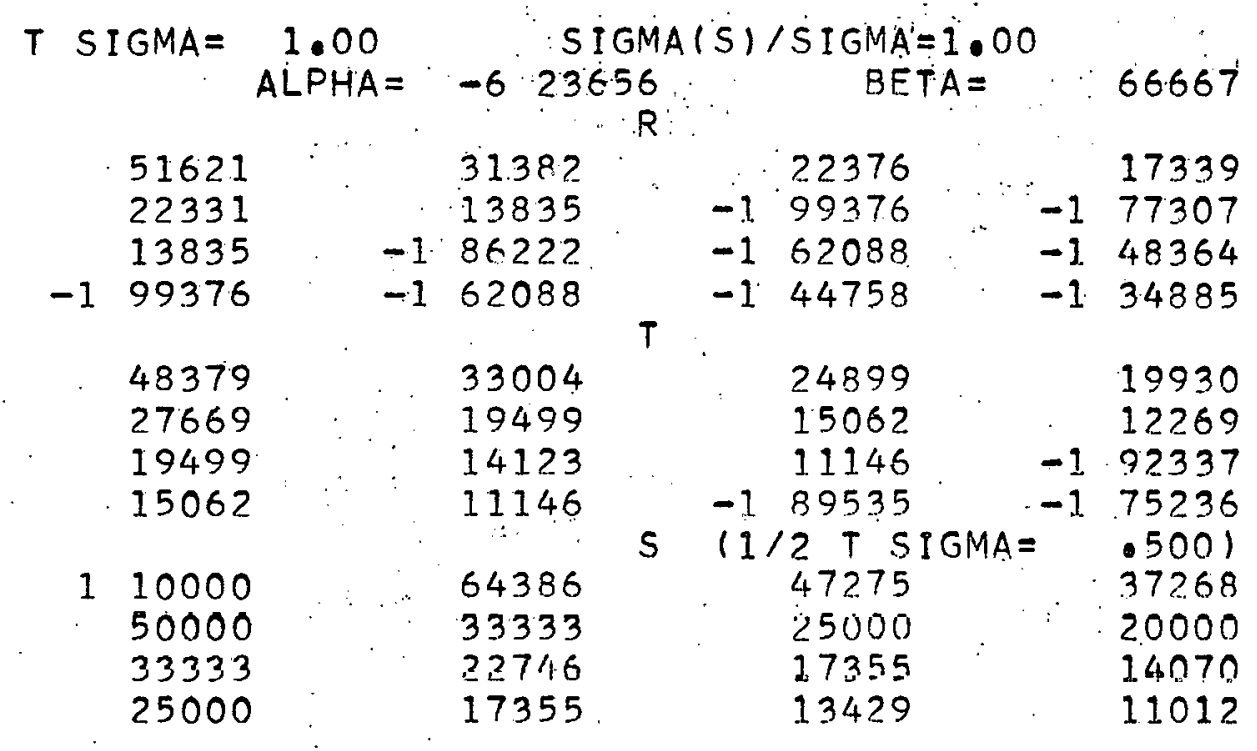

T SIGMA $=1.25 \quad \because \quad$ SIGMAIS) $/$ SIGMA $=1.00$

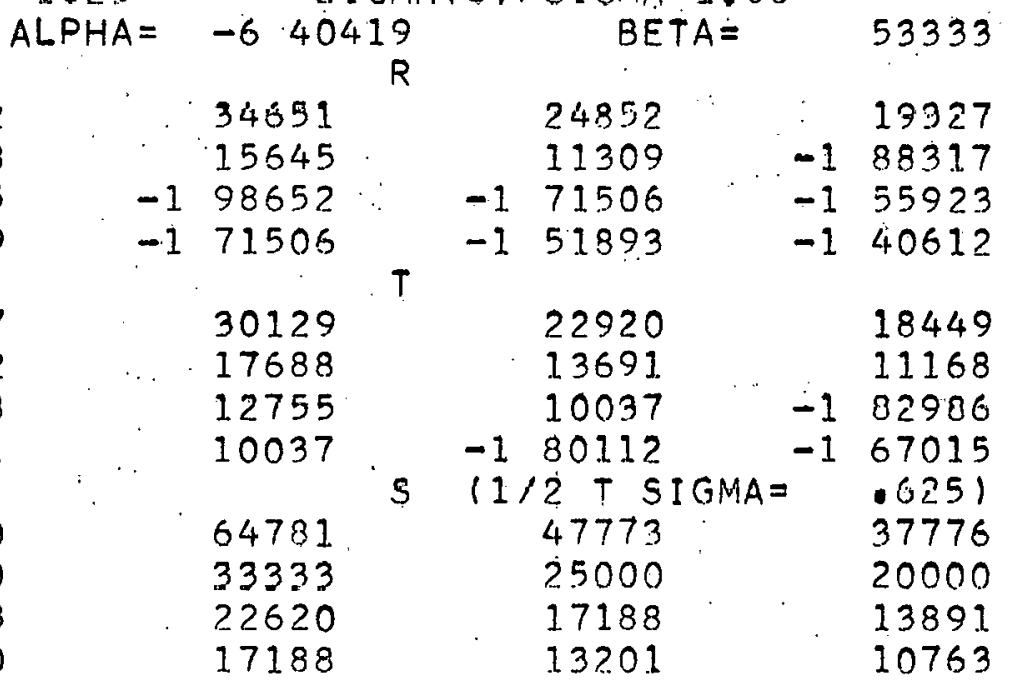

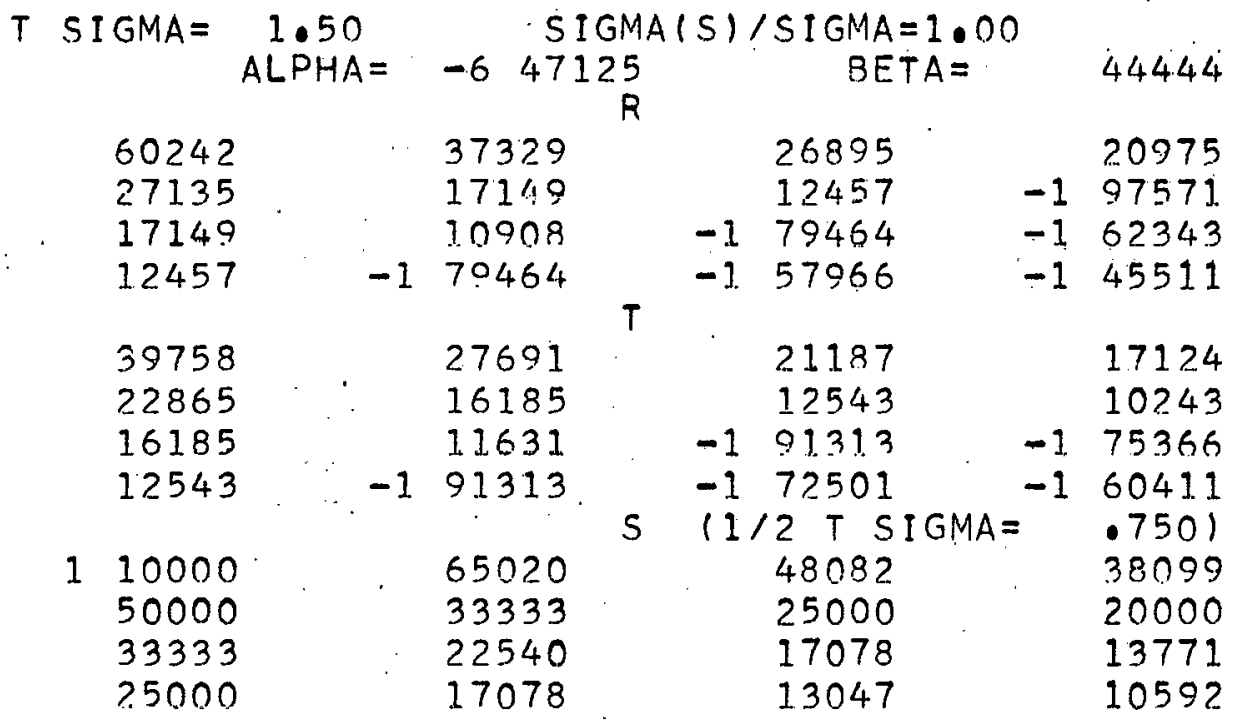

86

$\begin{array}{ll}837 & 088\end{array}$ 


\section{WAPD-TM-168}

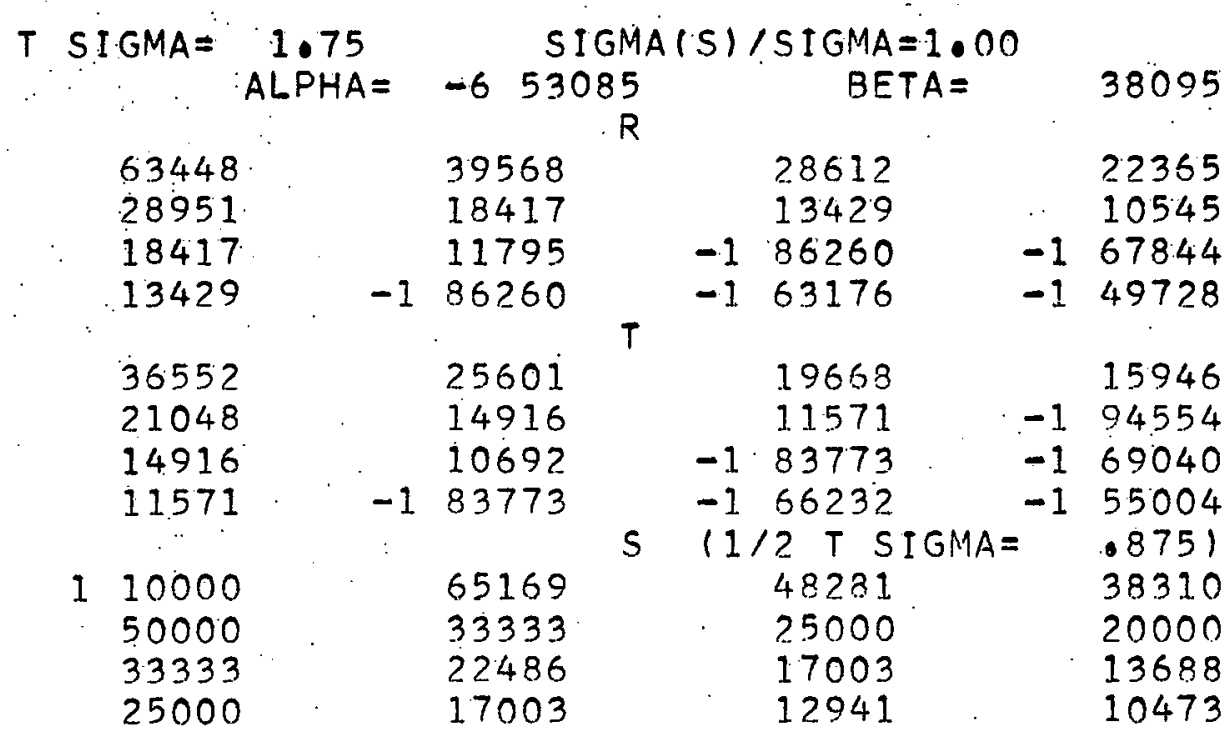

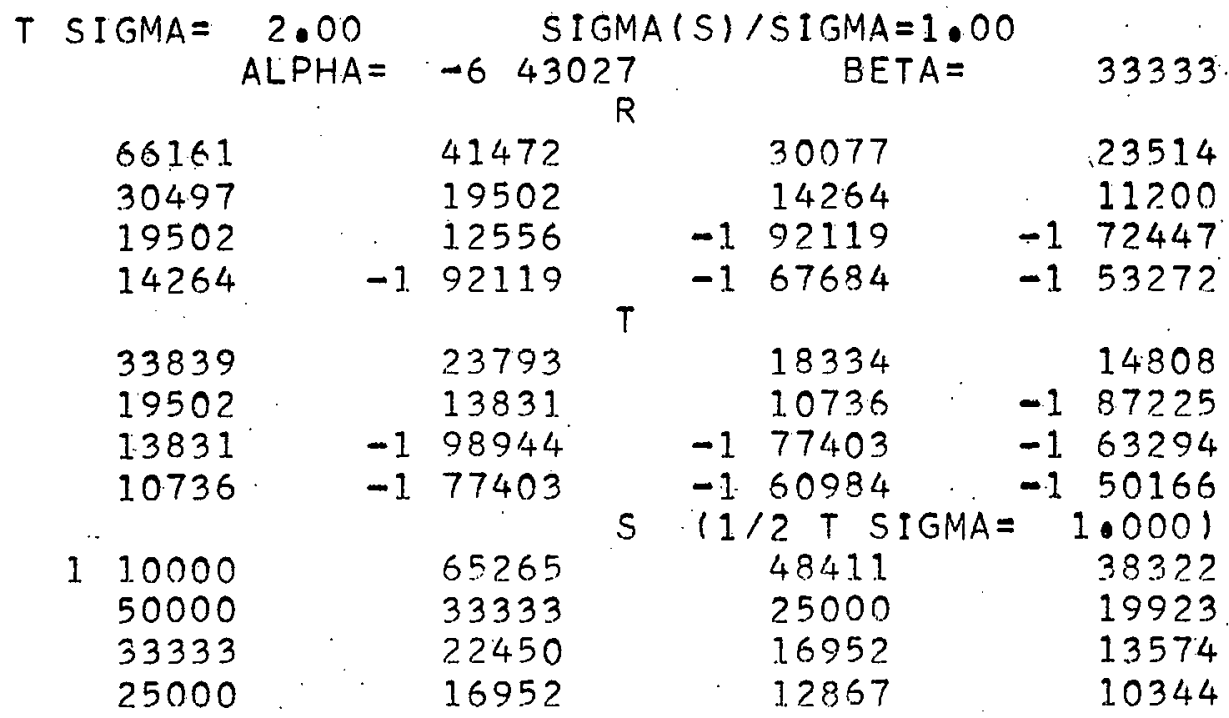

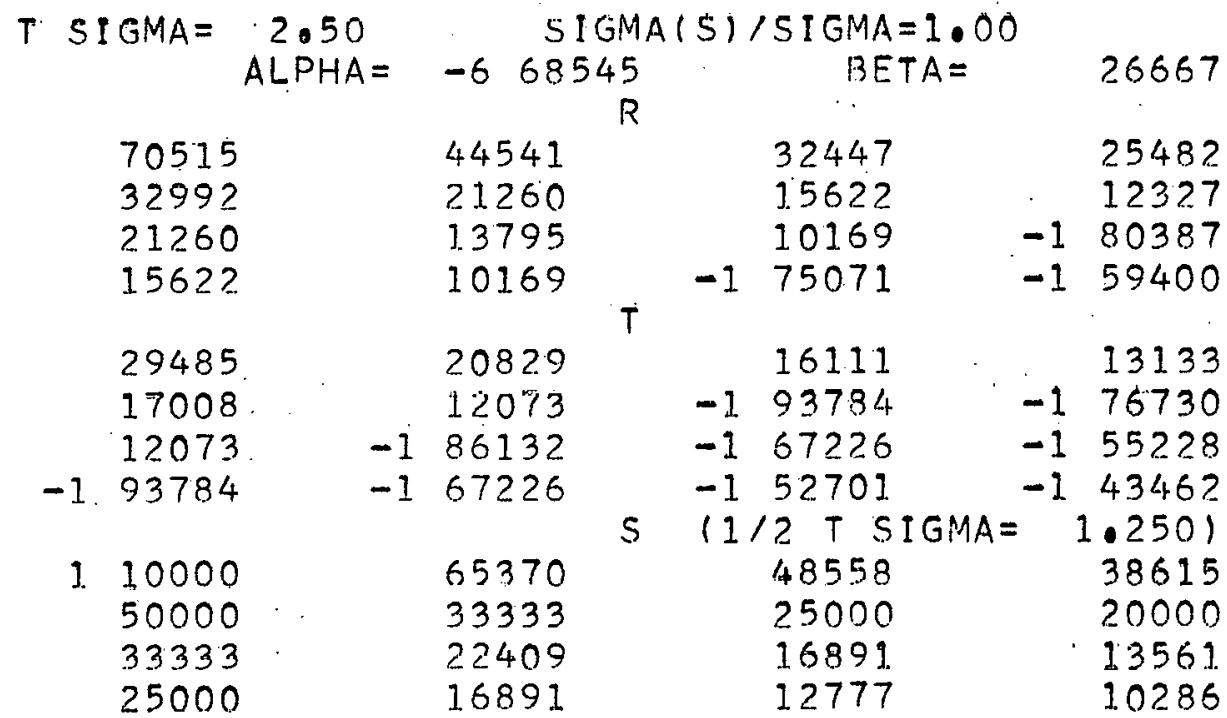




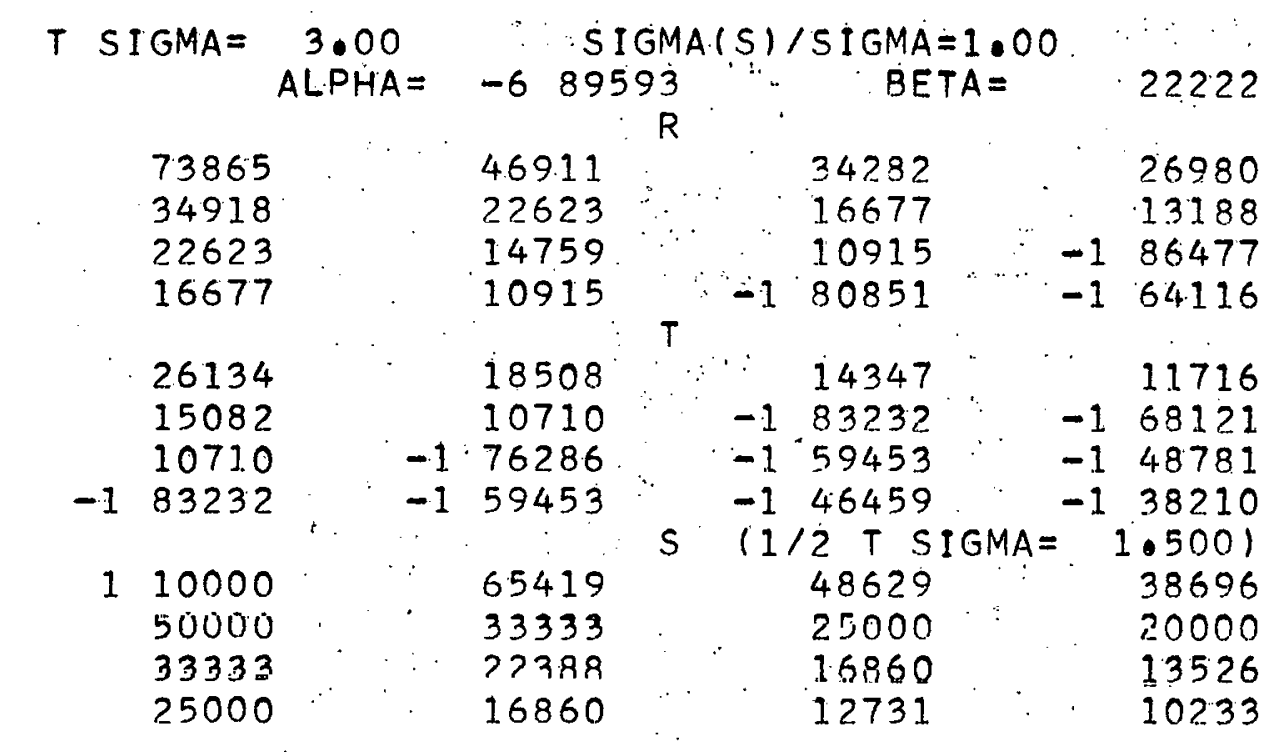

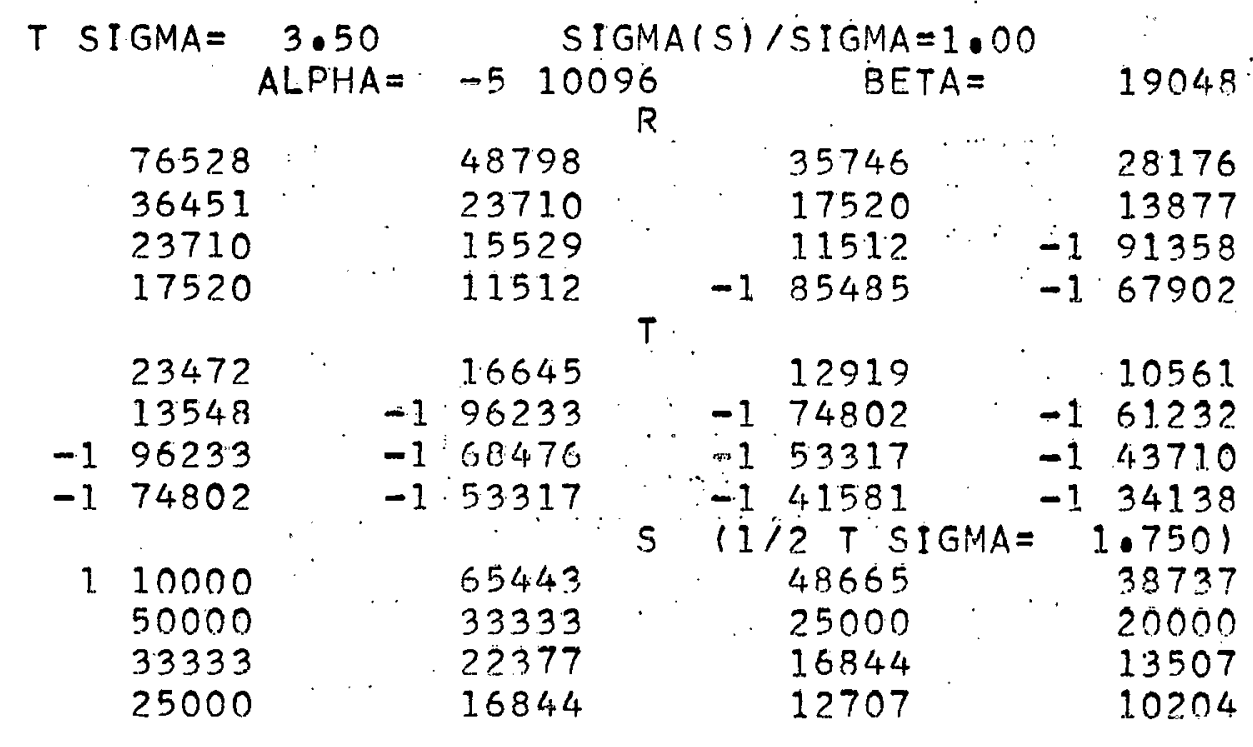

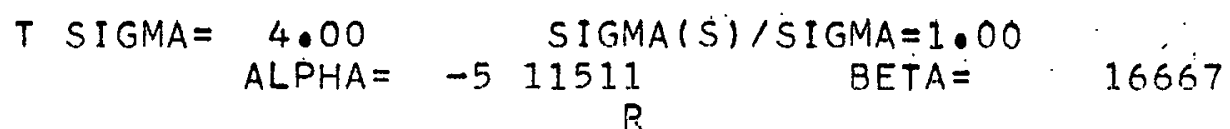

78696

37701

24597

18208

21304

12298

-1 87364

$-167916$

110000 50000 33333 25000
50336

24597

16159

12001

15120

-1. 87364

$\begin{array}{ll}-1 & 62127\end{array}$

$-148345$

65456

33333

22371

16836

$$
\text { P. }
$$

36940

18208

12001

$-189278$

14440

-1 95353

$-17.1004$

T

$11743=-196064$

$-167916 \quad-155601$

$\begin{array}{llll}-1 & 48345 & -1 & 39615\end{array}$

$\begin{array}{llll}-1 & 37657 & -1 & 30883\end{array}$

$511 / 2$ T SIGMA $=$ 48683 25000

16836

12694
38759

20000

13497

10189 
Table III

U

Normalized to a Unit Source Per Unit of Optical Thickness

\begin{tabular}{|c|c|c|c|c|c|c|c|c|c|c|}
\hline$\Sigma / \Sigma$ & 0 & 0.1 & 0.2 & 0.3 & 0.4 & 0.5 & 0.6 & 0.7 & 0.8 & 0.9 \\
\hline$\Sigma$ & $i$ & & & & & & & & . & \\
\hline 0.25 & 0.2411 & 0.2481 & 0.2559 & 0.2642 & 0.2730 & 0.2825 & 0.2927 & 0.3036 & 0.3155 & 0.3282 \\
\hline 0.50 & 0.3367 & 0.3520 & 0.3687 & 0.3871 & 0.4075 & 0.4303 & 0.4558 & 0.4847 & 0.5157 & 0.5553 \\
\hline 0.75 & 0.3914 & 0.4131 & 0.4372 & 0.4645 & 0.4956 & 0.5313 & 0.5727 & 0.6215 & 0.6796 & 0.7502 \\
\hline 1.00 & 0.4258 & 0.4521 & 0.4821 & 0.5166 & 0.5567 & 0.6040 & 0.6604 & 0.7290 & 0.8143 & 0.9232 \\
\hline 1.25 & 0.4483 & 0.4783 & 0.5128 & 0.5531 & 0.6007 & 0.6578 & 0.7277 & 0.8152 & 0.9281 & 1.0793 \\
\hline 1.50 & 0.4634 & 0.4962 & 0.5342 & 0.5790 & 0.6326 & 0.6980 & 0.7796 & 0.8844 & 1.0241 & 1.2200 \\
\hline 1.75 & 0.4739 & 0.5086 & 0.5494 & 0.5977 & 0.6562 & 0.7285 & 0.8202 & 0.9406 & 1.1059 & 1.3476 \\
\hline 2.00 & 0.4812 & 0.5175 & 0.5602 & 0.6113 & 0.6737 & 0.7516 & 0.8518 & 0.9858 & 1.1749 & 1.4625 \\
\hline 2.50 & 0.4901 & 0.5283 & 0.5737 & 0.6286 & 0.6964 & 0.7825 & 0.8958 & 1.0521 & 1.2828 & 1.6598 \\
\hline 3.00 & 0.4947 & 0.5341 & 0.5811 & 0.6383 & 0.7095 & 0.8010 & 0.9232 & 1.0959 & 1.3599 & 1.8187 \\
\hline 3.50 & 0.4971 & 0.5371 & 0.5851 & 0.6436 & 0.7770 & 0.8119 & 0.9402 & 1.1246 & 1.4146 & 1.9452 \\
\hline 4.00 & 0.4984 & 0.5388 & 0.5873 & 0.6467 & 0.7213 & 0.8185 & 0.9508 & 1.1435 & 1.4534 & 2.0462 \\
\hline 5.00 & 0.4995 & 0.5403 & 0.5892 & 0.6494 & 0.7253 & 0.8247 & 0.9616 & 1.1639 & 1.4998 & 2.1875 \\
\hline 6.00 & 0.4998 & 0.5407 & 0.5899 & 0.6503 & 0.7267 & 0.8271 & 0.9658 & 1.1728 & 1.5228 & 2.2740 \\
\hline 8.00 & 0.5000 & 0.5409 & 0.5901 & 0.6507 & 0.7274 & 0.8282 & 0.9681 & 1.1783 & 1.5397 & 2.3570 \\
\hline 10.00 & 0.5000 & 0.5409 & 0.5902 & 0.6508 & 0.7275 & 0.8284 & 0.9685 & 1.1794 & 1.5438 & 2.3865 \\
\hline 14.00 & 0.5000 & 0.5409 & 0.5902 & 0.6508 & 0.7275 & 0.8284 & 0.9686 & 1.1796 & $1.5450^{\circ}$ & 2.4006 \\
\hline 20.00 & 0.5000 & 0.5409 & 0.5902 & 0.6508 & 0.7275 & 0.8284 & 0.9686 & 1.1796 & 1.5451 & 2.4024 \\
\hline
\end{tabular}


1. D. Schiff and S. Stein, "Escape Probability and Capture Fraction for Gray Slabs," :WAPD 149 , June 1956.

2. E. L. Wachspress, Nuclear Science and Engineering, 3, 186 (1958).

3. L. A. Hageman, "HERD 1, 2, and 3-IBM 704 Codes Used to Solve the OneDimensional, one-Velocity Transport Equation with Isotropic Scattering," WAPD-TM-162, "No vember 1958.

4. C. W. Maynard; "Blackness Theory and Coefficients for Slab Geometry;" WAPD-T-871; October 1958.

5. S. Stein, "Resonance Capture in Heterogeneous Systems," WAPD 139, November" 1955.

6. M. Goldsmith, et al., "Theoretical Analysis of Highiy Enriched Light Water Moderated Ćritical Assemblies, "WAPD-T-720, June 1958.

7. J. Bengston, oRNL 56-3-170 (March 1956):

8. B. L. Anderson, et al.; "FLIP-An IBM 704 Code to Solve the $\mathrm{P}_{\ell}$ and Double $\mathrm{P}_{\ell}$ Equations in Slab Geometry," WAPD-TM-l'34, July 1958. *

9. E. Gelbard, J. Davis, and J. 'Pearson, Nuclear Science and Engineering, 5, (January 1959).

Available from the office of Technical Services, Washington, D. C. 